\title{
Decisive modification tools in coronary computed tomographic angiography
}

Citation for published version (APA):

Mihl, C. (2016). Decisive modification tools in coronary computed tomographic angiography: from phantom to patient. [Doctoral Thesis, Maastricht University]. Datawyse / Universitaire Pers Maastricht. https://doi.org/10.26481/dis.20161118cm

Document status and date:

Published: 01/01/2016

DOI:

$10.26481 /$ dis. $20161118 \mathrm{~cm}$

Document Version:

Publisher's PDF, also known as Version of record

\section{Please check the document version of this publication:}

- A submitted manuscript is the version of the article upon submission and before peer-review. There can be important differences between the submitted version and the official published version of record. People interested in the research are advised to contact the author for the final version of the publication, or visit the DOI to the publisher's website.

- The final author version and the galley proof are versions of the publication after peer review.

- The final published version features the final layout of the paper including the volume, issue and page numbers.

Link to publication

\footnotetext{
General rights rights.

- You may freely distribute the URL identifying the publication in the public portal. please follow below link for the End User Agreement:

www.umlib.nl/taverne-license

Take down policy

If you believe that this document breaches copyright please contact us at:

repository@maastrichtuniversity.nl

providing details and we will investigate your claim.
}

Copyright and moral rights for the publications made accessible in the public portal are retained by the authors and/or other copyright owners and it is a condition of accessing publications that users recognise and abide by the legal requirements associated with these

- Users may download and print one copy of any publication from the public portal for the purpose of private study or research.

- You may not further distribute the material or use it for any profit-making activity or commercial gain

If the publication is distributed under the terms of Article $25 \mathrm{fa}$ of the Dutch Copyright Act, indicated by the "Taverne" license above, 


\section{Decisive modification tools in coronary computed tomographic angiography}

* Wrom phantom topatient and

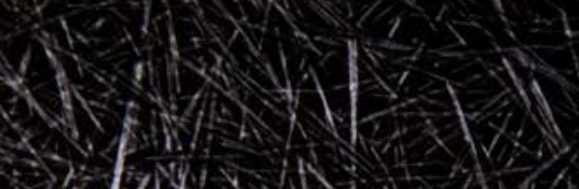
1) (2) (7) 10.20 (2)

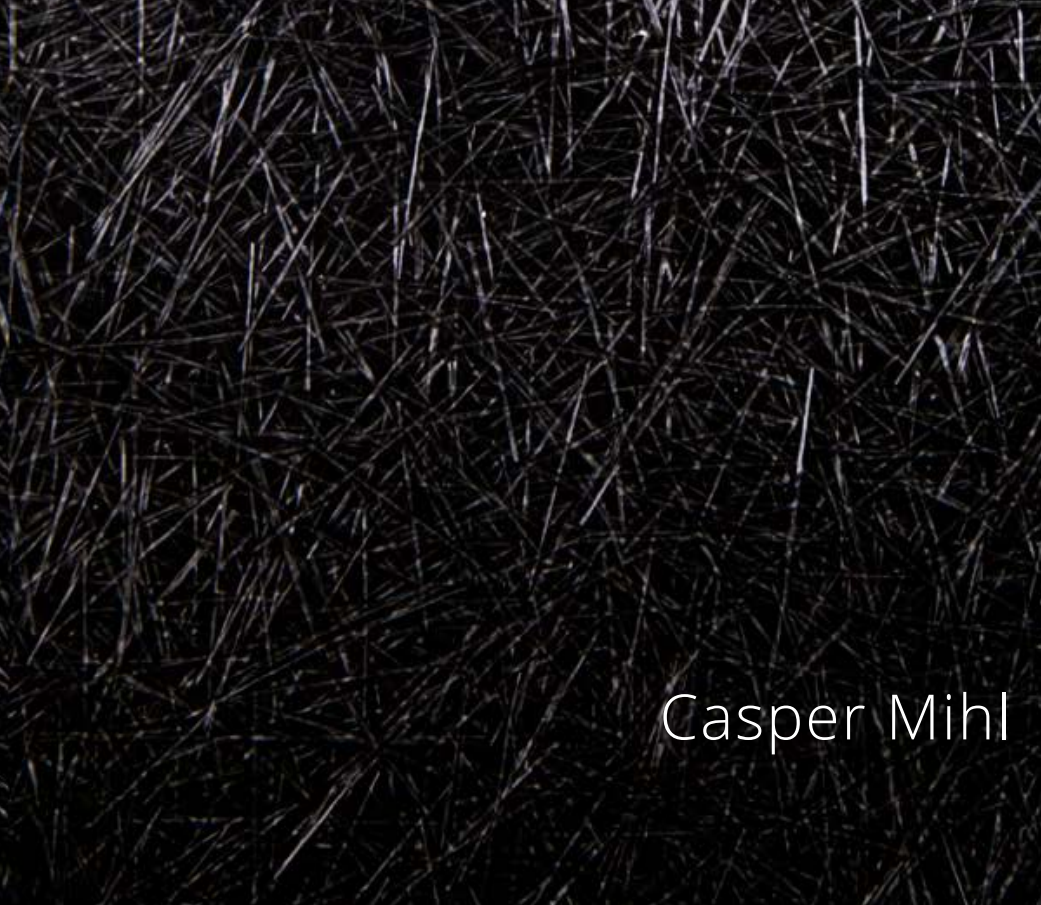


(C) copyright Casper Mihl, Maastricht 2016 ISBN 9789461595461

Cover design: Etienne van Sloun and Henk Mihl Printing: Datawyse | Universitaire Pers Maastricht 


\section{Decisive modification tools in coronary computed tomographic angiography \\ from phantom to patient}

PROEFSCHRIFT

ter verkrijging van de graad van doctor

aan de Universiteit Maastricht,

op gezag van de Rector Magnificus Prof. dr. Rianne M. Letschert

volgens het besluit van het College van Decanen,

in het openbaar te verdedigen

op vrijdag 18 november 2016 om 10.00 uur

door

Casper Mihl 


\section{PROMOTOR}

Prof. dr. J.E. Wildberger

\section{CO-PROMOTORES}

Dr. M. Das

Dr. B.L.J.H. Kietselaer

\section{BEOORDELINGSCOMMISSIE}

Prof. dr. H.J.G.M. Crijns (voorzitter/chair)

Dr. S.C.A.M. Bekkers

Prof. dr. T. Leiner (UMC Utrecht)

Prof. dr. T. Unger

Prof. dr. R. Vliegenthart (UMC Groningen) 


\section{CONTENTS}

CHAPTER 1 General Introduction

CHAPTER 2 Contrast media administration in coronary computed tomographic angiography: A systematic review

CHAPTER 3 Influence of contrast media viscosity and temperature on injection pressure in computed tomographic angiography: A phantom study

CHAPTER 4 Intravascular enhancement with identical iodine delivery rate using different iodine contrast media in a circulation phantom

CHAPTER 5 CT angiography with high flow rates: An in vitro and in vivo feasibility study

CHAPTER 6 Coronary CT angiography using low concentrated contrast media injected with high flow rates: Feasible in clinical practice

CHAPTER 7 Evaluation of individually body weight adapted contrast media injection in coronary CT angiography

CHAPTER 8 General Discussion

CHAPTER 9 Supplemental Material

Summary

Valorisation

Dankwoord

Curriculum Vitae

List of publications 

CHAPTER 1

General Introduction 


\section{CARDIOVASCULAR DISEASE; INCIDENCE AND TRENDS}

Cardiovascular disease ([CVD], e.g. ischemic heart disease and stroke) is considered to be a major cause of mortality and morbidity in Western countries. ${ }^{1}$ Not solely in Western countries, but also in developing countries, the prevalence of traditional risk factors (e.g. hypertension, smoking, diabetes, dyslipidemia, obesity) for CVD has been increasing, subsequently leading to an increase in cardiovascular event rates. ${ }^{2}$ According to the World Health Organization, an estimated 17.5 million people worldwide died from CVD in 2012, representing $31 \%$ of all global deaths. Of these deaths, an estimated 7.4 million were due to coronary artery disease (CAD, e.g. angina and myocardial infarction). ${ }^{3,4}$

In the Netherlands, CVD accounts for $27 \%$ of all deaths. ${ }^{5}$ A gradual decline in mortality was noticeable in the past decades, as the percentage was approximately $33 \%$ 10 years ago, 37\% in 1992 and between 45-50\% in earlier decades. ${ }^{5,6}$ In the entire Dutch population, 648.300 citizens were affected by CAD in 2007 (estimated prevalence in women $3 \%$ and $5 \%$ in men). As the incidence of newly diagnosed CAD in 2007 in the Netherlands equaled to 82.100 persons, this accumulates to an estimated total number of patients with CAD of $730.400 .^{7}$ In the near future, an increase in morbidity and thus prevalence is expected, which emphasizes the need for prevention, early detection of disease and treatment in this continuous health care problem. ${ }^{2,6}$

\section{THE ROLE OF CARDIAC COMPUTED TOMOGRAPHIC ANGIOGRAPHY IN DETECTION OF CAD}

Cardiac computed tomographic angiography (CCTA) is a non-invasive diagnostic imaging technique for visualization of the coronary arteries and the evaluation of CAD. ${ }^{8-10}$ High negative predictive value (NPV) and sensitivity of CCTA have been reported ( $99 \%$ and 94\% respectively), making this an ideal tool to rule out CAD in patients presenting with stable chest pain. ${ }^{11-13}$ In addition, presence of obstructive CAD on CCTA (defined as $\geq 50 \%$ diameter stenosis) has shown to be a strong predictor for the occurrence of a coronary event. ${ }^{14-16}$ CCTA allows for a good depiction of the degree of stenosis and characterization of plaque morphology (e.g. calcified plaques, non-calcified plaques and mixed plaques). ${ }^{17,18}$

\section{OPTIMIZING CONTRAST MEDIA ADMINISTRATION IN CCTA}

Computed tomographic (CT) technology is improving continuously, which allows for an ongoing amelioration of the image quality in clinical practice. ${ }^{19,20}$ Current technologies enable single-heartbeat CCTA with wide-area detectors, dual source technique (DSCT) and high pitch acquisition. ${ }^{21,22}$ This has led to a marked increase in diagnostic accuracy 
and reduction in the number of non-evaluable coronary artery segments. ${ }^{23}$ These technological advances not only increase diagnostic accuracy, but also provide a substantial reduction in radiation dose and scan acquisition time $(<1-6$ seconds, depending on scan protocol) as well as a decrease in artifacts by cardiac motion, breathing or patient movement.

Current technical developments are also moving towards clinical application of lower kV settings (e.g. 100-70kV). Lower kV settings lead to an increase in enhancement of the vessels while maintaining comparable signal-to-noise ratio. ${ }^{20}$ Presently, use of lower kV settings is not technically feasible for all patients and different types of scanners currently available.

All these modifications challenge optimal synchronization and timing of scan protocols in contrast media (CM) administration due to a shorter data acquisition window, hereby creating opportunities for injection strategies with a decrease in total amount of $\mathrm{CM}^{11,24,25}$

Multiple factors affect enhancement characteristics and scan timing; scan related parameters (e.g. scan delay, scan protocol, tube voltage, slice reconstruction and kernel), patient related factors (e.g. weight, blood volume, heart rate, cardiac output and breath holding), as well as various injection parameters. ${ }^{19,26-28}$ With regard to different injection parameters, major impact on intravascular attenuation have been contributed to a saline chaser, the iodine delivery rate (IDR; amount of iodine applied per second [IDR = CM concentration $\mathrm{x}$ injection rate]), injection rate, CM concentration, viscosity, injection needle type and size, CM volume as well as the temperature of injected $\mathrm{CM}{ }^{19,27-37}$ No consensus is reached in terms of an optimal CM protocol and many of these injection parameters have been postulated as decisive contributing factors of pivotal influence in the optimization of CM injection.

The influence of some of these injection parameters, such as the effect of a saline flush on bolus geometry and contrast enhancement has been well established. ${ }^{19,38-41}$ The influence of other factors, such as injection rate, CM concentration and IDR on coronary attenuation, on the other hand, have been an ongoing topic of debate. In daily clinical practice, flow rates $\leq 5 \mathrm{ml} / \mathrm{s}$ are used for intravenous injection of $\mathrm{CM}$. In the literature, injection rates $\geq 5 \mathrm{ml} / \mathrm{s}$ are considered to be high flow rates. ${ }^{42}$ It has been postulated in the literature, that high flow rates might result in increased incidence of extravasation due to increased injection pressures. Therefore, high flow rates are often feared and not used in daily routine practice. ${ }^{43}$ Contradictory statements with regard to optimal CM protocols for imaging of the coronary tree have been published, where some authors concluded that higher iodine concentrations (e.g. 350-400mg/ml) subsequently lead to higher attenuation of the coronary arteries. ${ }^{32,33,44}$ Other authors mention opposite findings, concluding that not the iodine concentration itself but the IDR is the determinant parameter in attenuation of the coronary arteries. ${ }^{36,45}$ In clinical practice, IDR's varying between $1.5-2.2 \mathrm{gl} / \mathrm{s}$ are commonly applied in CCTA. ${ }^{33,46}$ Optimal diagnostic peak enhancement of the arteries (e.g. $>300$ Hounsfield units) is considered a 
prerequisite for CCTA studies. ${ }^{19,30,32,46-48}$ As the IDR is considered the result of CM concentration and injection rate, both higher iodine concentration and higher flow rates will therefore result in an increase of the IDR. In previous in vitro experiments, conducted with standard intravenous injection needles, CM injection even with small cannulas did not reach the common standard pressure limit in CT power injectors of 325 pounds per square inch (psi). ${ }^{30,49}$ In vivo experiments are limited, but intravenous injection site complications associated with higher flow rates are not reported. ${ }^{42}$ As extravasation might be a multifactor incident (e.g. needle size/type and placement, injection location, vein size, injection rate, injection pressure and CM used), it remains unclear which factors have a decisive influence on extravasation. If the risk of extravasation with higher flow rates is indeed overestimated, this might have a substantial impact on $\mathrm{CM}$ injection protocols, paving the way for usage of a broad variety in flow rates.

In addition to the influence of higher flow rates on coronary attenuation, viscosity might play an important role in both $\mathrm{CM}$ delivery and injection pressure. Viscosity is directly influenced by temperature, which means viscosity decreases with increasing temperature. $^{32,49-52}$ Lower CM concentrations have a lower viscosity, which might lead to lower injection pressures in comparison to higher concentrated $\mathrm{CM}$ with identical flow rates. Furthermore, $\mathrm{CM}$ distribution in the blood might be facilitated with lower viscose $\mathrm{CM}$ concentrations. This might have a positive influence on the visualization of distal vessel segments. ${ }^{26,29}$ Therefore, injection with lower CM concentrations will not come at the expense of a subsequently lower IDR, if higher flow rates can be safely injected without increase of complications.

A thorough understanding on how all these injection parameters influence image quality is considered a primary step in the optimisation of CM injection protocols while keeping the amount of injected CM volume to a relative minimum. This is desirable, as important side effects of CM application are allergic reactions and the risk of contrastinduced nephropathy (CIN), the latter is related to the volume of the total iodine load. $\mathrm{CIN}$ is defined as an acute decrease in renal function manifested by an increase in baseline serum creatinine of at least $0.5 \mathrm{mg} / \mathrm{dl}(44 \mu \mathrm{mol} / \mathrm{l})$ within 48 hours of injection of $\mathrm{CM}^{53}$ Lowering the amount of $\mathrm{CM}$ could lower the risk for developing $\mathrm{CIN}^{54}$ Also, it has been shown in previous literature, that reduction of $\mathrm{CM}$ volume to a minimal effective dose can lead to a substantial reduction in costs. ${ }^{55}$

At present, a standard CM injection protocol is used with a standard injected CM volume, independent of weight and length of the patient. A standard injected CM volume potentially has consequences on image quality and attenuation of the coronary arteries in certain weight categories, where some patients (e.g. lower weight and/or length) might require less CM than other patients (e.g. higher weight) to reach the same attenuation value. ${ }^{19}$ Determining the influence on attenuation of each different 
injection parameter will provide the opportunity to further elaborate and develop individually tailored CM injection protocols.

\section{OUTLINE OF THIS THESIS}

Chapter 2 presents a comprehensive overview of the literature on current research in CM application protocols for CCTA in order to provide an update on determining factors for optimal contrast enhancement of the coronary arteries. In chapter 3, we systematically evaluated the viscosity of different CM concentrations in a standardized manner at different temperatures in an in vitro setup and investigated its influence on injection parameters, with a focus on injection pressures. In chapter 4 we aimed to investigate the influence of different $\mathrm{CM}$ concentrations on intravascular attenuation in a circulation phantom while standardizing IDR and keeping all other influencing factors constant. Chapter 5 evaluated the feasibility of high injection rates with usage of dedicated intravenous high-flow needles, shaped with three tear-drop holes positioned near the catheter tip. The aim of this in vitro study was to test high-flow application of $\mathrm{CM}$ in a circulation phantom and to assess feasibility of high flow rates in a dedicated patient population. In chapter 6 , a pilot study was conducted in which we evaluated peak injection pressures and both objective and subjective image quality in CCTA using low concentrated CM $(240 \mathrm{mg} / \mathrm{ml})$ injected at high flow rates in comparison to a standard injection protocol with identical IDR. In chapter 7, vascular attenuation of the coronary arteries as well as all major injection parameters were evaluated in clinical routine, using an individual tailored body weight adapted $\mathrm{CM}$ injection protocol. Chapter 8 encloses the general discussion and future perspectives. 


\section{REFERENCES}

1. Lopez AD, Mathers CD, Ezzati M, Jamison DT, Murray CJ. Global and regional burden of disease and risk factors, 2001: Systematic analysis of population health data. Lancet. 2006;367:1747-1757

2. Celermajer DS, Chow CK, Marijon E, Anstey NM, Woo KS. Cardiovascular disease in the developing world: Prevalences, patterns, and the potential of early disease detection. J Am Coll Cardiol. 2012;60:1207-1216

3. Mendis S. Global status report on noncommunicable diseases. Geneva, Switzerland: World Health Organization. 2014:14-15

4. Mozaffarian D, Benjamin EJ, Go AS, Arnett DK, Blaha MJ, Cushman M, de Ferranti S, Despres JP, Fullerton HJ, Howard VJ, Huffman MD, Judd SE, Kissela BM, Lackland DT, Lichtman JH, Lisabeth LD, Liu S, Mackey RH, Matchar DB, McGuire DK, Mohler ER, 3rd, Moy CS, Muntner P, Mussolino ME, Nasir K, Neumar RW, Nichol G, Palaniappan L, Pandey DK, Reeves MJ, Rodriguez CJ, Sorlie PD, Stein J, Towfighi A, Turan TN, Virani SS, Willey JZ, Woo D, Yeh RW, Turner MB, American Heart Association Statistics C, Stroke Statistics S. Heart disease and stroke statistics - 2015 update: A report from the American Heart Association. Circulation. 2015;131:e29-322

5. Vaartjes I KC, van Dis I, Visseren FLJ, Bots ML. Hart- en vaatziekten in Nederland 2013, cijfers over leefstijl, risicofactoren, ziekte en sterfte. 2013

6. Leening MJ, Siregar S, Vaartjes I, Bots ML, Versteegh MI, van Geuns RJ, Koolen JJ, Deckers JW. Heart disease in the Netherlands: A quantitative update. Neth Heart J. 2014;22:3-10

7. National institute for public health and the environment (RIVM). National public health compass. 2013 Available from: http://www.nationaalkompas.nl/gezondheid-en-ziekte/ziekten-en-aandoeningen/hartvaatstelsel. Accessed January 12, 2016

8. Achenbach S, Ulzheimer S, Baum U, Kachelriess M, Ropers D, Giesler T, Bautz W, Daniel WG, Kalender WA, Moshage W. Noninvasive coronary angiography by retrospectively ecg-gated multislice spiral ct. Circulation. 2000;102:2823-2828

9. Hoffmann MH, Shi H, Schmitz BL, Schmid FT, Lieberknecht M, Schulze R, Ludwig B, Kroschel U, Jahnke N, Haerer W, Brambs HJ, Aschoff AJ. Noninvasive coronary angiography with multislice computed tomography. JAMA. 2005;293:2471-2478

10. Nieman K, Oudkerk M, Rensing BJ, van Ooijen P, Munne A, van Geuns RJ, de Feyter PJ. Coronary angiography with multi-slice computed tomography. Lancet. 2001;357:599-603

11. Budoff MJ, Dowe D, Jollis JG, Gitter M, Sutherland J, Halamert E, Scherer M, Bellinger R, Martin A, Benton R, Delago A, Min JK. Diagnostic performance of 64-multidetector row coronary computed tomographic angiography for evaluation of coronary artery stenosis in individuals without known coronary artery disease: Results from the prospective multicenter accuracy (assessment by coronary computed tomographic angiography of individuals undergoing invasive coronary angiography) trial. J Am Coll Cardiol. 2008;52:1724-1732

12. Miller JM, Rochitte CE, Dewey M, Arbab-Zadeh A, Niinuma H, Gottlieb I, Paul N, Clouse ME, Shapiro EP, Hoe J, Lardo AC, Bush DE, de Roos A, Cox C, Brinker J, Lima JA. Diagnostic performance of coronary angiography by 64-row ct. N Engl J Med. 2008;359:2324-2336

13. Taylor AJ, Cerqueira M, Hodgson JM, Mark D, Min J, O'Gara P, Rubin GD, American College of Cardiology Foundation Appropriate Use Criteria Task F, Society of Cardiovascular Computed T, American College of R, American Heart A, American Society of E, American Society of Nuclear C, North American Society for Cardiovascular I, Society for Cardiovascular A, Interventions, Society for Cardiovascular Magnetic R. Accf/scct/acr/aha/ase/asnc/nasci/scai/scmr 2010 appropriate use criteria for cardiac computed tomography. A report of the American college of cardiology foundation appropriate use criteria task force, the society of cardiovascular computed tomography, the American college of radiology, the American heart association, the American society of echocardiography, the American society of nuclear cardiology, the North American society for cardiovascular imaging, the society for cardiovascular angiography and interventions, and the society for cardiovascular magnetic resonance. J Cardiovasc Comput Tomogr. 2010;4:407 e401-433

14. Versteylen MO, Joosen IA, Kietselaer BL, Wildberger JE, Crijns HJ, Hofstra L. Gender difference in the prognostic value of cta? JACC Cardiovasc Imaging. 2014;7:529-530

15. Schulman-Marcus J, Hartaigh BO, Giambrone AE, Gransar H, Valenti V, Berman DS, Budoff MJ, Achenbach S, Al-Mallah M, Andreini D, Cademartiri F, Callister TQ, Chang HJ, Chinnaiyan K, Chow BJ, Cury R, Delago A, Hadamitzky M, Hausleiter J, Feuchtner G, Kim YJ, Kaufmann PA, Leipsic J, Lin FY, Maffei E, Pontone G, Raff 
G, Shaw LJ, Villines TC, Dunning A, Min JK. Effects of cardiac medications for patients with obstructive coronary artery disease by coronary computed tomographic angiography: Results from the multicenter confirm registry. Atherosclerosis. 2015;238:119-125

16. Min JK, Dunning A, Lin FY, Achenbach S, Al-Mallah M, Budoff MJ, Cademartiri F, Callister TQ, Chang HJ, Cheng V, Chinnaiyan K, Chow BJ, Delago A, Hadamitzky M, Hausleiter J, Kaufmann P, Maffei E, Raff G, Shaw $L$, Villines T, Berman DS, Investigators C. Age- and sex-related differences in all-cause mortality risk based on coronary computed tomography angiography findings results from the international multicenter confirm (coronary ct angiography evaluation for clinical outcomes: An international multicenter registry) of 23,854 patients without known coronary artery disease. J Am Coll Cardiol. 2011;58:849-860

17. Schuijf JD, Beck T, Burgstahler C, Jukema JW, Dirksen MS, de Roos A, van der Wall EE, Schroeder S, Wijns W, Bax JJ. Differences in plaque composition and distribution in stable coronary artery disease versus acute coronary syndromes; non-invasive evaluation with multi-slice computed tomography. Acute card care. 2007;9:48-53

18. Lin F, Shaw LJ, Berman DS, Callister TQ, Weinsaft JW, Wong FJ, Szulc M, Tandon V, Okin PM, Devereux RB, Min JK. Multidetector computed tomography coronary artery plaque predictors of stress-induced myocardial ischemia by spect. Atherosclerosis. 2008;197:700-709

19. Bae KT. Intravenous contrast medium administration and scan timing at ct: Considerations and approaches. Radiology. 2010;256:32-61

20. Lell MM, Jost G, Korporaal JG, Mahnken AH, Flohr TG, Uder M, Pietsch H. Optimizing contrast media injection protocols in state-of-the art computed tomographic angiography. Invest Radiol. 2015;50:161167

21. Achenbach S, Marwan M, Schepis T, Pflederer T, Bruder H, Allmendinger T, Petersilka M, Anders K, Lell M, Kuettner A, Ropers D, Daniel WG, Flohr T. High-pitch spiral acquisition: A new scan mode for coronary ct angiography. J Cardiovasc Comp Tomogr. 2009;3:117-121

22. Otero HJ, Steigner ML, Rybicki FJ. The "post-64" era of coronary ct angiography: Understanding new technology from physical principles. Radiol Clin North Am. 2009;47:79-90

23. Hamon M, Morello R, Riddell JW, Hamon M. Coronary arteries: Diagnostic performance of 16- versus 64section spiral ct compared with invasive coronary angiography--meta-analysis. Radiology. 2007;245:720731

24. Bae KT. Optimization of contrast enhancement in thoracic mdct. Radiol Clin North Am. 2010;48:9-29

25. Meijboom WB, Meijs MF, Schuijf JD, Cramer MJ, Mollet NR, van Mieghem CA, Nieman K, van Werkhoven JM, Pundziute G, Weustink AC, de Vos AM, Pugliese F, Rensing B, Jukema JW, Bax JJ, Prokop M, Doevendans PA, Hunink MG, Krestin GP, de Feyter PJ. Diagnostic accuracy of 64-slice computed tomography coronary angiography: A prospective, multicenter, multivendor study. J Am Coll Cardiol. 2008; $52: 2135-2144$

26. Bae KT, Tran HQ, Heiken JP. Uniform vascular contrast enhancement and reduced contrast medium volume achieved by using exponentially decelerated contrast material injection method. Radiology. 2004;231:732-736

27. Johnson PT, Pannu HK, Fishman EK. Iv contrast infusion for coronary artery ct angiography: Literature review and results of a nationwide survey. AJR Am J Roentgenol. 2009;192:W214-221

28. Awai K, Hiraishi K, Hori S. Effect of contrast material injection duration and rate on aortic peak time and peak enhancement at dynamic ct involving injection protocol with dose tailored to patient weight. Radiology. 2004;230:142-150

29. Muhlenbruch G, Behrendt FF, Eddahabi MA, Knackstedt C, Stanzel S, Das M, Seidensticker P, Gunther RW, Wildberger JE, Mahnken AH. Which iodine concentration in chest ct? - A prospective study in 300 patients. Eur Radiol. 2008;18:2826-2832

30. Behrendt FF, Bruners P, Keil S, Plumhans C, Mahnken AH, Stanzel S, Das M, Gunther RW, Muhlenbruch G. Impact of different vein catheter sizes for mechanical power injection in ct: In vitro evaluation with use of a circulation phantom. Cardiovasc Intervent Radiol. 2009;32:25-31

31. Knollmann F, Schimpf K, Felix R. lodine delivery rate of different concentrations of iodine-containing contrast agents with rapid injection. RoFo. 2004;176:880-884

32. Cademartiri F, Mollet NR, van der Lugt A, McFadden EP, Stijnen T, de Feyter PJ, Krestin GP. Intravenous contrast material administration at helical 16-detector row ct coronary angiography: Effect of iodine concentration on vascular attenuation. Radiology. 2005;236:661-665 
33. Cademartiri F, de Monye C, Pugliese F, Mollet NR, Runza G, van der Lugt A, Midiri M, de Feyter PJ, Lagalla R, Krestin GP. High iodine concentration contrast material for noninvasive multislice computed tomography coronary angiography: lopromide 370 versus iomeprol 400. Invest Radiol. 2006;41:349-353

34. Brunette J, Mongrain R, Laurier J, Galaz R, Tardif JC. 3d flow study in a mildly stenotic coronary artery phantom using a whole volume piv method. Med Eng Phys. 2008;30:1193-1200

35. Nance JW, Jr., Henzler T, Meyer M, Apfaltrer P, Braunagel M, Krissak R, Schoepf UJ, Schoenberg SO, Fink C. Optimization of contrast material delivery for dual-energy computed tomography pulmonary angiography in patients with suspected pulmonary embolism. Invest Radiol. 2012;47:78-84

36. Rist C, Nikolaou K, Kirchin MA, van Gessel R, Bae KT, von Ziegler F, Knez A, Wintersperger BJ, Reiser MF, Becker CR. Contrast bolus optimization for cardiac 16-slice computed tomography: Comparison of contrast medium formulations containing 300 and 400 milligrams of iodine per milliliter. Invest Radiol. 2006; $41: 460-467$

37. Behrendt FF, Pietsch H, Jost G, Palmowski M, Gunther RW, Mahnken AH. Identification of the iodine concentration that yields the highest intravascular enhancement in mdct angiography. AJR Am J Roentgenol. 2013;200:1151-1156

38. Dorio PJ, Lee FT, Jr., Henseler KP, Pilot M, Pozniak MA, Winter TC 3rd, Shock SA. Using a saline chaser to decrease contrast media in abdominal ct. AJR Am J Roentgenol. 2003;180:929-934

39. Cademartiri F, Luccichenti G, Marano R, Runza G, Midiri M. Use of saline chaser in the intravenous administration of contrast material in non-invasive coronary angiography with 16-row multislice computed tomography. Radiol Med. 2004;107:497-505

40. Haage P, Schmitz-Rode T, Hubner D, Piroth W, Gunther RW. Reduction of contrast material dose and artifacts by a saline flush using a double power injector in helical ct of the thorax. AJR Am J Roentgenol. 2000;174:1049-1053

41. Cademartiri F, Mollet N, van der Lugt A, Nieman K, Pattynama PM, de Feyter PJ, Krestin GP. Non-invasive 16-row multislice ct coronary angiography: Usefulness of saline chaser. Eur Radiol. 2004;14:178-183

42. Wienbeck S, Fischbach R, Kloska SP, Seidensticker P, Osada N, Heindel W, Juergens KU. Prospective study of access site complications of automated contrast injection with peripheral venous access in mdct. AJR Am J Roentgenol. 2010;195:825-829

43. Sistrom CL, Gay SB, Peffley L. Extravasation of iopamidol and iohexol during contrast-enhanced ct: Report of 28 cases. Radiology. 1991;180:707-710

44. Christensen JD, Meyer LT, Hurwitz LM, Boll DT. Effects of iopamidol-370 versus iodixanol-320 on coronary contrast, branch depiction, and heart rate variability in dual-source coronary mdct angiography. AJR Am J Roentgenol. 2011;197:W445-451

45. Nakaura T, Awai K, Yauaga Y, Nakayama Y, Oda S, Hatemura M, Nagayoshi Y, Ogawa H, Yamashita Y. Contrast injection protocols for coronary computed tomography angiography using a 64-detector scanner: Comparison between patient weight-adjusted- and fixed iodine-dose protocols. Invest Radiol. 2008;43:512-519

46. Kumamaru KK, Steigner ML, Soga S, Signorelli J, Bedayat A, Adams K, Mitsouras D, Rybicki FJ. Coronary enhancement for prospective ecg-gated single r-r axial 320-mdct angiography: Comparison of 60- and 80ml iopamidol 370 injection. AJR Am J Roentgenol. 2011;197:844-850

47. Liu J, Gao J, Wu R, Zhang Y, Hu L, Hou P. Optimizing contrast medium injection protocol individually with body weight for high-pitch prospective ecg-triggering coronary ct angiography. Int J Cardiovasc Imaging. 2013;29:1115-1120

48. Johnson TR, Nikolaou K, Wintersperger BJ, Fink C, Rist C, Leber AW, Knez A, Reiser MF, Becker CR. Optimization of contrast material administration for electrocardiogram-gated computed tomographic angiography of the chest. J Comput Assist Tomogr. 2007;31:265-271

49. Schwab SA, Kuefner MA, Anders K, Adamietz B, Heinrich MC, Baigger JF, Janka R, Uder M, Kramer M. Peripheral intravenous power injection of iodinated contrast media: The impact of temperature on maximum injection pressures at different cannula sizes. Acad Radiol. 2009;16:1502-1508

50. Halsell RD. Heating contrast media: Role in contemporary angiography. Radiology. 1987;164:276-278

51. Halsell RD. Heating contrast media in a microwave oven. Radiology. 1987;163:279-280

52. Schwab SA, Uder M, Anders K, Heinrich MC, Kuefner MA. Peripheral intravenous power injection of iodinated contrast media through $22 \mathrm{~g}$ and $20 \mathrm{~g}$ cannulas: Can high flow rates be achieved safely? A clinical feasibility study. Rofo. 2009;181:355-361

53. Namasivayam S, Kalra MK, Torres WE, Small WC. Adverse reactions to intravenous iodinated contrast media: An update. Curr Probl Diagn Radiol. 2006;35:164-169 
54. Mitchell AM, Jones AE, Tumlin JA, Kline JA. Incidence of contrast-induced nephropathy after contrastenhanced computed tomography in the outpatient setting. Clin J Am Soc Nephrol. 2010;5:4-9

55. Kuhn MJ, Baker MR. Optimization of low-osmolality contrast media for cranial ct: A dose comparison of two contrast agents. AJNR Am J Neuroradiol. 1990;11:847-849 



\section{CHAPTER 2}

Contrast media administration in coronary computed tomographic angiography: A systematic review 


\section{ABSTRACT}

Various different injection parameters influence enhancement of the coronary arteries. No consensus exists in the literature on the optimal $\mathrm{CM}$ injection protocol. Aim is to provide an update on the effect of different $\mathrm{CM}$ injection parameters on the coronary attenuation in coronary computed tomographic angiography (CCTA). Studies published between January 2001 till May 2014 identified by Pubmed, Embase and MEDLINE were evaluated. Using predefined criteria and a data extraction form, the content of each eligible study was assessed. Initially, 2.551 potential studies were identified. After applying our criteria, 36 studies were found to be eligible. Extracted data proved to be heterogeneous and often incomplete. The injection protocol and outcome of the included publications were very diverse and therefore results are difficult to compare. Due to the substantial variability between studies, it remains unclear which of the injection parameters are the most important determinant for adequate attenuation. Given the multiple options as described in the literature, it is highly likely that one parameter that combines multiple parameters (e.g. IDR) will be the most suitable determinant of coronary attenuation in CCTA protocols. As future directions are aimed towards more individualized CM injection protocols, research should be tailored towards unraveling the influence of different injection parameters to understand which parameters play a pivotal role on attenuation of the coronary arteries. 


\section{INTRODUCTION}

Technical advances in coronary computed tomographic angiography (CCTA) continuously improved image quality. ${ }^{1}$ Current technologies enable single-heartbeat CCTA with wide-area detectors, ${ }^{2}$ dual source technique or high pitch acquisition. ${ }^{3}$ This leads to a substantial reduction in scan acquisition time $(<1-6 s$, depending on scan protocol) as well as a decrease in motion artifacts due to breathing and coronary motion. ${ }^{4}$ As these technical advances facilitate shorter scan acquisition times, smaller volumes of contrast media (CM) may be used (total iodine dose [TID])., 6

Previous studies have demonstrated that enhancement levels in the coronary arteries above 325 Hounsfield units (HU) are necessary for optimal diagnosis. ${ }^{7-9}$ Arterial attenuation depends on injection related parameters (e.g. iodine delivery rate [IDR; gI/s], injection rate $[\mathrm{ml} / \mathrm{s}], \mathrm{CM}$ concentration $[\mathrm{mg} / \mathrm{ml}], \mathrm{TID}, \mathrm{CM}$ volume, viscosity, saline flush, temperature of injected $\mathrm{CM}$ and injection needle type), scan related parameters (e.g. scan protocol, scan duration, scan delay, tube voltage, and reconstruction parameters [kernel]) and patient related factors (e.g. cardiac output, blood volume, heart rate, breath hold and weight). 10,11 Establishing the influence of these parameters is important as future directions are aimed towards more individualized $\mathrm{CM}$ injection protocols. Previous research has focused on the influence of saline flush, IDR, injection rate, CM concentration, injection needle size, CM volume, viscosity as well as the temperature of injected CM on intravascular attenuation with various outcomes. ${ }^{1,10-20}$ Specifically, the influence of CM concentration has been studied extensively, and current evidence is controversial as to whether higher concentrated $\mathrm{CM}$ is beneficial in intravascular attenuation, when the calculated IDR (e.g. CM concentration $\mathrm{x}$ injection rate) is kept identical. ${ }^{12,15,16,18-20}$ To date, no consensus exists on the decisive injection parameters influencing attenuation of the coronary arteries.

A systematic review of the literature on current CM application protocols for CCTA was performed in order to provide an overview of the influence of various injection factors on contrast enhancement of the coronary arteries with a special focus on IDR, $\mathrm{CM}$ concentration and injection rate and to identify areas for further research.

\section{MATERIALS AND METHODS}

\section{Data sources and study selection}

For this systematic review, we conducted a search through PubMed, Embase and MEDLINE between January 2001 and May 2014 using the search terms coronary computed tomography angiography, coronary computed tomography, iodine delivery rate, coronary attenuation, coronary enhancement, total iodine load, coronary arteries, iodine concentration, contrast media concentration, contrast material concentration. 
Inclusion criteria were: (1) studies had to compare different CM injection protocols in CCTA by providing attenuation levels in the coronaries achieved by a specific infusion protocol, (2) an evaluation of image quality or diagnostic accuracy was reported, (3) sample size of $\geq 30$ (>18 years old), (4) language English, German or French, (5) multidetector computed tomography (MDCT) $\geq 16$ slice and (6) IDR, injection rate, CM concentration, TID, CM volume had to be deducible. Studies conducted primarily on

radiation dosage, other technical aspects (e.g. reconstruction kernels, bolus tracking technique/test bolus method), central venous or intra-arterial CM delivery, or focusing on patients with stents or bypasses were excluded from this review. Three readers (CM, JT, AS) independently performed the searches and assessed eligibility of the studies by reading the abstract and application of these criteria. All potentially eligible articles were screened for references to additional eligible studies. Disagreement on inclusion was solved by consensus between the three readers.

\section{Data extraction}

Publications considered eligible were scored using a standardized extraction form, for the following variables: design (retrospective/prospective/both), population region/size, age, weight/body mass index (BMI), height, heart rate, cardiac output, blood pressure, MDCT technique, slice collimation, rotation time, acquisition mode, $k V$ settings, reconstructed slice thickness, reconstruction kernel, intravenous (i.v.) needle size, CM concentration, $\mathrm{CM}$ volume, injection rate, injection duration, saline flush, injection pattern, temperature, IDR, TID and enhancement level at different coronary arteries. In addition, the quality of the studies regarding selection and inclusion criteria, study aims, patient characteristics and methodology were assessed and a flow chart was created according to the Preferred Reporting Items for Systematic reviews and Meta-Analyses (PRISMA) guidelines. ${ }^{21}$

Additionally, the corresponding authors of all included articles were contacted to fill out a questionnaire providing additional parameters that could not be retrieved from the publication. The large heterogeneity observed between the included studies regarding patient population, scanning technique and infusion parameters precluded us from pooling the data and to only perform a systematic review. To account for heterogeneity with regard to the outcome measure a subgroup analysis of the most frequently studied anatomical location (right coronary artery [RCA]) was performed (30 studies) to evaluate the influence of injection related parameters on coronary attenuation. Since this study is a systematic literature review, no approval from our institutional review board was necessary. 


\section{RESULTS}

In the primary literature search, 5.007 potential studies (Pubmed: 2.457, Embase: 1.734, Medline: 816) were identified, of which 2.456 were duplicates, leaving 2.551 potential studies for analysis. 2.403 studies were excluded from further evaluation after scanning of the abstract. Of the remaining 148 studies, 91 studies did not meet the eligibility criteria and were further excluded, leaving 57 studies to be reviewed using the extraction form and consensus reading. Another 21 studies were excluded as they addressed other technical aspects or because basic inclusion criteria and/or injection parameters could not be derived. ${ }^{22-42}$ In total, 36 studies were included with a total of 4.339 patients. $^{7,15,16,19,43-74}$ Of the included studies, 18 authors responded to the questionnaire. $7,19,48,50,53-56,59,60,62-66,69,71,74$ A detailed overview of the inclusion and data extraction process is depicted in Figure 1. Study characteristics are presented in Tables 1-3 and the supplemental material.

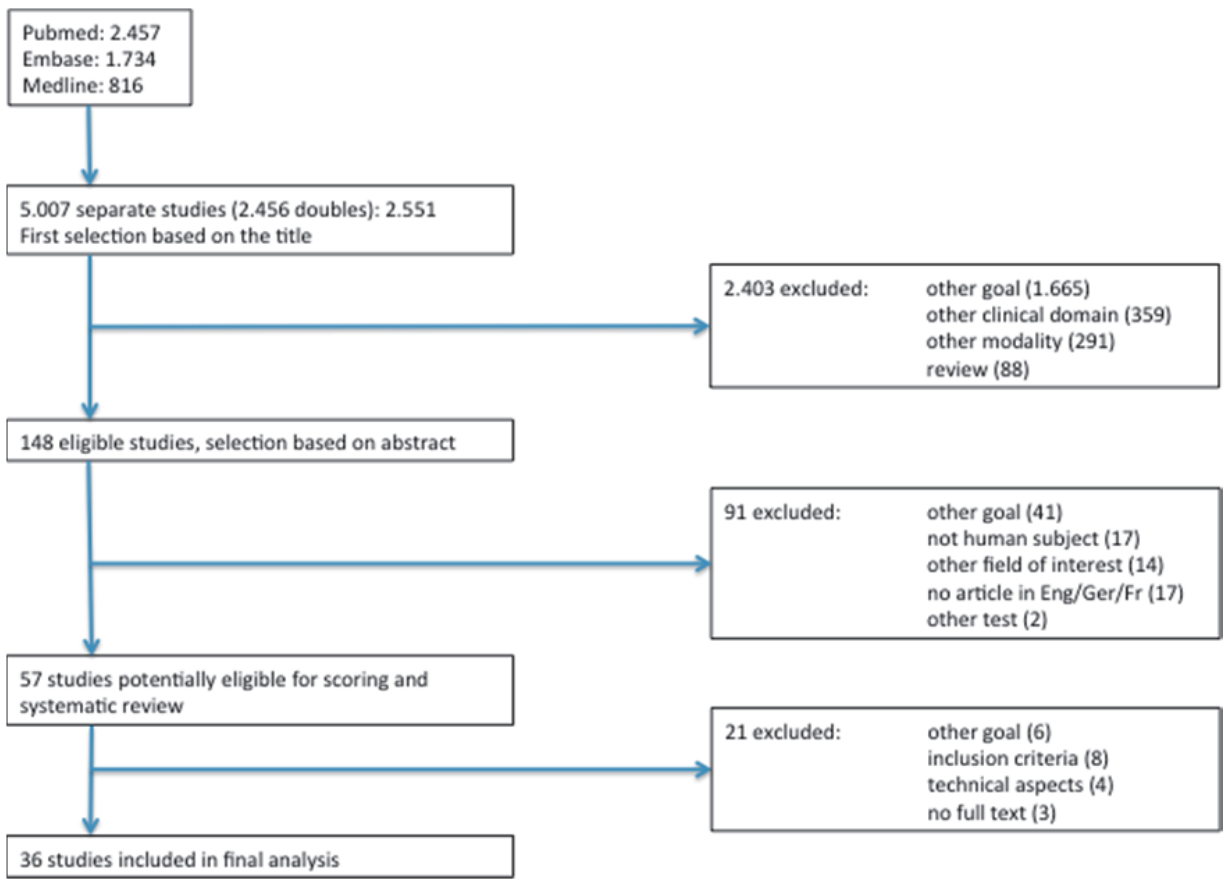

Figure 1: Detailed overview study selection.

The majority of the included publications focused primarily on evaluation of body weight adjusted CM injection protocols. $7,46,47,50,54,58-60,63-69,72,74$ Other publications investigated influence on coronary attenuation with saline flush, different $\mathrm{CM}$ volumes 
and/or biphasic CM injection protocols. ${ }^{43-45,48,49,52,56,62,70,71,73}$ In seven publications different CM concentrations between groups were evaluated. ${ }^{15,16,19,51,55,57,61}$

Table 1: Scan characteristics of the included studies. Rank according to year of publication. Coll: collimation, rot: rotation, reconstr: reconstruction, BMI: body mass index.

\begin{tabular}{|c|c|c|c|c|c|c|}
\hline Author & Coll (mm) & Rot time (ms) & Acquisition mode & kV setting & Slice reconstr (mm) & Kernel \\
\hline Cademartiri $^{43}$ & $12 \times 0.75$ & 420 & ECG gating & 120 & 1 & medium smooth (B30f) \\
\hline Cademartiri $^{15}$ & $16 \times 0.75$ & 420 & ECG gating & 120 & 1 & medium smooth (B30f) \\
\hline Cademartiri $^{44}$ & $16 \times 0.75$ & 420 & ECG gating & 120 & 1 & \\
\hline Cademartiri $^{16}$ & $16 \times 0.75$ & 375 & ECG gating & 120 & 1 & medium smooth (B30f) \\
\hline Rist $^{19}$ & $16 \times 0.75$ & 375 & ECG gating & 120 & 1 & B20f \\
\hline Utsunomiya $^{45}$ & $16 \times 0.5$ & 400 & ECG gating & 120 & & \\
\hline Yamamuro $^{46}$ & $64 \times 0.5$ & 400 & & 120 & 0.5 & \\
\hline Husmann $^{47}$ & $64 \times 0.625$ & 350 & ECG triggering & & & \\
\hline $\mathrm{Kerl}^{48}$ & $2 \times 32 \times 0.6$ & 330 & ECG gating & 120 & 0.75 & medium smooth (B25f) \\
\hline $\mathrm{Kim}^{49}$ & $64 \times 0.6$ & 370 & ECG gating & 120 & & medium smooth (B25f) \\
\hline Nakaura $^{50}$ & $64 \times 0.625$ & 420 & ECG gating & 120 & 0.67 & medium cardiac \\
\hline Tsai $^{51}$ & $40 \times 0.625$ & 420 & ECG gating & 120 & $1.4-3$ & \\
\hline Wuest $^{52}$ & $64 \times 0.6$ & 330 & ECG gating & 120 & 0.75 & medium sharp (B26f) \\
\hline Halpern ${ }^{53}$ & $64 \times 0.9$ & 420 & ECG gating/triggering & 120 & 0.8 & cardiac sharp C \\
\hline Seifarth ${ }^{54}$ & $2 \times 32 \times 0.6$ & 330 & & 120 & & \\
\hline $\mathrm{Kim}^{55}$ & $64 \times 0.5$ & 400 & ECG gating & 120 & 0.5 & $\mathrm{FC} 43$ \\
\hline $\mathrm{Lu}^{56}$ & $64 \times 0.625$ & 350 & ECG gating & 120 & & \\
\hline Ozbulbul ${ }^{57}$ & $16 \times 0.625$ & 500 & ECG gating & 120 & 0.625 & medium soft tissue \\
\hline Pazhenkottil ${ }^{58}$ & $64 \times 0.625$ & 350 & ECG triggering & $100-120$ & 0.625 & \\
\hline Tatsugami $^{59}$ & $320 \times 0.5$ & $350 / 375$ & ECG gating & 120 & 0.5 & $\mathrm{FC} 13$ \\
\hline Tatsugami ${ }^{60}$ & $64 \times 0.5$ & $350 / 400$ & ECG triggering & 135 & 0.5 & $\mathrm{FC} 13$ \\
\hline Becker $^{61}$ & & 330 & ECG gating & 120 & 0.6 & B26 \\
\hline Isogai $^{7}$ & $64 \times 0.625$ & 350 & ECG gating & 120 & 0.625 & cardiac \\
\hline Kumamaru ${ }^{62}$ & $320 \times 0.5$ & 350 & ECG triggering & $80 / 100 / 120$ & & $\mathrm{FCO3}$ \\
\hline Nakaura $^{63}$ & $64 \times 0.625$ & 420 & ECG gating & 120 & 0.67 & medium cardiac (XCB) \\
\hline Zhu $^{64}$ & $2 \times 64 \times 0.6$ & 330 & ECG gating & 120 & 0.75 & medium soft tissue (B26f) \\
\hline Zhu ${ }^{65}$ & $2 \times 64 \times 0.6$ & 330 & ECG gating & 120 & 0.75 & medium soft tissue (B26f) \\
\hline Zhu $^{66}$ & $2 \times 64 \times 0.6$ & 330 & ECG gating & 120 & 0.75 & medium soft tissue (B26f) \\
\hline Kidoh $^{67}$ & $64 \times 0.625$ & 420 & ECG gating & 120 & 0.67 & medium cardiac (XCB) \\
\hline Kidoh $^{68}$ & $64 \times 0.625$ & 420 & ECG gating & 120 & 0.67 & medium cardiac (XCB) \\
\hline $\mathrm{Liu}^{69}$ & $2 \times 128 \times 0.6$ & 280 & ECG triggering & 100 & 0.75 & medium smooth (B26) \\
\hline Yang $^{70}$ & $2 \times 128 \times 0.6$ & 280 & ECG triggering & 120 & 0.6 & media smooth (B26f) \\
\hline Tomizawa $^{71}$ & $320 \times 0.5$ & $350 / 375 / 400$ & ECG triggering & 120 & 0.5 & FCO4, AIDR \\
\hline \multirow[t]{2}{*}{ Zheng $^{72}$} & $2 \times 64 \times 0.6$ & 280 & ECG triggering & $80 / 100$ & 0.75 & $126 \mathrm{~F}$ \\
\hline & & & & $100 / 120$ & & B26f \\
\hline Lembcke $^{73}$ & $2 \times 128 \times 0.6$ & 280 & ECG triggering & 100 & & \\
\hline Kawaguchi $^{74}$ & $2 \times 128 \times 0.625$ & 270 & ECG gating & 120 & 0.8 & medium cardiac (XCB) \\
\hline
\end{tabular}


Table 2: Patient characteristics of the included studies. M: male, F: female, kg: kilograms, BMI: body mass index, BPM: beats per minute, CO: cardiac output, EF: ejection fraction, BP: blood pressure, syst: systolic, diast: diastolic.

\begin{tabular}{|c|c|c|c|c|c|c|}
\hline Author & $\begin{array}{c}\text { No. subjects } \\
(m ; f)\end{array}$ & Mean age (years) & Mean weight $(\mathrm{kg})$ & $\mathrm{BMI}\left(\mathrm{kg} / \mathrm{m}^{2}\right)$ & Heart rate (bpm) & $\begin{array}{l}\mathrm{CO}(\mathrm{l} / \mathrm{min}) / \mathrm{BP} \text { (syst;diast, } \mathrm{mmHg}) \\
\text { EF (\%) }\end{array}$ \\
\hline \multirow[t]{2}{*}{ Cademartiri $^{43}$} & $21(16 ; 5)$ & $59(34-74)$ & $72(53-90)$ & & $60(48-72)$ & \\
\hline & $21(14 ; 7)$ & $59(39-79)$ & $74(60-95)$ & & $60(49-80)$ & \\
\hline \multirow[t]{5}{*}{ Cademartiri ${ }^{15}$} & $25(22 ; 3)$ & $58 \pm 11$ & $74 \pm 7$ & & $59 \pm 8$ & \\
\hline & $25(20 ; 5)$ & $60 \pm 11$ & $72 \pm 7$ & & $59 \pm 7$ & \\
\hline & $25(21 ; 4)$ & $58 \pm 13$ & $72 \pm 7$ & & $61 \pm 9$ & \\
\hline & $25(21 ; 4)$ & $57 \pm 11$ & $74 \pm 9$ & & $60 \pm 9$ & \\
\hline & $25(20 ; 5)$ & $63 \pm 12$ & $71 \pm 8$ & & $57 \pm 8$ & \\
\hline \multirow[t]{3}{*}{ Cademartiri $^{44}$} & $15(11 ; 4)$ & $58(34-74)$ & $71(55-90)$ & & $58(46-72)$ & \\
\hline & $15(14 ; 1)$ & $58(28-73)$ & $72(60-88)$ & & $56(45-65)$ & \\
\hline & $15(14 ; 1)$ & $59(45-79)$ & $73(60-95)$ & & $56(45-68)$ & \\
\hline \multirow[t]{2}{*}{ Cademartiri $^{16}$} & $20(15 ; 5)$ & $59 \pm 12$ & $73 \pm 9$ & & $61 \pm 7$ & \\
\hline & $20(14 ; 6)$ & $63 \pm 10$ & $75 \pm 11$ & & $60 \pm 8$ & \\
\hline \multirow[t]{2}{*}{ Rist $^{19}$} & 30 & $58.13 \pm 11.16$ & $77.68 \pm 14.76$ & & $57.3 \pm 3.7$ & \\
\hline & 30 & $62.17 \pm 8.22$ & $84.86 \pm 16.24$ & & $57.4 \pm 4.3$ & \\
\hline \multirow[t]{3}{*}{ Utsunomiya $^{45}$} & 13 (total: 30;8) & $68.6 \pm 8.4$ & $59.5 \pm 7.0$ & & $61 \pm 11$ & \\
\hline & 12 & $63.9 \pm 8.9$ & $62.1 \pm 8.5$ & & $59 \pm 11$ & \\
\hline & 13 & $68.0 \pm 8.8$ & $64.3 \pm 7.1$ & & $58 \pm 8$ & \\
\hline \multirow[t]{2}{*}{ Yamamuro $^{46}$} & $30(16 ; 14)$ & $68.7 \pm 12.1$ & $59.5 \pm 11.7$ & & $70.1 \pm 13.1$ & \\
\hline & $30(17 ; 13)$ & $68.0 \pm 11.0$ & $57.3 \pm 7.8$ & & $72.7 \pm 18$ & \\
\hline \multirow[t]{2}{*}{ Husmann $^{47}$} & $70(48 ; 22)$ & $58 \pm 12$ & $79 \pm 16$ & $26.5 \pm 4.0$ & $57.7 \pm 7.0$ & \\
\hline & $70(51 ; 19)$ & $60 \pm 11$ & $80 \pm 15$ & $26.7 \pm 4.2$ & $57.6 \pm 6.0$ & \\
\hline \multirow[t]{3}{*}{$\mathrm{Kerl}^{48}$} & $25(14 ; 11)$ & 53.32 & 82.2 & & & \\
\hline & $25(20 ; 5)$ & 65.40 & 87.7 & & & \\
\hline & $25(14 ; 11)$ & 65.84 & 86.9 & & & \\
\hline \multirow[t]{5}{*}{$\mathrm{Kim}^{49}$} & 20 (total: 59;41) & $62(44-82)$ & $62(54-78)$ & & $55(42-67)$ & \\
\hline & 20 & $56(43-76)$ & $67(53-79)$ & & $58(47-74)$ & \\
\hline & 20 & $57(37-76)$ & $61(51-75)$ & & $59(43-79)$ & \\
\hline & 20 & $58(39-77)$ & $64(53-79)$ & & $58(41-71)$ & \\
\hline & 20 & $57(38-72)$ & $66(52-83)$ & & $61(51-74)$ & \\
\hline \multirow[t]{2}{*}{ Nakaura ${ }^{50}$} & $30(13 ; 17)$ & $62.4 \pm 12.5$ & $60.1 \pm 14.2$ & & $66.5 \pm 12.5$ & \\
\hline & $30(16 ; 14)$ & $67.5 \pm 12.9$ & $59.5 \pm 12.8$ & & $65.8 \pm 12.9$ & \\
\hline \multirow[t]{2}{*}{ Tsai ${ }^{51}$} & $38(22 ; 16)$ & $61.7 \pm 12.5$ & $64.9 \pm 10.9$ & & $71.5 \pm 13.2$ & $58.8 \pm 6.5 \quad 120.7 \pm 14.5 ; 75.4 \pm 10.5$ \\
\hline & $34(21 ; 13)$ & $61.7 \pm 11.3$ & $65.9 \pm 8.4$ & & $76.7 \pm 11.2$ & $57.0 \pm 5.6 \quad 118.9 \pm 12.6 ; 75.8 \pm 9.0$ \\
\hline \multirow[t]{2}{*}{ Wuest $^{52}$} & $53(38 ; 15)$ & $58 \pm 11.82$ & & & & \\
\hline & $53(40 ; 13)$ & $62 \pm 13.08$ & & & & \\
\hline
\end{tabular}


Chapter 2

\begin{tabular}{|c|c|c|c|c|c|c|}
\hline Author & $\begin{array}{l}\text { No. subjects } \\
(m ; f)\end{array}$ & Mean age (years) & Mean weight (kg) & $\mathrm{BMI}\left(\mathrm{kg} / \mathrm{m}^{2}\right)$ & Heart rate (bpm) & $\begin{array}{l}\mathrm{CO}(\mathrm{I} / \mathrm{min}) / \mathrm{BP} \text { (syst; diast, } \mathrm{mmHg}) \\
\text { EF (\%) }\end{array}$ \\
\hline \multirow[t]{2}{*}{ Halpern $^{53}$} & $260(\%: 57 ; 43)$ & $58 \pm 12$ & $89 \pm 25$ & $30.3 \pm 7.6$ & $61.5 \pm 0.8$ & Syst $>100$ \\
\hline & $168(\%: 45 ; 55)$ & $50 \pm 12$ & $85 \pm 21$ & $29.6 \pm 6.7$ & $63.0 \pm 1.0$ & \\
\hline \multirow[t]{3}{*}{ Seifarth $^{54}$} & 40 & $62.3 \pm 10.8$ & $80.8 \pm 14.2$ & $26.3 \pm 3.0$ & $64.7 \pm 13.0$ & \\
\hline & 40 & $62.6 \pm 9.6$ & $82.0 \pm 13.4$ & $26.2 \pm 3.7$ & $63.1 \pm 11.4$ & \\
\hline & 40 & $62.9 \pm 13.3$ & $81.7 \pm 15.3$ & $26.3 \pm 3.8$ & $63.7 \pm 13.3$ & \\
\hline \multirow[t]{2}{*}{$\mathrm{Kim}^{55}$} & $151(87 ; 64)$ & $55 \pm 9$ & $67 \pm 10.2$ & $24.6 \pm 3.0$ & $70 \pm 11$ & $124 \pm 18(85-169)$ \\
\hline & $146(88 ; 58)$ & $52 \pm 11$ & $68 \pm 9.9$ & $24.8 \pm 2.7$ & $71 \pm 11$ & $128 \pm 19(92-181)$ \\
\hline \multirow[t]{5}{*}{$\mathrm{Lu}^{56}$} & 30 (total: $71 ; 79)$ & $55.6 \pm 10.9$ & & $23.4 \pm 2.4$ & $58.0 \pm 8.0$ & \\
\hline & 30 & $58.8 \pm 12.2$ & & $23.8 \pm 2.6$ & $58.4 \pm 6.3$ & \\
\hline & 30 & $58.8 \pm 10.5$ & & $23.7 \pm 2.5$ & $57.9 \pm 7.5$ & \\
\hline & 30 & $58.3 \pm 11.5$ & & $23.5 \pm 2.3$ & $57.6 \pm 6.7$ & \\
\hline & 30 & $56.1 \pm 11.2$ & & $24.3 \pm 2.5$ & $56.1 \pm 6.8$ & \\
\hline \multirow[t]{2}{*}{ Ozbulbul ${ }^{57}$} & 24 (total: 20;32) & $56.4 \pm 13.6$ & & & $61.0 \pm 8.9$ & \\
\hline & 28 & $54.1 \pm 17.1$ & & & $62.8 \pm 7.0$ & \\
\hline \multirow[t]{2}{*}{ Pazhenkottil $^{58}$} & $80(59 ; 21)$ & $59 \pm 11$ & $82 \pm 12$ & & $56 \pm 7$ & \\
\hline & $80(68 ; 12)$ & $57 \pm 11$ & $82 \pm 12$ & & $56 \pm 7$ & \\
\hline \multirow[t]{2}{*}{ Tatsugami $^{59}$} & $48(57 ; 41)$ & $69.8 \pm 9.8$ & $59.3 \pm 8.4$ & & $57.1 \pm 9.7$ & \\
\hline & 50 & $68.7 \pm 9.0$ & $58.0 \pm 8.1$ & & $58.8 \pm 6.4$ & \\
\hline \multirow[t]{3}{*}{ Tatsugami ${ }^{60}$} & 16 (total: $27 ; 18)$ & $68.2 \pm 10.6$ & $57.4 \pm 6.0$ & & $53.8 \pm 7.6$ & \\
\hline & 15 & $69.1 \pm 10.3$ & $55.3 \pm 5.9$ & & $55.7 \pm 7.7$ & \\
\hline & 14 & $69.6 \pm 9.6$ & $56.2 \pm 7.8$ & & $59.0 \pm 12.2$ & \\
\hline \multirow[t]{2}{*}{ Becker $^{61}$} & $50(28)$ & $57.0 \pm 11.2$ & $77.4 \pm 17.7$ & & $66.5 \pm 14.26$ & \\
\hline & $54(31)$ & $60.4 \pm 11.6$ & $78.0 \pm 19.1$ & & $68.1 \pm 15.86$ & \\
\hline \multirow[t]{3}{*}{$\left.\right|_{\text {sogai }} ^{7}$} & $20(16 ; 4)$ & $63.5 \pm 11.4$ & $63.9 \pm 13.7$ & & $62.1 \pm 10.9$ & $133.8 \pm 14.3 ; 79.9 \pm 8.8$ \\
\hline & $20(12 ; 8)$ & $64.4 \pm 11.7$ & $64.4 \pm 13.3$ & & $63.0 \pm 8.2$ & $133 . \pm 17.9 ; 82.0 \pm 11.8$ \\
\hline & $20(5 ; 15)$ & $65.4 \pm 7.8$ & $66.0 \pm 8.5$ & & $62.9 \pm 10.5$ & $138.3 \pm 16.9 ; 80.6 \pm 12.7$ \\
\hline \multirow[t]{2}{*}{ Kumamaru $^{62}$} & $36(18 ; 18)$ & $56.7 \pm 12.9$ & $79.7 \pm 15.4$ & $22.8 \pm 4.8$ & $57.4 \pm 5.9$ & \\
\hline & $72(41 ; 31)$ & $54.8 \pm 11.9$ & $80.8 \pm 18.0$ & $27.8 \pm 4.8$ & $56.7 \pm 5.9$ & \\
\hline \multirow[t]{2}{*}{ Nakaura $^{63}$} & $30(21 ; 9)$ & $69.9 \pm 9.1$ & $56.8 \pm 9.2$ & $22.4 \pm 3.1$ & $60.0 \pm 9.7$ & $4.2 \pm 0.9$ \\
\hline & $30(20 ; 10)$ & $70.9 \pm 11.6$ & $57 \pm 10$ & $22.9 \pm 3$ & $59.8 \pm 10.9$ & $4.2 \pm 1.0$ \\
\hline \multirow[t]{3}{*}{ Zhu $^{64}$} & $96(57 ; 39)$ & $58.2(29-85)$ & $67.1(39-101)$ & $24.5(15.8-34)$ & $71.7(48-106)$ & $6.2 \pm 1.7$ \\
\hline & $100(53 ; 47)$ & $58.1(27-84)$ & $67.9(40-101)$ & $24.6(17.9-35.4)$ & 74.5 (51-107) & \\
\hline & $100(53 ; 47)$ & $59.8(30-83)$ & $65.9(41-104)$ & $24.1(15.2-34.9)$ & $73.0(50-104)$ & \\
\hline \multirow[t]{2}{*}{$\mathrm{Zhu}^{65}$} & $114(60 ; 54)$ & $60.8(30-85)$ & $66.9(34-100)$ & $24.7(16.4-32.7)$ & $74.5(49-107)$ & \\
\hline & $119(67 ; 52)$ & $59.8(28-83)$ & $67.1(38-94)$ & $24.7(16.9-32.0)$ & $75.7(50-111)$ & \\
\hline \multirow[t]{2}{*}{$\mathrm{Zhu}^{66}$} & $113(60 ; 53)$ & $58.2(30-85)$ & $66.9(34-100)$ & $24.7(16.4-32.7)$ & $74.5(49-107)$ & \\
\hline & $94(54 ; 40)$ & $60.4(32-87)$ & $64.8(42-101)$ & $23.9(16.4-33.0)$ & $74.3(37-106)$ & \\
\hline
\end{tabular}


CM administration in CCTA: A systematic review

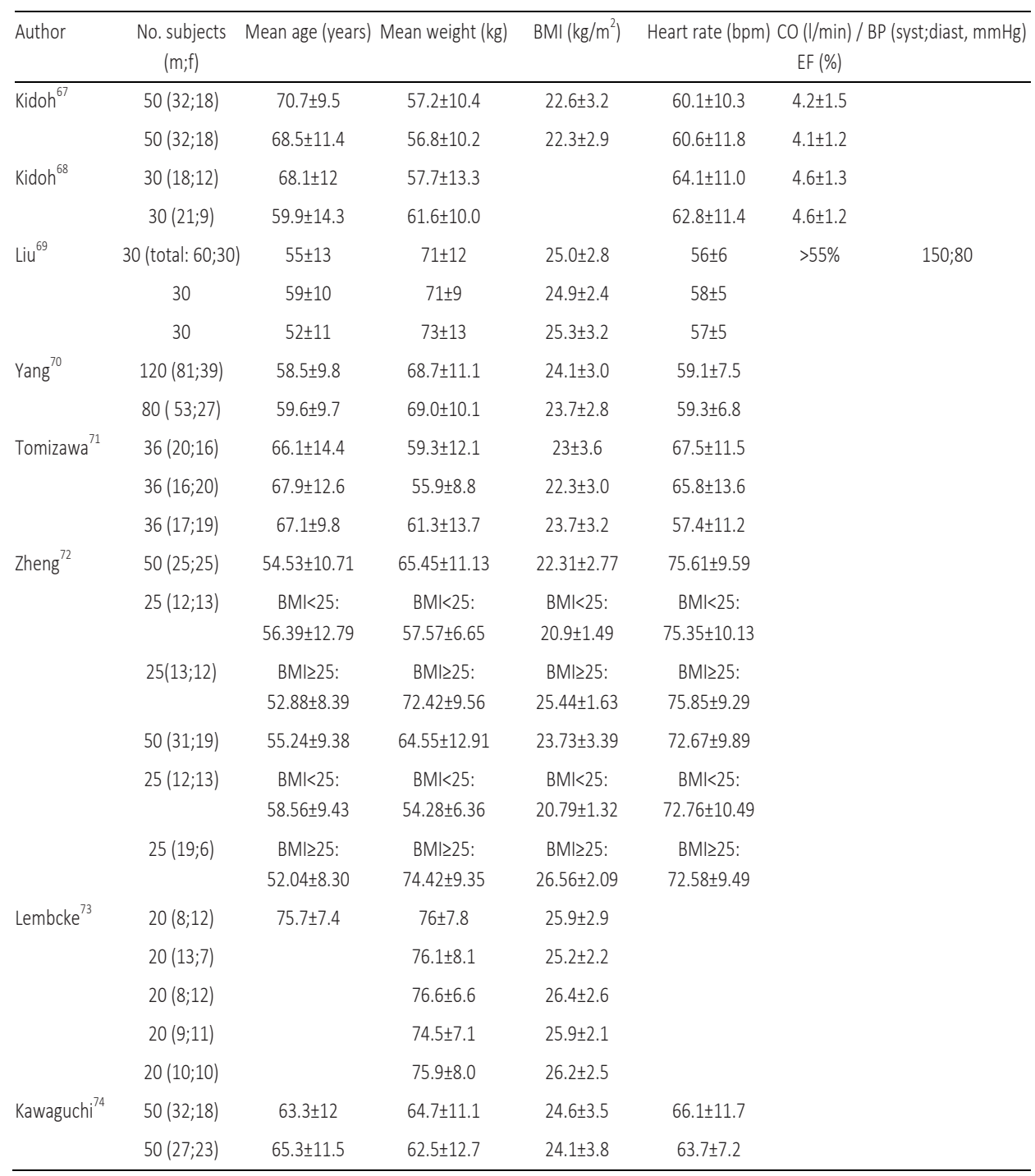


Table 3: Injection parameters of the included studies. CM: contrast media, mg: milligram, ml, milliliter, s: second, inj: injection, mix: mixed bolus (presented as total volume of mixed bolus), \%: percentage of CM in mixed bolus, $\rightarrow$ indicates second injection phase, IDR: iodine delivery rate, TID: total iodine dose.

\begin{tabular}{|c|c|c|c|c|c|c|c|c|c|c|}
\hline Author & Needle & $\mathrm{CM}(\mathrm{mg} / \mathrm{ml})$ & $\mathrm{CM}$ volume (ml) & Flow rate $(\mathrm{ml} / \mathrm{s})$ & $\begin{array}{c}\text { Injection } \\
\text { duration (s) }\end{array}$ & Saline & $\begin{array}{l}\text { Injection } \\
\text { pattern }\end{array}$ & $\operatorname{Temp}\left({ }^{\circ} \mathrm{C}\right)$ & IDR (gl/s) & TID (g) \\
\hline \multirow[t]{2}{*}{ Cademartiri $^{43}$} & $18 G$ & iodixanol 320 & 140 & 4 & 35 & no & uniphasic & & 1.28 & 44.8 \\
\hline & & iodixanol 320 & 100 & 4 & 25 & yes & uniphasic & & 1.28 & 32 \\
\hline \multirow[t]{5}{*}{ Cademartiri ${ }^{15}$} & $18 \mathrm{G}$ & iohexol 300 & 140 & 4 & 35 & no & uniphasic & & 1.2 & 42 \\
\hline & & iodixanol 320 & 140 & 4 & 35 & no & uniphasic & 37 & 1.28 & 44.8 \\
\hline & & iohexol 350 & 140 & 4 & 35 & no & uniphasic & 37 & 1.4 & 49 \\
\hline & & iomeprol 350 & 140 & 4 & 35 & no & uniphasic & 37 & 1.4 & 49 \\
\hline & & iomeprol 400 & 140 & 4 & 35 & no & uniphasic & 37 & 1.6 & 56 \\
\hline \multirow[t]{3}{*}{ Cademartiri ${ }^{44}$} & $18-20 \mathrm{G}$ & iodixanol 320 & 140 & 4 & 35 & no & uniphasic & & 1.28 & 44.8 \\
\hline & & iodixanol 320 & 140 & $5 \rightarrow 3$ & 39 & no & biphasic & & $1.6 \rightarrow 0.96$ & 44.8 \\
\hline & & iodixanol 320 & 100 & 4 & 25 & no & uniphasic & & 1.28 & 32 \\
\hline \multirow[t]{2}{*}{ Cademartiri $^{16}$} & $18 \mathrm{G}$ & iopromide 370 & 100 & 4 & & yes & uniphasic & & 1.48 & 37 \\
\hline & & iomeprol 400 & 100 & 4 & & yes & uniphasic & & 1.6 & 40 \\
\hline \multirow[t]{2}{*}{ Rist $^{19}$} & $18 \mathrm{G}$ & iomeron 300 & 83 & 3.3 & 25.2 & yes & uniphasic & 37 & 0.99 & 24.9 \\
\hline & & iomeron 400 & 63 & 2.5 & 25.2 & yes & uniphasic & 37 & 1.0 & 25.2 \\
\hline \multirow[t]{3}{*}{ Utsunomiya $^{45}$} & $20 G$ & iohexol 350 & $60+\operatorname{mix} 80(50 \%)$ & $3 \rightarrow 1.5$ & & no & biphasic & & $1.05 \rightarrow 0.26$ & 35 \\
\hline & & iohexol 350 & 100 & 3 & & yes & uniphasic & & 1.05 & 35 \\
\hline & & iohexol 350 & 100 & 3 & & no & uniphasic & & 1.05 & 35 \\
\hline \multirow[t]{2}{*}{ Yamamuro $^{46}$} & & iomeron 350 & 40 & $3.5 \rightarrow 2.8$ & & yes & biphasic & & $1.23 \rightarrow 0.98$ & 14 \\
\hline & & iomeron 350 & 50 & $3.5 \rightarrow 2.8$ & & yes & biphasic & & $1.23 \rightarrow 0.98$ & 17.5 \\
\hline \multirow[t]{2}{*}{ Husmann ${ }^{47}$} & $18 G$ & iodixanol 320 & 80 & 5 & & yes & uniphasic & & 1.6 & 25.6 \\
\hline & & iodixanol 320 & $73.9 \pm 11.2$ & $4.0-5.0$ & & yes & uniphasic & & $1.28-1.6$ & 23.6 \\
\hline \multirow[t]{3}{*}{$\mathrm{Kerl}^{48}$} & $18 G$ & iopamidol 370 & $50-75$ & 5 & & no & uniphasic & & 1.85 & $18.5-27.8$ \\
\hline & & iopamidol 370 & $50-75$ & 5 & & yes & uniphasic & & 1.85 & $18.5-27.8$ \\
\hline & & iopamidol 370 & $(50-75)+\operatorname{mix} 50(30 \%)$ & 5 & & yes & biphasic & & $1.85 \rightarrow 0.56$ & $18.5-27.8+5.6$ \\
\hline \multirow[t]{5}{*}{$\mathrm{Kim}^{49}$} & & iobitridol 350 & 60 & 4 & 15 & yes & uniphasic & & 1.4 & 21 \\
\hline & & iobitridol 350 & 60 & 4 & 15 & yes & uniphasic & & 1.4 & 21 \\
\hline & & iobitridol 350 & 60 & 4 & 15 & yes & uniphasic & & 1.4 & 21 \\
\hline & & iobitridol 350 & 60 & 4 & 15 & yes & uniphasic & & 1.4 & 21 \\
\hline & & iobitridol 350 & 60 & 4 & 15 & yes & uniphasic & & 1.4 & 21 \\
\hline \multirow[t]{2}{*}{ Nakaura $^{50}$} & $20 G$ & iopamiron 370 & 80 & 4 & 20 & yes & uniphasic & & 1.48 & 29.6 \\
\hline & & iopamiron 370 & $59.5 \pm 12.8$ & $3.96 \pm 0.85$ & 15 & yes & uniphasic & & 1.47 & $22.0 \pm 4.7$ \\
\hline \multirow[t]{2}{*}{ Tsai $^{51}$} & $20 G$ & iohexol 350 & 100 & 4 & & yes & uniphasic & 37 & 1.4 & 35 \\
\hline & & iodixanol 320 & 100 & 4 & & yes & uniphasic & 37 & 1.28 & 32 \\
\hline \multirow[t]{2}{*}{ Wuest $^{52}$} & & iomerol 350 & $45-65$ & 5 & & yes & uniphasic & & 1.75 & $15.75-22.75$ \\
\hline & & iomerol 350 & $\begin{array}{c}55-75 \\
\text { (incl mix 20\%) }\end{array}$ & 5 & & yes & biphasic & & $1.75 \rightarrow 0.35$ & $22.75-29.75$ \\
\hline
\end{tabular}




\begin{tabular}{|c|c|c|c|c|c|c|c|c|c|c|}
\hline Author & Needle & $\mathrm{CM}(\mathrm{mg} / \mathrm{ml})$ & CM volume (ml) & Flow rate $(\mathrm{ml} / \mathrm{s})$ & $\begin{array}{c}\text { Injection } \\
\text { duration (s) }\end{array}$ & Saline & $\begin{array}{l}\text { Injection } \\
\text { pattern }\end{array}$ & $\operatorname{Temp}\left({ }^{\circ} \mathrm{C}\right)$ & $\operatorname{IDR}(\mathrm{gl} / \mathrm{s})$ & $\operatorname{TID}(\mathrm{g})$ \\
\hline \multirow[t]{2}{*}{ Halpern $^{53}$} & $18-20 G$ & ioversol 350 & 70 & 5.5 & & yes & uniphasic & & 1.93 & 24.5 \\
\hline & & ioversol 350 & $70+\operatorname{mix} 50(50 \%)$ & 5 & & yes & biphasic & & $1.75 \rightarrow 0.88$ & 33.25 \\
\hline \multirow[t]{3}{*}{ Seifarth $^{54}$} & $18 \mathrm{G}$ & iopromide 370 & $80+\operatorname{mix} 50(30 \%)$ & 6 & $13.3 \pm 0$ & yes & biphasic & & $2.22 \rightarrow 0.67$ & 35.2 \\
\hline & & iopromide 370 & $\begin{array}{c}82.5 \pm 8.8+ \\
\operatorname{mix} 34.3 \pm 10.8(30 \%)\end{array}$ & $5.1 \pm 0.6$ & $16.4 \pm 2.0$ & yes & biphasic & & $1.89 \rightarrow 0.57$ & 35.6 \\
\hline & & iopromide 370 & $73.5 \pm 12.9+\operatorname{mix} 50(30 \%)$ & 5 & $14.7 \pm 2.5$ & yes & biphasic & & $1.85 \rightarrow 0.56$ & 32.8 \\
\hline \multirow[t]{2}{*}{$\mathrm{Kim}^{55}$} & $18 \mathrm{G}$ & iomeprol 370 & 70 & 4 & 17.5 & yes & uniphasic & 37 & 1.48 & 25.9 \\
\hline & & iomeprol 400 & 70 & 4 & 17.5 & yes & uniphasic & 37 & 1.6 & 28 \\
\hline \multirow[t]{5}{*}{$\mathrm{Lu}^{56}$} & $20 G$ & iohexol 350 & $67 \pm 5.3$ & 5 & & no & uniphasic & & 1.75 & 23.45 \\
\hline & & iohexol 350 & $59.9 \pm 4.9$ & 5 & & yes & uniphasic & & 1.75 & 20.97 \\
\hline & & iohexol 350 & $(56.9 \pm 3.2)+\operatorname{mix} 20(30 \%)$ & 5 & & yes & biphasic & & $1.75 \rightarrow 0.53$ & 22.02 \\
\hline & & iohexol 350 & $(59.2 \pm 5.7)+\operatorname{mix} 20(50 \%)$ & 5 & & yes & biphasic & & $1.75 \rightarrow 0.88$ & 24.22 \\
\hline & & iohexol 350 & $(56.9 \pm 4.6)+\operatorname{mix} 20(70 \%)$ & 5 & & yes & biphasic & & $1.75 \rightarrow 1.23$ & 24.82 \\
\hline \multirow[t]{2}{*}{ Ozbulbul $\left.\right|^{57}$} & $18 G$ & iodixanol 320 & 130 & 4 & & no & uniphasic & 37 & 1.28 & 41.6 \\
\hline & & iopamidol 370 & 130 & 4 & & no & uniphasic & 37 & 1.48 & 48.1 \\
\hline \multirow[t]{2}{*}{ Pazhenkottili ${ }^{58}$} & $18 \mathrm{G}$ & iodixanol 320 & 80 & 5 & & yes & uniphasic & & 1.6 & 25.6 \\
\hline & & iodixanol 320 & $70.9 \pm 14.1$ & $3.5-5.0$ & & yes & uniphasic & & $1.1-1.6$ & 22.7 \\
\hline \multirow[t]{2}{*}{ Tatsugami ${ }^{59}$} & $20 G$ & iomeron 350 & $47.5 \pm 7.4$ & $4 \pm 0.56$ & 12 & yes & uniphasic & 37 & 1.4 & 16.6 \\
\hline & & iomeron 350 & $41.5 \pm 5.5$ & $4.06 \pm 0.57$ & 10 & yes & uniphasic & 37 & 1.42 & 14.5 \\
\hline \multirow[t]{3}{*}{ Tatsugami $^{60}$} & $20 G$ & iomeron 350 & $46.5 \pm 5.25$ & $3.3 \pm 0.37$ & 14 & yes & uniphasic & 37 & 1.16 & 16.28 \\
\hline & & iomeron 350 & $44.3 \pm 4.71$ & $4.4 \pm 0.48$ & 10 & yes & uniphasic & 37 & 1.54 & 15.5 \\
\hline & & iomeron 350 & $39.3 \pm 5.41$ & $4.0 \pm 0.55$ & 10 & yes & uniphasic & 37 & 1.40 & 13.76 \\
\hline \multirow[t]{2}{*}{ Becker $^{61}$} & $18 \mathrm{G}$ & iodixanol 320 & 80 & 5 & 16 & yes & uniphasic & 37 & 1.6 & 25.6 \\
\hline & & iomeprol 400 & 80 & 5 & 16 & yes & uniphasic & 37 & 2 & 32 \\
\hline \multirow[t]{3}{*}{ Isogai ${ }^{7}$} & $18 \mathrm{G}$ & iohexol 300 & 44.7 & 4.5 & 10 & yes & uniphasic & & 1.35 & 13.42 \\
\hline & & iohexol 350 & 38.6 & 3.9 & 10 & yes & uniphasic & & 1.37 & 13.52 \\
\hline & & iohexol 350 & 46.2 & 4.6 & 10 & yes & uniphasic & & 1.61 & 16.17 \\
\hline \multirow[t]{2}{*}{ Kumamaru $^{62}$} & $20 G$ & iopamidol 370 & 60 & 6 & 10 & yes & uniphasic & & 2.22 & 22.2 \\
\hline & & iopamidol 370 & 80 & 6 & 13.3 & yes & uniphasic & & 2.22 & 29.6 \\
\hline \multirow[t]{2}{*}{ Nakaura ${ }^{63}$} & $20 G$ & iohexol 350 & $57 \pm 10.1$ & $3.8 \pm 0.7$ & 15 & yes & uniphasic & & $1.33 \pm 0.23$ & 20 \\
\hline & & iohexol 350 & $39.7 \pm 6.4$ & $4.4 \pm 0.7$ & 9 & yes & uniphasic & & $1.55 \pm 0.25$ & 13.9 \\
\hline \multirow[t]{3}{*}{ Zhu ${ }^{64}$} & $20 G$ & iopromide 370 & $66.3(42-92)$ & $4.15(2.6-5.7)$ & 16.0 & yes & uniphasic & 37 & 1.54 & 24.5 \\
\hline & & iopromide 370 & $66.4(40-92)$ & $4.19(2.6-6)$ & 16.0 & yes & uniphasic & 37 & 1.55 & 24.6 \\
\hline & & iopromide 370 & $66.4(37-95)$ & $4.08(2.7-5.9)$ & 16.3 & yes & uniphasic & 37 & 1.51 & 24.6 \\
\hline \multirow[t]{2}{*}{ Zhu ${ }^{65}$} & $20 G$ & iopromide 370 & $73.6 \pm 13.5$ & $4.69 \pm 0.95$ & 15.8 & yes & uniphasic & 37 & 1.74 & 27.23 \\
\hline & & iopromide 370 & $67.9 \pm 8.3$ & $4.38 \pm 0.66$ & 15.6 & yes & uniphasic & 37 & 1.62 & 25.12 \\
\hline \multirow[t]{2}{*}{ Zhu ${ }^{66}$} & $20 G$ & iopromide 370 & $73.6(37-110)$ & $4.69(2.3-7.4)$ & 15.8 & yes & uniphasic & 37 & 1.74 & 27.2 \\
\hline & & iopromide 370 & $68.5(42-111)$ & $4.37(2.5-6.6)$ & 15.8 & yes & uniphasic & 37 & 1.62 & 25.3 \\
\hline
\end{tabular}




\begin{tabular}{|c|c|c|c|c|c|c|c|c|c|c|}
\hline Author & Needle & $\mathrm{CM}(\mathrm{mg} / \mathrm{ml})$ & CM volume (ml) & Flow rate $(\mathrm{ml} / \mathrm{s})$ & $\begin{array}{c}\text { Injection } \\
\text { duration (s) }\end{array}$ & Saline & $\begin{array}{l}\text { Injection } \\
\text { pattern }\end{array}$ & $\operatorname{Temp}\left({ }^{\circ} \mathrm{C}\right)$ & IDR (gl/s) & $\mathrm{TID}(\mathrm{g})$ \\
\hline \multirow[t]{2}{*}{ Kidoh $^{67}$} & $20 G$ & iohexol 350 & $40.6 \pm 7.6$ & $4.5 \pm 0.9$ & 9 & yes & uniphasic & & 1.58 & 14.21 \\
\hline & & iohexol 350 & $39.7 \pm 7.1$ & 5 & $8.0 \pm 1.4$ & yes & uniphasic & & 1.75 & 13.90 \\
\hline \multirow[t]{2}{*}{ Kidoh $^{68}$} & $20 G$ & iohexol 350 & $36.9 \pm 9.2$ & 4.1 & 9 & yes & uniphasic & & 1.44 & 12.92 \\
\hline & & iohexol 350 & $43.1 \pm 7.0$ & 4.8 & 9 & yes & uniphasic & & 1.68 & 15.09 \\
\hline \multirow[t]{3}{*}{$\operatorname{Liu}^{69}$} & $18 \mathrm{G}$ & iopromide 370 & $47 \pm 8$ & $5.0 / 6.0$ & $9.7 \pm 1.7$ & yes & uniphasic & & $1.85 / 2.22$ & 17.39 \\
\hline & & iopromide 370 & $44 \pm 8$ & $5.0 / 6.0$ & $8.4 \pm 1.6$ & yes & uniphasic & & $1.85 / 2.22$ & 16.28 \\
\hline & & iopromide 370 & $36 \pm 6$ & $5.0 / 6.0$ & $6.7 \pm 1.4$ & yes & uniphasic & & $1.85 / 2.22$ & 13.32 \\
\hline \multirow[t]{2}{*}{ Yang $^{70}$} & $18 G$ & iopamidol 370 & $30-60$ & 4 & & yes & uniphasic & & 1.48 & $11.1-22.2$ \\
\hline & & iopamidol 370 & 60 & 4 & & yes & uniphasic & & 1.48 & 22.2 \\
\hline \multirow[t]{3}{*}{ Tomizawa $^{71}$} & $20-22 \mathrm{G}$ & iopamidol 370 & $49.3 \pm 10.1$ & $3.5 \pm 0.7$ & 14 & no & uniphasic & 37 & 1.3 & 18.24 \\
\hline & & iopamidol 370 & $46.8 \pm 7.6$ & $3.3 \pm 0.5$ & 14 & yes & uniphasic & 37 & 1.22 & 17.32 \\
\hline & & iopamidol 370 & $43.9 \pm 9.6$ & $3.6 \pm 0.8$ & 12 & yes & uniphasic & 37 & 1.33 & 16.24 \\
\hline \multirow[t]{2}{*}{ Zheng $^{72}$} & $18 \mathrm{G}$ & iodixanol 270 & $65.5 \pm 11.1$ & 5 & & yes & uniphasic & & 1.35 & 17.69 \\
\hline & & iopromide 370 & $64.6 \pm 12.9$ & 5 & & yes & uniphasic & & 1.85 & 23.9 \\
\hline \multirow[t]{5}{*}{ Lembcke $^{73}$} & $18 G$ & iopromide 370 & 30 & 5 & 6 & yes & uniphasic & & 1.85 & 11.1 \\
\hline & & iopromide 370 & 40 & 5 & 8 & yes & uniphasic & & 1.85 & 14.8 \\
\hline & & iopromide 370 & 50 & 5 & 10 & yes & uniphasic & & 1.85 & 18.5 \\
\hline & & iopromide 370 & 60 & 5 & 12 & yes & uniphasic & & 1.85 & 22.2 \\
\hline & & iopromide 370 & 70 & 5 & 14 & yes & uniphasic & & 1.85 & 25.9 \\
\hline \multirow[t]{3}{*}{ Kawaguchi $^{74}$} & $20 G$ & iohexol 350 or & $38.6 \pm 7.6$ & 5 & $10.1 \pm 0.4$ & yes & uniphasic & & 1.75 or 1.85 & $14.8 \pm 2.9$ \\
\hline & & iopamidol 370 & $43.9 \pm 6.9$ & & & & & & & \\
\hline & & iopamidol 370 & $37.6 \pm 7.6$ & $3.7 \pm 0.7$ & $10.1 \pm 0.5$ & yes & uniphasic & & 1.37 & $13.9 \pm 2.8$ \\
\hline
\end{tabular}

Scan and patient related parameters are described in Table 1 and Table 2. In the vast majority of the included publications, a tube voltage of $120 \mathrm{kV}$ was used. Only a few papers either did not mention tube voltage, or made mention of lower or various $\mathrm{kV}$ settings. ${ }^{47,58,62,69,72,73}$ One publication stated a tube voltage of $135 \mathrm{kV}$ for all included patients. ${ }^{60}$ As different vendors and scanners were used, scan related parameters such as collimation, slice reconstruction and kernel were not comparable and occasionally missing. Baseline characteristics were poorly described, only reporting, mean age, heart rate and weight. Approximately 20 publications state one or more additional baseline characteristics (e.g. BMI, cardiac output or blood pressure). 7, 47, 51, 53-56, 62-74

Injection related parameters are described in Table 3. Temperature of the injected CM concentration was only stated in a limited amount of publications. ${ }^{15,19,51,55,57,59-}$ 61,64-66,71 A saline flush was initially not used in all injection protocols, but has gained increasing popularity in more recent publications where only few publications used injection protocols without a saline flush. ${ }^{43-45,48,56,57,71}$ Only eight publications state usage of a biphasic protocol, often in comparison to a uniphasic injection protocol. ${ }^{44-}$ $46,48,52-54,56$ The total injected CM volume ranged between $30 \mathrm{ml}$ and $140 \mathrm{ml}$. Within the 
period of inclusion, a gradual decrease in total injected CM volume is noted, as earlier publications make mention of a total injected $\mathrm{CM}$ volume of $140 \mathrm{ml}^{15,43,44}$, whereas more recent publications reported $\mathrm{CM}$ injection protocols with total injected $\mathrm{CM}$ volumes below $40 \mathrm{ml} .{ }^{68,69,73,74}$ Subsequently, the TID has substantially lowered from anywhere between $44-56 \mathrm{~g}^{15,43,44}$ to less than $15 \mathrm{~g}$ (range: $11.1-56.0 \mathrm{~g}$ ). 7 , 46, 59, 60, 63, 67-70

\section{Injection related parameters and coronary attenuation}

The results of all included publications in relation to its three major injection parameters are listed in a supplementary table (Table 1, supplemental material). CM concentration varied between $270 \mathrm{mg} / \mathrm{ml}$ and $400 \mathrm{mg} / \mathrm{ml}$. However, only four CM injection protocols make use of $\mathrm{CM}$ concentrations below $320 \mathrm{mg} / \mathrm{ml}^{7,15,19,72}$ The variety in injection rate was higher than for the $\mathrm{CM}$ concentrations, varying between $2.5 \mathrm{ml} / \mathrm{s}^{19}$ and $6 \mathrm{ml} / \mathrm{s}^{54,62,69}$ The majority of the included papers keep injection rate relatively constant when comparing different groups. Only a few studies mention substantial differences in flow rates between groups. ${ }^{19,54,60,74}$ IDR ranged between $0.99 \mathrm{gl} / \mathrm{s}$ and $2.22 \mathrm{gl} / \mathrm{s}$ and proved to be very heterogeneous. A limited amount of injection protocols stated usage of an IDR above $1.9 \mathrm{gl} / \mathrm{s}^{53,54,62,69}$ All included publications that stated a flow rate below $4 \mathrm{ml} / \mathrm{s}$, also report an IDR $<1.4 \mathrm{gl} / \mathrm{s}$. 7, 45, 46, 60, 63, 74 However, lower CM concentrations were not always associated with lower IDR levels, as some publications state IDR levels $\geq 1.4 \mathrm{gl} / \mathrm{s}$ with usage of lower $(320 \mathrm{mg} / \mathrm{ml}) \mathrm{CM}$ concentrations indicating that CM injection rate might have a larger influence on the calculated IDR. ${ }^{44,47,58}$

Of the included studies evaluating differences in attenuation between CM concentrations, the majority did not report statistical significant differences between different CM concentrations. ${ }^{19,51,55,57}$ Three studies report significant differences between CM concentrations in favor of higher CM concentrations. ${ }^{15,16,61}$ However, in these three studies, other injection parameters such as IDR were not kept identical between groups. Conflicting results were reported with regard to influence of IDR on coronary attenuation. When IDR differed between subgroups, various publications found significant differences in attenuation of the coronary arteries in favor of higher IDR. ${ }^{7,15,16,54,60,61,67,68,74}$ When IDR between subgroups was kept identical, numerous publications did not find statistically significant differences in coronary attenuation. ${ }^{7,15,19,43-45,48,50,59,69,70}$ However, in both cases (variable and identical IDR) other injection related parameters varied substantially, making it difficult to extract the true influence of IDR on coronary attenuation. ${ }^{46,49,52,54,56,62,73}$

Diagnostic attenuation levels of the RCA were reached in the vast majority of the included studies when IDR levels $\geq 1.4 \mathrm{gl} / \mathrm{s}$ were used. Only seven studies report nondiagnostic attenuation levels of the RCA with usage of an IDR $\geq 1.4 \mathrm{gI} / \mathrm{s}^{16,44-46,48,53,57}$ of which four studies report the lack of usage of a saline chaser. $44,45,48,57$ 
When no saline flush was applied, virtually all publications report attenuation values of the RCA below diagnostic $(<325 \mathrm{HU})$ level, stressing the importance of a saline chaser. ${ }^{43-45,48,57}$ One publication reports attenuation values of the RCA above diagnostic levels without usage of a saline flush $(366.7 \pm 86.7 \mathrm{HU}){ }^{56}$ In this injection protocol however, an IDR of $1.75 \mathrm{gl} / \mathrm{s}$ was used. A trend towards higher attenuation levels was observed when biphasic injection protocols were used while injecting a higher IDR. ${ }^{45,46,52,54,56}$ Only one publication reports surprisingly low attenuation levels $(290 \pm 46 \mathrm{HU})$ with usage of an IDR of $1.6 \mathrm{gl} / \mathrm{s}$. However, a saline flush was not used in this injection protocol, again emphasizing the need for an additional saline flush in a standardized injection protocol. ${ }^{44}$

\section{DISCUSSION}

The aim of this systematic review was to provide an update on the effect of different CM injection parameters on the attenuation in CCTA. A large variation regarding scan technique, patient characteristics and $\mathrm{CM}$ injection protocols was found. This heterogeneity makes it difficult to draw sound conclusions and stresses the need for new studies in which such heterogeneity is avoided.

The influence of $\mathrm{CM}$ concentration solely on attenuation has been an ongoing topic of interest. The majority of the included studies evaluating differences in CM concentrations did not find statistical significant differences in attenuation between groups. ${ }^{19,51,55,57}$ Some studies do attribute higher attenuation to higher CM concentrations. ${ }^{15,16,61}$ Becker et al. conducted a double-blinded multicenter randomized controlled trial, which randomized patients in $2 \mathrm{CM}$ groups (iodixanol $320 \mathrm{mg} / \mathrm{ml}$ and iomeprol $400 \mathrm{mg} / \mathrm{ml}$ ) in order to assess whether CM characteristics affect diagnostic quality. In both groups $80 \mathrm{ml} \mathrm{CM}$ was injected at an identical injection rate of $5 \mathrm{ml} / \mathrm{s} .{ }^{61}$ A significant difference was found in coronary attenuation in favor of the $400 \mathrm{mg} / \mathrm{ml}$ group. The authors concluded that higher iodine concentration $\mathrm{CM}$ was beneficial to attenuation when administered at identical injection rate and volume. However, administering different $\mathrm{CM}$ concentrations at identical injection rate leads to differences in IDRs $(320 \mathrm{mg} / \mathrm{ml}$ : $1.6 \mathrm{gl} / \mathrm{s}$ vs. $400 \mathrm{mg} / \mathrm{ml}: 2.0 \mathrm{gl} / \mathrm{s})$. Therefore, the higher attenuation values found in the $400 \mathrm{mg} / \mathrm{ml}$ group might not be contributed to the CM concentration solely, but rather to the calculated product between CM concentration and injection rate (e.g. a higher IDR).

Comparable results are reported by Cademartiri et al. ${ }^{15}$ who evaluated coronary attenuation in five different CM groups where both injection rate and CM volume were kept identical in all groups. Mean attenuation values were significantly lower in the lower CM group and higher in the high concentrated CM group. Again, due to the use of an identical injection rate in both groups, IDR varied significantly (1.2 to $1.6 \mathrm{gl} / \mathrm{s}$ ), rendering doubtful conclusions with regard to sole superiority of higher CM concentrations. The results of our systematic review show diagnostic attenuation levels 
of the RCA in the vast majority of the included studies when IDR levels $\geq 1.4 \mathrm{gl} / \mathrm{s}$ were used and suggest that IDR levels are easier modified through usage of a large variety in flow rates rather than a limited variety in CM concentrations $(270-400 \mathrm{mg} / \mathrm{ml}$ ). Therefore, the subsequent influence of $\mathrm{CM}$ concentrations on IDR is expected to be lower in comparison to the flow rate.

Our results confirm the need for an additional saline flush in a CM injection protocol. ${ }^{75}$ A saline flush pushes the tail of the injected $\mathrm{CM}$ bolus into the central blood volume so utilizing $\mathrm{CM}$ that would otherwise remain behind in the injection tubing and peripheral veins. ${ }^{4}$ The additional value of a saline flush is illustrated by Cademartiri et al. ${ }^{43}$ Cademartiri et al. divided patients into two groups for CM administration: group 1 $(140 \mathrm{ml}$ at $4 \mathrm{ml} / \mathrm{s}$, no saline flush) and group $2(100 \mathrm{ml}$ at $4 \mathrm{ml} / \mathrm{s}$ followed by $40 \mathrm{ml}$ of saline chaser at $4 \mathrm{ml} / \mathrm{s})$ with identical IDR in both groups $(1.28 \mathrm{gl} / \mathrm{s})$. No significant differences in attenuation of the coronary arteries were found despite the difference in injected CM volume. ${ }^{43}$ As group 1 did not receive a saline flush, it is quite possible that some of the injected CM bolus was not dispensed into the central blood volume, leading to a decrease of effective $\mathrm{CM}$ volume and to the non-significant differences in intracoronary attenuation.

Attenuation values can not be attributed solely to a saline flush and the product of CM concentration and flow rate, as discussed in the above. Lembcke et al assessed the effect of lower CM volumes on image quality in high-pitch CCTA. ${ }^{73}$ Patients were randomly assigned to one of five groups with different $\mathrm{CM}$ volumes (e.g. 30-70ml). Flow rate and CM concentration remained identical in all groups $(5 \mathrm{ml} / \mathrm{s}$ and $370 \mathrm{mg} / \mathrm{ml}$, respectively). As volumes in all groups were different, calculated TID is also different (varying between $11.1 \mathrm{~g}$ and $25.9 \mathrm{~g}$ ). They reported significantly higher mean attenuation values in groups with higher $\mathrm{CM}$ volumes. ${ }^{73}$ An increased total $\mathrm{CM}$ volume administration injected at the same flow rate leads to a prolonged injection duration, which increases the magnitude of vascular enhancement. Similarly, injection of a dedicated $\mathrm{CM}$ with higher flow rates affects both the magnitude and timing of contrast enhancement, leading to a shorter, earlier and higher peak enhancement and thus a proportional increase in vascular and parenchymal enhancement. 1, 41,76,77 A short injection duration might be challenging and requires careful timing of $\mathrm{CM}$ bolus injection and data acquisition, especially in patients with abnormal hemodynamic parameters (e.g. irregular heart rate or low/high cardiac output). ${ }^{73}$ The authors recommend to take into account the patient's hemodynamic status, especially cardiac output, before imaging. Information regarding cardiac output has only been supplied in a very limited amount of included publications. ${ }^{51,63,64,67-69}$ Body weight and BMI are known to have a substantial impact on vascular attenuation and time to peak in CTA. ${ }^{11,78-80}$ Many included publications evaluated applicability of different body weight adjusted CM injection or biphasic injection protocols with various different outcomes. Seifarth et al. investigated, if individually tailored $\mathrm{CM}$ injection software resulted in 
higher vascular attenuation of coronary arteries compared to fixed injection protocols. ${ }^{54}$ They evaluated a body weight adapted individualized CM injection software in comparison to two different standard injection protocols and found comparable or increased attenuation values in favour of the individualized CM injection software. However, besides overall mean attenuation of the coronary arteries between groups, an analysis for differences in attenuation values between weight classes was not performed.

This study has several limitations. The study population inclusion criterion was set to a minimum of 30 patients. Furthermore, a limited number of prospective randomized trials is available on this topic. A well-known limitation in all systematic reviews is that studies with less favourable results have a tendency not to be published. A publication bias, therefore, cannot be ruled out. Another potential limitation is the heterogeneity of vendors and scanner types. Although technical advances have improved image quality substantially throughout the years, image quality can vary between vendors and scanner types. Finally, most studies provided only limited data concerning injection-, scanning- and patient-parameters. Not all corresponding authors of the included articles completed and sent back the questionnaire or provided additional information. Therefore, possible effects of patient level characteristics (e.g. BMI, cardiac output) could not be accounted for due to the lack of provided data. Nevertheless, these factors have a significant impact in clinical routine and should be addressed by individualized scan and CM injection protocols. Finally, most of the included studies were scanned with a tube voltage of $120 \mathrm{kV}$. As lower tube voltages have a strong influence on enhancement patterns, current technical developments are moving towards broad clinical application of lower kV settings, allowing a substantial decrease in various determinant injection parameters (e.g. IDR, CM volume).

\section{CONCLUSION}

This systematic review shows that an adequate attenuation in the coronary arteries can be achieved with very different CM injection protocols. However, given the substantial variability between studies, it remains unclear which of the injection parameters are the most important determinant for adequate attenuation. Given the multiple options as described in the literature, it is highly likely that one parameter that combines multiple parameters (e.g. IDR) will be the most suitable determinant of coronary attenuation in CCTA protocols. In a more pragmatic approach, an IDR level of $1.6 \mathrm{gl} / \mathrm{s}$ would probably suite most of the patients in an optimal way. In addition, a saline flush is an essential parameter in a CM injection protocol, pushing the tail of the injected CM bolus into the central blood volume. As future directions are aimed towards more individualized CM injection protocols, research should be tailored towards unraveling the influence of 
different injection parameters to understand which parameters play a pivotal role on attenuation of the coronary arteries. Then, the possibility will arise to offer a CM injection protocol with applicability of a broad variety in injection and scan related parameters tailored to each individual patient.

\section{REFERENCES}

1. Bae KT. Intravenous contrast medium administration and scan timing at ct: Considerations and approaches. Radiology. 2010;256:32-61

2. Otero HJ, Steigner ML, Rybicki FJ. The "post-64" era of coronary ct angiography: Understanding new technology from physical principles. Radiol Clinic North Am. 2009;47:79-90

3. Achenbach S, Marwan M, Schepis T, Pflederer T, Bruder H, Allmendinger T, Petersilka M, Anders K, Lell M, Kuettner A, Ropers D, Daniel WG, Flohr T. High-pitch spiral acquisition: A new scan mode for coronary ct angiography. J Cardiovasc Comput Tomogr. 2009;3:117-121

4. Bae KT. Optimization of contrast enhancement in thoracic mdct. Radiol Clinic North Am. 2010;48:9-29

5. Budoff MJ, Dowe D, Jollis JG, Gitter M, Sutherland J, Halamert E, Scherer M, Bellinger R, Martin A, Benton R, Delago A, Min JK. Diagnostic performance of 64-multidetector row coronary computed tomographic angiography for evaluation of coronary artery stenosis in individuals without known coronary artery disease: Results from the prospective multicenter accuracy (assessment by coronary computed tomographic angiography of individuals undergoing invasive coronary angiography) trial. J Am Coll Cardiol. 2008;52:1724-1732

6. Meijboom WB, Meijs MF, Schuijf JD, Cramer MJ, Mollet NR, van Mieghem CA, Nieman K, van Werkhoven JM, Pundziute G, Weustink AC, de Vos AM, Pugliese F, Rensing B, Jukema JW, Bax JJ, Prokop M, Doevendans PA, Hunink MG, Krestin GP, de Feyter PJ. Diagnostic accuracy of 64-slice computed tomography coronary angiography: A prospective, multicenter, multivendor study. J Am Coll Cardiol. 2008;52:2135-2144

7. Isogai T, Jinzaki M, Tanami Y, Kusuzaki H, Yamada M, Kuribayashi S. Body weight-tailored contrast material injection protocol for 64-detector row computed tomography coronary angiography. Jpn J Radiol. 2011;29:33-38

8. Cademartiri F, Mollet NR, Lemos PA, Saia F, Midiri M, de Feyter PJ, Krestin GP. Higher intracoronary attenuation improves diagnostic accuracy in mdct coronary angiography. AJR Am J Roentgenol. 2006;187:W430-433

9. Cademartiri F, Maffei E, Palumbo AA, Malago R, La Grutta L, Meiijboom WB, Aldrovandi A, Fusaro M, Vignali L, Menozzi A, Brambilla V, Coruzzi P, Midiri M, Kirchin MA, Mollet NR, Krestin GP. Influence of intra-coronary enhancement on diagnostic accuracy with 64-slice ct coronary angiography. Eur Radiol. 2008; 18:576-583

10. Johnson PT, Pannu HK, Fishman EK. IV contrast infusion for coronary artery ct angiography: Literature review and results of a nationwide survey. AJR. Am J Roentgenol. 2009;192:W214-221

11. Awai K, Hiraishi K, Hori S. Effect of contrast material injection duration and rate on aortic peak time and peak enhancement at dynamic ct involving injection protocol with dose tailored to patient weight. Radiology. 2004;230:142-150

12. Muhlenbruch G, Behrendt FF, Eddahabi MA, Knackstedt C, Stanzel S, Das M, Seidensticker P, Gunther RW, Wildberger JE, Mahnken AH. Which iodine concentration in chest ct? - A prospective study in 300 patients. Eur Radiol. 2008;18:2826-2832

13. Behrendt FF, Bruners P, Keil S, Plumhans C, Mahnken AH, Stanzel S, Das M, Gunther RW, Muhlenbruch G. Impact of different vein catheter sizes for mechanical power injection in ct: In vitro evaluation with use of a circulation phantom. Cardiovasc Intervent Radiol. 2009;32:25-31

14. Knollmann F, Schimpf K, Felix R. lodine delivery rate of different concentrations of iodine-containing contrast agents with rapid injection. RoFo. 2004;176:880-884

15. Cademartiri F, Mollet NR, van der Lugt A, McFadden EP, Stijnen T, de Feyter PJ, Krestin GP. Intravenous contrast material administration at helical 16-detector row ct coronary angiography: Effect of iodine concentration on vascular attenuation. Radiology. 2005;236:661-665 
16. Cademartiri F, de Monye C, Pugliese F, Mollet NR, Runza G, van der Lugt A, Midiri M, de Feyter PJ, Lagalla R, Krestin GP. High iodine concentration contrast material for noninvasive multislice computed tomography coronary angiography: lopromide 370 versus iomeprol 400. Invest Radiol. 2006;41:349-353

17. Brunette J, Mongrain R, Laurier J, Galaz R, Tardif JC. 3d flow study in a mildly stenotic coronary artery phantom using a whole volume piv method. Med Eng Phys. 2008;30:1193-1200

18. Nance JW, Jr., Henzler T, Meyer M, Apfaltrer P, Braunagel M, Krissak R, Schoepf UJ, Schoenberg SO, Fink C. Optimization of contrast material delivery for dual-energy computed tomography pulmonary angiography in patients with suspected pulmonary embolism. Invest Radiol. 2012;47:78-84

19. Rist C, Nikolaou K, Kirchin MA, van Gessel R, Bae KT, von Ziegler F, Knez A, Wintersperger BJ, Reiser MF, Becker CR. Contrast bolus optimization for cardiac 16-slice computed tomography: Comparison of contrast medium formulations containing 300 and 400 milligrams of iodine per milliliter. Invest Radiol. 2006; $41: 460-467$

20. Behrendt FF, Pietsch H, Jost G, Palmowski M, Gunther RW, Mahnken AH. Identification of the iodine concentration that yields the highest intravascular enhancement in mdct angiography. AJR Am J Roentgenol. 2013;200:1151-1156

21. Moher D, Liberati A, Tetzlaff J, Altman DG, Group P. Preferred reporting items for systematic reviews and meta-analyses: The prisma statement. J Clin Epidemiol. 2009;62:1006-1012

22. Malayeri AA, Zimmerman SL, Lake ST, Fishman EK, Johnson PT. 128-slice dual source coronary cta: Defining optimal arterial enhancement levels. Emer Radiol. 2014;21:499-504

23. Becker CR, Hong C, Knez A, Leber A, Bruening R, Schoepf UJ, Reiser MF. Optimal contrast application for cardiac 4-detector-row computed tomography. Invest Radiol. 2003;38:690-694

24. Cademartiri F, Luccichenti G, Marano R, Gualerzi M, Brambilla L, Coruzzi P. Comparison of monophasic vs biphasic administration of contrast material in non-invasive coronary angiography using a 16-row multislice computed tomography. Radiol Med. 2004;107:489-496

25. Cademartiri F, Luccichenti G, Marano R, Runza G, Midiri M. Use of saline chaser in the intravenous administration of contrast material in non-invasive coronary angiography with 16-row multislice computed tomography. Radiol Med. 2004;107:497-505

26. Cao L, Du X, Li P, Liu Y, Li K. Multiphase contrast-saline mixture injection with dual-flow in 64-row mdct coronary cta. Eur J Radiol. 2009;69:496-499

27. Fuchs TA, Stehli J, Bull S, Dougoud S, Clerc OF, Herzog BA, Buechel RR, Gaemperli O, Kaufmann PA. Coronary computed tomography angiography with model-based iterative reconstruction using a radiation exposure similar to chest x-ray examination. Eur Heart J. 2014;35:1131-1136

28. Hein PA, Romano VC, Lembcke A, May J, Rogalla P. Initial experience with a chest pain protocol using 320slice volume mdct. Eur Radiol. 2009;19:1148-1155

29. Christensen JD, Meyer LT, Hurwitz LM, Boll DT. Effects of iopamidol-370 versus iodixanol-320 on coronary contrast, branch depiction, and heart rate variability in dual-source coronary mdct angiography. AJR Am J Roentgenol. 2011;197:W445-451

30. Kalafut JF, Kemper CA, Suryani P, Schoepf U. A personalized and optimal approach for dosing contrast material at coronary computed tomography angiography. Conf Proc IEEE Eng Med Biol. 2009:3521-3524

31. Kidoh M, Nakaura T, Nakamura S, Nakamura S, Sakaino N, Harada K, Uemura S, Yamashita Y. Lowcontrast-dose protocol in cardiac ct: $20 \%$ contrast dose reduction using $100 \mathrm{kvp}$ and high-tube-currenttime setting in 256-slice ct. Acta Radiol. 2014;55:545-553

32. Kidoh M, Nakaura T, Nakamura S, Namimoto T, Nozaki T, Sakaino N, Harada K, Yamashita Y. Contrast material and radiation dose reduction strategy for triple-rule-out cardiac ct angiography: Feasibility study of non-ecg-gated low kvp scan of the whole chest following coronary ct angiography. Acta Radiol. 2014;55:1186-1196

33. Komatsu S, Kamata T, Imai A, Ohara T, Takewa M, Ohe R, Miyaji K, Yoshida J, Kodama K. Coronary computed tomography angiography using ultra-low-dose contrast media: Radiation dose and image quality. Int J Cardiovasc Imaging. 2013;29:1335-1340

34. Li S, Liu J, Peng L, Wu H, Wang C, Ni Q, Luo Y, Chen L, Zhu J, Dong R. Contrast volume reduction adapted to body mass index for 320-slice coronary computed tomography angiography: Results from four-year clinical routine at a single center. Int J Cardiol. 2014;172:e140-142

35. Litmanovich D, Zamboni GA, Hauser TH, Lin PJ, Clouse ME, Raptopoulos V. Ecg-gated chest ct angiography with 64-mdct and tri-phasic iv contrast administration regimen in patients with acute non-specific chest pain. Eur Radiol. 2008;18:308-317 
36. Mitsumori LM, Wang E, May JM, Lockhart DW, Branch KR, Dubinsky TJ, Shuman WP. Triphasic contrast bolus for whole-chest ecg-gated 64-mdct of patients with nonspecific chest pain: Evaluation of arterial enhancement and streak artifact. AJR Am J Roentgenol. 2010;194:W263-271

37. Rienmuller R, Brekke O, Kampenes VB, Reiter U. Dimeric versus monomeric nonionic contrast agents in visualization of coronary arteries. Eur J Radiol. 2001;38:173-178

38. Rutten A, Meijs MF, de Vos AM, Seidensticker PR, Prokop M. Biphasic contrast medium injection in cardiac ct: Moderate versus high concentration contrast material at identical iodine flux and iodine dose. Eur Radiol. 2010;20:1917-1925

39. Stenzel F, Rief M, Zimmermann E, Greupner J, Richter F, Dewey M. Contrast agent bolus tracking with a fixed threshold or a manual fast start for coronary ct angiography. Eur Radiol. 2014;24:1229-1238

40. Tatsugami F, Husmann L, Herzog BA, Burkhard N, Valenta I, Gaemperli O, Kaufmann PA. Evaluation of a body mass index-adapted protocol for low-dose 64-mdct coronary angiography with prospective ecg triggering. AJR Am J Roentgenol. 2009;192:635-638

41. Wuest W, Anders K, Scharf M, May M, Brand M, Uder M, Ropers D, Achenbach S, Kuettner A. Which concentration to choose in dual flow cardiac ct?: Dual flow cardiac ct. Eur J Radiol. 2012;81:e461-466

42. Yuki H, Utsunomiya D, Funama Y, Tokuyasu S, Namimoto T, Hirai T, Itatani R, Katahira K, Oshima S, Yamashita Y. Value of knowledge-based iterative model reconstruction in low-kv 256-slice coronary ct angiography. J Cardiovasc Comput Tomogr. 2014;8:115-123

43. Cademartiri F, Mollet N, van der Lugt A, Nieman K, Pattynama PM, de Feyter PJ, Krestin GP. Non-invasive 16-row multislice ct coronary angiography: Usefulness of saline chaser. Eur Radiol. 2004;14:178-183

44. Cademartiri F, Luccichenti G, Gualerzi M, Brambilla L, Brambilla V, Coruzzi P. Intravenous contrast material administration in multislice computed tomography coronary angiography. Acta Biomed. 2005;76:86-94

45. Utsunomiya D, Awai K, Sakamoto T, Nishiharu T, Urata J, Taniguchi A, Nakaura T, Yamashita Y. Cardiac 16mdct for anatomic and functional analysis: Assessment of a biphasic contrast injection protocol. AJR Am J Roentgenol. 2006;187:638-644

46. Yamamuro M, Tadamura E, Kanao S, Wu YW, Tambara K, Komeda M, Toma M, Kimura T, Kita T, Togashi K. Coronary angiography by 64-detector row computed tomography using low dose of contrast material with saline chaser: Influence of total injection volume on vessel attenuation. J Comput Assist Tomogr. 2007;31:272-280

47. Husmann L, Valenta I, Gaemperli O, Adda O, Treyer V, Wyss CA, Veit-Haibach P, Tatsugami F, von Schulthess GK, Kaufmann PA. Feasibility of low-dose coronary ct angiography: First experience with prospective ecg-gating. Eur Heart J. 2008;29:191-197

48. Kerl JM, Ravenel JG, Nguyen SA, Suranyi P, Thilo C, Costello P, Bautz W, Schoepf UJ. Right heart: Splitbolus injection of diluted contrast medium for visualization at coronary ct angiography. Radiology. 2008;247:356-364

49. Kim DJ, Kim TH, Kim SJ, Kim DP, Oh CS, Ryu YH, Kim YJ, Choi BW. Saline flush effect for enhancement of aorta and coronary arteries at multidetector ct coronary angiography. Radiology. 2008;246:110-115

50. Nakaura T, Awai K, Yauaga Y, Nakayama Y, Oda S, Hatemura M, Nagayoshi Y, Ogawa H, Yamashita Y. Contrast injection protocols for coronary computed tomography angiography using a 64-detector scanner: Comparison between patient weight-adjusted- and fixed iodine-dose protocols. Invest Radiol. 2008;43:512-519

51. Tsai IC, Lee T, Tsai WL, Chen MC, Wu MJ, Lee WL, Ting HJ. Contrast enhancement in cardiac mdct: Comparison of iodixanol 320 versus iohexol 350. AJR Am J Roentgenol. 2008;190:W47-53

52. Wuest W, Zunker C, Anders K, Ropers D, Achenbach S, Bautz W, Kuettner A. Functional cardiac ct imaging: A new contrast application strategy for a better visualization of the cardiac chambers. Eur J Radiol. 2008;68:392-397

53. Halpern EJ, Levin DC, Zhang S, Takakuwa KM. Comparison of image quality and arterial enhancement with a dedicated coronary cta protocol versus a triple rule-out coronary cta protocol. Acad Radiol. 2009;16:1039-1048

54. Seifarth H, Puesken M, Kalafut JF, Wienbeck S, Wessling J, Maintz D, Heindel W, Juergens KU. Introduction of an individually optimized protocol for the injection of contrast medium for coronary ct angiography. Eur Radiol. 2009;19:2373-2382

55. Kim EY, Yeh DW, Choe YH, Lee WJ, Lim HK. Image quality and attenuation values of multidetector ct coronary angiography using high iodine-concentration contrast material: A comparison of the use of iopromide 370 and iomeprol 400. Acta Radiol. 2010;51:982-989 
56. Lu JG, Lv B, Chen XB, Tang X, Jiang SL, Dai RP. What is the best contrast injection protocol for 64-row multi-detector cardiac computed tomography? Eur J Radiol. 2010;75:159-165

57. Ozbulbul NI, Yurdakul M, Tola M. Comparison of a low-osmolar contrast medium, iopamidol, and an isoosmolar contrast medium, iodixanol, in mdct coronary angiography. Coron Artery Dis. 2010;21:414-419

58. Pazhenkottil AP, Husmann L, Buechel RR, Herzog BA, Nkoulou R, Burger IA, Vetterli A, Valenta I, Ghadri JR, von Schulthess $P$, Kaufmann PA. Validation of a new contrast material protocol adapted to body surface area for optimized low-dose ct coronary angiography with prospective ecg-triggering. Int J Cardiovasc Imaging. 2010;26:591-597

59. Tatsugami F, Matsuki M, Inada Y, Kanazawa S, Nakai G, Takeda Y, Morita H, Takada H, Ashida K, Yoshikawa S, Fukumura K, Narumi Y. Feasibility of low-volume injections of contrast material with a body weightadapted iodine-dose protocol in 320-detector row coronary ct angiography. Acad Radiol. 2010;17:207211

60. Tatsugami F, Kanamoto T, Nakai G, Takeda Y, Morita H, Morinaga I, Yoshikawa S, Narabayashi I. Reduction of the total injection volume of contrast material with a short injection duration in 64-detector row ct coronary angiography. Br J Radiol. 2010;83:35-39

61. Becker CR, Vanzulli A, Fink C, de Faveri D, Fedeli S, Dore R, Biondetti P, Kuettner A, Krix M, Ascenti G. Multicenter comparison of high concentration contrast agent iomeprol-400 with iso-osmolar iodixanol320: Contrast enhancement and heart rate variation in coronary dual-source computed tomographic angiography. Invest Radiol. 2011;46:457-464

62. Kumamaru KK, Steigner ML, Soga S, Signorelli J, Bedayat A, Adams K, Mitsouras D, Rybicki FJ. Coronary enhancement for prospective ecg-gated single r-r axial 320-mdct angiography: Comparison of 60- and 80$\mathrm{ml}$ iopamidol 370 injection. AJR Am J Roentgenol. 2011;197:844-850

63. Nakaura T, Awai K, Yanaga Y, Namimoto T, Utsunomiya D, Hirai T, Sugiyama S, Ogawa H, Aoyama M, Yamashita Y. Low-dose contrast protocol using the test bolus technique for 64-detector computed tomography coronary angiography. Jpn J Radiol. 2011;29:457-465

64. Zhu X, Chen W, Li M, Xu Y, Xu H, Zhu Y, Wang D, Tang L. Contrast material injection protocol with the flow rate adjusted to the heart rate for dual source ct coronary angiography. Int J Cardiovasc Imaging. 2012;28:1557-1565

65. Zhu X, Zhu Y, Xu H, Yang G, Tang L, Xu Y. Dual-source ct coronary angiography involving injection protocol with iodine load tailored to patient body weight and body mass index: Estimation of optimal contrast material dose. Acta Radiol. 2013;54:149-155

66. Zhu $X$, Zhu Y, Xu H, Tang L, Xu Y. The influence of body mass index and gender on coronary arterial attenuation with fixed iodine load per body weight at dual-source ct coronary angiography. Acta Radiol. 2012;53:637-642

67. Kidoh M, Nakaura T, Awai K, Utsunomiya D, Sakaino N, Harada K, Uemura S, Yamashita Y. Compact-bolus dynamic ct protocol with a test bolus technique in 64-mdct coronary angiography: Comparison of fixed injection rate and duration protocol. Jpn J Radiol. 2013;31:115-122

68. Kidoh M, Nakaura T, Nakamura S, Awai K, Utsunomiya D, Namimoto T, Harada K, Yamashita Y. Novel contrast-injection protocol for coronary computed tomographic angiography: Contrast-injection protocol customized according to the patient's time-attenuation response. Heart Vessels. 2013

69. Liu J, Gao J, Wu R, Zhang Y, Hu L, Hou P. Optimizing contrast medium injection protocol individually with body weight for high-pitch prospective ecg-triggering coronary ct angiography. Int J Cardiovasc Imaging. 2013;29:1115-1120

70. Yang WJ, Chen KM, Liu B, Pang LF, Zhang H, Pan ZL, Yan FH. Contrast media volume optimization in highpitch dual-source ct coronary angiography: Feasibility study. Int J Cardiovasc Imaging. 2013;29:245-252

71. Tomizawa N, Suzuki F, Akahane M, Torigoe R, Kiryu S, Ohtomo K. Effect of saline flush on enhancement of proximal and distal segments using 320-row coronary ct angiography. Eur J Radiol. 2013;82:1255-1259

72. Zheng M, Liu Y, Wei M, Wu Y, Zhao H, Li J. Low concentration contrast medium for dual-source computed tomography coronary angiography by a combination of iterative reconstruction and low-tube-voltage technique: Feasibility study. European journal of radiology. 2014;83:e92-99

73. Lembcke A, Schwenke C, Hein PA, Knobloch G, Durmus T, Hamm B, Huppertz A. High-pitch dual-source ct coronary angiography with low volumes of contrast medium. Eur Radiol. 2014;24:120-127

74. Kawaguchi N, Kurata A, Kido T, Nishiyama Y, Kido T, Miyagawa M, Ogimoto A, Mochizuki T. Optimization of coronary attenuation in coronary computed tomography angiography using diluted contrast material. Circ J. 2014; 78:662-670 
75. Schoellnast H, Tillich M, Deutschmann HA, Deutschmann MJ, Fritz GA, Stessel U, Schaffler GJ, Uggowitzer MM. Abdominal multidetector row computed tomography: Reduction of cost and contrast material dose using saline flush. J Comput Assist Tomogr. 2003;27:847-853

76. Schoellnast H, Deutschmann HA, Berghold A, Fritz GA, Schaffler GJ, Tillich M. Mdct angiography of the pulmonary arteries: Influence of body weight, body mass index, and scan length on arterial enhancement at different iodine flow rates. AJR Am J Roentgenol. 2006;187:1074-1078

77. Bae KT, Heiken JP. Scan and contrast administration principles of mdct. Eur Radiol. 2005;15 Suppl 5:E4659

78. Bae KT, Seeck BA, Hildebolt CF, Tao C, Zhu F, Kanematsu M, Woodard PK. Contrast enhancement in cardiovascular mdct: Effect of body weight, height, body surface area, body mass index, and obesity. AJR Am J Roentgenol. 2008;190:777-784

79. Platt JF, Reige KA, Ellis JH. Aortic enhancement during abdominal ct angiography: Correlation with test injections, flow rates, and patient demographics. AJR Am J Roentgenol. 1999;172:53-56

80. Husmann L, Leschka S, Boehm T, Desbiolles L, Schepis T, Koepfli P, Gaemperli O, Marincek B, Kaufmann P, Alkadhi $\mathrm{H}$. Influence of body mass index on coronary artery opacification in 64-slice ct angiography. RoFo. 2006;178:1007-1013 

CHAPTER 3 Influence of contrast media viscosity and temperature on injection pressure in computed tomographic angiography:

A phantom study

C. Mihl*, M. Kok M*, A.A. Mingels, B.L.J.H. Kietselaer, G. Mühlenbruch, A. Seehofnerova, J.E. Wildberger, M. Das 


\section{ABSTRACT}

\section{Purpose}

lodinated contrast media (CM) in computed tomographic angiography (CTA) is characterized by its concentration and, consecutively, by its viscosity. Viscosity itself is directly influenced by temperature, which will furthermore affect injection pressure. Therefore, the purposes of this study were to systematically evaluate the viscosity of different $\mathrm{CM}$ at different temperatures and to assess their impact on injection pressure in a circulation phantom.

\section{Materials and methods}

Initially, viscosity of different CM concentrations (240,300, 370 and 400mg/ml) was measured at different temperatures $\left(20^{\circ} \mathrm{C}-40^{\circ} \mathrm{C}\right)$ with a commercially available viscosimeter. In the next step, a circulation phantom with physical conditions was used. $\mathrm{CM}$ was prepared at different temperatures $\left(20^{\circ} \mathrm{C}, 30^{\circ} \mathrm{C}, 37^{\circ} \mathrm{C}\right)$ and injected through a standard 18-gauge needle. All other relevant parameters were kept constant (iodine delivery rate: $1.9 \mathrm{gl} / \mathrm{s}$, total amount of iodine: $15 \mathrm{~g}$ ). Peak flow rate (in milliliter per second) and injection pressure (psi) were monitored. Differences in significance were tested using Kruskal-Wallis test (SPSS Inc; Chicago, IL, USA).

\section{Results}

Viscosities for iodinated CM of $240,300,370$ and $400 \mathrm{mg} / \mathrm{ml}$ at $20^{\circ} \mathrm{C}$ were $5.1,9.1,21.2$, and $28.8 \mathrm{mPa}$.s, respectively, whereas, at $40^{\circ} \mathrm{C}$, these were substantially lower $(2.8,4.4$, 8.7 , and $11.2 \mathrm{mPa} . \mathrm{s})$. In the circulation phantom, mean (SD) peak pressures for $\mathrm{CM}$ of $240 \mathrm{mg} / \mathrm{ml}$ at $20^{\circ} \mathrm{C}, 30^{\circ} \mathrm{C}$, and $37^{\circ} \mathrm{C}$ were: $107 \pm 1.5,95 \pm 0.6,92 \pm 2.1 \mathrm{psi}$, for $\mathrm{CM} 300 \mathrm{mg} / \mathrm{ml}$ : $119 \pm 1.5,104 \pm 0.6,100 \pm 3.6 \mathrm{psi}$, for CM $370 \mathrm{mg} / \mathrm{ml}: 150 \pm 0.6,133 \pm 4.4,120 \pm 3.5 \mathrm{psi}$, and for CM 400mg/ml: 169 $\pm 1.0,140 \pm 2.1,135 \pm 2.9 p s i$ respectively, with all $P$ values less than 0.05 .

\section{Conclusion}

Low concentration, low viscosity and high temperatures of CM are beneficial in terms of injection pressure. This should be considered for individual tailored contrast protocols in daily routine scanning. 


\section{INTRODUCTION}

The quality of computed tomographic angiography (CTA), especially coronary CTA, depends mostly on the degree of intravascular enhancement. Sufficient vessel attenuation is crucial for proper evaluation of vascular pathology, especially with respect to smaller vessels. ${ }^{1}$ Enhancement characteristics are influenced by scan technique, patient-related factors, contrast media (CM) characteristics, and injection parameters. $^{2-5}$ Previous studies already investigated the influence of iodine concentration, injection rates and iodine delivery rate (IDR) on diagnostic intravascular attenuation. ${ }^{1,6-12}$

Another factor that plays an important role in CM delivery and thus enhancement is viscosity. Viscosity is directly influenced by temperature, which means viscosity decreases with increasing temperature. ${ }^{7,13-16}$ On the other hand, viscosity of $\mathrm{CM}$ increases with higher iodine concentrations. Low viscosity will be advantageous in several ways: injection pressure is lower and CM distribution in the blood might be facilitated. This can potentially be advantageous for the visualization of distal vessel segments. ${ }^{2,6}$ However, this comes at the expenditure of higher flow rates when an identical IDR has to be maintained. Only few studies investigated differences in injection pressure with different injection protocols. ${ }^{1,17}$

The literature about CM characteristics and injection parameters remains heterogeneous and controversial. Intravascular attenuation will not significantly change with iodine concentration in a standardized setting. ${ }^{11}$ Thus, the purpose of this study was to evaluate different CM with different iodine concentrations in a standardized manner at different temperatures and to further investigate its influence on injection parameters, with special regard to injection pressure.

\section{MATERIALS AND METHODS}

\section{Viscosity analysis}

Viscosity was measured in a standard laboratory environment as depicted in Figure 1, using a commercially available viscosimeter (Ostwald viscosimeter; Julabo $\mathrm{GmbH}$, Seelbach, Germany). Monomeric nonionic and low-osmolar CMs were used (iopromide 240, 300, 370 [Ultravist; Bayer Healthcare, Berlin, Germany] and iomeprol 400 [Iomeron; Bracco Imaging, Milan, Italy]) containing 240, 300, 370, and 400 mg/ml, respectively. CM was warmed up in a standardized and controllable fashion in a water bath, which was immediately followed by loading the U-tube of the viscosimeter with $2 \mathrm{ml}$ of $\mathrm{CM}$. The measurements were performed between $20^{\circ} \mathrm{C}$ and $40^{\circ} \mathrm{C}$ with steps of $2^{\circ} \mathrm{C}$. All measurements were repeated 2 times to determine reproducibility. 


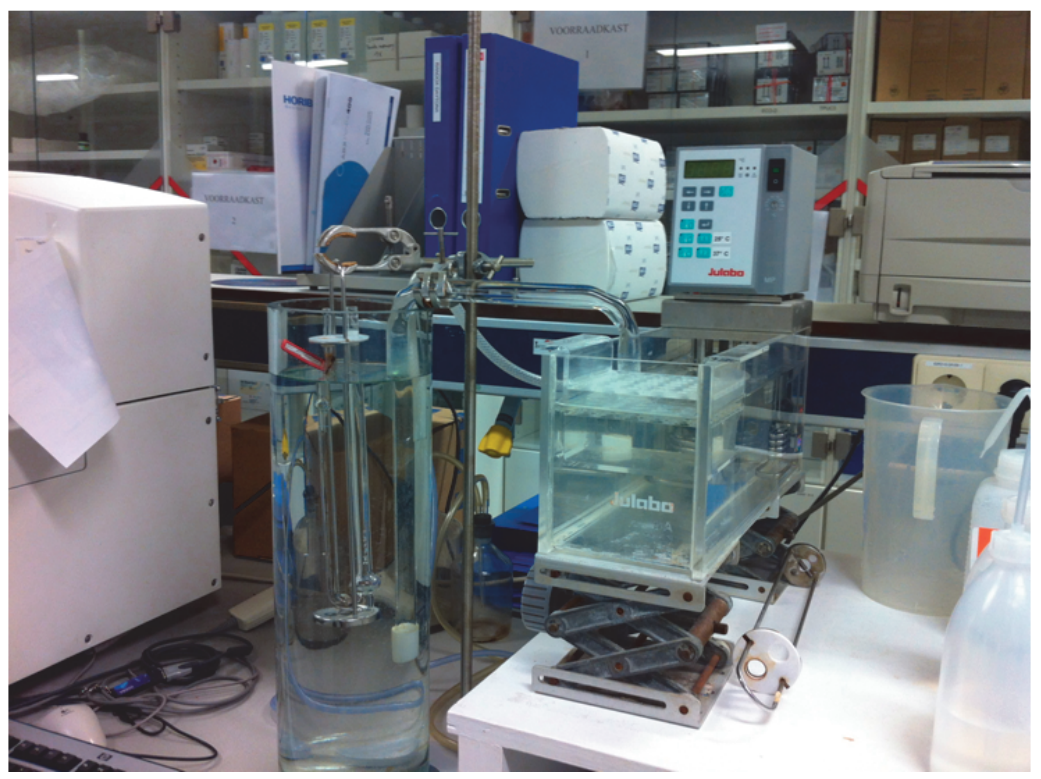

Figure 1: The U-tube of the viscosimeter: hanging in a water bath (left), which is connected with a tube to the main water bath with temperature control (right).

Kinematic viscosity (in square millimeter per second $\left[\mathrm{mm}^{2} / \mathrm{s}\right]$ ) was defined by multiplying the constant of the $U$-tube with the exact time that was required for each $\mathrm{CM}$ to run through the $\mathrm{U}$-tube. Dynamic viscosity (in millipascal per second) was defined by multiplying the kinematic viscosity $\left(\mathrm{mm}^{2} / \mathrm{s}\right)$ with the corresponding density of CM (in grams of iodine per milliliter). Density of CM (in grams of iodine per milliliter) was measured using a commercially available density instrument (Mettler Toledo Densito 30PX; Columbus, OH, USA).

\section{Circulation phantom}

A modified circulation phantom with physiological circulation parameters was used as first described by Behrendt et al. ${ }^{18}$ This phantom consists of a low-pressure lung and a high-pressure body circulation system, with accurate replicas of the entire aorta and those of the coronary arteries (Figure 2). In addition, the phantom consists of connecting tubes, a water filled acrylic container, two pressure meters and a pressure relieve valve for modulation of arterial and venous pressure. The phantom was filled with water at body temperature $\left(37^{\circ} \mathrm{C}\right)$; subsequently, circulation was driven by a pulsatile Harvard medical heart pump (BS4; Harvard Apparatus, Holliston, MA, USA). All values were set within physiological limits: heart rate: 60 beats per minute, stroke volume: $60 \mathrm{ml}$, diastole/systole ratio: $60: 40$ and blood pressure: 120/80 mmHg. Both aortic and coronary elements of the phantom were encased in a water-filled acrylic 
container, mimicking CT-attenuation characteristics of the mediastinum. The phantom was connected to the scanner's electrocardiogram lead inputs to provide a synchronized ECG waveform on the basis of the phantom's parameters.

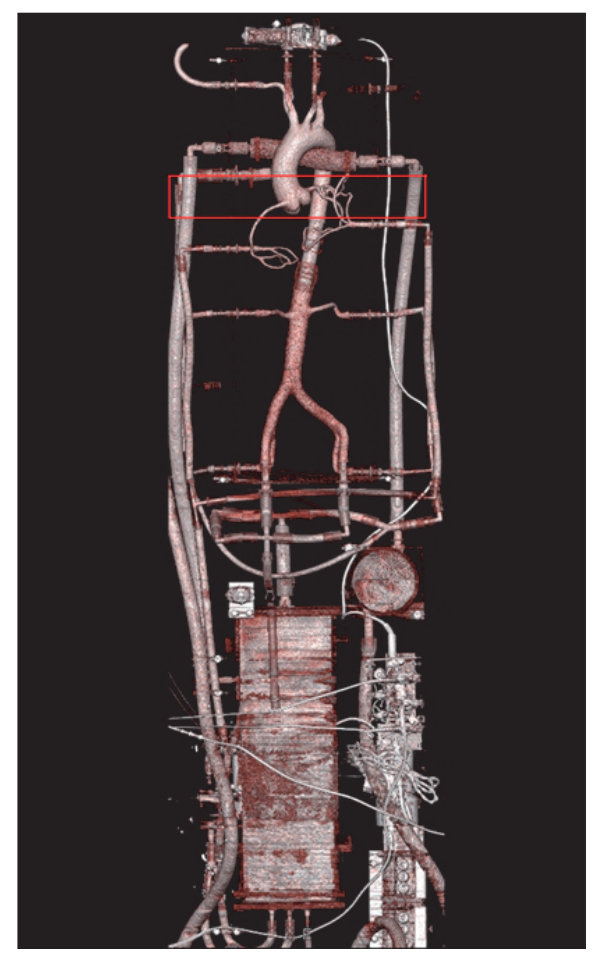

Figure 2: Three-dimensional reconstruction of the circulation phantom with scan range outlined.

\section{Injection and scan protocol}

CM with consecutive iodine concentrations of $240,300,370$, and $400 \mathrm{mg} / \mathrm{ml}$ was injected with different preheated temperatures $\left(20^{\circ} \mathrm{C}, 30^{\circ} \mathrm{C}\right.$ and $\left.37^{\circ} \mathrm{C}\right)$. The IDR and total amount of iodine in all groups were kept identical $(1.9 \mathrm{gl} / \mathrm{s}$ and $15 \mathrm{~g}$, respectively). Flow rates and applied CM injection protocols used are listed in Table 1. After every scan, the phantom was flushed with water. CM was injected into the phantom using a standard CT power injector (Stellant/MEDRAD; Pittsburgh, PA, USA), through a 3-way stopcock extension tube and a standard 18-gauge needle (Sterican; Braun, Melsungen, Germany), into the injection port (Figure 3). Injection time was set to 7.9 seconds (s) for all injections throughout the experiment; no saline chaser was used. 
Table 1: Injection parameters for all contrast material (CM) protocols. CM: contrast media, IDR: iodine delivery rate.

\begin{tabular}{|c|c|c|c|c|c|}
\hline $\begin{array}{l}\text { CM concentration } \\
(\mathrm{mg} / \mathrm{ml})\end{array}$ & CM Volume (ml) & $\begin{array}{l}\text { CM flow rate } \\
(\mathrm{ml} / \mathrm{s})\end{array}$ & $\operatorname{IDR}(\mathrm{gl} / \mathrm{s})$ & $\begin{array}{l}\text { Total amount of } \\
\text { iodine }(\mathrm{g})\end{array}$ & $\begin{array}{l}\text { Injection time } \\
\text { (s) }\end{array}$ \\
\hline 240 & 62.5 & 7.9 & 1.9 & 15.0 & 7.9 \\
\hline 300 & 50 & 6.3 & 1.9 & 15.0 & 7.9 \\
\hline 370 & 40.5 & 5.1 & 1.9 & 15.0 & 7.9 \\
\hline 400 & 38 & 4.8 & 1.9 & 15.0 & 7.9 \\
\hline
\end{tabular}

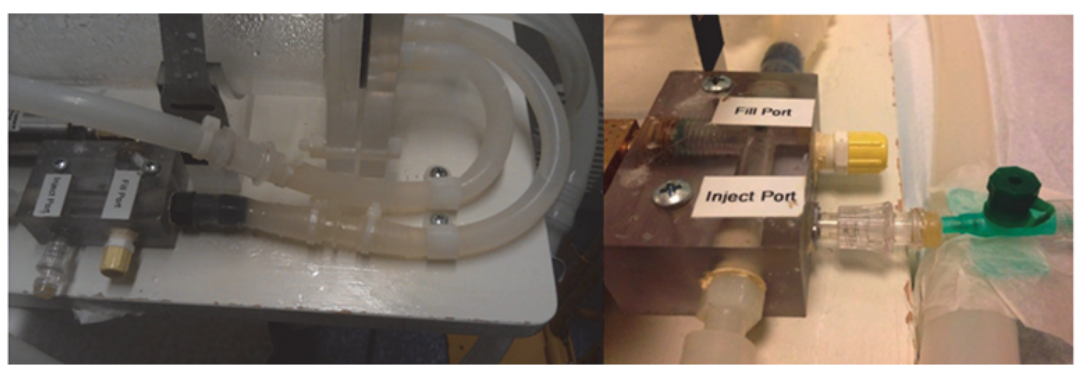

Figure 3: Left: injection port connected to a tube that enters the circulation phantom.

Right: close-up of 18-gauge needle connected to the CM injector and inserted in the injection port of the circulation phantom.

Temperature of the pre-heated $\mathrm{CM}$ was measured before scanning. All relevant injection-related parameters such as total amount of CM used, flow rate, peak flow rate, and peak pressure were closely monitored using the Certegra ${ }^{\mathrm{TM}}$ Informatics Platform (MEDRAD; Indianola, PA, USA). In addition, an independent data acquisition system (National Instruments Corporation; Austin, TX, USA) was used to monitor the physiological parameters of the phantom throughout the experiments.

Serial CT scans were performed at the level of the ascending aorta (AA), descending aorta (DA) and the coronary arteries (at the level of the left main coronary artery [LM]), using a second-generation dual source CT scanner (Somatom Definition Flash; Siemens Healthcare, Forchheim, Germany) with a sequential examination protocol (128x0.6mm of slice collimation, a tube voltage of $120 \mathrm{kV}, 150 \mathrm{mAs}$, a gantry rotation time of $500 \mathrm{~ms}$, a cycle time of $1000 \mathrm{~ms})$. Reconstruction was performed with an adapted field of view at $5 \mathrm{~mm}$ thick sections using a soft reconstruction kernel (Siemens B30f). All protocols were repeated 3 times each to determine reproducibility.

\section{Quantitative analysis}

All injection-related parameters were read out after each injection.

Peak attenuation was measured on all serial CT-scan images by delineating a circular region of interest (ROI) in the AA, DA and LM (Figure 4). A constant maximum size of intraluminal ROI was set and maintained at all anatomic sites. Resulting average 
attenuation values for each CM protocol were compared graphically using timeenhancement curves for all vessels. All measurements were independently analyzed by 2 experienced observers, blinded to each other's results. Peak enhancement and time to peak (TTP) were determined for all vessels.

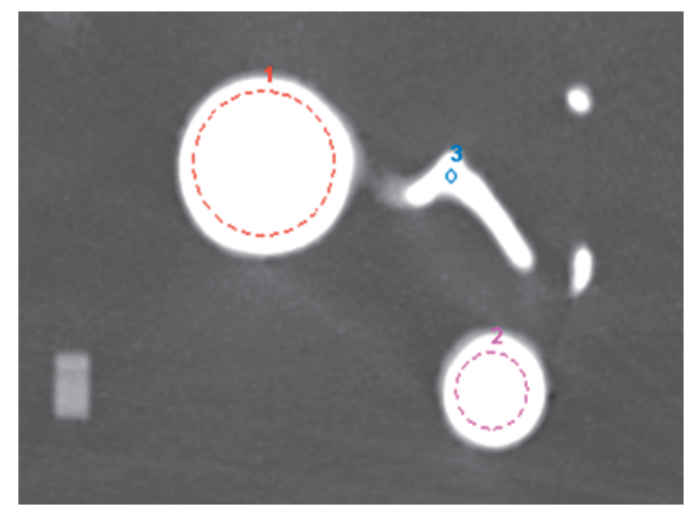

Figure 4: Mean attenuation was measured on all images of the serial CT scans by placing a circular region of interest (ROI) in the AA (1), DA (2) and LM (3). AA: ascending aorta, DA: descending aorta, LM: left main coronary artery.

\section{Statistical analysis}

Peak pressures in different concentrations $\mathrm{CM}$ and different temperatures were compared using the nonparametric Kruskal-Wallis 1-way analysis of variance by ranks. Also, TTP and attenuation values in both AA and DA as well as LM were compared using the nonparametric Kruskal-Wallis 1-way analysis of variance by ranks. In addition, the attenuation values of $A A, D A$, and $L M$ in all $C M$ groups were compared individually by means of independent samples $t$ test. The values are expressed as the mean (SD). Interobserver agreement was calculated using the intraclass correlation coefficient in a 2-way mixed effects model. Data analysis was conducted using the Statistical Package for the Social Sciences (SPSS Inc; Chicago, IL, USA). All $P$ values were 2 -sided, and a $P$ value less than 0.05 was considered statistically significant.

\section{RESULTS}

The exact time required for each $\mathrm{CM}$ to run through the $\mathrm{U}$-tube was measured twice and varied between $213 \mathrm{~s}$ (for $240 \mathrm{mg} / \mathrm{ml}$ in $40^{\circ} \mathrm{C}$ ) and $1740 \mathrm{~s}$ (for $400 \mathrm{mg} / \mathrm{ml}$ in $20^{\circ} \mathrm{C}$ ). The average of 2 measurements was used to calculate the viscosity because of the high reproducibility of the experiments (the difference between times was a maximum of 1second). The viscosity values for iodinated CM of $240,300,370$, and $400 \mathrm{mg} / \mathrm{ml}$ of 


\section{Chapter 3}

iodine as measured with the viscosimeter between $20^{\circ} \mathrm{C}$ and $40^{\circ} \mathrm{C}$ in the laboratory are given in Table 2 and Figure 5. The lowest viscosity was found for the lowest concentrated $\mathrm{CM}$ of $240 \mathrm{mg} / \mathrm{ml}$ at the highest temperature $\left(2.8 \mathrm{mPa}\right.$.s at $\left.40^{\circ} \mathrm{C}\right)$. The highest viscosity was found at room temperature for the highest concentrated $\mathrm{CM}$ of $400 \mathrm{mg} / \mathrm{ml}\left(28.8 \mathrm{mPa} . \mathrm{s}\right.$ at $\left.20^{\circ} \mathrm{C}\right)$. At body temperature, the viscosity of highest concentrated CM $\left(400 \mathrm{mg} / \mathrm{ml}: 12.6 \mathrm{mPa} . \mathrm{s}\right.$ at $\left.37^{\circ} \mathrm{C}\right)$ is still higher than $\mathrm{CM}$ of $300 \mathrm{mg} / \mathrm{ml}$ at room temperature $\left(9.1 \mathrm{mPa} . \mathrm{s}\right.$ at $\left.20^{\circ} \mathrm{C}\right)$.

Table 2: Viscosity levels (in millipascal per second) of different iodine concentrations (in milligrams of iodine per milliliter) at different temperatures (in degree Celsius).

\begin{tabular}{lllll}
\hline Temperature $\left({ }^{\circ} \mathrm{C}\right)$ & $\begin{array}{l}\text { lopromide } \\
(240 \mathrm{mg} / \mathrm{ml})\end{array}$ & $\begin{array}{l}\text { lopromide } \\
(300 \mathrm{mg} / \mathrm{ml})\end{array}$ & $\begin{array}{l}\text { lopromide } \\
(370 \mathrm{mg} / \mathrm{ml})\end{array}$ & $\begin{array}{l}\text { lomeprol } \\
(400 \mathrm{mg} / \mathrm{ml})\end{array}$ \\
\hline 20 & 5.1 & 9.1 & 21.2 & 28.8 \\
21 & 4.9 & 8.7 & 19.7 & 27.2 \\
23 & 4.6 & 8.0 & 17.8 & 24.1 \\
25 & 4.3 & 7.3 & 16.0 & 22.2 \\
27 & 4.0 & 6.8 & 14.2 & 20.1 \\
29 & 3.7 & 6.3 & 13.0 & 18.3 \\
31 & 3.5 & 6.0 & 12.0 & 16.4 \\
33 & 3.4 & 5.6 & 11.1 & 15.0 \\
35 & 3.2 & 5.2 & 10.2 & 13.7 \\
37 & 3.1 & 4.9 & 9.8 & 12.6 \\
38 & 3.0 & 4.7 & 9.4 & 12.1 \\
39 & 2.9 & 4.6 & 9.0 & 11.6 \\
40 & 2.8 & 4.4 & 8.7 & 11.2 \\
\hline
\end{tabular}

The effect of temperature and iodine concentration was further examined in the circulation phantom. No pressure or circulation related problems were encountered throughout the experiments. 


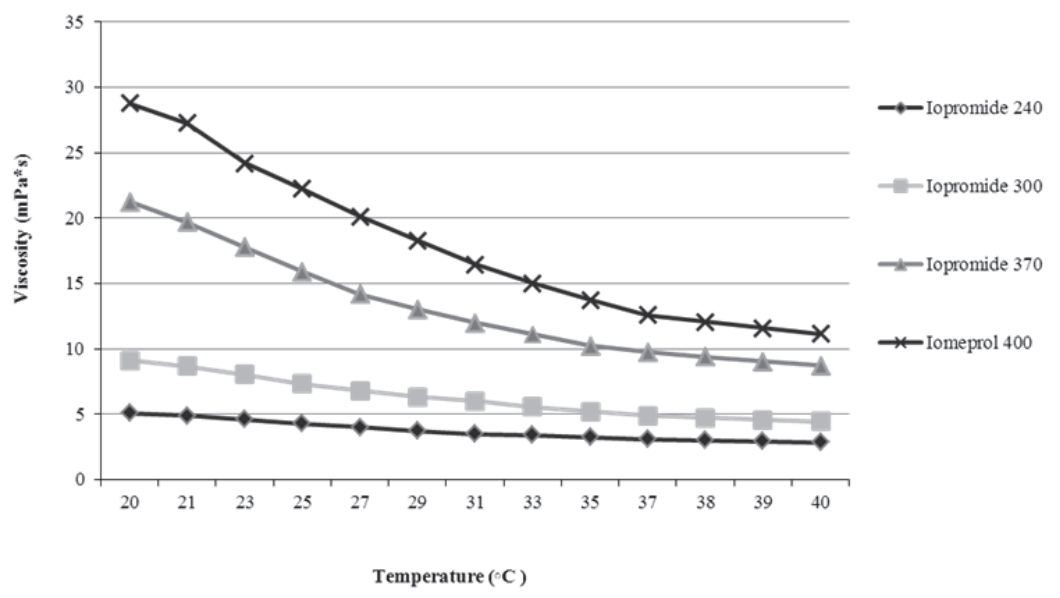

Figure 5: Graph lines showing the effect of different temperatures on the viscosity (in millipascal per second) of iodinated CM with different iodine concentrations.

Table 3 shows that significant differences in peak pressure (in pounds per square inch [psi]) were found at $20^{\circ} \mathrm{C}, 30^{\circ} \mathrm{C}$, and $37^{\circ} \mathrm{C}$ for iodinated $\mathrm{CM} 240,300,370$, and $400 \mathrm{mg} / \mathrm{ml}$. Figures 6 and 7 further show that significant differences in peak pressure (in psi) were found between all different CMs. Overall, the lowest peak pressure was found for the lowest concentrated $\mathrm{CM}$ of $240 \mathrm{mg} / \mathrm{ml}$ at body temperature $\left(92 \mathrm{psi}\right.$ at $\left.37^{\circ} \mathrm{C}\right)$.

Table 3: Mean peak pressure (in pounds per square inch) in different iodine concentrations of CM (240, 300, 370 and $400 \mathrm{mg} / \mathrm{ml}$ ) and temperatures $\left(20^{\circ} \mathrm{C}, 30^{\circ} \mathrm{C}\right.$ and $\left.37^{\circ} \mathrm{C}\right)$. $P$ values less than 0.05 were considered to be statistically significant. CM: contrast media, SD: standard deviation.

\begin{tabular}{lcccc}
\hline $\begin{array}{l}\mathrm{CM} \\
(\mathrm{mg} / \mathrm{ml})\end{array}$ & $\begin{array}{c}\text { Peak pressure, } \\
\text { mean } \pm \mathrm{SD}(\mathrm{psi}) 20^{\circ} \mathrm{C}\end{array}$ & $\begin{array}{c}\text { Peak pressure, } \\
\text { mean } \pm \mathrm{SD}(\mathrm{psi}) 30^{\circ} \mathrm{C}\end{array}$ & $\begin{array}{c}\text { Peak pressure, } \\
\text { mean } \pm \mathrm{SD}(\mathrm{psi}) 37^{\circ} \mathrm{C}\end{array}$ & $P$ \\
\hline 240 & $107 \pm 1.5$ & $95 \pm 0.6$ & $92 \pm 2.1$ & 0.027 \\
300 & $119 \pm 1.5$ & $104 \pm 0.6$ & $100 \pm 3.6$ & 0.027 \\
370 & $150 \pm 0.6$ & $133 \pm 4.4$ & $120 \pm 3.5$ & 0.026 \\
400 & $169 \pm 1.0$ & $140 \pm 2.1$ & $135 \pm 2.9$ & 0.027 \\
$P$ & 0.015 & 0.017 & 0.015 & \\
\hline
\end{tabular}




\section{Chapter 3}

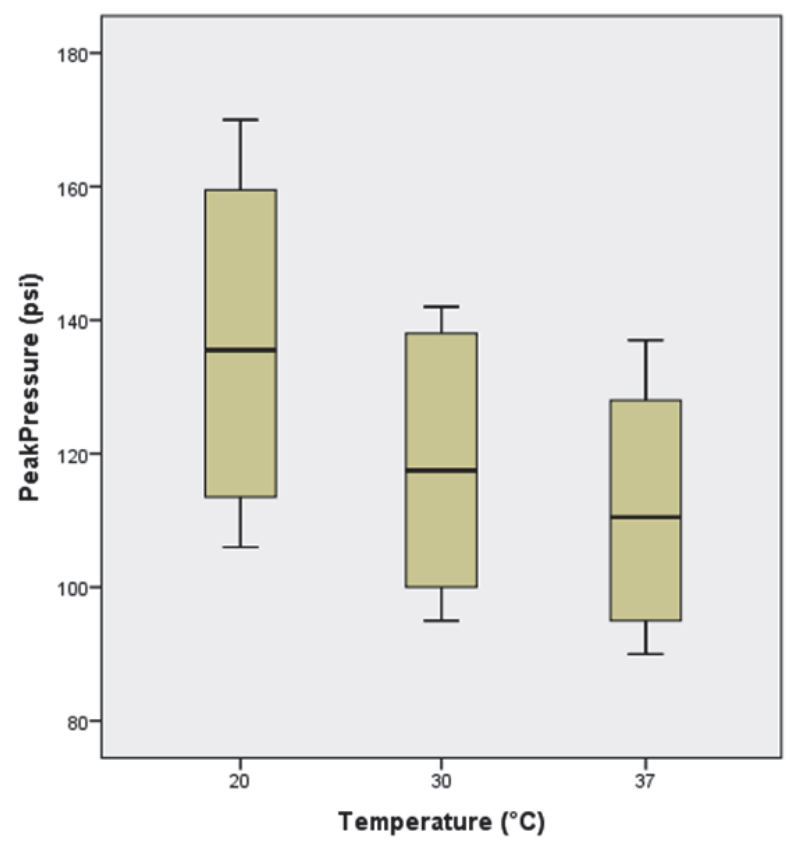

Figure 6: Pooled box plots showing different temperatures on the $x$ axis and peak pressure values for the tested CM concentrations on the $y$ axis. The horizontal line is the median, the ends of the box are the upper and lower quartiles, and the vertical lines are the full range of values in the data.

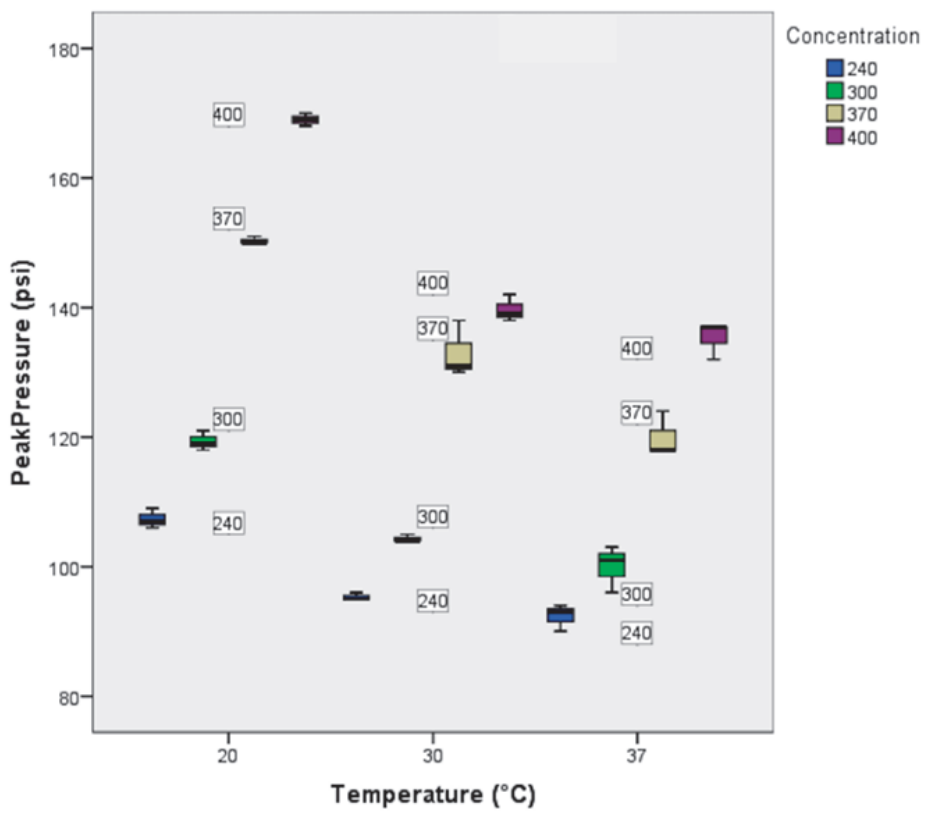

Figure 7: Detailed box plots showing different temperatures on the $x$ axis and peak pressure values in different concentrations $\mathrm{CM}$ on the $y$ axis. These boxplots are clustered by the concentration of $\mathrm{CM}$. 
No significant differences could be detected in TTP (s) for AA, DA and LM, respectively, as can be seen in Table 4. Consecutively, mean peak attenuation values were comparable and not statistically different for all protocols at different temperatures and with different iodine concentrations (Table 5). The reproducibility of the attenuation values proved to be very good: interobserver correlation was high (all k values $>0.910$ ).

Table 4: Mean (SD) time to peak (in seconds) in the ascending aorta, the descending aorta, and the left main coronary artery. $P$ values less than 0.05 were considered to be statistically significant. CM: contrast media, TTP: time to peak, AA: ascending aorta, DA: descending aorta, LM: left main coronary artery.

\begin{tabular}{lccccccccc}
\hline $\begin{array}{c}\mathrm{CM} \\
(\mathrm{mg} / \mathrm{ml})\end{array}$ & \multicolumn{3}{c}{$\mathrm{AA}(\mathrm{s})$} & \multicolumn{3}{c}{$\mathrm{DA}(\mathrm{s})$} & & \multicolumn{3}{c}{$\mathrm{LM}(\mathrm{s})$} \\
& $20^{\circ} \mathrm{C}$ & $30^{\circ} \mathrm{C}$ & $37^{\circ} \mathrm{C}$ & $20^{\circ} \mathrm{C}$ & $30^{\circ} \mathrm{C}$ & $37^{\circ} \mathrm{C}$ & $20^{\circ} \mathrm{C}$ & $30^{\circ} \mathrm{C}$ & $37^{\circ} \mathrm{C}$ \\
\hline 240 & $10.4 \pm 0.5$ & $11.0 \pm 0.0$ & $10.0 \pm 0.0$ & $12.1 \pm 0.1$ & $12.7 \pm 0.6$ & $12.1 \pm 1.1$ & $10.7 \pm 0.5$ & $11.0 \pm 0.0$ & $10.7 \pm 0.6$ \\
300 & $10.1 \pm 0.9$ & $10.3 \pm 0.6$ & $10.7 \pm 0.6$ & $11.7 \pm 0.5$ & $12.0 \pm 0.0$ & $12.1 \pm 0.1$ & $10.1 \pm 0.9$ & $10.3 \pm 0.6$ & $11.1 \pm 0.1$ \\
370 & $10.7 \pm 0.6$ & $11.8 \pm 0.7$ & $11.1 \pm 0.1$ & $12.4 \pm 0.5$ & $13.8 \pm 0.7$ & $13.1 \pm 0.1$ & $11.1 \pm 1.1$ & $11.8 \pm 0.5$ & $10.7 \pm 1.1$ \\
400 & $11.3 \pm 0.6$ & $12.0 \pm 0.0$ & $11.5 \pm 0.5$ & $13.4 \pm 0.5$ & $13.7 \pm 0.6$ & $13.1 \pm 0.1$ & $11.4 \pm 1.2$ & $11.7 \pm 0.6$ & $12.5 \pm 1.1$ \\
$P$ & 0.595 & 0.445 & 0.155 & 0.179 & 0.216 & 0.287 & 0.577 & 0.167 & 0.120 \\
\hline
\end{tabular}

Table 5: Mean (SD) peak attenuation values (in Hounsfield units) of AA, DA and LM at different temperature levels for all different CM concentrations for a constant IDR of $1.9 \mathrm{gl} / \mathrm{s}$. $P$ values less than 0.05 were considered to be statistically significant. TTP: time to peak, CM: contrast media, HU: Hounsfield unit, IDR: iodine delivery rate, $A A$ : ascending aorta, DA: descending aorta, LM: left main coronary artery.

\begin{tabular}{cccccccccc}
\hline $\begin{array}{l}\mathrm{CM} \\
(\mathrm{mg} / \mathrm{ml})\end{array}$ & \multicolumn{3}{c}{$\mathrm{AA}(\mathrm{HU})$} & \multicolumn{3}{c}{$\mathrm{DA}(\mathrm{HU})$} & \multicolumn{3}{c}{$\mathrm{LM}(\mathrm{HU})$} \\
& $20^{\circ} \mathrm{C}$ & $30^{\circ} \mathrm{C}$ & $37^{\circ} \mathrm{C}$ & $20^{\circ} \mathrm{C}$ & $30^{\circ} \mathrm{C}$ & $37^{\circ} \mathrm{C}$ & $20^{\circ} \mathrm{C}$ & $30^{\circ} \mathrm{C}$ & $37^{\circ} \mathrm{C}$ \\
\hline 240 & $424 \pm 10$ & $419 \pm 2$ & $418 \pm 6$ & $418 \pm 3$ & $412 \pm 5$ & $414 \pm 4$ & $418 \pm 2$ & $419 \pm 6$ & $417 \pm 2$ \\
300 & $429 \pm 8$ & $420 \pm 6$ & $420 \pm 5$ & $427 \pm 4$ & $413 \pm 4$ & $416 \pm 5$ & $414 \pm 6$ & $410 \pm 6$ & $407 \pm 2$ \\
370 & $424 \pm 5$ & $420 \pm 8$ & $430 \pm 7$ & $417 \pm 5$ & $416 \pm 4$ & $423 \pm 9$ & $417 \pm 10$ & $412 \pm 10$ & $422 \pm 10$ \\
400 & $433 \pm 27$ & $426 \pm 4$ & $432 \pm 8$ & $417 \pm 27$ & $422 \pm 17$ & $425 \pm 5$ & $417 \pm 20$ & $427 \pm 10$ & $417 \pm 14$ \\
$P$ & 0.680 & 0.275 & 0.172 & 0.259 & 0.742 & 0.170 & 0.889 & 0.141 & 0.213 \\
\hline
\end{tabular}

\section{DISCUSSION}

Different CMs have different characteristics, mainly because of their amount of iodine. Viscosity is directly correlated to the amount of iodine per milliliter. This was confirmed with our experiments as it was shown that the highest concentrated CM $(400 \mathrm{mg} / \mathrm{ml})$ was associated with the highest viscosity of the CMs studied. Interestingly, even under optimal conditions (at body temperature of $37^{\circ} \mathrm{C}$ ), the highest concentrated $\mathrm{CM}$ had a higher viscosity as, for example, $300 \mathrm{mg} / \mathrm{ml}$ at room temperature. 
Viscosity itself plays an important role in CM delivery and enhancement. ${ }^{3,19,20}$ Cademartiri et al. stated that preheating $\mathrm{CM}(400 \mathrm{mg} / \mathrm{ml})$ from $20^{\circ} \mathrm{C}$ to $37^{\circ} \mathrm{C}$ decreases the viscosity by more than $50 \%$ (27.5 to $12.6 \mathrm{mPa} . \mathrm{s})$, as confirmed in our study. ${ }^{7}$

Knollmann et al. showed that high iodinated CMs $(370 \mathrm{mg} / \mathrm{ml}$ and $400 \mathrm{mg} / \mathrm{ml}$ ) reached the pressure limit at certain high injection rates and concluded that these were problematic due to their high viscosity. ${ }^{17}$

Low viscosity should reduce injection pressure and may accelerate $\mathrm{CM}$ distribution within the blood. ${ }^{3,6}$ Until now, several studies focused on optimization of intravascular contrast enhancement and, in particular, on the influence of injection rate, iodine concentration, and IDR, respectively. 2,8,9,21-25 However, none of these studies systematically investigated the effect of preheated $\mathrm{CM}$ on intravascular enhancement or that on these injection parameters. Schwab et al. concluded that heating CM $(300 \mathrm{mg} / \mathrm{ml})$ effectively reduces injection pressure, when tested with injection cannulas of different sizes. ${ }^{15,16}$

Significant differences in peak pressure were found for all concentrations at different temperatures. Inversely, significant differences in peak pressure were found for all temperatures in the different concentration groups. The highest efficacy of reduced viscosity by preheating $\mathrm{CM}$ (from $20^{\circ} \mathrm{C}$ to $37^{\circ} \mathrm{C}$ ) was found for highest concentrated CM $(400 \mathrm{mg} / \mathrm{ml}): 56 \%$ reduced viscosity compared with $41 \%$ reduced viscosity in $240 \mathrm{mg} / \mathrm{ml}$, the peak pressure for the highest concentrated CM $(400 \mathrm{mg} / \mathrm{ml})$ was even higher at body temperature $\left(135 \mathrm{psi}\right.$ at $\left.37^{\circ} \mathrm{C}\right)$ when compared with $\mathrm{CM}$ with $240 \mathrm{mg} / \mathrm{ml}$ at room temperature $\left(107 \mathrm{psi}\right.$ at $\left.20^{\circ} \mathrm{C}\right)$. Given the statistical significance of these findings, the positive effect of preheating $\mathrm{CM}$ to reduce viscosity and, therefore, to reduce injection pressure, is stressed.

Furthermore, low viscosity should allow an accelerated distribution within the blood and thus potentially better visualization of small-sized vessels and for advanced perfusion protocols. This could potentially be helpful in the assessment of tumor patients as dedicated workup on blood flow, time to peak and blood volume as a marker of angiogenesis. ${ }^{26}$

Last but not least, attenuation levels were comparable for all CM, which again underlines the fact, that IDR is the most important parameter when different CMs are compared. The results of our study will have major implications for the logistical workup within a CT suite. For instance, incubators and heating cabinets will allow standardized preheating of $\mathrm{CM}$ to the desired temperature. Furthermore, if single vials and disposables are not used for a single patient, CM temperature has to be maintained after the CM bottles are taken out and are opened up. This can be guaranteed by using dedicated injection power injectors or other preheating devices at the scanner site (Figure 8). 


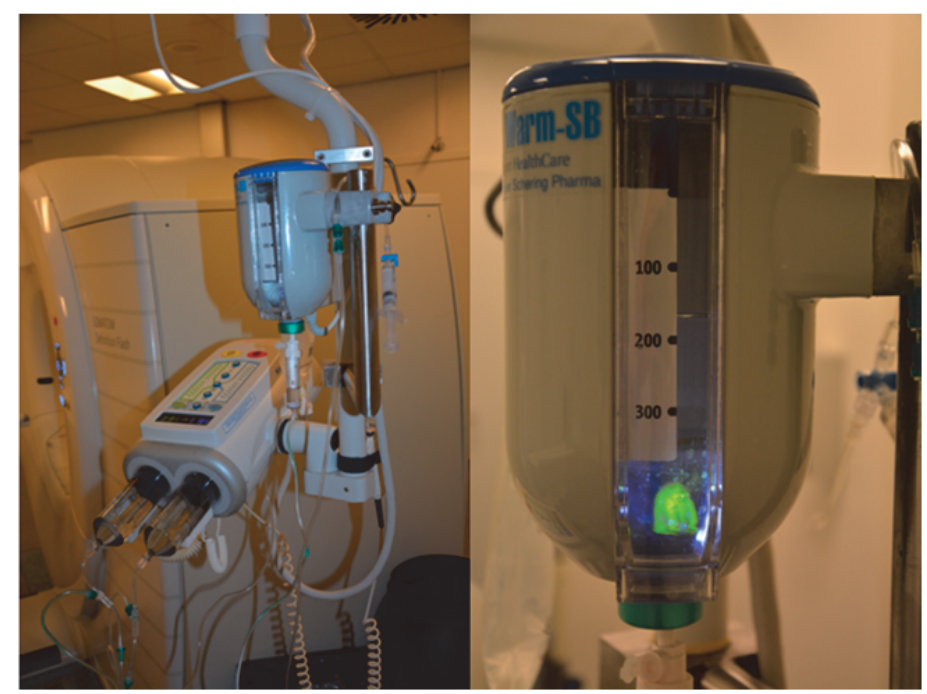

Figure 8: Photograph of the prewarming device (WARM-SB; Nemoto International, Herent, Belgium) next to the CT scanner which facilititates constant temperature, even if the CM bottles are opened up. The maximum bottle volume for this setup is $500 \mathrm{ml}$.

\section{Limitations}

Pre-heating $\mathrm{CM}$ and precise registering of temperature before injection are mandatory in this phantom study to evaluate the influence of viscosity on these parameters. In this experiment, pre-heated $\mathrm{CM}$ in bottles of $100 \mathrm{ml}$ was used. Scanning was commenced, directly after measurement of the temperature, to keep temperatures constant. However, the preheated $\mathrm{CM}$ was used in 2 or 3 repetitive scans. The possibility exists that temperature will decrease within small margins exists; with that, viscosity could have increased after several minutes. However, injection parameters such as peak flow rate and peak pressure did not differ significantly from each other.

\section{CONCLUSION}

The results of these experiments show in a standardized way that high temperature, low-concentration iodine and low viscosity decrease injection pressure. This impacts individual tailored contrast protocols in daily routine scanning. Standardized prewarming should be a prerequisite for clinical CM administration. 


\section{REFERENCES}

1. Behrendt FF, Bruners P, Keil S, Plumhans C, Mahnken AH, Stanzel S, Das M, Gunther RW, Muhlenbruch G. Impact of different vein catheter sizes for mechanical power injection in ct: In vitro evaluation with use of a circulation phantom. Cardiovasc Intervent Radiol. 2009;32:25-31

2. Bae KT, Tran HQ, Heiken JP. Uniform vascular contrast enhancement and reduced contrast medium volume achieved by using exponentially decelerated contrast material injection method. Radiology. 2004;231:732-736

3. Bae KT. Intravenous contrast medium administration and scan timing at ct: Considerations and approaches. Radiology. 2010;256:32-61

4. Johnson PT, Pannu HK, Fishman EK. IV contrast infusion for coronary artery ct angiography: Literature review and results of a nationwide survey. AJR Am J Roentgenol. 2009;192:W214-221

5. Awai K, Hiraishi K, Hori S. Effect of contrast material injection duration and rate on aortic peak time and peak enhancement at dynamic ct involving injection protocol with dose tailored to patient weight. Radiology. 2004;230:142-150

6. Muhlenbruch G, Behrendt FF, Eddahabi MA, Knackstedt C, Stanzel S, Das M, Seidensticker P, Gunther RW, Wildberger JE, Mahnken AH. Which iodine concentration in chest ct? - A prospective study in 300 patients. Eur Radiol. 2008;18:2826-2832

7. Cademartiri F, Mollet NR, van der Lugt A, McFadden EP, Stijnen T, de Feyter PJ, Krestin GP. Intravenous contrast material administration at helical 16-detector row ct coronary angiography: Effect of iodine concentration on vascular attenuation. Radiology. 2005;236:661-665

8. Cademartiri F, de Monye C, Pugliese F, Mollet NR, Runza G, van der Lugt A, Midiri M, de Feyter PJ, Lagalla R, Krestin GP. High iodine concentration contrast material for noninvasive multislice computed tomography coronary angiography: Iopromide 370 versus iomeprol 400. Invest Radiol. 2006;41:349-353

9. Nance JW, Jr., Henzler T, Meyer M, Apfaltrer P, Braunagel M, Krissak R, Schoepf UJ, Schoenberg SO, Fink C. Optimization of contrast material delivery for dual-energy computed tomography pulmonary angiography in patients with suspected pulmonary embolism. Invest Radiol. 2012;47:78-84

10. Rist C, Nikolaou K, Kirchin MA, van Gessel R, Bae KT, von Ziegler F, Knez A, Wintersperger BJ, Reiser MF, Becker CR. Contrast bolus optimization for cardiac 16-slice computed tomography: Comparison of contrast medium formulations containing 300 and 400 milligrams of iodine per milliliter. Invest Radiol. 2006;41:460-467

11. Mihl C, Wildberger JE, Jurencak T, Yanniello MJ, Nijssen EC, Kalafut JF, Nalbantov G, Muhlenbruch G, Behrendt FF, Das M. Intravascular enhancement with identical iodine delivery rate using different iodine contrast media in a circulation phantom. Invest Radiol. 2013;48:813-818

12. Behrendt FF, Pietsch H, Jost G, Palmowski M, Gunther RW, Mahnken AH. Identification of the iodine concentration that yields the highest intravascular enhancement in mdct angiography. AJR Am J Roentgenol. 2013;200:1151-1156

13. Halsell RD. Heating contrast media: Role in contemporary angiography. Radiology. 1987;164:276-278

14. Halsell RD. Heating contrast media in a microwave oven. Radiology. 1987;163:279-280

15. Schwab SA, Kuefner MA, Anders K, Adamietz B, Heinrich MC, Baigger JF, Janka R, Uder M, Kramer M. Peripheral intravenous power injection of iodinated contrast media: The impact of temperature on maximum injection pressures at different cannula sizes. Acad Radiol. 2009;16:1502-1508

16. Schwab SA, Uder M, Anders K, Heinrich MC, Kuefner MA. Peripheral intravenous power injection of iodinated contrast media through $22 \mathrm{~g}$ and $20 \mathrm{~g}$ cannulas: Can high flow rates be achieved safely? A clinical feasibility study. Rofo. 2009;181:355-361

17. Knollmann F, Schimpf K, Felix R. lodine delivery rate of different concentrations of iodine-containing contrast agents with rapid injection. Rofo. 2004;176:880-884

18. Behrendt FF, Bruners P, Kalafut J, Mahnken AH, Keil S, Plumhans C, Das M, Stanzel S, Wildberger JE, Pfeffer J, Gunther RW, Muhlenbruch G. Introduction of a dedicated circulation phantom for comprehensive in vitro analysis of intravascular contrast material application. Invest Radiol. 2008;43:729736

19. Behrendt FF, Bruners P, Keil S, Plumhans C, Mahnken AH, Stanzel S, Das M, Gunther RW, Muhlenbruch G. Impact of different vein catheter sizes for mechanical power injection in ct: In vitro evaluation with use of a circulation phantom. Cardiovasc Intervent Radiol. 2009;32:25-31 
20. Brunette J, Mongrain R, Laurier J, Galaz R, Tardif JC. 3d flow study in a mildly stenotic coronary artery phantom using a whole volume piv method. Med Eng Phys. 2008;30:1193-1200

21. Becker CR, Vanzulli A, Fink C, de Faveri D, Fedeli S, Dore R, Biondetti P, Kuettner A, Krix M, Ascenti G. Multicenter comparison of high concentration contrast agent iomeprol-400 with iso-osmolar iodixanol320: Contrast enhancement and heart rate variation in coronary dual-source computed tomographic angiography. Invest Radiol. 2011;46:457-464

22. Cademartiri F, Mollet NR, Runza G, Bruining N, Hamers R, Somers P, Knaapen M, Verheye S, Midiri M, Krestin GP, de Feyter PJ. Influence of intracoronary attenuation on coronary plaque measurements using multislice computed tomography: Observations in an ex vivo model of coronary computed tomography angiography. Eur Radiol. 2005;15:1426-1431

23. Christensen JD, Meyer LT, Hurwitz LM, Boll DT. Effects of iopamidol-370 versus iodixanol-320 on coronary contrast, branch depiction, and heart rate variability in dual-source coronary mdct angiography. AJR Am J Roentgenol. 2011;197:W445-451

24. Tsai IC, Lee T, Tsai WL, Chen MC, Wu MJ, Lee WL, Ting HJ. Contrast enhancement in cardiac mdct: Comparison of iodixanol 320 versus iohexol 350. AJR Am J Roentgenol. 2008;190:W47-53

25. Yamamuro M, Tadamura E, Kanao S, Wu YW, Tambara K, Komeda M, Toma M, Kimura T, Kita T, Togashi K. Coronary angiography by 64-detector row computed tomography using low dose of contrast material with saline chaser: Influence of total injection volume on vessel attenuation. J Comput Assist Tomogr. 2007; $31: 272-280$

26. Garcia-Figueiras R, Goh VJ, Padhani AR, Baleato-Gonzalez S, Garrido M, Leon L, Gomez-Caamano A. Ct perfusion in oncologic imaging: A useful tool? AJR Am J Roentgenol. 2013;200:8-19 



\section{CHAPTER 4}

Intravascular enhancement with identical iodine delivery rate using different iodine contrast media in a circulation phantom

C. Mihl, J.E. Wildberger, T. Jurencak, M.J. Yanniello, E.C. Nijssen, J.F. Kalafut,

G. Nalbantov, G. Mühlenbruch, F.F. Behrendt, M. Das

Investigative Radiology 2013;48:813-818. 


\section{ABSTRACT}

\section{Purpose}

Both iodine delivery rate (IDR) and iodine concentration are decisive factors for vascular enhancement in CT angiography (CTA). It is unclear, however, whether the use of high iodine concentration contrast media is beneficial to lower iodine concentrations when IDR is kept identical. This study evaluates the effect of using different iodine concentrations on intravascular attenuation in a circulation phantom, while maintaining a constant IDR.

\section{Materials and methods}

A circulation phantom with a low-pressure venous compartment and a high-pressure arterial compartment simulating physiological circulation parameters was used (heart rate: 60 beats per minute, stroke volume: $60 \mathrm{ml}$, blood pressure: $120 / 80 \mathrm{mmHg}$ ). Maintaining a constant IDR $(2.0 \mathrm{gl} / \mathrm{s})$ and a constant total iodine load $(20 \mathrm{~g})$, prewarmed $\left(37^{\circ} \mathrm{C}\right)$ contrast media with different iodine concentrations $(240-400 \mathrm{mg} / \mathrm{ml})$ were injected into the phantom using a double-headed power injector. Serial computed tomographic scans at the level of the ascending aorta (AA), descending aorta (DA) and left main coronary artery (LM) were obtained. Total amount of contrast volume (milliliters), iodine delivery (grams of iodine), peak flow rate (milliliter per second) and intravascular pressure (pounds per square inch) were monitored using a dedicated data acquisition program. Attenuation values in AA, DA and LM were constantly measured (Hounsfield unit [HU]). In addition, time-enhancement curves, aortic peak enhancement and time to peak (in seconds [s]) were determined.

\section{Results}

All contrast injection protocols resulted in similar attenuation values: AA (516 \pm 11 to $531 \pm 37 \mathrm{HU}), \mathrm{DA}(514 \pm 17$ to $531 \pm 32 \mathrm{HU})$ and $\mathrm{LM}(490 \pm 10$ to $507 \pm 17 \mathrm{HU})$. No significant differences were found between the AA, DA and LM for either peak enhancement (all $P>0.05$ ), or mean time to peak (AA: $19.4 \pm 0.58$ to $20.1 \pm 1.05 \mathrm{~s}, \mathrm{DA}: 21.1 \pm 1.0$ to $21.4 \pm 1.15$ s, LM: $19.8 \pm 0.58$ to $20.1 \pm 1.05 s$ ).

\section{Conclusion}

This phantom study demonstrates that constant injection parameters (IDR, overall iodine load) lead to robust enhancement patterns, regardless of the contrast media used. Higher iodine concentrations itself do not lead to higher attenuation levels. These results may stimulate a shift in paradigm towards clinical usage of contrast media with lower iodine concentrations (e.g. $240 \mathrm{mg} / \mathrm{ml}$ ) in individual tailored contrast protocols. The use of low-iodine concentration contrast media is desirable because of the low viscosity and the resulting lower injection pressure. 


\section{INTRODUCTION}

In computed tomographic angiography (CTA), the degree of intravascular contrast enhancement is an important factor for image quality. Sufficient vessel attenuation is crucial for the evaluation of vessel pathology, especially in smaller vessels such as the coronary arteries. ${ }^{1}$ Enhancement characteristics are closely related to the contrast application protocol and scan parameters used, as well as to patient related characteristics. $^{2-4}$ Optimal vascular enhancement requires perfect timing and rapid bolus injection of intravenous contrast media $(\mathrm{CM})^{4,5}$ and both iodine delivery rate (IDR; the amount of iodine delivered to the patient per second) and iodine concentration (amount of iodine per milliliter of $\mathrm{CM}$ ) are determining factors. Currently, no good consensus exists on optimal parameters of contrast infusion, iodine concentration or delivery rate for CTA or coronary CTA. Previous research on intravascular contrast attenuation of the coronary arteries was performed using high iodine concentration contrast, varying from 300 to $400 \mathrm{mg} / \mathrm{ml} .^{6-8}$ In addition, studies using CM with different iodine concentrations report heterogeneous results, probably because studied parameters such as IDR were not comparable between populations. ${ }^{9}$ However, no uniform conclusion can be drawn even from studies in which IDR was standardized. ${ }^{10-12}$

Viscosity of CM is another factor that plays an important role in CM delivery and enhancement. ${ }^{1,4,13,14}$ Generally speaking, viscosity decreases with temperature (e.g. by warming contrast to temperatures between $20^{\circ} \mathrm{C}$ to $37^{\circ} \mathrm{C}$ ) and increases with iodine concentration. ${ }^{4,9}$ Lower iodine concentration $\mathrm{CM}$ might therefore be advantageous, its lower viscosity inducing lower injection pressure and possibly accelerated distribution within the blood. ${ }^{4,9}$

The aim of this study is to evaluate intravascular attenuation in a circulation phantom using CM of varying iodine concentrations $(240-400 \mathrm{mg} / \mathrm{ml})$, the IDR and all other influencing factors being standardized. The working hypothesis was that, in this setting, intravascular attenuation will not significantly change with iodine concentration.

\section{MATERIALS AND METHODS}

\section{Circulation phantom}

A previously introduced and completely revised circulation phantom with physiological circulation parameters was used. ${ }^{15}$ This phantom consists of low-pressure lung and highpressure body circulation systems, with accurate replicas of the entire aorta and the coronary arteries. The phantom consists of connecting tubes, a water filled acrylic container, 2 pressure meters and a pressure relieve valve for modulation of arterial and venous pressure (Figure 1). The phantom was filled with water at body temperature $\left(37^{\circ} \mathrm{C}\right)$, and subsequently circulation was driven by a pulsatile Harvard medical heart pump 
(BS4; Harvard Apparatus, Holliston, MA, USA). All values were set within physiological limits, heart rate: 60 beats per minute, stroke volume: $60 \mathrm{ml}$, diastole/systole ratio: 60:40, and blood pressure: $120 / 80 \mathrm{mmHg}$. Both aortic and coronary elements of the phantom were encased in a water-filled acrylic container, mimicking computed tomographic (CT) attenuation characteristics of the mediastinum (Figure 2). The phantom was connected to the scanner's electrocardiogram (ECG) lead inputs, in order to provide a synchronized ECG waveform based on the phantom's parameters.

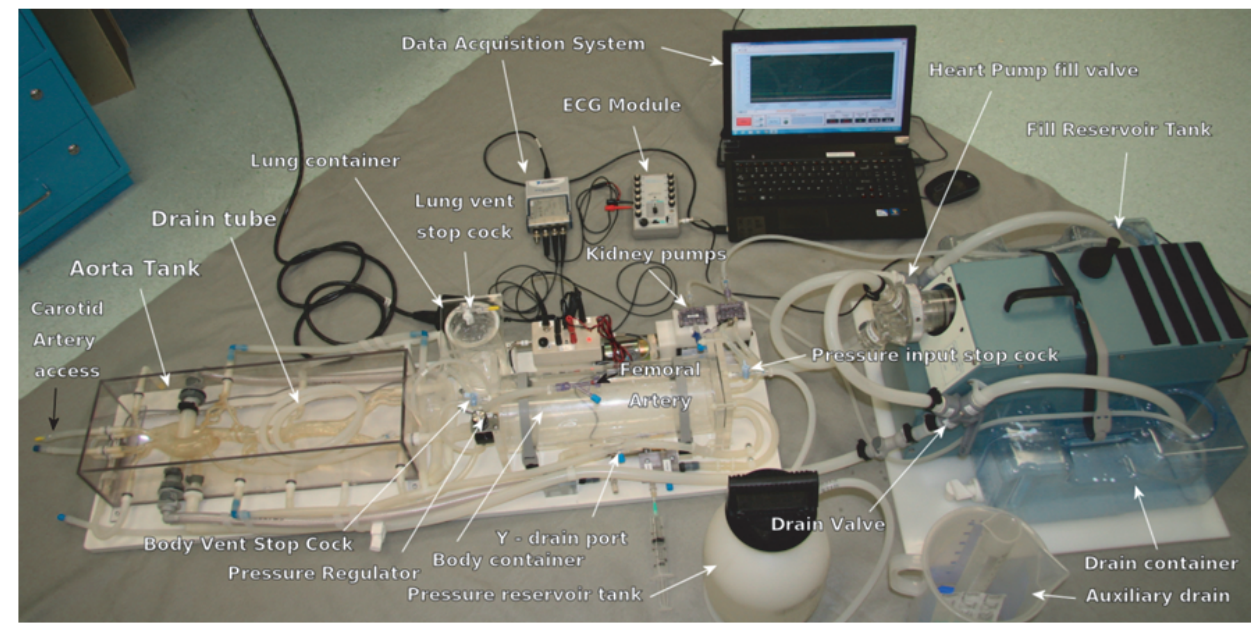

Figure 1: Revised circulation phantom with physiological circulation parameters.

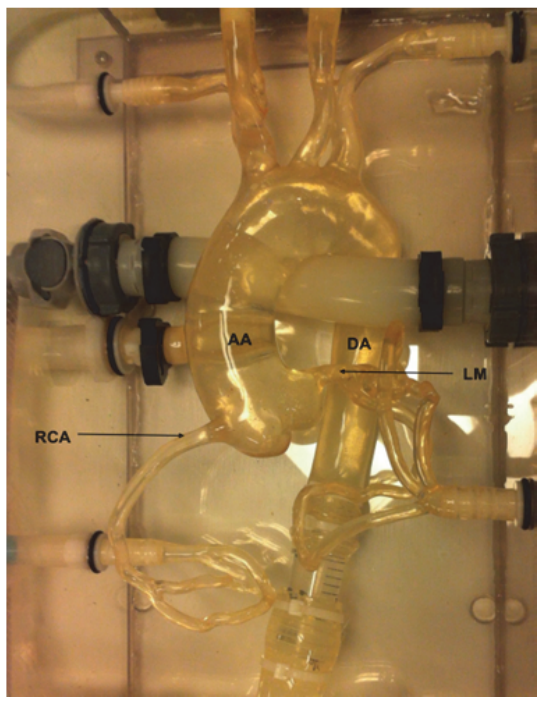

Figure 2: Aortic and coronary elements of the phantom encased in a water-filled acrylic container mimicking $\mathrm{CT}$ attenuation characteristics of the mediastinum. 


\section{Injection and scan protocol}

Maintaining a constant IDR $(2.0 \mathrm{gl} / \mathrm{s})$, prewarmed $\left(37^{\circ} \mathrm{C}\right) \mathrm{CM}$ with iodine concentrations of 240,300, 370, and 400 mg/ml (Ultravist; iopromide, Bayer Healthcare, Berlin, Germany and Iomeron; iomeprol, Bracco, Imaging, Milan, Italy) was injected at different flow rates. Flow rates and applied CM injection protocols used are listed in Table 1.

Table 1: Estimated injection parameters for all CM protocols. CM: contrast media, IDR: iodine delivery rate, g: grams.

\begin{tabular}{lllll}
\hline CM concentration $(\mathrm{mg} / \mathrm{ml})$ & CM volume $(\mathrm{ml})$ & CM flow rate $(\mathrm{ml} / \mathrm{s})$ & IDR $(\mathrm{gl} / \mathrm{s})$ & Total amount of iodine $(\mathrm{g})$ \\
\hline 240 & 83 & 8.3 & 2.0 & 20.0 \\
300 & 67 & 6.7 & 2.0 & 20.0 \\
370 & 54 & 5.4 & 2.0 & 20.0 \\
400 & 50 & 5.0 & 2.0 & 20.0 \\
\hline
\end{tabular}

CM was injected into the phantom using a standard CT power injector (Stellant/MEDRAD; Pittsburgh, PA, USA), through a 3-way stopcock extension tube, into the injection port. The power injector pressure cut-off limit was set to 325 pounds per square inch (psi), which is regarded as being the standard pressure limit for the CT power injector used. Time of injection and total amount of iodine remained constant throughout the experiment (10 seconds [s] and $20 \mathrm{~g}$ respectively). Every examination was closely monitored using the Certegra ${ }^{\mathrm{TM}}$ Informatics Platform (MEDRAD; Indianola, PA, USA) which enables monitoring of injection-related parameters such as pressure and flow curves. In addition, an independent data acquisition system (National Instruments Corporation; Austin, TX, USA) was used to monitor physiological parameters of the circulation phantom.

Serial CT scans were performed at the level of the simulated ascending aorta (AA), the descending aorta (DA), and the coronary arteries (at the level of the left main coronary artery [LM]), using a second generation DSCT scanner (Somatom Definition Flash; Siemens Healthcare, Forchheim, Germany) with a $128 \times 0.6 \mathrm{~mm}$ slice collimation, a tube voltage of $120 \mathrm{kV}$, a gantry rotation time of $300 \mathrm{~ms}$, a cycle time of $1000 \mathrm{~ms}$ at $5 \mathrm{~mm}$ slice thickness. All protocols were repeated three times each to determine reproducibility.

\section{Quantitative analysis}

Mean attenuation was measured on all serial CT scan images by delineating a circular region of interest (ROI) in the replicas of the AA, the DA and the LM. A constant maximum size of intraluminal ROI was set and maintained at all anatomic sites (Figure 3). Resulting average attenuation values for each CM protocol were compared graphically using time-enhancement curves for all vessels. All measurements were 
independently analyzed by 2 experienced observers, blinded to each other's results. Peak enhancement and time to peak were determined for all vessels. Total amounts of $\mathrm{CM}$ volume (milliliters) and iodine (grams of iodine) delivered, peak flow rate (milliliter per second) and intraluminal pressure (psi) were continuously monitored by the data acquisition program Certegra ${ }^{\mathrm{TM}}$ Informatics Platform (MEDRAD; Indianola, PA, USA) and read out after each injection.

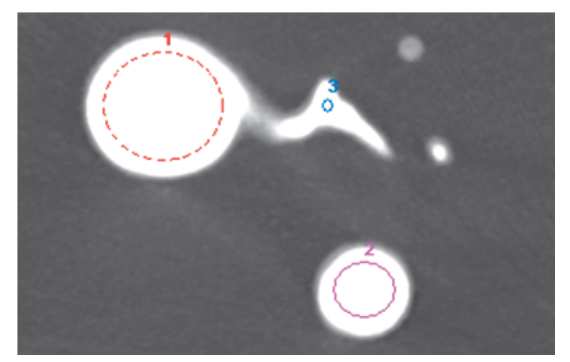

Figure 3: Mean attenuation was measured on all serial CT scan images by placing a ROI in the AA (1), DA (2) and LM (3).

\section{Statistical analysis}

The average of 3 repeated measurements was used to obtain mean contrast enhancement values for each $\mathrm{CM}$ injection protocol. Interobserver agreement was calculated using the intraclass correlation coefficient in a 2-way mixed effects model. Attenuation values in the $A A$, the $D A$ and the $L M$ were compared using the nonparametric Kruskal-Wallis 1-way analysis of variance by ranks. In addition, attenuation values of the AA, DA and LM in all CM groups were compared individually by means of paired samples $t$ test. Mean contrast injection parameters (total amount of contrast, iodine delivered, peak flow enhancement, time to peak and intraluminal pressure) were calculated for each protocol. The values are expressed as mean \pm standard deviation (SD). Data analysis was conducted with SPSS version 19.0 (SPSS Inc; Chicago, IL, USA). All $P$ values are 2 -sided, and a $P$ value below 0.05 is considered statistically significant.

\section{RESULTS}

Mean attenuations of the AA, the DA and the LM are shown in Table 2 and Figure 4. All contrast injection protocols provided similar attenuation of the AA $(516 \pm 11$ to $531 \pm 37$ Hounsfield unit [HU]), DA (514 \pm 17 to $531 \pm 32 \mathrm{HU})$, and LM (490 \pm 10 to $507 \pm 17 \mathrm{HU})$. No statistically significant differences in peak enhancement of AA, DA and LM were found between protocols (all $P>0.05$ ). 
Table 2: Mean attenuation values (HU) of the AA, DA and LM were compared using the nonparametric Kruskal-Wallis 1-way analysis of variance by ranks. No significant differences in attenuation were found for the different contrast media protocols. AA: ascending aorta, DA: descending aorta, LM: left main coronary artery, HU: Hounsfield unit.

\begin{tabular}{lccc}
\hline $\mathrm{CM}(\mathrm{mg} / \mathrm{ml})$ & AA (HU) & DA (HU) & LM (HU) \\
\hline 240 & $516 \pm 11$ & $514 \pm 17$ & $490 \pm 10$ \\
300 & $524 \pm 18$ & $523 \pm 20$ & $497 \pm 17$ \\
370 & $523 \pm 16$ & $518 \pm 18$ & $500 \pm 12$ \\
400 & $531 \pm 37$ & $531 \pm 32$ & $507 \pm 17$ \\
$P$ & 0.919 & 0.686 & 0.606 \\
\hline
\end{tabular}
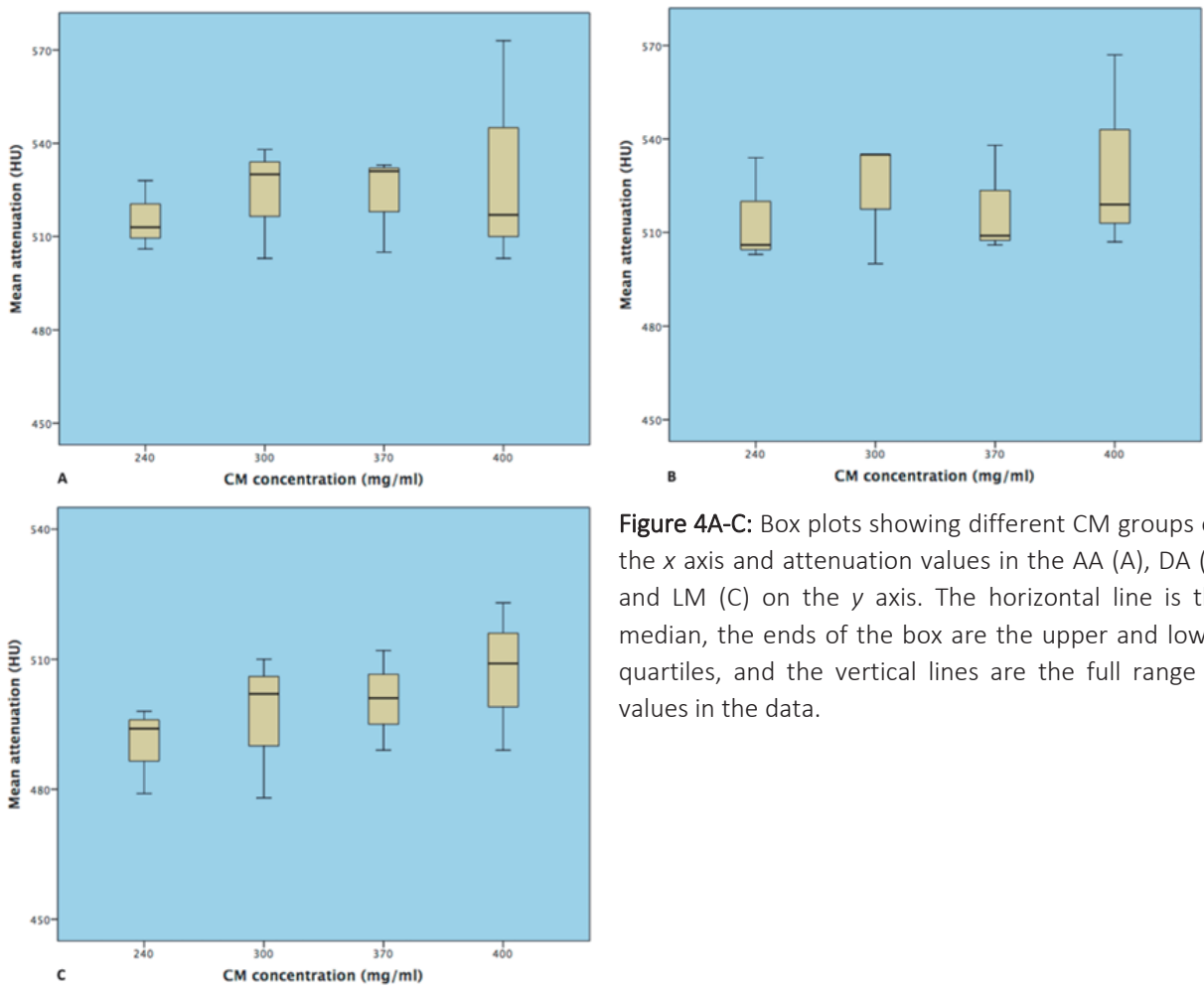

Figure 4A-C: Box plots showing different $\mathrm{CM}$ groups on the $x$ axis and attenuation values in the AA (A), DA (B) and $L M(C)$ on the $y$ axis. The horizontal line is the median, the ends of the box are the upper and lower quartiles, and the vertical lines are the full range of values in the data.

All peak enhancement curves were comparable and showed similar enhancement values and curve pattern; examples are shown in Figure 5. There were no significant differences between protocols in mean time to peak (AA: $19.4 \pm 0.58$ to $20.1 \pm 1.05 s$, DA: $21.1 \pm 1.0$ to $21.4 \pm 1.15$ s, LM: $19.8 \pm 0.58$ to $20.1 \pm 1.05$ s, Table 3 and Figure 6). 

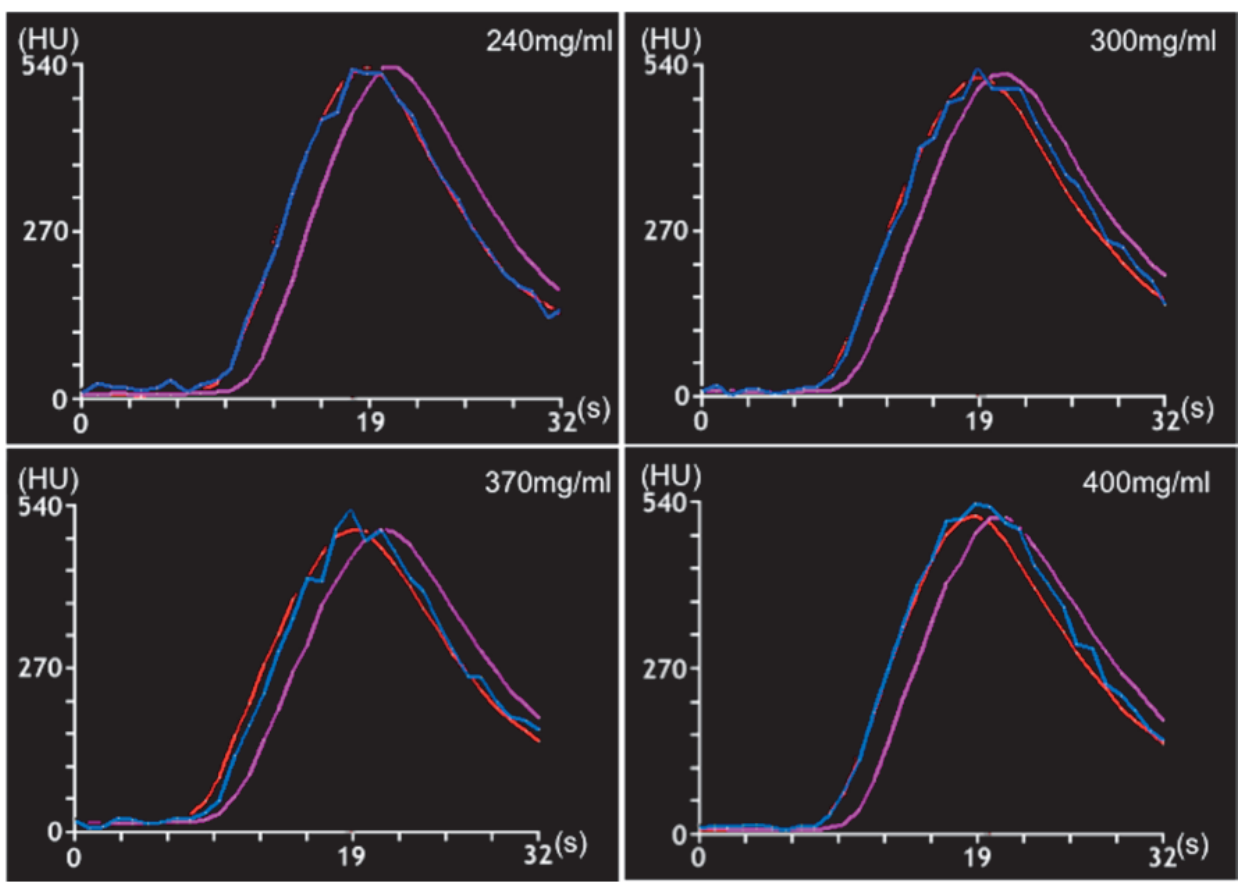

Figure 5: Example of enhancement curves of all 3 vessels. Red line: AA, purple line: DA, blue line: LM. No significant differences in attenuation were found between protocols.

Table 3: Mean time to peak (s) in the AA, the DA and the LM. No significant differences in attenuation were found between protocols. CM: contrast media, AA: ascending aorta, DA: descending aorta, LM: left main coronary artery, TTP: time to peak.

\begin{tabular}{lccc}
\hline $\mathrm{CM}(\mathrm{mg} / \mathrm{ml})$ & TTP AA $(\mathrm{s})$ & TTP DA $(\mathrm{s})$ & TTP LM $(\mathrm{s})$ \\
\hline 240 & $20.1 \pm 1.05$ & $21.4 \pm 1.15$ & $19.8 \pm 1.57$ \\
300 & $19.4 \pm 0.58$ & $21.2 \pm 0.0$ & $19.8 \pm 0.58$ \\
370 & $19.4 \pm 0.58$ & $21.2 \pm 0.0$ & $19.8 \pm 0.58$ \\
400 & $19.5 \pm 0.55$ & $21.1 \pm 1.0$ & $20.1 \pm 1.05$ \\
$P$ & 0.688 & 0.873 & 0.955 \\
\hline
\end{tabular}

There was a significant increase in peak pressures (psi) in relation to higher iodine concentrations ( $240 \mathrm{mg} / \mathrm{ml}: 69.3 \pm 2.08$ to $400 \mathrm{mg} / \mathrm{ml}: 97.3 \pm 4.16, P=0.019$ ). Mean peak pressures (psi) in all groups are shown in Table 4. The pressure limit of 325 psi was never reached. 

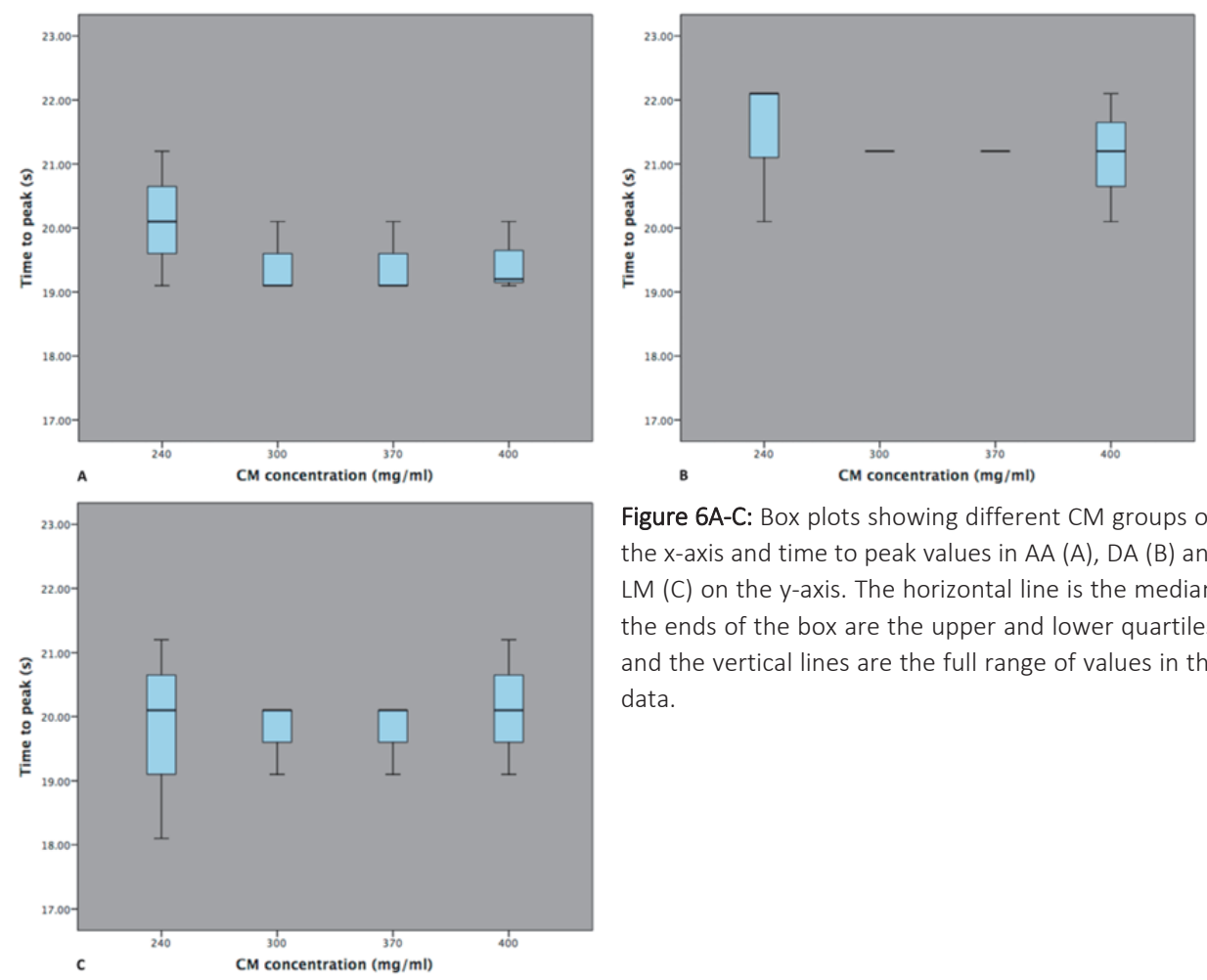

Figure 6A-C: Box plots showing different $\mathrm{CM}$ groups on the $x$-axis and time to peak values in $A A(A), D A(B)$ and LM (C) on the $y$-axis. The horizontal line is the median, the ends of the box are the upper and lower quartiles, and the vertical lines are the full range of values in the data.

Table 4: Mean peak pressures (psi) were compared using the nonparametric Kruskal-Wallis 1-way analysis of variance by ranks. A significant difference in peak pressure was found for the different CM protocols. CM: contrast media, psi: pounds per square inch.

\begin{tabular}{lc}
\hline $\mathrm{CM}(\mathrm{mg} / \mathrm{ml})$ & Mean peak pressure $(\mathrm{psi})$ \\
\hline 240 & $69.3 \pm 2.08$ \\
300 & $79.7 \pm 4.93$ \\
370 & $91.3 \pm 3.21$ \\
400 & $97.3 \pm 4.16$ \\
$P$ & 0.019 \\
\hline
\end{tabular}

The reproducibility of the attenuation values was very good: interobserver correlation was high (all $\mathrm{k}$ values $>0.78$ ). All parameters measured using the data monitoring software showed remarkable similarity in all 3 measurements (Table 5). Pre-programmed injection flow rate and contrast volumes (Table 1) were realized on all occasions, variations over time being negligible. There were no significant differences in total amounts of iodine delivered. No pressure- or circulation-related problems were encountered. 
Table 5: Mean values were calculated for all CM protocols. CM: contrast media, g: grams, psi: pounds per square inch.

\begin{tabular}{lccc}
\hline $\mathrm{CM}(\mathrm{mg} / \mathrm{ml})$ & Total contrast $(\mathrm{ml})$ & Total iodine $(\mathrm{g})$ & Mean peak flow $(\mathrm{ml} / \mathrm{s})$ \\
\hline 240 & $82.9 \pm 0.23$ & $19.9 \pm 0.58$ & $8.7 \pm 0.58$ \\
300 & $66.7 \pm 0.15$ & $20.0 \pm 0.06$ & $7.0 \pm 0.0$ \\
370 & $53.6 \pm 0.35$ & $19.9 \pm 0.12$ & $5.7 \pm 0.58$ \\
400 & $49.8 \pm 0.29$ & $19.9 \pm 0.12$ & $5.3 \pm 0.58$ \\
\hline
\end{tabular}

\section{DISCUSSION}

Ongoing advances in CT technology necessitate continuous investigation and optimization of injection protocols and bolus characteristics. Basic enhancement and bolus characteristics can easily be evaluated in a circulation phantom. ${ }^{15}$ The use of a circulation phantom provides a unique opportunity for repetitive scanning of an identical subject, ruling out variables such as varying heart rate, blood pressure and cardiac output. Controllable, consistent and repeatable phantom parameters, in effect, reduce a number of variables encountered in clinical studies, and allow discriminating predictions of delivery rate- and iodine concentration effects to be made. The data acquisition software used in this experiment precisely registered all injection and scanning parameters, providing a unique insight into total usage of contrast, iodine load, peak flow and intravascular pressure.

Optimization of intravascular contrast enhancement, in particular, the influence of iodine concentration and IDR, has been subject of several studies. ${ }^{6,8,12,16-21}$ Many publications describe significant differences in contrast enhancement, or in the detection of intravascular pathology in the coronary tree with the use of lower iodine concentration contrast (e.g. $300 \mathrm{mg} / \mathrm{ml}$ ) as compared to higher iodine concentration contrast (e.g. 370 and $400 \mathrm{mg} / \mathrm{ml}$ ). ${ }^{6-8,16,18,19}$ However, most studies base their findings on differences in attenuation level of the coronary arteries using variable IDR and/or total iodine load. The influence of these factors, in combination with individual physiological aspects, does not allow for conclusions to be drawn at any but a global level regarding iodine concentration for optimal attenuation of vessels. Therefore, some of the previously mentioned results in literature must be viewed with caution.

Even under standardized circumstances, no uniform results have been obtained in the clinical setting. Nance et al. concluded that high iodine concentration and high IDR $\mathrm{CM}$ delivery protocols provide the best image quality of the pulmonary arteries and perfusion map images of the lung. ${ }^{12}$ Other authors, however, found no significant differences in intravascular attenuation of arterial vessels with varying iodine concentration of contrast used when both IDR and total iodine load were kept identical. ${ }^{9,10}$ Mühlenbruch et al. prospectively included 300 patients and compared CM with iodine concentrations of 300,370 and $400 \mathrm{mg} / \mathrm{ml}$ in chest $\mathrm{CT}^{9}$. Their study 
population did not include coronary CTA patients, but both IDR $(1.3 \mathrm{gl} / \mathrm{s})$ and total iodine load (33g) were kept constant in all groups. Intravascular attenuation values were measured in the pulmonary trunk and the AA, and no statistically significant differences in contrast enhancement were found.

Rist et al. prospectively included 60 patients with known or suspected coronary artery disease in a double-blinded study, and compared contrast injection protocols with CM containing 300 and $400 \mathrm{mg} / \mathrm{ml}^{10}$ In the iomeron 300 group, $83 \mathrm{ml}$ of CM was used at a flow rate of $3.3 \mathrm{ml} / \mathrm{s}$, whereas in the iomeron 400 group, $63 \mathrm{ml}$ of CM was used at a flow rate of $2.5 \mathrm{ml} / \mathrm{s}$. Total iodine load in both groups was kept constant $(25 \mathrm{~g})$, as was the calculated IDR $(0.99 \mathrm{gl} / \mathrm{s}$ in the iomeron 300 group versus $1.0 \mathrm{gl} / \mathrm{s}$ in the iomeron 400 group), and equivalent homogenous enhancement of the coronary arteries was found for both groups. This finding is supported by the results of our standardized phantom experiment, even at the high IDR of $2.0 \mathrm{gl} / \mathrm{s}$.

In current practice, contrast agents with iodine concentrations between 300 and $400 \mathrm{mg} / \mathrm{ml}$ are routinely used to achieve target coronary attenuation levels. No studies investigating attenuation levels and anatomical detail of the coronary tree using CM with iodine concentrations lower than $300 \mathrm{mg} / \mathrm{ml}$ have been published.

In this circulation phantom study, no significant differences in intravascular attenuation were found for different iodine concentration contrast at a constant IDR. When IDR is kept identical, target attenuation levels can be reached with CM containing iodine concentrations as low as $240 \mathrm{mg} / \mathrm{ml}$. These results shed some doubt on the superiority of high iodine concentration $\mathrm{CM}$ over lower iodine concentration $\mathrm{CM}$ if the IDR remains identical. Low iodine concentration CM might be advantageous in clinical practice in terms of lower viscosity and subsequently lower injection pressure. A fluid with lower viscosity may distribute more easily and more evenly in the vessels and may subsequently provide a more homogeneous CM bolus. ${ }^{49}$ This, in turn, may have positive consequences for the visualization of smaller vessel segments such as the distal coronary arteries, even at the expense of higher flow rates. Standard clinical dual-head injectors can technically deliver $\mathrm{CM}$ at a flow rate of up to $10 \mathrm{ml} / \mathrm{s}$.

\section{Limitations}

Our study has its limitations in the small number of measurements $(n=3)$ and the use of a circulation phantom. Even though this phantom was designed to simulate physiological conditions, including a low- and a high-pressure system, physiological flow volumes and velocities, in vivo conditions are determined by many more patient related variants such as cardiac output.

This study evaluated attenuation as well as flow- and pressure-related parameters in a circulation phantom. No other parameters for image quality (e.g. contrast to noise ratio $[C N R])$ were evaluated in this study. Szucs-Farkas et al. evaluated CNR in a phantom study for 300 and $400 \mathrm{mg} / \mathrm{ml} \mathrm{CM}$ using variable $x$-ray tube parameters and 
patient sizes and found, that the same CNR for $400 \mathrm{mg} / \mathrm{ml} \mathrm{CM}$ was achieved at a lower CT dose index by $18 \%$ to $40 \%$, depending on phantom size and applied tube voltage when compared to the $300 \mathrm{mg} / \mathrm{ml}$ concentration. ${ }^{21}$

Statistically significant differences were found in peak pressure reached using higher iodine contrast agents as compared to lower iodine agents. However, the higher flow rates used for the administration of lower iodine concentrations is expected to (partially) negate any differences in peak pressure. This is probably attributable to the lower viscosity of the latter.

Viscosity is substantially decreased if $\mathrm{CM}$ is prewarmed to $37^{\circ} \mathrm{C}$ (iopromide 370 : 10.0mPa.s at $37^{\circ} \mathrm{C}\left[99^{\circ} \mathrm{F}\right.$ ] and $22.0 \mathrm{mPa} . \mathrm{s}$ at $20^{\circ} \mathrm{C}\left[68^{\circ} \mathrm{F}\right]$, iopromide 240 : $2.8 \mathrm{mPa} . \mathrm{s}$ at $37^{\circ} \mathrm{C}\left[99^{\circ} \mathrm{F}\right]$ and $4.9 \mathrm{mPa} . \mathrm{s}$ at $\left.20^{\circ} \mathrm{C}\left[68^{\circ} \mathrm{F}\right]\right) .{ }^{22}$ Although pressure limits were not reached and peak pressures did not pose a problem in the current phantom experiments, the conditions were considered ideal (all iodine concentrations were prewarmed at $37^{\circ} \mathrm{C}$ ), which is probably not the case in clinical practice. If contrast agents are not properly prewarmed, estimated peak pressures will presumably be higher, especially for higher concentrated contrast agents, potentially causing pressure-related problems such as contrast extravasation.

\section{CONCLUSION}

Comparison of protocols using different iodine concentration CM $(240-400 \mathrm{mg} / \mathrm{ml})$ in a circulation phantom led to robust intravascular enhancement patterns when IDR and total iodine load were kept constant and all other influencing factors, including temperature at injection, were standardized. Higher iodine concentrations themselves do not lead to higher attenuation levels. These results imply that IDR, and not iodine concentration, is the determinant factor in the opacification of vessels. When identical IDR is maintained, lower iodine concentration CM provides attenuation levels equal to those obtained using higher iodine concentration CM.

These results might stimulate a shift in paradigm towards clinical usage of CM with lower iodine concentrations (e.g. $240 \mathrm{mg} / \mathrm{ml}$ ) for individual tailored contrast protocols. Low iodine concentration CM are attractive due to their lower viscosity and, hence, lower injection pressure. 


\section{REFERENCES}

1. Behrendt FF, Bruners P, Keil S, Plumhans C, Mahnken AH, Stanzel S, Das M, Gunther RW, Muhlenbruch G. Impact of different vein catheter sizes for mechanical power injection in ct: In vitro evaluation with use of a circulation phantom. Cardiovasc Intervent Radiol. 2009;32:25-31

2. Awai K, Inoue M, Yagyu Y, Watanabe M, Sano T, Nin S, Koike R, Nishimura Y, Yamashita Y. Moderate versus high concentration of contrast material for aortic and hepatic enhancement and tumor-to-liver contrast at multi-detector row ct. Radiology. 2004;233:682-688

3. Johnson PT, Pannu HK, Fishman EK. IV contrast infusion for coronary artery ct angiography: Literature review and results of a nationwide survey. AJR Am J Roentgenol. 2009;192:W214-221

4. Bae KT. Intravenous contrast medium administration and scan timing at ct: Considerations and approaches. Radiology. 2010;256:32-61

5. Kumamaru KK, Steigner ML, Soga S, Signorelli J, Bedayat A, Adams K, Mitsouras D, Rybicki FJ. Coronary enhancement for prospective ecg-gated single r-r axial 320-mdct angiography: Comparison of 60- and 80ml iopamidol 370 injection. AJR Am J Roentgenol. 2011;197:844-850

6. Cademartiri F, de Monye C, Pugliese F, Mollet NR, Runza G, van der Lugt A, Midiri M, de Feyter PJ, Lagalla R, Krestin GP. High iodine concentration contrast material for noninvasive multislice computed tomography coronary angiography: lopromide 370 versus iomeprol 400. Invest Radiol. 2006;41:349-353

7. Cademartiri F, Mollet NR, van der Lugt A, McFadden EP, Stijnen T, de Feyter PJ, Krestin GP. Intravenous contrast material administration at helical 16-detector row ct coronary angiography: Effect of iodine concentration on vascular attenuation. Radiology. 2005;236:661-665

8. Becker CR, Vanzulli A, Fink C, de Faveri D, Fedeli S, Dore R, Biondetti P, Kuettner A, Krix M, Ascenti G. Multicenter comparison of high concentration contrast agent iomeprol-400 with iso-osmolar iodixanol320: Contrast enhancement and heart rate variation in coronary dual-source computed tomographic angiography. Invest Radiol. 2011;46:457-464

9. Muhlenbruch G, Behrendt FF, Eddahabi MA, Knackstedt C, Stanzel S, Das M, Seidensticker P, Gunther RW, Wildberger JE, Mahnken AH. Which iodine concentration in chest ct? - A prospective study in 300 patients. Eur Radiol. 2008;18:2826-2832

10. Rist C, Nikolaou K, Kirchin MA, van Gessel R, Bae KT, von Ziegler F, Knez A, Wintersperger BJ, Reiser MF, Becker CR. Contrast bolus optimization for cardiac 16-slice computed tomography: Comparison of contrast medium formulations containing 300 and 400 milligrams of iodine per milliliter. Invest Radiol. 2006;41:460-467

11. Behrendt FF, Plumhans C, Keil S, Muhlenbruch G, Das M, Seidensticker P, Mutscher C, Gunther RW, Mahnken $\mathrm{AH}$. Contrast enhancement in chest multidetector computed tomography: Intraindividual comparison of $300 \mathrm{mg} / \mathrm{ml}$ versus $400 \mathrm{mg} / \mathrm{ml}$ iodinated contrast medium. Acad Radiol. 2009;16:144-149

12. Nance JW, Jr., Henzler T, Meyer M, Apfaltrer P, Braunagel M, Krissak R, Schoepf UJ, Schoenberg SO, Fink C. Optimization of contrast material delivery for dual-energy computed tomography pulmonary angiography in patients with suspected pulmonary embolism. Invest Radiol. 2012;47:78-84

13. Knollmann F, Schimpf K, Felix R. lodine delivery rate of different concentrations of iodine-containing contrast agents with rapid injection. RoFo. 2004;176:880-884

14. Brunette J, Mongrain R, Laurier J, Galaz R, Tardif JC. 3d flow study in a mildly stenotic coronary artery phantom using a whole volume piv method. Med Eng Phys. 2008;30:1193-1200

15. Behrendt FF, Bruners P, Kalafut J, Mahnken AH, Keil S, Plumhans C, Das M, Stanzel S, Wildberger JE, Pfeffer J, Gunther RW, Muhlenbruch G. Introduction of a dedicated circulation phantom for comprehensive in vitro analysis of intravascular contrast material application. Invest Radiol. 2008;43:729736

16. Christensen JD, Meyer LT, Hurwitz LM, Boll DT. Effects of iopamidol-370 versus iodixanol-320 on coronary contrast, branch depiction, and heart rate variability in dual-source coronary mdct angiography. AJR Am J Roentgenol. 2011;197:W445-451

17. Cademartiri F, Mollet NR, Runza G, Bruining N, Hamers R, Somers P, Knaapen M, Verheye S, Midiri M, Krestin GP, de Feyter PJ. Influence of intracoronary attenuation on coronary plaque measurements using multislice computed tomography: Observations in an ex vivo model of coronary computed tomography angiography. Eur Radiol. 2005;15:1426-1431

18. Tsai IC, Lee T, Tsai WL, Chen MC, Wu MJ, Lee WL, Ting HJ. Contrast enhancement in cardiac mdct: Comparison of iodixanol 320 versus iohexol 350. AJR. Am J Roentgenol. 2008;190:W47-53 


\section{Chapter 4}

19. Yamamuro M, Tadamura E, Kanao S, Wu YW, Tambara K, Komeda M, Toma M, Kimura T, Kita T, Togashi K. Coronary angiography by 64-detector row computed tomography using low dose of contrast material with saline chaser: Influence of total injection volume on vessel attenuation. J Comp Assist Tomogr. 2007;31:272-280

20. Bae $\mathrm{KT}$, Tran $\mathrm{HQ}$, Heiken JP. Uniform vascular contrast enhancement and reduced contrast medium volume achieved by using exponentially decelerated contrast material injection method. Radiology. 2004;231:732-736

21. Szucs-Farkas Z, Verdun FR, von Allmen G, Mini RL, Vock P. Effect of x-ray tube parameters, iodine concentration, and patient size on image quality in pulmonary computed tomography angiography: A chest-phantom-study. Invest Radiol. 2008;43:374-381

22. Inc. BHP. Data sheet Ultravist ${ }^{\circledR}$. Available at: http://www.bayerresources.com.au/resources/uploads/ DataSheet/file9512.pdf. Accessed July 11, 2012. 


\section{CHAPTER 5}

\section{CT angiography with high flow rates: An in vitro and in vivo feasibility study}




\section{ABSTRACT}

\section{Purpose}

The aims of this study were to test high flow application of contrast media (CM) using novel high flow needles and to assess injection- and flow-related parameters in a circulation phantom and in an in vivo population.

\section{Materials and methods}

A circulation phantom simulating physiological parameters was used. Preheated CM $(300 \mathrm{mg} / \mathrm{ml})$ was injected at flow rates varying between $5-15 \mathrm{ml} / \mathrm{s}$ through a novel 18 gauge high flow intravenous injection needle. In addition, feasibility of these high flow needles was tested with administration of flow rates of $9 \mathrm{ml} / \mathrm{s}$ in 20 patients referred for pre-transcatheter aortic valve implantation assessment. Injection parameters (e.g. peak pressures, peak flow rates) in both phantom and in vivo setup were continuously monitored by a data acquisition program. Attenuation at predefined levels of the aorta (e.g. aortic root to common femoral arteries) was measured in all patients to determine clinical applicability.

\section{Results}

In the phantom setup, injections rates up to $15 \mathrm{ml} / \mathrm{s}$ were feasible. An enhancement plateau was reached at $11 \mathrm{~m} / \mathrm{s}(464 \pm 20 \mathrm{HU})$. In patients, no pressure- or flow-related complications (e.g. extravasation) were recorded (mean peak pressure: $154 \pm 8 \mathrm{psi}$, mean peak flow rate: $9.2 \pm 0.1 \mathrm{ml} / \mathrm{s}$, range: $9.1-9.6 \mathrm{ml} / \mathrm{s}$ ). Diagnostic attenuation values were reached at all predefined levels of the aorta $(330.8 \pm 113.1 \mathrm{HU}$ to $622.9 \pm 81.5 \mathrm{HU})$.

\section{Conclusion}

These results indicate that injections with $9 \mathrm{ml} / \mathrm{s}$ using high flow injection needles are safe. The pressure limit of 325 psi was not reached and the injections resulted in diagnostic attenuation values. Using this dedicated needle, high flow rates should not be considered a drawback for CM application in routine CT angiography examinations. 


\section{INTRODUCTION}

Computed tomographic angiography (CTA) has moved towards shorter scan acquisition times to reduce motion artefacts and radiation dose for the individual patient. Shorter scan acquisition times require a special contrast media (CM) bolus design with shorter injection duration and higher iodine delivery rates (IDRs; iodine delivered per second), which makes optimal timing crucial. ${ }^{1}$ As was shown in previous studies, higher IDRs result in higher peak enhancement, which is considered a prerequisite for CTA studies, especially in coronary CTA. ${ }^{2-6}$ As the IDR is determined by the CM concentration and the flow rate, higher iodine concentration or higher flow rates will increase the IDR. Reluctance towards usage of higher flow rates for clinical routine remains because it has been hypothesized that higher flow rates possibly lead to increased incidence of extravasation due to increased injection pressures. ${ }^{7}$ An overall extravasation incidence of $0.14 \%$ was reported in early literature, where none of these patients required medical or surgical intervention as a result of extravasation. ${ }^{7}$

However, it is not clear what leads to extravasation, but it can be hypothesized that extravasation might be a multifactor incident of needle size/type and injection location, vein size, injection rate, injection pressure and CM used.

The injection pressure itself is determined by the pressure needed to inject a certain amount of iodine in a certain amount of time. It is usually measured at the CT power injector itself and is influenced by CM characteristics (viscosity) as well as tubing to the patient including the intravenous (i.v.) needle. Each CM has a certain viscosity, which increases with increasing iodine concentration. Furthermore, viscosity is largely influenced by temperature and decreases with increasing temperature. ${ }^{5,8-14}$ It has been stated previously, that viscosity substantially decreases if $\mathrm{CM}$ is prewarmed to $37^{\circ} \mathrm{C}$ (iopromide 370 : $10.0 \mathrm{mPa}$.s at $37^{\circ} \mathrm{C}\left[99^{\circ} \mathrm{F}\right]$ and $22.0 \mathrm{mPa}$.s at $20^{\circ} \mathrm{C}\left[68^{\circ} \mathrm{F}\right]$, iopromide 300 : $4.7 \mathrm{mPa} . \mathrm{s}$ at $37^{\circ} \mathrm{C}\left[99^{\circ} \mathrm{F}\right]$ and $8.9 \mathrm{mPa} . \mathrm{s}$ at $\left.20^{\circ} \mathrm{C}\left[68^{\circ} \mathrm{F}\right]\right) .{ }^{10,15}$ Lower temperatures (e.g. $20^{\circ} \mathrm{C}$ ) as well as high iodine concentration have a negative impact on viscosity. Increased viscosity increases the friction resistance and the pressure needed for the same flow rate. ${ }^{9}$ It has been stated that $\mathrm{CM}$ of high iodine concentration in combination with high injection rates may potentially result in disconnection of the cannula due to their nonlinear increase in viscosity and consecutively increase in injection pressure. 2,12 On the other hand, Wienbeck et al. prospectively evaluated 4457 patients and assessed the frequency and type of i.v. injection site complications associated with high flow power injection up to $8 \mathrm{ml} / \mathrm{s}^{9}$. They concluded, that automated $\mathrm{CM}$ injection is performed without increased risk of extravasation or injection-related complications.

The use of high flow rates in clinical routine imaging might be beneficial in several ways. With the concept of the IDR, increasing flow rates also increases IDR, which leads to increased attenuation in the target region. Current power injectors in CT are limited to $10 \mathrm{ml} / \mathrm{s}$, which leads to a maximum IDR between 3 and $4 \mathrm{gl} / \mathrm{s}$ depending on the used iodine concentration. High attenuation levels are desirable, for example in the 
assessment of coronary arteries and specifically in CT perfusion imaging when a short and dense bolus is desirable. ${ }^{16,17}$ Furthermore, individualized injection protocols require a broad spectrum of injections rates, for example, in heavier patients to achieve the same enhancement levels.

To facilitate high injection rates, dedicated i.v. needles have been developed, shaped with 3 tear-drop holes positioned near the catheter tip. The strengthened design reduces the forces that can cause catheter motion in the veins.

The aim of this study was to test high flow application of CM using novel high flow needles in a circulation phantom and to assess feasibility of high flow rates in a patient population.

\section{MATERIALS AND METHODS}

\section{Injection and scan protocol}

\section{Circulation phantom}

A circulation phantom with physiological parameters was used as described elsewhere. ${ }^{10,18,19}$ Preheated $\mathrm{CM}\left(37^{\circ} \mathrm{C}\right)$ with a concentration of $300 \mathrm{mg} / \mathrm{ml}$ (Ultravist 300; iopromide, Bayer Healthcare, Berlin, Germany) was administered via high-flow i.v. injection needles (18-gauge BD Nexiva Diffusics ${ }^{\circledR}$ i.v. Catheters, Sandy, UT, USA). The catheter consists of BD Vialon material, which is a proprietary biomaterial developed for vascular access. These needles have 3 teardrop-shaped holes positioned near the catheter tip and a strengthened design (Figure 1). CM was injected at different flow rates of 5 to $15 \mathrm{ml} / \mathrm{s}$ in steps of $1 \mathrm{ml} / \mathrm{s}$ with subsequently higher IDR $(1.5-4.5 \mathrm{gl} / \mathrm{s}$, Table 1). Contrast medium was injected into the phantom using a standard CT power injector (Stellant/MEDRAD; Pittsburgh, PA, USA), through a 3-way stopcock extension tube with a maximum pressure setting of 325 pounds per square inch (psi). As injection with flow rates at $10 \mathrm{ml} / \mathrm{s}$ and above is not possible with a standard CT power injector, an angio power injector (Angiomat Illumena; Liebel-Flarsheim, Cincinnati, OH, USA) was used for administration of $\mathrm{CM}$ at flow rates of $10 \mathrm{ml} / \mathrm{s}$ and higher. Accordingly, the pressure limit cutoff was set to $325 \mathrm{psi}$. Overall volume and total amount of iodine in all groups were kept identical (50ml and $15 \mathrm{~g}$, respectively). After every scan, the phantom was flushed with water. All protocols were repeated 5 times to provide reproducibility. All scans were performed on a second-generation dual-source CT (MDCT) scanner (Somatom Definition Flash; Siemens Healthcare, Forchheim, Germany) with a $128 \times 0.6 \mathrm{~mm}$ slice collimation, a gantry rotation time of 0.5 seconds (s), a tube voltage of $120 \mathrm{kV}$ at $150 \mathrm{mAs}$, and a cycle time of $1000 \mathrm{~ms}$. Serial CT scans at the level of the ascending aorta $(A A)$, descending aorta (DA) and the left main coronary artery (LM) were obtained. Scan delay was determined by means of a test bolus. The phantom was connected to the scanner's electrocardiogram (ECG) lead inputs to provide a synchronized ECG waveform 
based on the phantoms set parameters. An independent data acquisition system (National Instruments Corporation; Austin, TX, USA) was utilized to monitor the physiological parameters of the phantom experiments. In addition, injection-related parameters (e.g. total amount of CM injected, flow rate, peak flow rate and peak pressure) were monitored using the Certegra ${ }^{\mathrm{TM}}$ Informatics Platform (Bayer Healthcare, Berlin, Germany) for flow rates between 5 and $10 \mathrm{ml} / \mathrm{s}$. As an angio power injector prohibits us from using this data acquisition program, data with regard to peak flow rate and peak pressure at flow rates above $10 \mathrm{ml} / \mathrm{s}$ could not be monitored by the software.

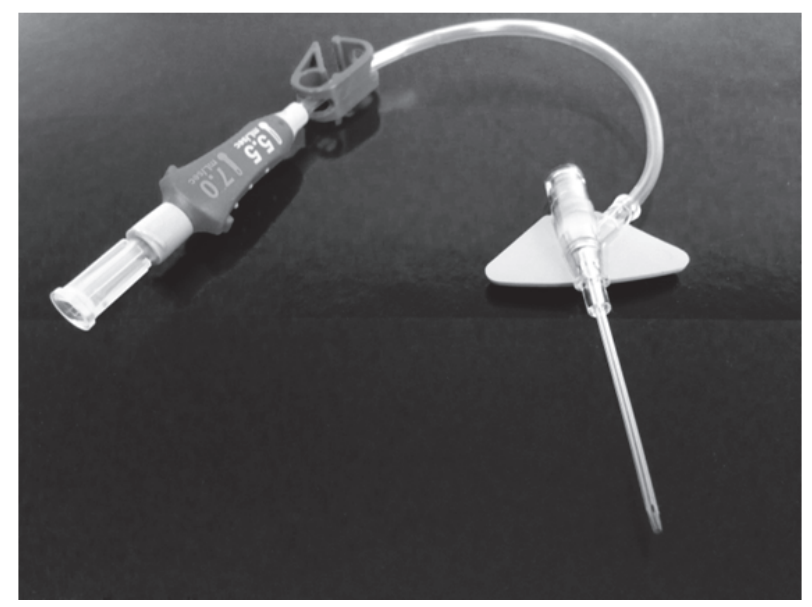

Figure 1: Close-up photograph of the needle used (BD Nexiva Diffusics ${ }^{\circledR}$ i.v. Catheters). 3 teardrop-shaped holes positioned near the catheter tip and strengthened design that enables use with power injectors set up to 325 psi. Needle size was 18-gauge.

Table 1: Phantom injection parameters for all CM groups. CM: contrast media, IDR: iodine delivery rate.

\begin{tabular}{llllll}
\hline Protocol & CM $(\mathrm{mg} / \mathrm{ml})$ & Volume $(\mathrm{ml})$ & Flow rate $(\mathrm{ml} / \mathrm{s})$ & IDR $(\mathrm{gl} / \mathrm{s})$ & Injection time $(\mathrm{s})$ \\
\hline A & 300 & 50 & 5.0 & 1.5 & 10 \\
B & 300 & 50 & 6.0 & 1.8 & 8.3 \\
C & 300 & 50 & 7.0 & 2.1 & 7.1 \\
D & 300 & 50 & 8.0 & 2.4 & 6.3 \\
E & 300 & 50 & 9.0 & 2.7 & 5.6 \\
F & 300 & 50 & 10 & 3.0 & 5.0 \\
G & 300 & 50 & 11 & 3.3 & 4.5 \\
H & 300 & 50 & 12 & 3.6 & 4.2 \\
I & 300 & 50 & 13 & 3.9 & 3.8 \\
J & 300 & 50 & 14 & 4.2 & 3.6 \\
K & 300 & 50 & 15 & 4.5 & 3.3 \\
\hline
\end{tabular}


In vivo setup

In addition, a feasibility study in 20 nonselected transcatheter aortic valve implantation candidates was performed. Patients with severe symptomatic aortic stenosis were referred from the outpatient clinic for $\mathrm{CT}$ evaluation of aortic root dimensions and peripheral arteries. For assessment of aortic root dimension, a dual energy (DE) retrospective ECG-gated helical scan was performed with the following parameters: a slice collimation of $128 \times 0.6 \mathrm{~mm}$, a tube voltage of $100 / \mathrm{Sn} 140 \mathrm{kV}$, a reference tube current of $110 / 94 \mathrm{mAs}$, a gantry rotation time of $280 \mathrm{~ms}$, a pitch of 0.21 and $126 \mathrm{f}$ medium soft convolution kernel (strength 2 ). This acquisition was directly followed by a prospective high pitch non-ECG triggered scan (Flash) for evaluation of the peripheral arteries with the following parameters: slice collimation of $128 \times 0.6 \mathrm{~mm}$, a tube voltage of $100 \mathrm{kV}$, a reference tube current of $150 \mathrm{mAs}$, gantry rotation time of $280 \mathrm{~ms}$, pitch of 3.0 and medium soft convolution kernel $130 f$ (strength 2). Patients were scanned in craniocaudal direction, and dose modulation (CareDose $4 \mathrm{D}^{\mathrm{TM}}$; Siemens Medical Solutions) was used. Patients were injected with identical preheated CM concentration of $300 \mathrm{mg} / \mathrm{ml}$ through an identical 18-gauge high flow needle as described before in the antecubital vein.

First, a CM bolus of $90 \mathrm{ml}$ was injected, followed by $60 \mathrm{ml} \mathrm{CM}$ with a $50 \%$ dilution. A saline chaser was injected afterwards (volume: $40 \mathrm{ml}$ ). All CM and saline volumes were injected at a predetermined flow rate of $9 \mathrm{ml} / \mathrm{s}$. A test bolus was injected at the level of the AA to assess optimal start time after administration of the bolus $(20 \mathrm{ml}$ of $\mathrm{CM}$ followed by $40 \mathrm{ml}$ of saline, flow rate: $9 \mathrm{ml} / \mathrm{s})$. Total iodine dose $(36 \mathrm{~g})$ and IDR $(2.7 \mathrm{gl} / \mathrm{s})$ were kept constant in all patients. Peak flow rates are known to be slightly higher than the pre-determined injection rates. Therefore, in this in vivo setup, a flow rate of $9 \mathrm{ml} / \mathrm{s}$ was applied because the maximal feasible flow rate due to variations in maximum flow rate in the individual patient might vary up to higher values than $9 \mathrm{ml} / \mathrm{s}$ and $10 \mathrm{ml} / \mathrm{s}$ is the maximum flow rate possible with current CT power injectors. The injection parameters were monitored by the monitoring system. Any contrast injection-related complications (e.g. extravasation and material damage) were recorded. Ethical approval and waiver of informed consent was given by the local ethical committee (decision number, METC 14-4-089).

\section{Quantitative and qualitative analysis}

\section{Circulation phantom}

The mean time to peak (TTP, s) for each flow rate was compared graphically by means of time enhancement curves for all vessels. Peak pressures in the phantom setup were evaluated and compared. In addition, mean attenuation values of the vessels in the phantom were measured on all images of the serial CT scans by placing a circular region of interest (ROI) in the AA, DA and LM. At all anatomic sites a constant size of a largest intraluminal ROI possible was used. Resulting average mean contrast enhancement 
values for each time point were compared graphically between the CM protocols in flow enhancement curves. The peak enhancement was followed as an indicator of the maximal flow through the needle.

In vivo setup

Images were analyzed by using the source images on a dedicated post processing workstation (SyngoVia; Siemens Healthcare, Forchheim, Germany). Intravascular enhancement was measured using a manually placed ROI at predefined levels of the aorta; $A A(D E, 120 \mathrm{kV}$ mixed phase; DE, 100kV), DA, abdominal aorta, left and right common femoral artery (Flash, 100kV). Image noise was defined as a standard deviation (SD) of the attenuation. Signal-to-noise ratio (SNR) was calculated as vessel attenuation divided by image noise. Contrast-to-noise ratio (CNR) was determined as a difference between attenuation of the vessel and attenuation of adjacent muscle tissue divided by image noise. Previous literature stated, that a CNR greater than 10 can be considered an acceptable threshold for diagnostic imaging. ${ }^{20}$ All complications caused by CM application (e.g. extravasations) were monitored. In addition, all datasets were analyzed with respect to artifacts, possibly caused by the injection protocol (e.g. streak artifacts, reflux).

\section{Statistical analysis}

Mean peak pressures were calculated for all flow rates in the phantom setup. Mean contrast enhancement values obtained were averaged over the 5 repeated measurements for all injection protocols. In patients, descriptive data for continuous variables were presented as means $\pm S D$. In patients, mean and maximal peak flow rates $(\mathrm{ml} / \mathrm{s})$ and peak pressures (psi) were calculated. In addition, mean attenuations, image noise as well as CNR and SNR were calculated. The values were expressed as mean \pm SD. Data analysis was conducted with SPSS version 22.0 (SPSS Inc; Chicago, IL, USA). All $P$ values were 2 -sided, and a $P$ value below 0.05 was considered to be statistically significant.

\section{RESULTS}

\section{Circulation phantom}

Mean peak pressures for flow rates from 5 to $10 \mathrm{ml} / \mathrm{s}$ were as follows: $5.0 \mathrm{ml} / \mathrm{s}: 81 \pm 1 \mathrm{psi}$, $6.0 \mathrm{ml} / \mathrm{s}: 97 \pm 3 \mathrm{psi}, 7.0 \mathrm{ml} / \mathrm{s}: 107 \pm 1 \mathrm{psi}, 8.0 \mathrm{ml} / \mathrm{s}: 129 \pm 2 \mathrm{psi}, 9.0 \mathrm{ml} / \mathrm{s}: 143 \pm 2 \mathrm{psi}, 10.0 \mathrm{ml} / \mathrm{s}$ : $157 \pm 5$ psi (Figure 2). The injection pressure of the high flow needles was attained during all injections without problems, and the pressure limit of 325psi was not reached on any occasion. No material damage to the needle was seen. A decrease was noted for mean 
TTP for all vessels in close relation to the flow rates (TTP AA: $13.4 \pm 0.5 \mathrm{~s}$ to $8.8 \pm 0.4 \mathrm{~s}$, TTP DA: $14.8 \pm 0.5$ s to $10.0 \pm 0.0$ s, TTP LM: $13.2 \pm 0.4 \mathrm{~s}$ to $9.0 \pm 0.0$ s (Table 2, Figure $3 \mathrm{~A}$ ). An increase in attenuation of AA $(358 \pm 18 \mathrm{HU}$ to $464 \pm 2 \mathrm{HU}), \mathrm{DA}(348 \pm 20 \mathrm{HU}$ to $446 \pm 22 \mathrm{HU})$, and $\mathrm{LM}(353 \pm 13 \mathrm{HU}$ to $460 \pm 31 \mathrm{HU})$ was noted in relation to the high flow rates and subsequently higher IDR (Table 2, Figure 3B), potentially reaching a plateau at $11 \mathrm{ml} / \mathrm{s}$.

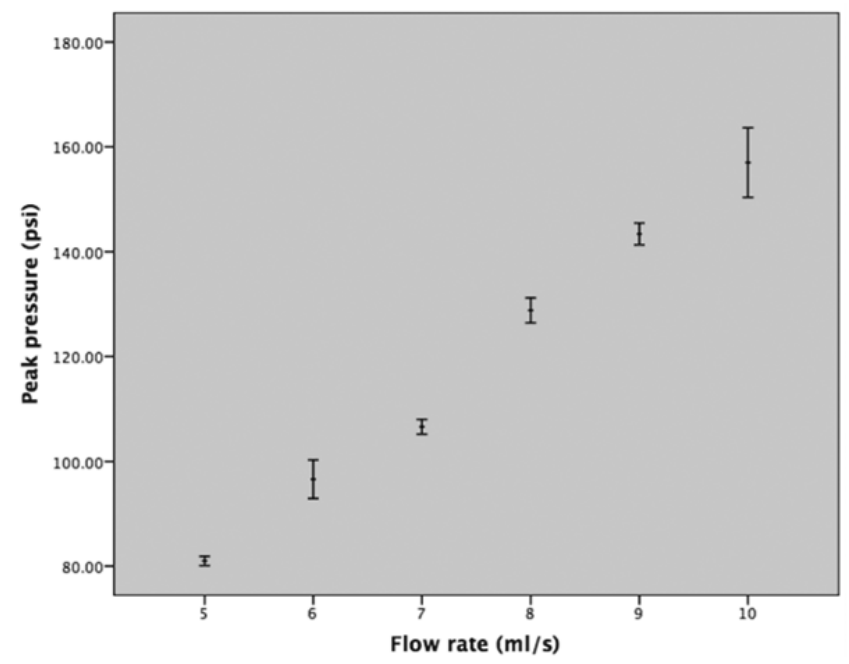

Figure 2: Graph showing different flow rates (millilitres per second) on the $x$ axis and peak pressures (pounds per square inch) on the $y$ axis. The error bars represent the mean and $95 \%$ confidence interval.

Table 2: Mean time to peak and mean attenuation values in the AA, DA and LM with different flow rates in a phantom setup. The values are expressed as mean \pm SD. HU: Hounsfield units, TTP: time to peak, AA: ascending aorta, DA: descending aorta, LM: left main coronary artery.

\begin{tabular}{|c|c|c|c|c|c|c|}
\hline \multirow[b]{2}{*}{ Flow rate $(\mathrm{ml} / \mathrm{s})$} & \multicolumn{3}{|c|}{ Time to peak (s) } & \multicolumn{3}{|c|}{ Attenuation (HU) } \\
\hline & AA & DA & LM & AA & DA & LM \\
\hline 5.0 & $13.4 \pm 0.5$ & $14.8 \pm 0.5$ & $13.2 \pm 0.4$ & $358 \pm 18$ & $348 \pm 20$ & $353 \pm 13$ \\
\hline 6.0 & $12.1 \pm 0.1$ & $13.5 \pm 0.6$ & $12.1 \pm 0.1$ & $386 \pm 27$ & $375 \pm 18$ & $373 \pm 18$ \\
\hline 7.0 & $11.2 \pm 0.4$ & $12.4 \pm 0.5$ & $10.8 \pm 0.4$ & $405 \pm 16$ & $398 \pm 12$ & $400 \pm 16$ \\
\hline 8.0 & $10.5 \pm 0.5$ & $12.1 \pm 0.1$ & $10.7 \pm 0.5$ & $413 \pm 24$ & $400 \pm 27$ & $406 \pm 22$ \\
\hline 9.0 & $9.8 \pm 0.4$ & $10.8 \pm 0.4$ & $10.0 \pm 0.6$ & $431 \pm 26$ & $413 \pm 25$ & $417 \pm 26$ \\
\hline 10.0 & $9.6 \pm 0.5$ & $11.0 \pm 0.1$ & $9.6 \pm 0.6$ & $425 \pm 28$ & $412 \pm 29$ & $409 \pm 25$ \\
\hline 11.0 & $9.0 \pm 0.0$ & $10.0 \pm 0.0$ & $9.0 \pm 0.0$ & $464 \pm 20$ & $446 \pm 22$ & $460 \pm 31$ \\
\hline 12.0 & $8.8 \pm 0.4$ & $10.4 \pm 0.5$ & $9.2 \pm 0.4$ & $445 \pm 12$ & $428 \pm 10$ & $439 \pm 16$ \\
\hline 13.0 & $8.9 \pm 0.4$ & $10.5 \pm 0.4$ & $9.3 \pm 0.4$ & $440 \pm 8$ & $428 \pm 7$ & $444 \pm 8$ \\
\hline 14.0 & $9.0 \pm 0.1$ & $10.6 \pm 0.5$ & $9.2 \pm 0.4$ & $416 \pm 25$ & $401 \pm 20$ & $409 \pm 19$ \\
\hline 15.0 & $9.0 \pm 0.0$ & $10.2 \pm 0.4$ & $9.0 \pm 0.0$ & $456 \pm 14$ & $436 \pm 20$ & $448 \pm 15$ \\
\hline
\end{tabular}



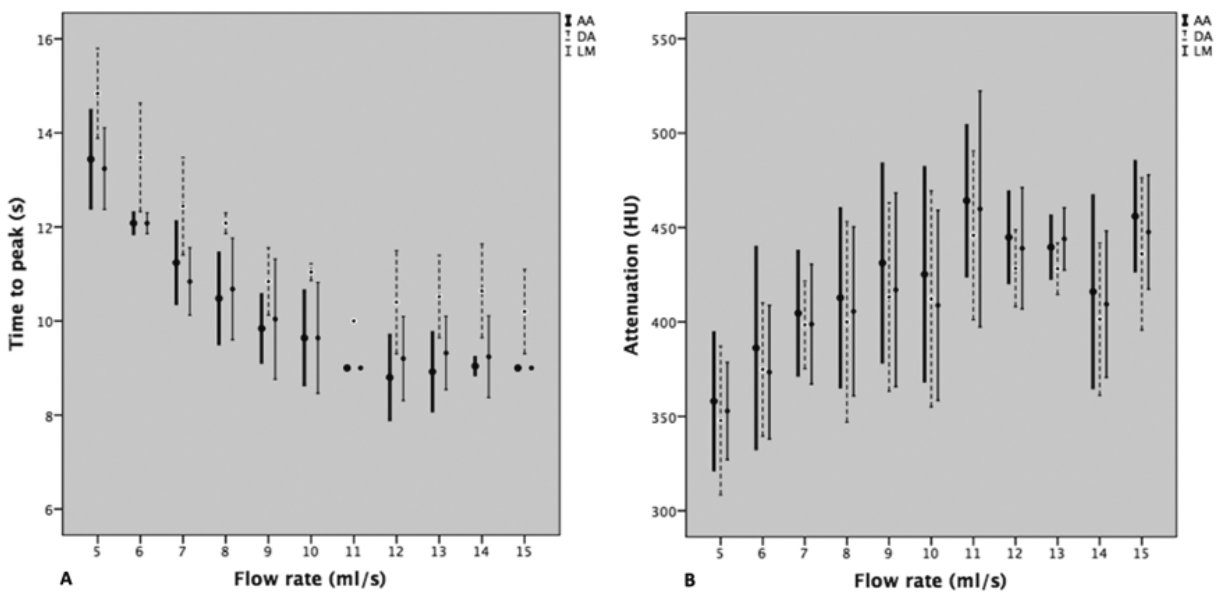

Figure 3: Graph A showing different flow rates (milliliters per second) on the $x$ axis and TTP values (seconds) of AA, DA, and LM on the $y$ axis. The error bars represent the mean and 95\% confidence interval. Graph B showing different flow rates (milliliters per second) on the $x$ axis and attenuation values (Hounsfield units) of AA, DA, and LM on the $y$ axis. The error bars represent the mean and 95\% confidence interval. TTP: time to peak, AA: ascending aorta, DA: descending aorta, LM: left main coronary artery.

\section{In vivo setup}

Patient characteristics are stated in Table 3. Mean peak flow rate was $9.2 \pm 0.1 \mathrm{ml} / \mathrm{s}$ (range: $9.1-9.6 \mathrm{ml} / \mathrm{s}$ ). The mean peak pressure reached $154 \pm 8 \mathrm{psi}$, which is comparable to the peak pressures reached in the phantom setup at similar flow rates. In none of the patients, a pressure limit of 325 psi was reached. The high flow needles did not cause any flow- or pressure-related problems and remained stable throughout the injection. No contrast-related problems (extravasation at the injection site) or negative right-sided effects (e.g. streak artifacts or CM reflux) were encountered. Attenuation values at all predefined levels of the aorta as well as image noise, SNR, and CNR are summarized in Table 4. Diagnostic attenuation values were reached at all predefined levels of the aorta (Figure 4).

Table 3: Patient characteristics. The values are expressed as mean \pm SD. SD: standard deviation.

\begin{tabular}{lc}
\hline Baseline characteristics & Mean \pm SD \\
\hline Age $(\mathrm{y})$ & $77.9 \pm 12.3$ \\
Weight $(\mathrm{kg})$ & $70.7 \pm 9.8$ \\
Height $(\mathrm{cm})$ & $170 \pm 10$ \\
Body mass index $\left(\mathrm{kg} / \mathrm{m}^{2}\right)$ & $25.2 \pm 2.2$ \\
Peak flow rate $(\mathrm{ml} / \mathrm{s})$ & $9.2 \pm 0.1$ \\
Peak pressure $(\mathrm{psi})$ & $153.7 \pm 7.8$ \\
CM volume $(\mathrm{ml})$ & $139.9 \pm 0.2$ \\
Ejection fraction $(\%)$ & $54.4 \pm 11.9$ \\
\hline
\end{tabular}




\section{Chapter 5}

Table 4: Image quality evaluated by attenuation, image noise, SNR and CNR in patient population. The values are expressed as mean \pm SD. HU: Hounsfield units, SNR: signal-to-noise ratio, CNR: contrast-to-noise ratio, DE: dual energy, AA: ascending aorta, DE: dual energy, DA: descending aorta, Abd aorta: abdominal aorta, AFC: common femoral artery.

\begin{tabular}{lcccc}
\hline & Attenuation (HU) & Image noise (HU) & SNR & CNR \\
\hline AA (DE mix 120kV) & $484.2 \pm 59.7$ & $21.0 \pm 3.8$ & $23.8 \pm 4.6$ & $19.9 \pm 4.3$ \\
AA (DE 100kV) & $622.9 \pm 81.5$ & $34.6 \pm 8.7$ & $19.1 \pm 5.0$ & $16.6 \pm 4.4$ \\
DA (Flash 100kV) & $330.8 \pm 113.1$ & $25.2 \pm 5.6$ & $13.4 \pm 4.5$ & $11.3 \pm 4.1$ \\
Abd aorta (Flash 100kV) & $382.7 \pm 127.1$ & $30.0 \pm 7.2$ & $13.2 \pm 4.5$ & $11.5 \pm 4.4$ \\
AFC right (Flash 100kV) & $511.3 \pm 153.7$ & $26.1 \pm 7.4$ & $20.5 \pm 7.3$ & $18.0 \pm 7.0$ \\
AFC left (Flash 100kV) & $519.4 \pm 143.4$ & $28.0 \pm 10.7$ & $20.8 \pm 7.1$ & $18.2 \pm 6.8$ \\
\hline
\end{tabular}

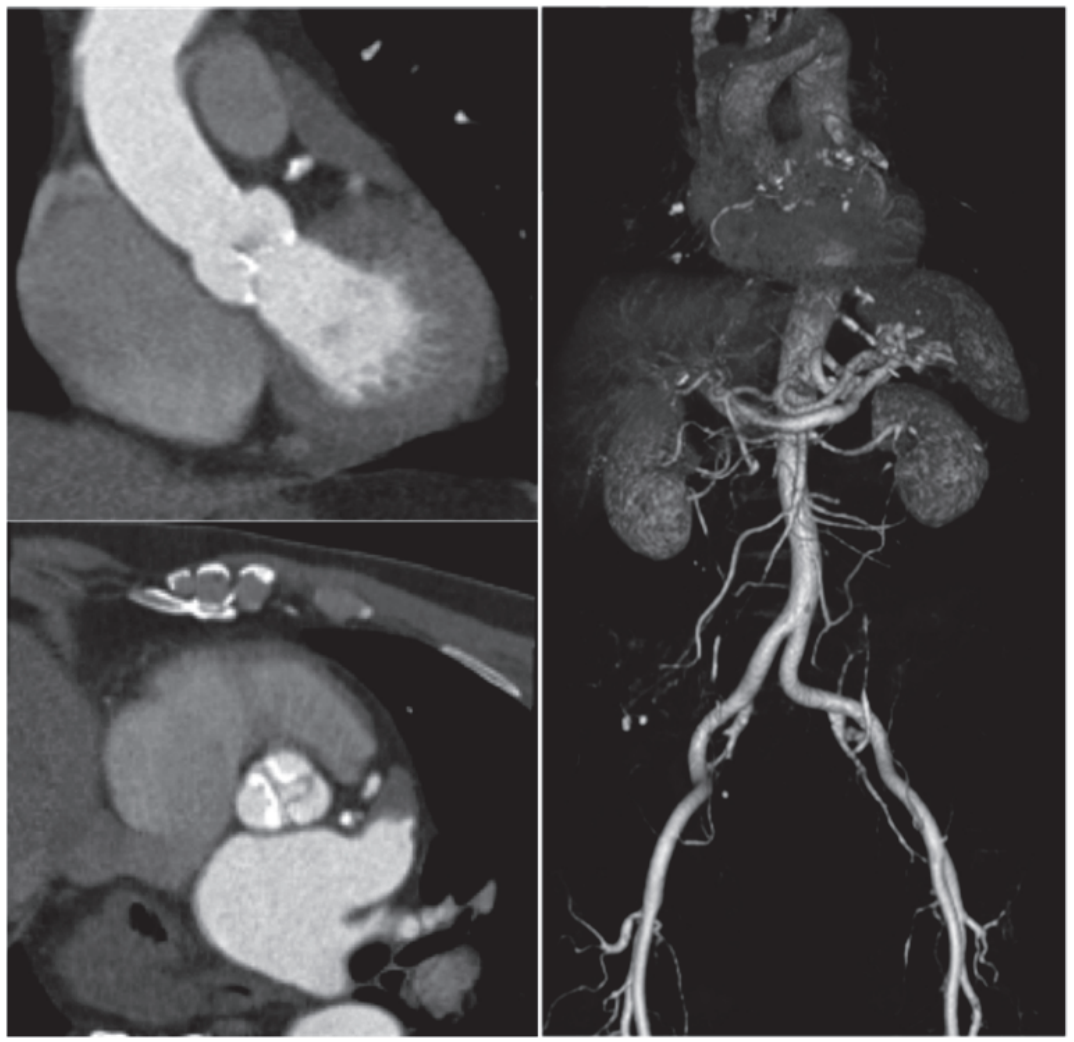

Figure 4: Volume-rendered CTA with corresponding axial and coronal source images at the level of the aortic valve, demonstrating calcifications in the region of the aortic valve leaflets and adequate diagnostic image quality of the aorta and the iliofemoral arteries. 


\section{DISCUSSION}

High flow injection rates proved to be feasible in a phantom setting (up to $15 \mathrm{ml} / \mathrm{s}$ ) as well as in a clinical cohort (maximum flow rate: $9.6 \mathrm{ml} / \mathrm{s}$ ). No flow related problems were seen and the maximum injection pressure of 325 psi was never reached in phantom and patient setting.

In the phantom experiment, attenuation increased as expected with increasing flow rates, reaching a plateau at $11 \mathrm{ml} / \mathrm{s}$. Thus, a flow rate of $11 \mathrm{ml} / \mathrm{s}$ appears to be the maximal technically feasible flow rate in this setup. It is questionable whether the applicable maximum flow rate can be attributed to flow- or pressure-related limits of the phantom, the injector, or the needles itself. Most likely it is the distribution of CM within the phantom, which does not allow further increase of the attenuation.

Previous study groups investigated the peak pressures of flow rates and conventional cannula sizes in different experimental setups. Behrendt et al. evaluated the influence of regular peripheral vein catheter sizes on injector output, injection pressure, and time enhancement curves in a less advanced phantom with a flow rate of $5 \mathrm{ml} / \mathrm{s}$ and preheated $\mathrm{CM}$ of $370 \mathrm{mg} / \mathrm{ml}$. They found an increase in peak pressure (14gauge: 208.5psi, 22-gauge: $260.5 \mathrm{psi}$ ) with regard to smaller size cannulas. ${ }^{2}$ Schwab et al. investigated the maximum injection pressures with different $\mathrm{CM}$ at different temperatures in the most common i.v. cannula sizes. ${ }^{13}$ Experiments were performed using a pressure limited power injector including dedicated 1-way components. The maximum injection pressures with different CM (Solutrast 300, Imeron 350 and Imeron 400) were measured at $20^{\circ} \mathrm{C}$ and $37^{\circ} \mathrm{C}$ using increasing flow rates $(1-9 \mathrm{ml} / \mathrm{s})$. They measured peak pressures up to $161 \mathrm{psi}$ (preheated Solutrast 300 , flow rate: $8 \mathrm{ml} / \mathrm{s}$ with 22 -gauge catheter). Although the experimental setup is very different from this phantom setup, findings are similar indicating that CM injection is safe even with small cannulas without reaching the common standard pressure limit in CT power injectors of 325 psi.

In patients, flow rates of $9 \mathrm{ml} / \mathrm{s}$ did not cause injection-related problems (extravasation at the injection site, material damage, cannula placement) or negative right-sided effects (e.g. streak artifacts or CM reflux) while reaching optimal arterial enhancement levels. Wienbeck et al. prospectively assessed the frequency and type of i.v. injection site complications associated with high flow power injection up to $8 \mathrm{ml} / \mathrm{s}$ and concluded that automated i.v. contrast injection is performed without increased risk of extravasation. ${ }^{9}$

The question remains whether high flow injection protocols are clinically applicable. In our patient cohort, flow rates of up to $9.6 \mathrm{ml} / \mathrm{s}$ proved to be feasible and safe. Very high attenuation values were measured, which offer potential to reduce the total amount of volume. The use of high flow rates in combination with lower viscose CM allows for individual adaptation of injection protocols, where smaller patients might require less CM (lower flow rate, lower volume), whereas heavier patients might need 
more CM (higher flow rates, higher volumes) to reach the same attenuation value. ${ }^{6}$ Furthermore, new scan techniques such as high pitch scanning with acquisition times of less than 1second might benefit from a shorter bolus geometry (thus higher IDR), for example, in the imaging of the coronary arteries.

\section{Limitations}

Usage of a circulation phantom provides the unique opportunity to do repetitive scanning on an identical subject under standard conditions; anyhow, it does not resemble a broad patient population as is encountered during clinical routine. Because this study aimed to assess feasibility of high flow rates in a patient population, all in vitro and in vivo experiments were performed with sole usage of iopromide 300, which is considered the standard CM concentration in this institution. There are known differences in physicochemical properties (e.g. osmolality and viscosity) between different monomeric and dimeric $\mathrm{CM}$ as well as different iodine concentrations. Results (e.g. peak attenuation, pressure curves and TTP) might be different with regard to usage of other nonionic monomers and dimeric contrast agents. The use of flow rates above $10 \mathrm{ml} / \mathrm{s}$ could not be monitored, as an angiography power injector had to be used. Thus, we can only hypothesize about injection pressure above that level. The feasibility study in patients is a nonrandomized single-center study, investigating a limited number of patients. Cannula placement and individual comfort during $\mathrm{CM}$ administration with these flow rates was not monitored in this study population. A distinct validation of these results in a larger cohort and evaluation of comfort during CM injection in particular is deemed necessary.

\section{CONCLUSION}

This study demonstrates the feasibility of high flow rates in an in vitro and in vivo setup. No flow- or pressure-related problems were seen during the experiments. Use of high flow rates proved to be safe in a clinical setup. Higher flow rates should not be considered a drawback for CM application in routine CTA examinations and might be desirable in terms of optimal bolus shaping for future protocols. 


\section{REFERENCES}

1. Lell MM, Jost G, Korporaal JG, Mahnken AH, Flohr TG, Uder M, Pietsch H. Optimizing contrast media injection protocols in state-of-the art computed tomographic angiography. Invest Radiol. 2014

2. Behrendt FF, Bruners P, Keil S, Plumhans C, Mahnken AH, Stanzel S, Das M, Gunther RW, Muhlenbruch G. Impact of different vein catheter sizes for mechanical power injection in ct: In vitro evaluation with use of a circulation phantom. Cardiovasc Intervent Radiol. 2009;32:25-31

3. Liu J, Gao J, Wu R, Zhang Y, Hu L, Hou P. Optimizing contrast medium injection protocol individually with body weight for high-pitch prospective ecg-triggering coronary ct angiography. Int J Cardiovasc Imaging. 2013;29:1115-1120

4. Kumamaru KK, Steigner ML, Soga S, Signorelli J, Bedayat A, Adams K, Mitsouras D, Rybicki FJ. Coronary enhancement for prospective ecg-gated single r-r axial 320-mdct angiography: Comparison of 60- and 80ml iopamidol 370 injection. AJR Am J Roentgenol. 2011;197:844-850

5. Cademartiri F, Mollet NR, van der Lugt A, McFadden EP, Stijnen T, de Feyter PJ, Krestin GP. Intravenous contrast material administration at helical 16-detector row ct coronary angiography: Effect of iodine concentration on vascular attenuation. Radiology. 2005;236:661-665

6. Bae KT. Intravenous contrast medium administration and scan timing at ct: Considerations and approaches. Radiology. 2010;256:32-61

7. Sistrom CL, Gay SB, Peffley L. Extravasation of iopamidol and iohexol during contrast-enhanced ct: Report of 28 cases. Radiology. 1991;180:707-710

8. Halsell RD. Heating contrast media: Role in contemporary angiography. Radiology. 1987;164:276-278

9. Wienbeck S, Fischbach R, Kloska SP, Seidensticker P, Osada N, Heindel W, Juergens KU. Prospective study of access site complications of automated contrast injection with peripheral venous access in mdct. AJR Am J Roentgenol. 2010;195:825-829

10. Kok M, Mihl C, Mingels AA, Kietselaer BL, Muhlenbruch G, Seehofnerova A, Wildberger JE, Das M. Influence of contrast media viscosity and temperature on injection pressure in computed tomographic angiography: A phantom study. Invest Radiol. 2014;49:217-223

11. Halsell RD. Heating contrast media in a microwave oven. Radiology. 1987;163:279-280

12. Knollmann F, Schimpf K, Felix R. lodine delivery rate of different concentrations of iodine-containing contrast agents with rapid injection. RoFo. 2004;176:880-884

13. Schwab SA, Kuefner MA, Anders K, Adamietz B, Heinrich MC, Baigger JF, Janka R, Uder M, Kramer M. Peripheral intravenous power injection of iodinated contrast media: The impact of temperature on maximum injection pressures at different cannula sizes. Acad Radiol. 2009;16:1502-1508

14. Schwab SA, Uder M, Anders K, Heinrich MC, Kuefner MA. Peripheral intravenous power injection of iodinated contrast media through $22 \mathrm{~g}$ and $20 \mathrm{~g}$ cannulas: Can high flow rates be achieved safely? A clinical feasibility study. Rofo. 2009;181:355-361

15. Inc. BHP. Data sheet Ultravist ${ }^{\oplus}$. Available at: http://www.bayerresources.com.au/resources/uploads/ DataSheet/file9512.pdf. Accessed November 13, 2012.

16. Kim SH, Kamaya A, Willmann JK. Ct perfusion of the liver: Principles and applications in oncology. Radiology. 2014;272:322-344

17. Ng CS, Chandler AG, Wei W, Anderson EF, Herron DH, Kurzrock R, Charnsangavej C. Effect of duration of scan acquisition on ct perfusion parameter values in primary and metastatic tumors in the lung. Eur $J$ Radiol. 2013;82:1811-1818

18. Behrendt FF, Bruners P, Kalafut J, Mahnken AH, Keil S, Plumhans C, Das M, Stanzel S, Wildberger JE, Pfeffer J, Gunther RW, Muhlenbruch G. Introduction of a dedicated circulation phantom for comprehensive in vitro analysis of intravascular contrast material application. Invest Radiol. 2008;43:729-736

19. Mihl C, Wildberger JE, Jurencak T, Yanniello MJ, Nijssen EC, Kalafut JF, Nalbantov G, Muhlenbruch G, Behrendt FF, Das M. Intravascular enhancement with identical iodine delivery rate using different iodine contrast media in a circulation phantom. Invest Radiol. 2013;48:813-818

20. Lee SM, Lee W, Chung JW, Park EA, Park JH. Effect of kvp on image quality and accuracy in coronary ct angiography according to patient body size: A phantom study. Int J Cardiovasc Imaging. 2013;29 Suppl 2:83-91 



\section{CHAPTER 6}

\section{Coronary CT angiography using low}

concentrated contrast media injected with high flow rates:

Feasible in clinical practice 


\section{ABSTRACT}

\section{Purpose}

Aim of this study was to test the hypothesis that peak injection pressures and image quality using low concentrated contrast media (CM: $240 \mathrm{mg} / \mathrm{ml}$ ) injected with high flow rates will be comparable to a standard injection protocol in coronary computed tomographic angiography (CCTA).

\section{Materials and methods}

100 consecutive patients were scanned on a $2^{\text {nd }}$ generation dual-source CT scanner. Group $1(n=50)$ received prewarmed iopromide $240 \mathrm{mg} / \mathrm{ml}$ at an injection rate of $9 \mathrm{ml} / \mathrm{s}$, followed by a saline chaser. Group $2(n=50)$ received the standard injection protocol: prewarmed iopromide $300 \mathrm{mg} / \mathrm{ml}$, flow rate: $7.2 \mathrm{ml} / \mathrm{s}$. For both protocols, the iodine delivery rate (IDR: $2.16 \mathrm{gl} / \mathrm{s}$ ) and the total iodine load $(22.5 \mathrm{~g})$ were kept identical. Injection pressure (psi) was continuously monitored by a data acquisition program. Contrast enhancement was measured in the thoracic aorta and all proximal and distal coronary segments. Subjective and objective image quality was evaluated between both groups.

\section{Results}

No significant differences in peak injection pressures were found between both groups (121 \pm 5.6 psi vs. $120 \pm 5.3 p s i, P=0.54$ ). Flow rates of $9 \mathrm{ml} / \mathrm{s}$ were safely injected without any complications. No significant differences in contrast-to-noise ratio, signal-to-noise ratio and subjective image quality were found (all $P>0.05$ ). No significant differences in attenuation levels were found in the thoracic aorta and all segments of the coronary arteries (all $P>0.05$ ).

\section{Conclusion}

Usage of low iodine concentration CM and injection with high flow rates is feasible. High flow rates $(9 \mathrm{ml} / \mathrm{s})$ of iopromide 240 were safely injected without complications and should not be considered a drawback in clinical practice. No significant differences in peak pressure and image quality were found. This creates a doorway towards applicability of a broad variety in flow rates and IDR's and subsequently more individually tailored injection protocols. 


\section{INTRODUCTION}

Image quality of computed tomographic angiography (CTA) and notably coronary computed tomographic angiography (CCTA) is substantially influenced by the degree of intravascular enhancement. Sufficient vessel attenuation is crucial for proper evaluation of vessel pathology, especially in smaller arteries. ${ }^{1}$ Enhancement characteristics are based on scan technique, patient-related factors as well as all major parameters of the injection protocol applied (e.g. contrast media [CM] concentration, flow rate, added saline chaser and CM volume). Amount of iodine within the blood at a dedicated tube voltage is considered to be key determinant of vessel attenuation. ${ }^{2-6}$ Lowering tube voltage yields stronger contrast enhancement for a given injection protocol. ${ }^{2,7-9}$ Current CM application protocols should deal with shorter acquisition times of modern scanner technology and, thus, result in smaller CM boli, which might necessitate sharper bolus geometry (e.g. higher flow rates). A high iodine delivery rate (IDR; expressed as grams of iodine per second) is desirable in order to achieve optimal diagnostic intravascular attenuation for CTA. ${ }^{1}$ Previous studies investigated the influence of iodine concentration, injection rates and IDR on diagnostic intravascular attenuation. ${ }^{10-16}$ Contradictory statements have been made in the literature with regard to optimal CM protocols for imaging of the coronary tree. In order to enable a comparison between $\mathrm{CM}$ with different iodine concentrations, adapted injection parameters ensuring identical and constant IDR are mandatory. ${ }^{11}$ In current clinical practice, CM with iodine concentrations between $300 \mathrm{mg} / \mathrm{ml}$ and $400 \mathrm{mg} / \mathrm{ml}$ are routinely used. Recent experiments in a circulation phantom revealed that comparison of protocols using CM with different iodine concentrations $(240 \mathrm{mg} / \mathrm{ml}-400 \mathrm{mg} / \mathrm{ml})$ did not show significant differences in vascular attenuation between all groups when IDR and total iodine load were standardized and kept constant. ${ }^{17}$ As lower concentrated CM have to be injected at higher flow rates in order to achieve the desired IDR, concern might be raised about injecting high flow rates. Nevertheless, the use of lower concentrated CM might be advantageous in terms of lower viscosity and consecutively lower injection pressure. Viscosity of CM has been shown to play an important role in the overall enhancement pattern. ${ }^{1,2,18,19}$ Aim of this study was to test the hypothesis that peak injection pressures and overall objective and subjective image quality using low concentrated CM $(240 \mathrm{mg} / \mathrm{ml})$ injected with high flow rates will be comparable to a standard injection protocol (CM: $300 \mathrm{mg} / \mathrm{ml})$ in CCTA. 


\section{MATERIALS AND METHODS}

\section{Study population}

A total of one hundred consecutive patients with stable symptoms of chest discomfort and suspected coronary artery disease (CAD), referred for CCTA from the cardiology outpatient department, were retrospectively included in this study within 6 months. For this study, ethics approval and informed consent for the use of (coded) images was waived by the local ethical committee (decision number: METC 13-4-022).

\section{Injection and scan protocol}

Scans were performed using a $2^{\text {nd }}$ generation dual-source CT scanner (Somatom Definition Flash; Siemens Healthcare, Forchheim, Germany) with a $128 \times 0.6 \mathrm{~mm}$ slice collimation, a gantry rotation time of $280 \mathrm{~ms}$, a tube voltage of $100 \mathrm{kV}$, tube current

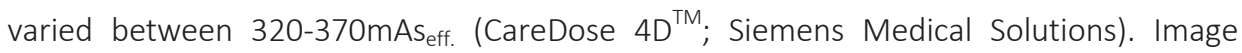
reconstruction was done with individually adapted FOV at $0.75 \mathrm{~mm}$ slice thickness with an increment of $0.5 \mathrm{~mm}$ using an $126 \mathrm{f}$ kernel (SAFIRE, Iterative reconstruction strength 2).

In patients with a stable heart rate $(<60$ beats per minute [bpm]), a prospectively ECG-triggered 'high pitch' spiral protocol was used ('Flash'-technique, 1s). In patients with a stable heart rate between 60-90bpm, a prospectively triggered 'adaptive sequence' protocol was used (prospective sequential data acquisition, 7s). Patients received an oral dose of $50 \mathrm{mg}$ metoprolol tartrate (Selokeen ${ }^{\circledR}$; AstraZeneca, Zoetermeer, the Netherlands), two hours before CCTA. When indicated, an additional dose of 5-20mg metoprolol tartrate was administered to lower the heart rate to $<60 \mathrm{bpm}$, if possible. A maximum dose of $0.8 \mathrm{mg}$ nitroglycerine (Isordil ${ }^{\circledR}$; Pohl-Boskamp, Hohenlockstedt, Germany) was given sublingually just prior to CCTA. Heart rate and ECG were monitored during CCTA.

$\mathrm{CM}$ was administered through dedicated high flow intravenous (i.v.) injection needles (18-gauge BD Nexiva Diffusics ${ }^{\circledR}$ i.v. Catheters, Sandy, UT, USA) in an antecubital vein (length i.v. catheter: $1.25 \mathrm{inch}$, maximum registered flow rate: $15 \mathrm{ml} / \mathrm{s}$ ). These needles have 3 tear-drop shaped holes positioned near the catheter tip and a strengthened design that enables use with power injectors set up to $325 \mathrm{psi}$, and proved to be feasible in both in vitro and in vivo experiments. ${ }^{20} \mathrm{CM}$ was administered with usage of a standard extension tube (length: 15.7inch) between i.v. catheter and injection pump.

Prewarmed $\mathrm{CM}$ was used for all patients $\left(37^{\circ} \mathrm{C}\left[99^{\circ} \mathrm{F}\right]\right.$; Ultravist; iopromide, Bayer Healthcare, Berlin, Germany) and was injected in a biphasic injection protocol to ensure adequate opacification of the coronary arteries using a dual-head power injector (Stellant/MEDRAD; Pittsburgh, PA, USA). A non-enhanced scan was performed to determine the calcium score using the Agatston method as part of the standard 
screening protocol. ${ }^{21}$ Patients with a heartrate $>90 \mathrm{bpm}$ or a calcium score $>1000$ were not included in this study.

Group $1(\mathrm{n}=50)$ received $94 \mathrm{ml}$ iopromide 240 at a flow rate of $9 \mathrm{ml} / \mathrm{s}$ (IDR: $2.16 \mathrm{gl} / \mathrm{s}$ ), directly followed by $63 \mathrm{ml}$ saline at the same flow rate. Group $2(\mathrm{n}=50)$ received $75 \mathrm{ml}$ iopromide 300 at a flow rate of $7.2 \mathrm{ml} / \mathrm{s}$ (IDR: $2.16 \mathrm{gl} / \mathrm{s}$ ), directly followed by $50 \mathrm{ml}$ saline (flow rate: $7.2 \mathrm{ml} / \mathrm{s}$ ). Total injection time was $17.4 \mathrm{~s}$ (including saline chaser) for both protocols. In both groups, a test bolus was performed at the level of the ascending aorta to assess optimal start time after administration of the bolus (group 1: $25 \mathrm{ml}$ of $\mathrm{CM}$ at a flow rate $9 \mathrm{ml} / \mathrm{s}$, group 2: $20 \mathrm{ml}$ of $\mathrm{CM}$ at a flow rate of $7.2 \mathrm{ml} / \mathrm{s}$, followed by $3 \mathrm{~s}$ administration of saline at the same flow rates). Total iodine load remained identical for both groups $(22.5 \mathrm{~g})$. Injection pressure (psi) and total amount of $\mathrm{CM}(\mathrm{ml})$ were continuously monitored by a data acquisition program (Certegra ${ }^{\mathrm{TM}}$ Informatics Platform; Bayer Healthcare, Berlin, Germany) and read out after each injection.

\section{Quantitative and qualitative efficacy assessments}

The acquired data regarding presence of CAD was independently analyzed by an experienced radiologist and an experienced cardiologist who were both blinded to the injection protocol. In case of disagreement, consensus was reached by jointly reviewing findings. The coronary artery tree was assessed using the source images on a dedicated workstation (SyngoVia ${ }^{\circledR}$; Siemens Healthcare, Forchheim, Germany). Presence of CAD was determined using axial images and curved multiplanar reformatted images. Any coronary plaque (e.g. calcified, non-calcified or mixed) was considered to be positive for the presence of CAD. Axial thin slices were used for allocating all anatomic sites for measurement of the attenuation in Hounsfield units (HU). Contrast enhancement (HU) was measured by two experienced observers in consensus using manually placed regions of interest (ROIs) in the ascending aorta (AA), descending aorta (DA), left main $(L M)$ as well as proximal and distal segments of the left anterior descending artery $(L A D)$, the circumflex artery $(C x)$ and the right coronary artery (RCA). The ROls were placed in the vessels, care taken to avoid calcifications, plaques and stenosis (Figure 1).

Objective image quality was analyzed in consensus and defined by several parameters: attenuation of all designated vessels, image noise (standard deviation [SD] of the attenuation in ROIs), contrast-to-noise ratio (CNR) and signal-to-noise ratio (SNR).

CNR was defined by the following equation:

CNR $=\frac{\text { vessel enhancement } \mathrm{AA}(\mathrm{HU})-\text { adjacent muscle enhancement }(\mathrm{HU})}{\text { adjacent muscle enhancement SD }(\mathrm{HU})}$

SNR was defined by the following equation: 
SNR $=\frac{\text { vessel enhancement } \mathrm{AA}(\mathrm{HU}))}{\text { SD vessel enhancement }(\mathrm{HU})}$

Additionally, subjective scan quality of all datasets was evaluated and graded using a semi qualitative 4-point scale (4: excellent, 3: good with some artifacts, 2: below average, 1: poor). All datasets were analyzed with respect to occurrence of artifacts and other injection related factors, which might be secondary to the injection protocol (e.g. streak artifacts, step artifacts, cardiac motion artifacts, reflux).

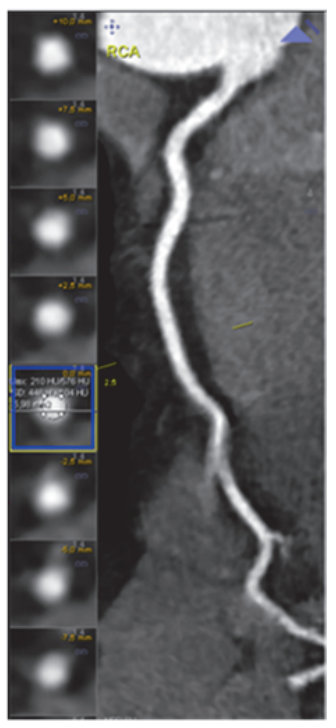

Figure 1: CCTA of RCA shows measurement of contrast opacification in $\mathrm{HU}$ by manual placement of regions of interest (ROIs) in segment of the right coronary artery (RCA).

\section{Statistical analysis}

Continuous variables were reported as mean \pm SD or median (interquartile range [IQR]) for parameters that were not normally distributed. Normality of data distribution was evaluated using the Shapiro-Wilk test. For continuous variables, independent $t$ test or Mann-Whitney test was performed to assess differences between the two groups, depending on normality of distribution. Proportions (\%) were used for categorical values. The chi-square test was used to measure differences between categorical variables. Mean peak pressures (psi) were calculated for both groups. Data analysis was conducted with SPSS version 20.0 (SPSS Inc; Chicago, IL, USA). All $P$ values are 2 -sided, and a $P$ value below 0.05 was considered statistically significant. 


\section{RESULTS}

Baseline characteristics of the study population are summarized in Table 1 . No statistical significant differences in presence of CAD were demonstrated between both groups $(P=0.61)$. According to the informatics platform, the total amount of contrast delivered in $\mathrm{ml}$, including the test bolus, was as expected in both groups (group 1: $118.7 \pm 0.4 \mathrm{ml}$, group 2: $94.7 \pm 0.5 \mathrm{ml})$. No significant differences in peak injection pressures were found between both CM groups (121 \pm 5.6 psi vs. $120 \pm 5.3 p s i, P=0.54$ ). The pressure limit of 325 psi was never reached.

Table 1: Baseline characteristics. All variables are described as mean \pm SD or median (IQR) for parameters that were not normally distributed. Proportions (\%) were used for categorical values. BMI: body mass index, bpm: beats per minute, DLP: dose length product, CAD: coronary artery disease.

\begin{tabular}{lccc}
\hline & Group 240mg/ml & Group 300mg/ml & $P$ \\
& $(\mathrm{n}=50)$ & $(\mathrm{n}=50)$ & \\
Age (years) & $56 \pm 12$ & $55 \pm 12$ & 0.90 \\
Male (\%) & $27(54)$ & $22(44)$ & 0.32 \\
BMI (kg/m ${ }^{2}$ ) & $26 \pm 3.2$ & $25 \pm 3.1$ & 0.15 \\
Hypertension (\%) & 40 & 38 & 0.81 \\
Heart rate (bpm) & $70 \pm 12$ & $66 \pm 13$ & 0.41 \\
Agatston score & $0.4(0-43.9)$ & $4.9(0-93)$ & 0.37 \\
CAD positive (\%) & $25(50)$ & $27(54)$ & 0.61 \\
DLP (mGy*cm) & $211(134-280)$ & $158(111-236)$ & 0.11 \\
Scan protocol & Flash 25 (50\%) & Flash 24 (48\%) & 0.84 \\
& Adaptive 25 (50\%) & Adaptive 26 (52\%) & 0.69 \\
\hline
\end{tabular}

Mean diagnostic attenuation $>300 \mathrm{HU}$ was reached for all vessels in both protocols. ${ }^{22}$ No statistically significant differences in attenuation between AA, DA and coronary arteries (proximal and distal) were found. Mean attenuation values of the, AA, DA, LM and proximal and distal coronary segments are stated in Table 2. No significant differences in attenuation levels were found in the thoracic aorta and all segments of the coronary arteries (all $P>0.05$ ). Figure 2 shows curved multiplanar reformation CCTA images of all three coronary arteries in two patients using $240 \mathrm{mg} / \mathrm{ml}$ (left) and $300 \mathrm{mg} / \mathrm{ml}$ (right). Note an equal homogeneous attenuation through the course of both proximal and distal segments of the CM groups. 
Table 2: Mean attenuations of thoracic aorta and all coronary arteries (HU). CM: contrast media, AA: ascending aorta, DA: descending aorta, LM: left main artery, LAD: left anterior descending artery, Cx: circumflex artery, RCA: right coronary artery, dist: distal, prox: proximal.

\begin{tabular}{lccccccccc}
\hline CM $(\mathrm{mg} / \mathrm{ml})$ & AA & DA & LM & LAD prox & LAD dist & Cx prox & Cx dist & RCA prox & RCA dist \\
\hline Group 240 & $505 \pm 107$ & $458 \pm 110$ & $528 \pm 99$ & $500 \pm 98$ & $428 \pm 103$ & $526 \pm 97$ & $440 \pm 109$ & $536 \pm 102$ & $524 \pm 120$ \\
Group 300 & $510 \pm 94$ & $462 \pm 102$ & $525 \pm 113$ & $506 \pm 119$ & $417 \pm 94$ & $502 \pm 102$ & $412 \pm 85$ & $540 \pm 97$ & $523 \pm 121$ \\
$P$ & 0.83 & 0.85 & 0.89 & 0.80 & 0.57 & 0.22 & 0.16 & 0.83 & 0.98 \\
\hline
\end{tabular}

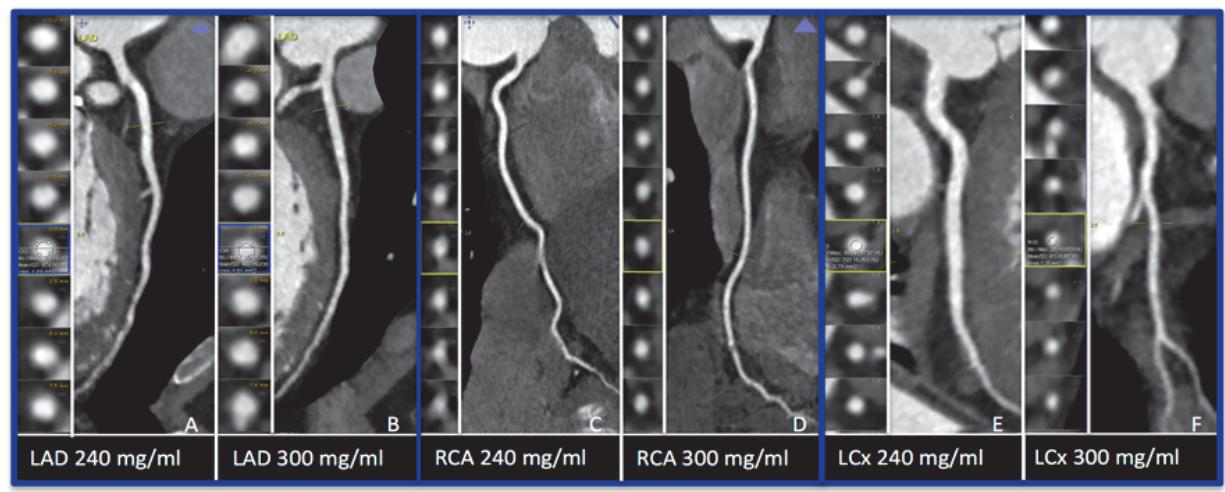

Figure 2: Sample curved multiplanar reformation images of LAD/ RCA/Cx at CCTA with usage of 240mg/ml $(A, C, E))$ and $300 \mathrm{mg} / \mathrm{ml}(B, D, F)$. Note an equal homogeneous attenuation through the course of both proximal and distal segments of both CM groups.

All mean image quality parameters are stated in Table 3. CNR proved to be sufficient in both scan groups and no statistically significant differences were found between both groups $(32.7 \pm 12.6 \mathrm{HU}$ vs. $33.5 \pm 9.6 \mathrm{HU}, P=0.72)$. No statistically significant differences in SNR and image noise were found between both groups (SNR: 29.6 $\pm 9.7 \mathrm{HU}$ vs. $31.3 \pm 7.6 \mathrm{HU}, P=0.34$, image noise: $18.2 \pm 5.0 \mathrm{HU}$ vs. $16.8 \pm 3.4 \mathrm{HU}, P=0.11$ ). No statistical significant differences in scan quality of both datasets were found $(P=0.47)$. No contrast related problems (extravasation at the injection site) or negative right-sided effects (e.g. streak artifacts or CM reflux) were encountered in this study.

Table 3: Mean image quality parameters. CNR: contrast-to-noise ratio, SNR: signal-to-noise ratio, Scan Quality, 4: excellent, 3: good with some artifacts, 2: below average, 1: poor.

\begin{tabular}{lccc}
\hline & Group 240mg/ml & Group 300mg/ml & $P$ \\
\hline SNR & $29.6 \pm 9.7$ & $31.3 \pm 7.6$ & 0.34 \\
CNR & $32.7 \pm 12.6$ & $33.5 \pm 9.6$ & 0.72 \\
Image noise & $18.2 \pm 5.0$ & $16.8 \pm 3.4$ & 0.11 \\
Scan quality 1, sum (\%) & $0(0)$ & $1(2)$ & \\
Scan quality 2, sum (\%) & $7(14)$ & $5(10)$ & 0.47 \\
Scan quality 3, sum (\%) & $11(22)$ & $16(32)$ & \\
Scan quality 4, sum (\%) & $32(64)$ & $28(56)$ & \\
\hline
\end{tabular}




\section{DISCUSSION}

This study demonstrates that no relevant peak pressure levels were reached despite injection rates as high as $9 \mathrm{ml} / \mathrm{s}$ using prewarmed low concentrated CM.

In daily clinical routine, the usage of higher flow rates might be a major concern. However, these results give a strong indication that high flow protocols up to $9 \mathrm{ml} / \mathrm{s}$ (using iopromide 240) can be safely administered. By using dedicated high flow needles no flow related problems were encountered. Peak flow rates of $9 \mathrm{ml} / \mathrm{s}$ were reached in all patients without significant increase in peak pressure. Most likely, this is attributed to the reduced viscosity of the lower iodine concentrated $\mathrm{CM}$. The viscosity of iopromide 300 used in this study is $4.7 \mathrm{mPa}$.s at $37^{\circ} \mathrm{C}\left(99^{\circ} \mathrm{F}\right)$, whilst the viscosity of iopromide 240 is substantially lower: $2.8 \mathrm{mPa}$.s at $37^{\circ} \mathrm{C}\left(99^{\circ} \mathrm{F}\right) .{ }^{23}$ As evaluation of overall image quality (e.g. evaluation of coronary plaques, attenuation and CNR) also proved to be not statistically different, injection protocols with high flow rates should not be considered a drawback in daily clinical practice.

It would be interesting to further evaluate patient discomfort at the injection site, as was done in a previous study conducted by Mühlenbruch et al. injecting flow rates up to $4.3 \mathrm{ml} / \mathrm{s}$; using these lower flow rates no significant differences were found in terms of discomfort. ${ }^{11}$ Injection with higher flow rates proved to be an independent predictor of retrograde inferior vena cava or hepatic vein opacification. ${ }^{24}$ As the bolus in our scanning protocol was timed at the left side, no negative effects of the used injection protocols were encountered in this study.

Constant diagnostic attenuation levels were reached in the clinical setting with iodine concentrations as low as $240 \mathrm{mg} / \mathrm{ml}$. No significant differences in intravascular attenuation in AA, DA and proximal and distal segments of the coronary arteries were found in comparison to the standard CM group $(300 \mathrm{mg} / \mathrm{ml})$. The standard deviation of the attenuation values in all groups is considered somewhat broad, but within range of previous published data. ${ }^{25-27}$ This is an indication that attenuation values were quite variable, which might have been attributed to the variable body weight as well as other patient related factors (e.g. cardiac output, heart rate). These results stress the fact that the IDR as the product of flow rate and iodine concentration is key for intravascular attenuation. However, this is a continuing topic of research. ${ }^{5,13,17,28-32}$ In previous studies comparing groups with different iodine concentrated CM, heterogeneous results for contrast enhancement have been reported. ${ }^{12,13,28-30,32}$ However, in these studies, often IDR was not normalized or in favour of higher concentrated CM. No significant differences in intravascular attenuation have been found for clinical studies where indeed the IDR was kept constant. ${ }^{11,14,15}$ Mühlenbruch et al. prospectively included 300 patients and compared CM with iodine concentrations of 300, 370 and $400 \mathrm{mg} / \mathrm{ml}$ for chest-CT. ${ }^{11}$ They found no statistically significant differences in contrast enhancement with identical IDR. Rist et al. prospectively included sixty patients with known or suspected CAD in a double-blinded study and compared contrast injection 
protocols using CM containing 300 and $400 \mathrm{mg} / \mathrm{ml}$ with constant IDR. ${ }^{15}$ Equivalent homogenous enhancement of the coronary arteries was found in both groups. The results of our study strongly support the hypothesis that a normalized IDR is the determining factor for CCTA, the absolute iodine concentration is just part of the story.

Ideally, low concentrated CM would be even more advantageous, as injection pressures proved to be lower and CM distribution within the blood may be accelerated. ${ }^{2,11}$ This creates the doorway towards applicability of a broad variety in flow rates and IDR's and subsequently more individually tailored injection protocols. In addition, usage of lower concentrated CM is hypothesized to be beneficial in subjects without large-caliber i.v. access due to its lower peak pressures. ${ }^{8}$ A recent study conducted in animals has shown that arterial enhancement can be reduced even further by adjusting the IDR to the tube voltage $(\mathrm{kV}) .^{8}$ Lower $\mathrm{kV}$ settings lead to an increase in enhancement of the vessels while maintaining comparable SNR. By adjusting the IDR, low tube voltage CTA was able to achieve comparable aortic enhancement with a significant reduction in $\mathrm{CM}$ dosage. ${ }^{8}$ In addition, iterative reconstruction is an alternative image reconstruction method, that allows scanning with lower radiation doses with similar noise-levels and image quality in comparison to filtered back projection. ${ }^{33-36}$ Willemink et al. proved, that iterative reconstruction can lead to decreased noise levels and increased SNR and CNR. ${ }^{36}$ Usage of low kV (e.g. 70kV/80kV) concepts for CTA with advanced platforms (e.g. newer generation iterative reconstruction algorithms), bare the potential for further reduction of CM volume in the near future.

\section{Limitations}

Our study has several limitations. This is a nonrandomized single-center study, investigating a limited number of patients. Additionally, the reported pressure values are valid for the combination of prewarmed $\mathrm{CM}$ and the i.v. access used, only. Another potential limitation of this study is that comfort (e.g. pain, heat sensation or heart rate response) during contrast administration with higher flow rates was not quantified in this study population. However, no flow-associated problems were noted. As this is a pilot study, investigating only a limited amount of patients, risk of extravasation needs to be investigated further in a larger cohort, as the study groups were possibly too small to detect differences. As these higher flow rates were administered through dedicated high flow i.v. injection needles, this injection setup is not applicable to regular i.v. catheters. Additionally, peak pressures were measured at the injection pump. A decrease of pressure is expected along the course of the extension tube. Therefore, measured peak pressures in all patients are likely to be overestimated. In addition, it would be interesting to perform a subset analysis of subjective image quality in patients with different calcium scores. This would attribute as an additional factor to underline the fact that lower concentrated CM can be used with comparable diagnostic quality. As 
this is a pilot study group, limited to 50 patients in each group, only a very small number of scans were graded as lower quality (e.g. scan quality 1 and 2, table 3). Due to the relatively small group sizes, it is not possible to perform a statistical evaluation of the relation between scan quality and calcium score in this study. Larger patient subgroups are necessary to exclude the possibility of incidental findings. Finally, as this study focused on the technical aspects of i.v. injection with high flow rates and scan quality, no gold standard with regard to plaque stenosis and quantification was performed.

\section{CONCLUSION}

Usage of low iodine concentrated $\mathrm{CM}$ and injection with high flow rates is feasible in CCTA. High flow rates $(9 \mathrm{ml} / \mathrm{s})$ of iopromide 240 were safely injected without complications and should not be considered a drawback in clinical practice. No significant differences in peak pressure and both subjective and objective image quality were found. Use of low concentrated CM is advantageous as injection pressure is lower and $\mathrm{CM}$ distribution in the blood might be facilitated. This creates a doorway towards applicability of a broad variety in flow rates and IDR's and subsequently more individually tailored injection protocols. 


\section{REFERENCES}

1. Behrendt FF, Bruners P, Keil S, Plumhans C, Mahnken AH, Stanzel S, Das M, Gunther RW, Muhlenbruch G. Impact of different vein catheter sizes for mechanical power injection in ct: In vitro evaluation with use of a circulation phantom. Cardiovasc Intervent Radiol. 2009;32:25-31

2. Bae KT. Intravenous contrast medium administration and scan timing at ct: Considerations and approaches. Radiology. 2010;256:32-61

3. Fleischmann D. Use of high-concentration contrast media in multiple-detector-row ct: Principles and rationale. Eur Radiol. 2003;13 Suppl 5:M14-20

4. Johnson PT, Pannu HK, Fishman EK. Iv contrast infusion for coronary artery ct angiography: Literature review and results of a nationwide survey. AJR Am J Roentgenol. 2009;192:W214-221

5. Bae KT, Tran HQ, Heiken JP. Uniform vascular contrast enhancement and reduced contrast medium volume achieved by using exponentially decelerated contrast material injection method. Radiology. 2004;231:732-736

6. Awai K, Hiraishi K, Hori S. Effect of contrast material injection duration and rate on aortic peak time and peak enhancement at dynamic ct involving injection protocol with dose tailored to patient weight. Radiology. 2004;230:142-150

7. Hausleiter J, Meyer T, Hadamitzky M, Huber E, Zankl M, Martinoff S, Kastrati A, Schomig A. Radiation dose estimates from cardiac multislice computed tomography in daily practice: Impact of different scanning protocols on effective dose estimates. Circulation. 2006;113:1305-1310

8. Lell MM, Jost G, Korporaal JG, Mahnken AH, Flohr TG, Uder M, Pietsch H. Optimizing contrast media injection protocols in state-of-the art computed tomographic angiography. Invest Radiol. 2015;50:161167

9. Feuchtner GM, Jodocy D, Klauser A, Haberfellner B, Aglan I, Spoeck A, Hiehs S, Soegner P, Jaschke W. Radiation dose reduction by using 100-kv tube voltage in cardiac 64-slice computed tomography: A comparative study. Eur J Radiol. 2010;75:e51-56

10. Behrendt FF, Bruners P, Keil S, Plumhans C, Mahnken AH, Stanzel S, Das M, Gunther RW, Muhlenbruch G. Impact of different vein catheter sizes for mechanical power injection in ct: In vitro evaluation with use of a circulation phantom. Cardiovasc Intervent Radiol. 2009;32:25-31

11. Muhlenbruch G, Behrendt FF, Eddahabi MA, Knackstedt C, Stanzel S, Das M, Seidensticker P, Gunther RW, Wildberger JE, Mahnken AH. Which iodine concentration in chest ct? - A prospective study in 300 patients. Eur Radiol. 2008;18:2826-2832

12. Cademartiri F, Mollet NR, van der Lugt A, McFadden EP, Stijnen T, de Feyter PJ, Krestin GP. Intravenous contrast material administration at helical 16-detector row ct coronary angiography: Effect of iodine concentration on vascular attenuation. Radiology. 2005;236:661-665

13. Cademartiri F, de Monye C, Pugliese F, Mollet NR, Runza G, van der Lugt A, Midiri M, de Feyter PJ, Lagalla R, Krestin GP. High iodine concentration contrast material for noninvasive multislice computed tomography coronary angiography: Iopromide 370 versus iomeprol 400. Invest Radiol. 2006;41:349-353

14. Nance JW, Jr., Henzler T, Meyer M, Apfaltrer P, Braunagel M, Krissak R, Schoepf UJ, Schoenberg SO, Fink C. Optimization of contrast material delivery for dual-energy computed tomography pulmonary angiography in patients with suspected pulmonary embolism. Invest Radiol. 2012;47:78-84

15. Rist C, Nikolaou K, Kirchin MA, van Gessel R, Bae KT, von Ziegler F, Knez A, Wintersperger BJ, Reiser MF, Becker CR. Contrast bolus optimization for cardiac 16-slice computed tomography: Comparison of contrast medium formulations containing 300 and 400 milligrams of iodine per milliliter. Invest Radiol. 2006; 41:460-467

16. Behrendt FF, Pietsch H, Jost G, Palmowski M, Gunther RW, Mahnken AH. Identification of the iodine concentration that yields the highest intravascular enhancement in mdct angiography. AJR Am J Roentgenol. 2013;200:1151-1156

17. Mihl C, Wildberger JE, Jurencak T, Yanniello MJ, Nijssen EC, Kalafut JF, Nalbantov G, Muhlenbruch G, Behrendt FF, Das M. Intravascular enhancement with identical iodine delivery rate using different iodine contrast media in a circulation phantom. Invest Radiol. 2013;48:813-818

18. Knollmann F, Schimpf K, Felix R. lodine delivery rate of different concentrations of iodine-containing contrast agents with rapid injection. RoFo. 2004;176:880-884

19. Brunette J, Mongrain R, Laurier J, Galaz R, Tardif JC. 3d flow study in a mildly stenotic coronary artery phantom using a whole volume piv method. Med Eng Phys. 2008;30:1193-1200 
20. Mihl C, Kok M, Wildberger JE, Turek J, Muehlenbruch G, Das M. Computed tomography angiography with high flow rates: An in vitro and in vivo feasibility study. Invest Radiol. 2015;50:464-469

21. Agatston AS, Janowitz WR, Hildner FJ, Zusmer NR, Viamonte M, Jr., Detrano R. Quantification of coronary artery calcium using ultrafast computed tomography. J Am Coll Cardiol. 1990;15:827-832

22. Johnson TR, Nikolaou K, Wintersperger BJ, Fink C, Rist C, Leber AW, Knez A, Reiser MF, Becker CR. Optimization of contrast material administration for electrocardiogram-gated computed tomographic angiography of the chest. J Comput Assist Tomogr. 2007;31:265-271

23. Inc. BHP. Data sheet ultravist ${ }^{\circledR}$. Available at: http://www.bayerresources.com.au/resources/uploads/ DataSheet/file9512.pdf. Accessed November 13, 2012.

24. Yeh BM, Kurzman P, Foster E, Qayyum A, Joe B, Coakley F. Clinical relevance of retrograde inferior vena cava or hepatic vein opacification during contrast-enhanced ct. AJR Am J Roentgenol. 2004;183:12271232

25. Zheng M, Liu Y, Wei M, Wu Y, Zhao H, Li J. Low concentration contrast medium for dual-source computed tomography coronary angiography by a combination of iterative reconstruction and low-tube-voltage technique: Feasibility study. Eur J Radiol. 2014;83:e92-99

26. Nakaura T, Awai K, Yauaga Y, Nakayama Y, Oda S, Hatemura M, Nagayoshi Y, Ogawa H, Yamashita Y. Contrast injection protocols for coronary computed tomography angiography using a 64-detector scanner: Comparison between patient weight-adjusted- and fixed iodine-dose protocols. Invest Radiol. 2008;43:512-519

27. Pazhenkottil AP, Husmann L, Buechel RR, Herzog BA, Nkoulou R, Burger IA, Vetterli A, Valenta I, Ghadri JR, von Schulthess $P$, Kaufmann PA. Validation of a new contrast material protocol adapted to body surface area for optimized low-dose ct coronary angiography with prospective ecg-triggering. Int J Cardiovasc Imaging. 2010;26:591-597

28. Christensen JD, Meyer LT, Hurwitz LM, Boll DT. Effects of iopamidol-370 versus iodixanol-320 on coronary contrast, branch depiction, and heart rate variability in dual-source coronary mdct angiography. AJR Am J Roentgenol. 2011;197:W445-451

29. Yamamuro M, Tadamura E, Kanao S, Wu YW, Tambara K, Komeda M, Toma M, Kimura T, Kita T, Togashi K. Coronary angiography by 64-detector row computed tomography using low dose of contrast material with saline chaser: Influence of total injection volume on vessel attenuation. J Comp Assist Tomogr. 2007;31:272-280

30. Tsai IC, Lee T, Tsai WL, Chen MC, Wu MJ, Lee WL, Ting HJ. Contrast enhancement in cardiac mdct: Comparison of iodixanol 320 versus iohexol 350. AJR Am J Roentgenol. 2008;190:W47-53

31. Cademartiri F, Mollet NR, Runza G, Bruining N, Hamers R, Somers P, Knaapen M, Verheye S, Midiri M, Krestin GP, de Feyter PJ. Influence of intracoronary attenuation on coronary plaque measurements using multislice computed tomography: Observations in an ex vivo model of coronary computed tomography angiography. Eur Radiol. 2005;15:1426-1431

32. Becker CR, Vanzulli A, Fink C, de Faveri D, Fedeli S, Dore R, Biondetti P, Kuettner A, Krix M, Ascenti G. Multicenter comparison of high concentration contrast agent iomeprol-400 with iso-osmolar iodixanol320: Contrast enhancement and heart rate variation in coronary dual-source computed tomographic angiography. Invest Radiol. 2011;46:457-464

33. Prakash P, Kalra MK, Digumarthy SR, Hsieh J, Pien H, Singh S, Gilman MD, Shepard JA. Radiation dose reduction with chest computed tomography using adaptive statistical iterative reconstruction technique: Initial experience. J Comput Assist Tomogr. 2010;34:40-45

34. Gervaise A, Osemont B, Lecocq S, Noel A, Micard E, Felblinger J, Blum A. Ct image quality improvement using adaptive iterative dose reduction with wide-volume acquisition on 320-detector ct. Eur Radiol. 2012;22:295-301

35. Funama Y, Taguchi K, Utsunomiya D, Oda S, Yanaga Y, Yamashita Y, Awai K. Combination of a low-tubevoltage technique with hybrid iterative reconstruction (idose) algorithm at coronary computed tomographic angiography. J Comput Assist Tomogr. 2011;35:480-485

36. Willemink MJ, Takx RA, de Jong PA, Budde RP, Bleys RL, Das M, Wildberger JE, Prokop M, Buls N, de Mey J, Leiner T, Schilham AM. Computed tomography radiation dose reduction: Effect of different iterative reconstruction algorithms on image quality. J Comput Assist Tomogr. 2014;38:815-823 



\section{CHAPTER 7}

\section{Evaluation of individually body weight adapted contrast media injection in coronary CT angiography}




\section{ABSTRACT}

\section{Objectives}

Contrast media (CM) injection protocols should be customized to the individual patient. Aim of this study was to determine if software tailored CM injections result in diagnostic enhancement of the coronary arteries in computed tomographic angiography (CTA) and if attenuation values were comparable between different weight categories.

\section{Materials and methods}

265 consecutive patients referred for routine coronary CTA were scanned on a $2^{\text {nd }}$ generation dual-source CT. Group $1(n=141)$ received an individual CM bolus based on weight categories (39-59kg; 60-74kg; 75-94kg; 95-109kg) and scan duration ('highpitch': 1s; 'dual-step prospective triggering': 7s), as determined by contrast injection software (Certegra ${ }^{\text {TM }}$ P3T; Bayer Healthcare, Berlin, Germany). Group 2 ( $\left.n=124\right)$ received a standard fixed CM bolus; iopromide $300 \mathrm{mg} / \mathrm{ml}$, volume: $75 \mathrm{ml}$, flow rate: $7.2 \mathrm{ml} / \mathrm{s}$. Contrast enhancement was measured in all proximal and distal coronary segments. Subjective and objective image quality was evaluated. Statistical analysis was performed using SPSS version 20.0 (SPSS Inc; Chicago, IL, USA).

\section{Results}

For group 1, mean attenuation values of all segments were diagnostic $(>325 \mathrm{HU})$ without statistical significant differences between different weight categories ( $P>0.17)$, proximal vs. distal: $449 \pm 65$ vs. $373 \pm 58 \mathrm{HU}(39-59 \mathrm{~kg}), 443 \pm 69 \mathrm{vs} .367 \pm 81 \mathrm{HU}(60-74 \mathrm{~kg}), 427 \pm 59 \mathrm{vs}$. $370 \pm 61 \mathrm{HU}(75-94 \mathrm{~kg}), 427 \pm 73$ vs. $347 \pm 61 \mathrm{HU}(95-109 \mathrm{~kg})$. Mean CM volumes were: $55 \pm 6 \mathrm{ml}(39-59 \mathrm{~kg}), 61 \pm 7 \mathrm{ml}(60-74 \mathrm{~kg}), 71 \pm 8 \mathrm{ml}(75-94 \mathrm{~kg}), 84 \pm 9 \mathrm{ml}(95-109 \mathrm{~kg})$. For group 2 , mean attenuation values were not all diagnostic with differences between weight categories $(P<0.01)$, proximal vs. distal: $611 \pm 142$ vs. $408 \pm 69 \mathrm{HU}(39-59 \mathrm{~kg}), 562 \pm 135 \mathrm{vs}$. $389 \pm 98 \mathrm{HU}(60-74 \mathrm{~kg}), 481 \pm 83$ vs. $329 \pm 81 \mathrm{HU}(75-94 \mathrm{~kg}), 420 \pm 73$ vs. $305 \pm 35 \mathrm{HU}$ (95$109 \mathrm{~kg})$. Comparable image noise and image quality were found between groups $(P \geq 0.330)$.

\section{Conclusion}

Individually tailored $\mathrm{CM}$ injection protocols yield diagnostic attenuation and a more homogeneous enhancement pattern between different weight groups. CM volumes could be reduced for the majority of patients utilizing individualized CM bolus application. 


\section{INTRODUCTION}

Contrast media (CM) injection parameters, CT scan technique and patient-related factors are the most important factors influencing contrast enhancement characteristics. ${ }^{1,2}$ As current CM application protocols in coronary computed tomographic angiography (CCTA) are aimed at shorter acquisition times and reduced tube voltage (kV), CM bolus shaping necessitates adaptation and optimal synchronization with the scan protocols. ${ }^{3-5}$

In terms of patient related factors, a correlation between intravascular attenuation and body weight has been previously suggested. ${ }^{6,7}$ Additionally, physical factors such as cardiac output and muscle mass (concept of lean body weight) can differ substantially between patients with comparable body weight, which may be the cause of variability in solid organ and vascular enhancement. ${ }^{8-10}$ A standard protocol with a standard injected CM volume, independent of weight and length of the patient, will undoubtedly lead to an over- and underestimation of the injected $\mathrm{CM}$ volume in certain weight categories, which potentially has consequences on image quality and attenuation of the coronary arteries. ${ }^{1}$ Therefore, various study groups investigated solutions to overcome this non-homogeneous enhancement by usage of individually tailored injection protocols with promising results. ${ }^{11-16}$

A dedicated contrast protocol software (P3T ${ }^{\mathrm{TM}}$; Bayer Healthcare, Berlin, Germany) customizes a triphasic injection protocol for each patient and procedure, using patient weight, scan duration, $\mathrm{CM}$ concentration and timing attributes of a test bolus scan. The $\mathrm{P}^{\mathrm{TM}} \mathrm{T}^{\mathrm{M}}$ software adapts the iodine delivery rate (IDR, iodine delivered per second) and total iodine load (TIL) based upon a non-linear relationship between patient weight and scan duration in order to achieve diagnostic attenuation (>325 Hounsfield units $[\mathrm{HU}])^{8,13,17}$

Customized injection software might lead to diagnostic and comparable attenuation values of the coronary arteries for each individual patient and a more efficient use of injected $\mathrm{CM}$ volumes.

Aim of this study was to evaluate vascular attenuation of the coronary arteries as well as image quality and injection parameters within different weight classes by using software tailored body weight adapted CM bolus injection protocols and to compare this to a standardized injection protocol with fixed parameters.

\section{MATERIALS AND METHODS}

\section{Study population}

329 consecutive patients with stable symptoms of chest discomfort and suspected coronary artery disease (CAD) were referred for CCTA from the cardiology outpatient department within a period of 6 months. Patients with a calcium score $>1000$ were 
excluded from the study ( $n=9$ ). Additionally, patients weighing $>109 \mathrm{~kg}$ were excluded as these patients were scanned with a tube voltage of $120 \mathrm{kV}(n=50)$. Patients with a heart rate $>90$ beats per minute (bpm) were excluded as these patients were scanned with a retrospectively gated helical protocol $(n=5)$. Thus, a total of 265 patients were prospectively included in this study. The included patients were divided into two groups: group 1 ( $n=141$ ) received an individually adapted injection protocol and group 2 $(n=124)$ received a fixed injection protocol.

Ethical approval was given and informed consent for the use of (coded) images was waived by the local ethical committee, as the data was analyzed anonymously in accordance with the Institutional Review Board guidelines (METC 14-4-049).

\section{Injection and scan protocol}

Scans were performed using a $2^{\text {nd }}$ generation Dual-source CT scanner (Somatom Definition Flash; Siemens Healthcare, Forchheim, Germany) with a $128 \times 0.6 \mathrm{~mm}$ slice collimation, gantry rotation time of $280 \mathrm{~ms}$, tube voltage of $100 \mathrm{kV}$, tube current of 320 or $370 \mathrm{mAs}_{\text {ref }}$ (CareDose $4 \mathrm{D}^{\mathrm{TM}}$; Siemens Medical Solutions), depending on the scan protocol. Image reconstruction was done with individually adapted field of view (FOV) at $0.75 \mathrm{~mm}$ slice thickness with an increment of $0.5 \mathrm{~mm}$ using an $126 \mathrm{f}$ kernel (SAFIRE, Iterative reconstruction strength 2).

A non-contrast enhanced scan was performed to determine the calcium score (Agatston score). All patients received an oral dose of $50 \mathrm{mg}$ metoprolol tartrate (Selokeen; AstraZeneca, Zoetermeer, the Netherlands), two hours before CCTA. When indicated, an additional dose of 5-20mg metoprolol tartrate was administered intravenously to lower the heart rate to $<60 \mathrm{bpm}$, if possible. A maximum dose of $0.8 \mathrm{mg}$ nitroglycerine (Isordil ${ }^{\circledR}$; Pohl-Boskamp, Hohenlockstedt, Germany) was given sublingually prior to CCTA. Heart rate and ECG were monitored during CCTA. In patients with a stable heart rate $<60 \mathrm{bpm}$, a prospectively ECG-triggered 'high pitch' spiral protocol was used ('Flash'-technique, 1s). In patients with a stable heart rate between 60-90bpm a prospectively triggered 'adaptive sequence' protocol was used (prospective sequential data acquisition, $7 \mathrm{~s})$. $\mathrm{CM}$ was prewarmed to standardized $37^{\circ} \mathrm{C}\left(99^{\circ} \mathrm{F}\right)$. The same CM was used for all patients (Ultravist $300 \mathrm{mg} / \mathrm{ml}$; iopromide, Bayer Healthcare, Berlin, Germany).

Group 1 ( $n=141$ ) received an individual triphasic bolus based on the weight of the patient using dedicated contrast injection software (P3T Cardiac ${ }^{\text {TM }}$; Bayer Healthcare, Berlin, Germany) (Table 1). This software allows adaption of injection rate, injection duration and contrast volume for each individual patient. The software individually adapts both the TIL (g) and the IDR (gI/s) based upon a nonlinear relationship between patient weight and duration of the CT data acquisition. ${ }^{8,13}$ For this purpose, the weight of the patient was measured on a weighing scale in the CT room and entered into the system prior to the scan. The individually tailored triphasic bolus injection consists of a 
CM phase, a mixed phase (20\% CM and $80 \%$ saline) and a saline phase. The mixed phase will be calculated as $20 \%-80 \%$ when the attenuation level reached the threshold using the test bolus methodology.

Group 2 ( $n=124)$ received a standard contrast bolus injection, using $75 \mathrm{ml}$ of $\mathrm{CM}$, which was injected in the antecubital vein at a rate of $7.2 \mathrm{ml} / \mathrm{s}$, directly followed by $50 \mathrm{ml}$ of saline (Table 1). In all patients, a test bolus injection at the level of the ascending aorta was performed to assess optimal start delay (group 1: $20 \mathrm{ml}$ of CM at a flow rate according to P3T protocol [Table 1], group 2: $20 \mathrm{ml}$ of CM at a flow rate $7.2 \mathrm{ml} / \mathrm{s}$ ). Test bolus in both groups was followed by $40 \mathrm{ml}$ of saline flush at the same flow rate.

Injection pressures (psi), flow rates $(\mathrm{ml} / \mathrm{s})$ and total amount of $\mathrm{CM}(\mathrm{ml})$ were continuously monitored by a data acquisition program (Certegra ${ }^{\mathrm{TM}}$ Informatics Platform; Bayer Healthcare, Berlin, Germany) and read out after each injection.

Table 1: Injection parameters. Prewarmed $\left(37^{\circ}\right) \mathrm{CM}$ was used (iopromide $\left.300 \mathrm{mg} / \mathrm{ml}\right)$. CM: contrast media, TIL: total iodine load, IDR: iodine delivery rate, Adapt Seq: adaptive sequence.

\begin{tabular}{|c|c|c|c|c|c|c|c|c|}
\hline Group & $\begin{array}{l}\text { CM bolus } \\
(\mathrm{ml})\end{array}$ & $\begin{array}{l}\text { Mixed bolus } \\
(20 \% \mathrm{CM}, \mathrm{ml})\end{array}$ & $\begin{array}{l}\text { Total volume } \\
\text { (CM, ml) }\end{array}$ & TIL (g) & $\begin{array}{l}\text { Saline flush } \\
(\mathrm{ml})\end{array}$ & $\begin{array}{l}\text { Flow rate } \\
(\mathrm{ml} / \mathrm{s})\end{array}$ & IDR (gl/s) & $\begin{array}{l}\text { Injection } \\
\text { time (s) }\end{array}$ \\
\hline \multicolumn{9}{|l|}{$\begin{array}{l}1 \text { (Р3T) } \\
39-59 \mathrm{~kg}\end{array}$} \\
\hline Adapt Seq & 52 & $50(10)$ & $102(62)$ & 18.6 & 30 & 5.2 & 1.6 & 19.6 \\
\hline \multicolumn{9}{|l|}{$60-74 \mathrm{~kg}$} \\
\hline Adapt Seq & 56 & $67(13.4)$ & $123(69.4)$ & 20.8 & 30 & 5.6 & 1.7 & 22 \\
\hline $\begin{array}{l}\text { High pitch } \\
75-94 \mathrm{~kg}\end{array}$ & 45 & $67(13.4)$ & $112(58.4)$ & 17.5 & 30 & \multicolumn{2}{|c|}{$75-94 \mathrm{~kg}$} & 20 \\
\hline Adapt Seq & 66 & $84(16.8)$ & $150(82.8)$ & 24.8 & 30 & 6.6 & 2.0 & 22.7 \\
\hline High pitch & 53 & $84(16.8)$ & $137(69.8)$ & 20.9 & 30 & 6.6 & 2.0 & 20.8 \\
\hline \multicolumn{9}{|l|}{$95-109 \mathrm{~kg}$} \\
\hline Adapt Seq & 74 & $102(20.4)$ & $176(94.4)$ & 28.3 & 30 & 7.4 & 2.2 & 23.8 \\
\hline High pitch & 60 & $102(20.4)$ & $162(80.4)$ & 24.1 & 30 & 7.4 & 2.2 & 21.9 \\
\hline 2 (Control) & 75 & - & $75(75)$ & 22.5 & 50 & 7.2 & 2.2 & 10.4 \\
\hline
\end{tabular}

\section{Coronary and quantitative efficacy assessments}

Two experienced radiologists who were both blinded to the injection protocol performed attenuation measurements in consensus. The coronary artery tree was assessed using the source images on a dedicated workstation (SyngoVia ${ }^{\mathrm{TM}}$; Siemens Healthcare). Axial thin slices and curved multiplanar reformatted images were used for allocating all anatomic sites for measurement of the attenuation in Hounsfield units (HU). Contrast opacification as well as image noise (standard deviation [SD]) in HU were measured using manually placed regions of interest (ROIs) in proximal and distal 
segments of the left anterior descending artery (LAD), the circumflex artery (CX) and the right coronary artery (RCA), using the 16 coronary segment model of the American Heart Association (AHA). ${ }^{18}$ Intraluminal ROls were formed as large as possible, paying attention to avoid the vessel wall (Figure 1). ROI measurement was performed in a section free of calcified plaques, as partial volume effects might influence the attenuation values.

Additionally, subjective scan quality of all datasets was evaluated and graded in consensus by an experienced radiologist and cardiologist based on a combination of the level of intra-vascular attenuation, the amount of image noise and usage of a 4-point grading scale (4: excellent, 3: good with some artefacts, 2: below average, still diagnostic, 1: poor, non diagnostic). ${ }^{19}$

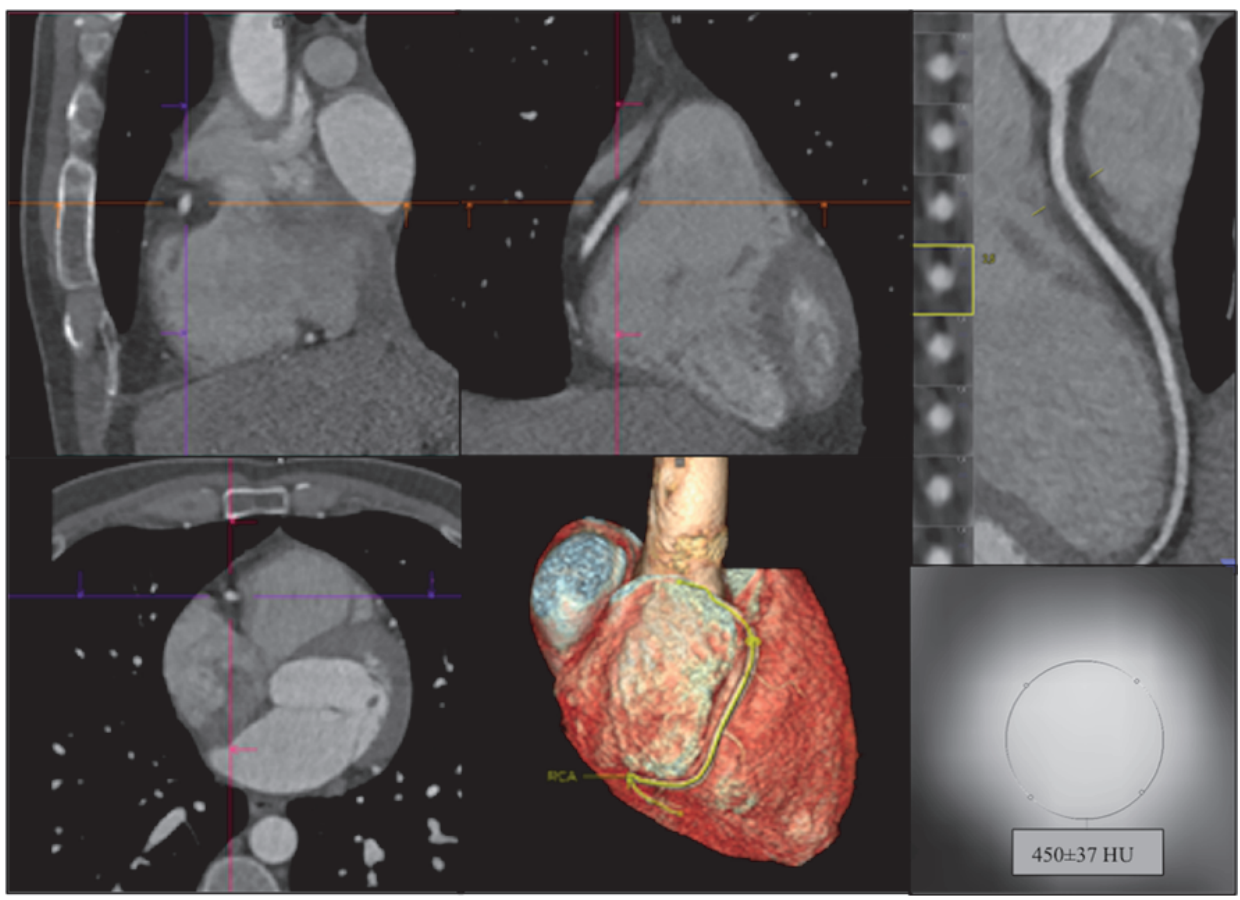

Figure 1: manually placed regions of interest (ROI) measurement in $\mathrm{HU}$ in proximal right coronary artery (RCA). Intraluminal ROIs were formed as large as possible, paying attention to avoid the vessel wall.

\section{Statistical analysis}

Continuous variables were reported as the mean \pm SD or median (interquartile range $[I Q R])$ for parameters that were not normally distributed. Normality of data distribution was evaluated using the Shapiro-Wilk test. For continuous variables, independent $t$ test or Mann-Whitney test was performed to assess differences between two groups, 
depending on normality of distribution. Proportions (\%) were used for categorical values. The chi-square test was used to measure differences between categorical variables. Mean attenuation values between weight classes were compared for both groups using one-way ANOVA followed by Tukey test for post hoc comparisons between each weight class. Mean peak pressures (psi) as well as CM volume and peak flow rate were calculated for all weight classes and separately compared to the control group using independent $t$ test. Data analysis was conducted with SPSS version 22.0 (SPSS Inc; Chicago, IL, USA). All $P$ values are 2 -sided, and a $P$ value below 0.05 was considered statistically significant.

\section{RESULTS}

68 men and 73 women were included in group 1 (median age: $56 \pm 11$ years). The control group consisted of 50 men and 74 women (mean age: $55 \pm 12$ years). The distribution among the four weight classes $(P=0.515)$ as well as among scan protocols $(P=0.308)$ did not show significant differences between both groups. Other baseline characteristics are listed in Table 2.

Table 2: Baseline characteristics. All variables are described as mean \pm SD or median (IQR) for parameters that were not normally distributed. Proportions (\%) were used for categorical values. BMI: body mass index, bpm: beats per minute.

\begin{tabular}{llll}
\hline & $\begin{array}{l}\text { Group 1 (P3T) } \\
(\mathrm{n}=141)\end{array}$ & $\begin{array}{l}\text { Group 2 (Control) } \\
(\mathrm{n}=124)\end{array}$ & $P$ \\
\hline Age (years) & $56 \pm 11$ & $55 \pm 12$ & 0.290 \\
Male (\%) & $68(48 \%)$ & $50(40 \%)$ & 0.197 \\
BMI (kg/m $\left.{ }^{2}\right)$ & $26 \pm 0.3$ & $25 \pm 0.3$ & 0.271 \\
Weight classes & & & 0.515 \\
$39-59 \mathrm{~kg}$ & $20(14 \%)$ & $18(14 \%)$ & 0.143 \\
$60-74 \mathrm{~kg}$ & $51(36 \%)$ & $50(40 \%)$ & 0.308 \\
$75-94 \mathrm{~kg}$ & $52(37 \%)$ & $47(38 \%)$ & $9(8 \%)$ \\
$95-109 \mathrm{~kg}$ & $18(13 \%)$ & $60 \pm 0.7$ & Adaptive Sequence 35 (28\%) \\
Heart rate (bpm) & $59 \pm 0.7$ & High pitch 89 (72\%) & \\
Scan protocol & Adaptive Sequence 48 (34\%) & & \\
& High pitch 93 (66\%) & & \\
\hline
\end{tabular}

In group 1, sufficient overall enhancement levels of $>325 \mathrm{HU}$ were reached in all weight groups. No significant differences were found in mean attenuation values between different weight classes ( $P>0.173)$, proximal vs. distal: $449 \pm 65$ vs. $373 \pm 58 \mathrm{HU}(39-59 \mathrm{~kg})$, $443 \pm 69$ vs. $367 \pm 81 \mathrm{HU}(60-74 \mathrm{~kg}), 427 \pm 59$ vs. $370 \pm 61 \mathrm{HU}(75-94 \mathrm{~kg}), 427 \pm 73$ vs. $347 \pm 61 \mathrm{HU}(95-109 \mathrm{~kg})$. Furthermore, in none of the vascular segments or weight classes a mean attenuation $<325 \mathrm{HU}$ was reached (Table 3 and Figure 2). In addition, standard 
deviation was lowest in group 1, indicating that attenuation was more homogeneous among patients of this group.

Table 3: Mean attenuation (HU) and standard deviation (SD) of proximal and distal coronary segments. Mean image noise (HU) and standard deviation (SD) of proximal and distal coronary segments.

\begin{tabular}{|c|c|c|c|c|c|c|c|}
\hline Group & & $\begin{array}{l}\text { RCA prox } \\
(\mathrm{HU})\end{array}$ & $\begin{array}{l}\text { RCA dist } \\
(\mathrm{HU})\end{array}$ & $\begin{array}{l}\text { LAD prox } \\
(\mathrm{HU})\end{array}$ & $\begin{array}{l}\text { LAD dist } \\
(\mathrm{HU})\end{array}$ & $\begin{array}{l}\text { Cx prox } \\
(\mathrm{HU})\end{array}$ & $\begin{array}{l}\text { Cx dist } \\
(\mathrm{HU})\end{array}$ \\
\hline \multirow[t]{5}{*}{1 (P3T) } & $39-59 k g$ & $448 \pm 74$ & $431 \pm 73$ & $449 \pm 65$ & $379 \pm 55$ & $448 \pm 72$ & $373 \pm 58$ \\
\hline & $60-74 \mathrm{~kg}$ & $443 \pm 69$ & $421 \pm 79$ & $437 \pm 72$ & $367 \pm 81$ & $441 \pm 62$ & $373 \pm 65$ \\
\hline & $75-94 \mathrm{~kg}$ & $426 \pm 68$ & $413 \pm 83$ & $427 \pm 59$ & $370 \pm 61$ & $424 \pm 72$ & $378 \pm 57$ \\
\hline & $95-109 \mathrm{~kg}$ & $427 \pm 73$ & $396 \pm 55$ & $406 \pm 56$ & $347 \pm 61$ & $423 \pm 53$ & $348 \pm 47$ \\
\hline & $P$ & 0.465 & 0.530 & 0.173 & 0.532 & 0.384 & 0.321 \\
\hline \multirow[t]{5}{*}{2 (Control) } & $39-59 \mathrm{~kg}$ & $611 \pm 142$ & $477 \pm 151$ & $592 \pm 109$ & $408 \pm 69$ & $609 \pm 104$ & $419 \pm 146$ \\
\hline & $60-74 \mathrm{~kg}$ & $562 \pm 135$ & $482 \pm 140$ & $539 \pm 115$ & $389 \pm 98$ & $545 \pm 116$ & $392 \pm 84$ \\
\hline & $75-94 \mathrm{~kg}$ & $481 \pm 83$ & $416 \pm 97$ & $435 \pm 82$ & $329 \pm 81$ & $460 \pm 83$ & $343 \pm 72$ \\
\hline & $95-109 \mathrm{~kg}$ & $398 \pm 43$ & $344 \pm 70$ & $408 \pm 69$ & $305 \pm 35$ & $420 \pm 73$ & $337 \pm 63$ \\
\hline & $P$ & $<0.001$ & 0.005 & $<0.001$ & $<0.001$ & $<0.001$ & 0.008 \\
\hline \multicolumn{8}{|c|}{ Image noise (SD) } \\
\hline $1(\mathrm{P3T})$ & & $35 \pm 13$ & $40 \pm 14$ & $34 \pm 13$ & $37 \pm 14$ & $37 \pm 14$ & $37 \pm 13$ \\
\hline \multirow[t]{2}{*}{2 (Control) } & & $35 \pm 16$ & $42 \pm 19$ & $34 \pm 16$ & $38 \pm 18$ & $36 \pm 16$ & $37 \pm 17$ \\
\hline & $P$ & 0.992 & 0.330 & 0.855 & 0.380 & 0.499 & 0.995 \\
\hline
\end{tabular}

In the control group, significantly lower attenuation levels were seen in higher weight groups, while slender patients did show markedly increased enhancement levels. Mean attenuation values between proximal and distal segments in the control group decreased significantly $(P<0.008)$ within higher weight classes and mean attenuation of the distal LAD for patients weighing $95-109 \mathrm{~kg}$ did not reach diagnostic attenuation values at $305 \pm 35 \mathrm{HU}$ (Table 3 and Figure 2).

Comparable image noise was found for both groups in all proximal and distal segments of the coronary arteries (Table 3). No significant differences in subjective scan quality were found between both datasets $(P=0.311)$. Post hoc comparisons for the different weight groups showed no significant differences. Within both groups, there were no significant differences found between the different weight groups, $P$ values 0.43 and 0.65 for group 1 and group 2, respectively. In group 1, 5\% ( $n=7)$ of the scans was graded as 'below average' (scan quality 2) or 'poor' (scan quality 1) compared to $10 \%(n=13)$ in group 2 (Table 4). The scan graded as 'poor, non diagnostic' in group 2 was due to multiple motion artifacts. 


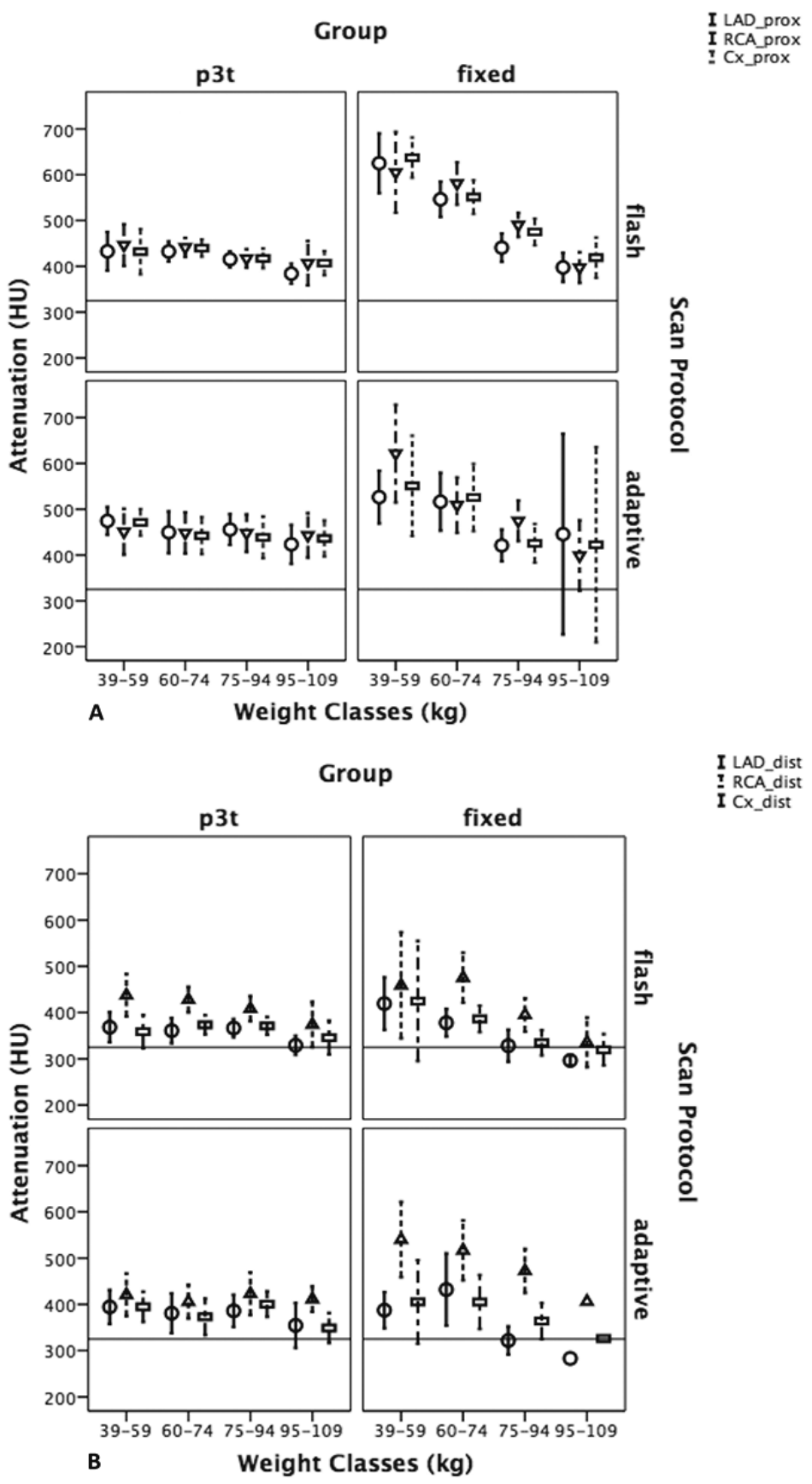

Figure 2A/B: Error bars show the mean attenuation values with standard errors of the mean for proximal (A) and distal segments (B) as well as for both injection protocols, both scan protocols and all weight classes. Reference line for attenuation was set to $325 \mathrm{HU}$. Mean attenuation <325 HU was found in the distal LAD of the control group, only (using fixed injection parameters). 
Table 4: Mean image quality parameters. Scan Quality: 4: excellent, 3: good with some artifacts, 2: below average, still diagnostic, 1: poor, non diagnostic. *Percentages may not total 100 due to rounding.

\begin{tabular}{|c|c|c|c|c|c|c|}
\hline \multirow[t]{2}{*}{ Group } & & \multicolumn{5}{|c|}{ Scan image quality, sum (\%) } \\
\hline & & $39-59 \mathrm{~kg}$ & $60-74 \mathrm{~kg}$ & $75-94 \mathrm{~kg}$ & $95-109 \mathrm{~kg}$ & $P$ \\
\hline \multirow[t]{4}{*}{1 (P3T) } & Quality 1 & $0(0)$ & $0(0)$ & $0(0)$ & $0(0)$ & \multirow{4}{*}{0.43} \\
\hline & Quality 2 & $1(5)$ & $3(6)$ & $2(4)$ & $1(6)$ & \\
\hline & Quality 3 & $6(30)$ & $29(57)$ & $21(40)$ & $8(44)$ & \\
\hline & Quality 4 & $13(65)$ & $19(37)$ & $29(56)$ & $9(50)$ & \\
\hline \multirow[t]{4}{*}{2 (Control) } & Quality 1 & $0(0)$ & $1(2)$ & $0(0)$ & $0(0)$ & \multirow{4}{*}{0.65} \\
\hline & Quality 2 & $4(22)$ & $3(6)$ & $4(9)$ & $1(11)$ & \\
\hline & Quality 3 & $6(33)$ & $23(46)$ & $24(51)$ & $3(33)$ & \\
\hline & Quality 4 & $8(44)$ & $23(46)$ & $19(40)$ & $5(56)$ & \\
\hline$P$ & & 0.24 & 0.56 & 0.26 & 0.79 & \\
\hline
\end{tabular}

In addition, less $\mathrm{CM}$ volume, lower peak flow rates and decreased peak pressures were found in patients weighing $<95 \mathrm{~kg}$ of the P3T group compared to the control group. Mean CM volumes of group 1 were: $55 \pm 6 \mathrm{ml}(39-59 \mathrm{~kg}), 61 \pm 7 \mathrm{ml}(60-74 \mathrm{~kg}), 71 \pm 8 \mathrm{ml}$ (75$94 \mathrm{~kg})$. This equates to a reduction in $\mathrm{CM}$ volume in $87 \%$ of the P3T population. Mean peak flow rates varied between $5.4 \pm 0.1$ and $6.9 \pm 0.3 \mathrm{ml} / \mathrm{s}$. Mean peak pressures varied between $89 \pm 24$ and $111 \pm 13$ psi for these weight groups, respectively. For patients of the highest weight class, injection parameters increased for group 1 in comparison to the control group (Table 5).

Table 5: Mean contrast media delivered, peak flow rate and peak pressure. CM: contrast media.

\begin{tabular}{lllllll}
\hline & \multicolumn{4}{l}{ Mean CM delivered $(\mathrm{ml})$} & Peak flow $(\mathrm{ml} / \mathrm{s})$ & Peak pressure $(\mathrm{psi})$ \\
\hline Group 1 (P3T) & & & & & \\
$39-59 \mathrm{~kg}$ & $54 \pm 6$ & $P<0.001$ & $5.4 \pm 0.1$ & $P<0.001$ & $89 \pm 24$ & $P<0.001$ \\
$60-74 \mathrm{~kg}$ & $61 \pm 7$ & $P<0.001$ & $5.9 \pm 0.2$ & $P<0.001$ & $91 \pm 9$ & $P<0.001$ \\
$75-94 \mathrm{~kg}$ & $71 \pm 8$ & $P<0.001$ & $6.9 \pm 0.3$ & $P<0.001$ & $111 \pm 13$ & $P<0.001$ \\
$95-109 \mathrm{~kg}$ & $84 \pm 9$ & $P<0.001$ & $7.7 \pm 0.4$ & $P=0.08$ & $128 \pm 12$ & $P=0.02$ \\
Group 2 (Control) & $75 \pm 0.1$ & & $7.5 \pm 0.0$ & & $122 \pm 9$ & \\
\hline
\end{tabular}

\section{DISCUSSION}

Individual adapted CM injection protocols provided diagnostically sufficient subjective and objective image quality in all patient groups. In comparison, a fixed injection protocol did show large variation between different weight groups indicating suboptimal use of $\mathrm{CM}$ in different patient weight groups, ranging from very high contrast levels in patients with low body weight (e.g. too much contrast) to very low 
contrast levels in heavy patients (e.g. not enough contrast). These findings show a clear benefit for individual tailored CM injection software in CCTA for optimal diagnostic attenuation of the coronary segments. Additionally, a more homogeneous attenuation was found throughout the proximal and distal segments of all coronary arteries in the P3T group, which can possibly be attributed to the triphasic injection protocol of the software used.

Body weight and body mass index (BMI) have a substantial impact on peak vascular attenuation and time to peak in CT angiography. ${ }^{7,10,20,21}$ Therefore, many authors have proposed to adapt CM volume to the individual patient's weight. ${ }^{13,17,22-26}$ Zhu et al. investigated different CM injection protocols in CCTA by individually tailoring iodine dose to the patient's body weight, BMI and heart rate. Patients received a BMI tailored $\mathrm{CM}$ dose (0.91-1.24*body weight, respectively depending on BMI category). Mean total volumes in different groups varied between $66.7-80 \mathrm{ml}$. They found comparable attenuation values in both ascending aorta and coronary arteries in different weight categories when $\mathrm{CM}$ dose was adapted to body weight and $\mathrm{BMI}^{27}$ These findings are comparable to our results. However, the authors calculated mean attenuation values of all weight classes according to the different scan protocols. An additional sub-analysis for the difference in attenuation values between different weight classes of the individually tailored CM injection protocols was not calculated and would have been of additional value.

Nakaura et al. designed a weight-adjusted protocol in CCTA, where the iodine dose was tailored to the patient body weight $(1.0 \mathrm{ml} / \mathrm{kg}$ body weight, injection duration: $15 \mathrm{~s})$. They found non-significant differences in attenuation between the lower and higher weight adjusted subgroups (e.g. bodyweight: $<58$ and $\geq 58 \mathrm{~kg}$ ) and concluded, that shorter injection duration yielded adequate enhancement of the coronary arteries and ascending aorta and reduced the average contrast volume required for CCTA. ${ }^{14}$ The authors divided the Asian study population in two weight classes. In the European population, a subdivision in more consecutive weight classes would be more appropriate, especially with regard to body weight $\geq 58 \mathrm{~kg}$, which is regarded a substantial percentage of our study population. The TIL used in the body weight adjusted protocol is still rather high $(22.0 \pm 4.7 \mathrm{~g})$, which is comparable to the TIL used in our fixed protocol. According to our findings, $\mathrm{CM}$ volume could be reduced in patients up to $94 \mathrm{~kg}$. This means a reduction of $24 \%$ for patients $\leq 58 \mathrm{~kg}$ and $3-17 \%$ for patients $59-94 \mathrm{~kg}$, still resulting in optimal and robust contrast enhancement.

Seifarth et al. investigated if individually tailored protocols for the injection of CM resulted in higher vascular attenuation of coronary arteries compared to fixed injection protocols. ${ }^{13}$ They evaluated an injection protocol using P3T software in comparison to two different standard injection protocols and found comparable or increased attenuation values using P3T compared to fixed protocols. In addition, lowest volume and flow rates were used in the P3T group. They compared overall mean attenuation of the coronary arteries between groups, where they did not specify mean attenuation of 
the different weight classes or perform sub analysis for differences in attenuation values between weight classes. As P3T software is based upon an adaptation of IDR and TIL for weight classes in particular, a sub analysis provides the best insight in the functionality of this software, which is a major difference and benefit of our study.

With respect to diagnostic attenuation of the coronary arteries, several opinions do exist. Attenuation levels above $325 \mathrm{HU}$ are usually considered diagnostically sufficient. ${ }^{17}$ On the other hand, it is known from the literature, that attenuation values over $500 \mathrm{HU}$ may lead to underestimation of the degree of stenosis. ${ }^{28}$ In this study, attenuation was diagnostic for all patients in all weight categories using P3T. For the control group, however, insufficient mean attenuation $(305 \pm 35 \mathrm{HU})$ was seen in the distal LAD. Furthermore, mean attenuations over $500 \mathrm{HU}$ were reached in several proximal segments, while these high enhancement levels were not reached in group 1. Additionally, CM volume decreased significantly in group 1 for patients $<95 \mathrm{~kg}$ compared to the control group. In our hospital, a very large percentage (e.g. 84\%) of the general CCTA population will benefit from reduction of CM volume, as the mean weight of patients referred for CCTA is $80 \pm 16 \mathrm{~kg}$ (based on 4091 patients) and 658 patients (16\%) had a body weight $>94 \mathrm{~kg}$.

$\mathrm{CM}$ volume might be decreased even further as the attenuation values of the proximal segments were still well above the diagnostic level. This could be accomplished by lowering designated IDR and CM volume at the same time. However, for distal segments, attenuation values were more close to the reference value of $325 \mathrm{HU}$, which makes it challenging to reduce TIL. TIL, however, could be reduced as well by lowering the concentration of the $\mathrm{CM}$ itself and this, in turn, may provide a more easily and evenly distribution in the vessels due to the reduced viscosity of the fluid. ${ }^{1,29,30}$ Usage of lower viscose CM concentrations might bare the potential for better visualization of smaller vascular segments such as the distal coronary arteries. In this respect, Bae et al. investigated in clinical CT angiography that an exponentially decelerated CM injection method, as compared with the standard constant-rate injection method, can facilitate uniform vascular contrast enhancement with a reduced $\mathrm{CM}$ volume. ${ }^{15}$ Furthermore, if $\mathrm{CT}$ scan parameters will be adapted to lower kV settings (e.g. 70/80kV), even further reduction might be possible in the future.

\section{Limitations}

Our study has several limitations. This is a nonrandomized single-center study, investigating a limited number of patients. In addition, kV settings were adapted to body weight by using $120 \mathrm{kV}$ in patients weighing $>109 \mathrm{~kg}$ to overcome the problem of increased image noise. Therefore, patients weighing $>109 \mathrm{~kg}$ were excluded in this study. In addition, aim of this study was to evaluate feasibility of software tailored body weight adapted triphasic CM bolus injection protocol in comparison to a standardized injection protocol. As the latter is considered a biphasic injection protocol, this might 
potentially have had some influence on attenuation values, in particular in the more distal segments. However, differences in outcome with regard to attenuation of the coronary segments in the control group are not expected, as all patients received an identical CM volume, which would have been the same with usage of a triphasic protocol.

\section{CONCLUSION}

Automated body weight adapted CM injection in CCTA results in diagnostically sufficient and comparable attenuation values between different weight groups. No significant differences in subjective and objective image quality were found. In clinical practice, overall CM volumes could be reduced for the majority of patients of the general population referred for CCTA utilizing body weight adapted individualized CM bolus. 


\section{REFERENCES}

1. Bae KT. Intravenous contrast medium administration and scan timing at ct: Considerations and approaches. Radiology. 2010;256:32-61

2. Johnson PT, Pannu HK, Fishman EK. Iv contrast infusion for coronary artery ct angiography: Literature review and results of a nationwide survey. AJR Am J Roentgenol. 2009;192:W214-221

3. Otero HJ, Steigner ML, Rybicki FJ. The "post-64" era of coronary ct angiography: Understanding new technology from physical principles. Radiol Clin North Am. 2009;47:79-90

4. Dewey M, Zimmermann E, Deissenrieder F, Laule M, Dubel HP, Schlattmann P, Knebel F, Rutsch W, Hamm B. Noninvasive coronary angiography by 320-row computed tomography with lower radiation exposure and maintained diagnostic accuracy: Comparison of results with cardiac catheterization in a head-to-head pilot investigation. Circulation. 2009;120:867-875

5. Kumamaru KK, Steigner ML, Soga S, Signorelli J, Bedayat A, Adams K, Mitsouras D, Rybicki FJ. Coronary enhancement for prospective ecg-gated single r-r axial 320-mdct angiography: Comparison of 60- and 80ml iopamidol 370 injection. AJR Am J Roentgenol. 2011;197:844-850

6. Yamamuro M, Tadamura E, Kanao S, Wu YW, Tambara K, Komeda M, Toma M, Kimura T, Kita T, Togashi K. Coronary angiography by 64-detector row computed tomography using low dose of contrast material with saline chaser: Influence of total injection volume on vessel attenuation. J Comp Assist Tomogr. 2007;31:272-280

7. Bae KT, Seeck BA, Hildebolt CF, Tao C, Zhu F, Kanematsu M, Woodard PK. Contrast enhancement in cardiovascular mdct: Effect of body weight, height, body surface area, body mass index, and obesity. AJR Am J Roentgenol. 2008;190:777-784

8. Bae KT, Heiken JP, Brink JA. Aortic and hepatic contrast medium enhancement at ct. Part ii. Effect of reduced cardiac output in a porcine model. Radiology. 1998;207:657-662

9. Ho LM, Nelson RC, Delong DM. Determining contrast medium dose and rate on basis of lean body weight: Does this strategy improve patient-to-patient uniformity of hepatic enhancement during multi-detector row ct? Radiology. 2007;243:431-437

10. Platt JF, Reige KA, Ellis JH. Aortic enhancement during abdominal ct angiography: Correlation with test injections, flow rates, and patient demographics. AJR Am J Roentgenol. 1999;172:53-56

11. Fleischmann D. Use of high-concentration contrast media in multiple-detector-row ct: Principles and rationale. Eur Radiol. 2003;13 Suppl 5:M14-20

12. Rist C, Becker CR, Kirchin MA, Johnson TR, Busch S, Bae KT, Leber AW, Reiser MF, Nikolaou K. Optimization of cardiac msct contrast injection protocols: Dependency of the main bolus contrast density on test bolus parameters and patients' body weight. Acad Radiol. 2008;15:49-57

13. Seifarth H, Puesken M, Kalafut JF, Wienbeck S, Wessling J, Maintz D, Heindel W, Juergens KU. Introduction of an individually optimized protocol for the injection of contrast medium for coronary ct angiography. Eur Radiol. 2009;19:2373-2382

14. Nakaura T, Awai K, Yauaga Y, Nakayama Y, Oda S, Hatemura M, Nagayoshi Y, Ogawa H, Yamashita Y. Contrast injection protocols for coronary computed tomography angiography using a 64-detector scanner: Comparison between patient weight-adjusted- and fixed iodine-dose protocols. Invest Radiol. 2008;43:512-519

15. Bae KT, Tran HQ, Heiken JP. Uniform vascular contrast enhancement and reduced contrast medium volume achieved by using exponentially decelerated contrast material injection method. Radiology. 2004;231:732-736

16. Fleischmann D, Rubin GD, Bankier AA, Hittmair K. Improved uniformity of aortic enhancement with customized contrast medium injection protocols at ct angiography. Radiology. 2000;214:363-371

17. Isogai T, Jinzaki M, Tanami Y, Kusuzaki H, Yamada M, Kuribayashi S. Body weight-tailored contrast material injection protocol for 64-detector row computed tomography coronary angiography. Jpn J Radiol. 2011;29:33-38

18. Austen WG, Edwards JE, Frye RL, Gensini GG, Gott VL, Griffith LS, McGoon DC, Murphy ML, Roe BB. A reporting system on patients evaluated for coronary artery disease. Report of the ad hoc committee for grading of coronary artery disease, council on cardiovascular surgery, american heart association. Circulation. 1975;51:5-40

19. Hausleiter J, Martinoff S, Hadamitzky M, Martuscelli E, Pschierer I, Feuchtner GM, Catalan-Sanz P, Czermak B, Meyer TS, Hein F, Bischoff B, Kuse M, Schomig A, Achenbach S. Image quality and radiation 
exposure with a low tube voltage protocol for coronary ct angiography results of the protection II trial. JACC Cardiovasc Imaging. 2010;3:1113-1123

20. Awai K, Hiraishi K, Hori S. Effect of contrast material injection duration and rate on aortic peak time and peak enhancement at dynamic ct involving injection protocol with dose tailored to patient weight. Radiology. 2004;230:142-150

21. Husmann L, Leschka S, Boehm T, Desbiolles L, Schepis T, Koepfli P, Gaemperli O, Marincek B, Kaufmann P, Alkadhi $\mathrm{H}$. Influence of body mass index on coronary artery opacification in 64-slice ct angiography. RoFo;2006;178:1007-1013

22. Cademartiri F, van der Lugt A, Luccichenti G, Pavone P, Krestin GP. Parameters affecting bolus geometry in cta: A review. J Comp Assist Tomogr. 2002;26:598-607

23. Tatsugami F, Matsuki M, Inada Y, Kanazawa S, Nakai G, Takeda Y, Morita H, Takada H, Ashida K, Yoshikawa S, Fukumura K, Narumi Y. Feasibility of low-volume injections of contrast material with a body weightadapted iodine-dose protocol in 320-detector row coronary ct angiography. Acad Radiol. 2010;17:207211

24. Zhu X, Zhu Y, Xu H, Tang L, Xu Y. The influence of body mass index and gender on coronary arterial attenuation with fixed iodine load per body weight at dual-source ct coronary angiography. Acta Radiol. 2012;53:637-642

25. Liu J, Gao J, Wu R, Zhang Y, Hu L, Hou P. Optimizing contrast medium injection protocol individually with body weight for high-pitch prospective ecg-triggering coronary ct angiography. Int J Cardiovasc Imaging. 2013;29:1115-1120

26. Awai K, Hatcho A, Nakayama Y, Kusunoki S, Liu D, Hatemura M, Funama Y, Denbo M, Sato N, Yamashita Y. Simulation of aortic peak enhancement on mdct using a contrast material flow phantom: Feasibility study. AJR Am J Roentgenol. 2006;186:379-385

27. Zhu X, Zhu Y, Xu H, Wan Y, Choo KS, Yang G, Tang L, Xu Y. An individualized contrast material injection protocol with respect to patient-related factors for dual-source ct coronary angiography. Clin Radiol. 2014;69:e86-92

28. Fei X, Du X, Yang Q, Shen Y, Li P, Liao J, Li K. 64-mdct coronary angiography: Phantom study of effects of vascular attenuation on detection of coronary stenosis. AJR Am J Roentgenol. 2008;191:43-49

29. Kok M, Mihl C, Mingels AA, Kietselaer BL, Muhlenbruch G, Seehofnerova A, Wildberger JE, Das M. Influence of contrast media viscosity and temperature on injection pressure in computed tomographic angiography: A phantom study. Invest Radiol. 2014;49:217-223

30. Muhlenbruch G, Behrendt FF, Eddahabi MA, Knackstedt C, Stanzel S, Das M, Seidensticker P, Gunther RW, Wildberger JE, Mahnken $\mathrm{AH}$. Which iodine concentration in chest ct? - A prospective study in 300 patients. Eur Radiol. 2008;18:2826-2832 

CHAPTER 8

General Discussion 


\section{TECHNICAL ADVANCES IN CORONARY COMPUTED TOMOGRAPHIC ANGIOGRAPHY}

Coronary computed tomographic angiography (CCTA) has proven to be an important non-invasive imaging technique for the assessment of coronary artery disease (CAD). ${ }^{1}$ Due to ongoing technological advances, spatial and temporal resolution increased significantly, making CCTA a highly accurate method to rule out CAD in comparison to invasive coronary angiography (CAG)..$^{2-5}$ In addition, prospectively ECG-triggered scan protocols, high pitch protocols and strategies such as automatic tube current modulation have resulted in a substantial reduction of radiation dose. ${ }^{6-8}$ The decrease in scan acquisition time (<1-6 seconds, depending on scan protocol and scanner technique) has reduced artifacts due to breathing and coronary motion substantially. ${ }^{9}$ These shorter scan acquisition times necessitate a more challenging timing of contrast media (CM) application as the temporal data acquisition window will be shorter. ${ }^{10-13}$

\section{PARAMETERS INFLUENCING ENHANCEMENT OF THE CORONARY ARTERIES}

Enhancement characteristics are based on multiple factors, which can be divided in three major subgroups (Figure 1). ${ }^{2,12,14}$

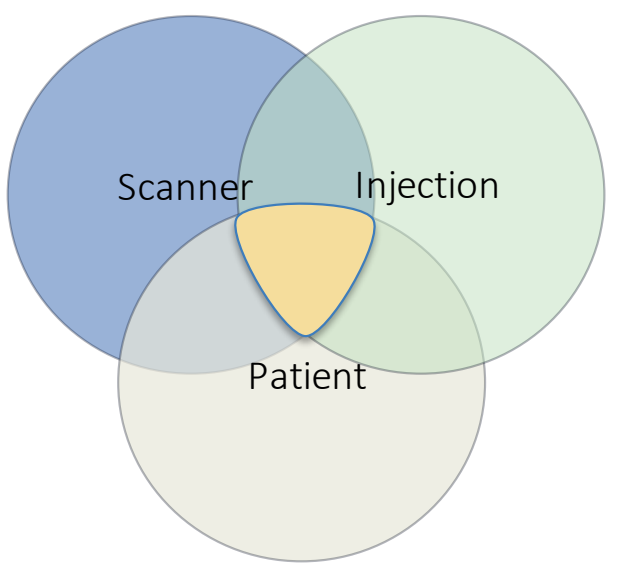

Figure 1: major subgroups influencing enhancement in CCTA

All these parameters may have a substantial effect on the attenuation and overall scan quality. In this thesis, various injection related parameters were evaluated in order to determine the individual influence of these parameters on attenuation of the coronary arteries in CCTA. 
In the first part of this thesis, literature was systematically reviewed to analyze the determining factors for optimal contrast enhancement of the coronary arteries. Based on the included publications, an adequate attenuation in the coronary arteries can be achieved with very different CM injection protocols. However, given the substantial variability between studies, it remains unclear which of the injection parameters are the most important determinant parameters for adequate attenuation. Questionable outcomes and conclusions are drawn when different CM concentrations are injected without keeping other injection parameters comparable.

For example, Becker et al. wanted to assess whether CM characteristics affect diagnostic quality in CCTA. They conducted a randomized controlled trial in which patients were randomized in 2 different CM groups (iodixanol $320 \mathrm{mg} / \mathrm{ml}$ and iomeprol $400 \mathrm{mg} / \mathrm{ml}$ ). In both groups, $80 \mathrm{ml} \mathrm{CM}$ was injected at an identical flow rate of $5 \mathrm{ml} / \mathrm{s}{ }^{15} \mathrm{~A}$ significantly higher attenuation of the coronary arteries was found in the $400 \mathrm{mg} / \mathrm{ml}$ group and the authors concluded that higher iodine concentration CM was beneficial to attenuation. However, administering different iodine concentrations while keeping the injection rate in both groups identical creates a difference in IDR (e.g. group $320 \mathrm{mg} / \mathrm{ml}$ : $1.6 \mathrm{gl} / \mathrm{s}$ vs. group $400 \mathrm{mg} / \mathrm{ml}: 2.0 \mathrm{gl} / \mathrm{s}$ ). As CM concentration and IDR are different, it is questionable whether the differences in attenuation should be attributed to the CM concentration solely. Higher CM concentrations at a given flow rate as well as injection of a dedicated CM concentration with an increase in flow rate automatically lead to a higher IDR. This critically affects both the magnitude and timing of contrast enhancement, leading to a higher but shorter peak enhancement and thus a proportional increase in vascular and parenchymal enhancement. ${ }^{2,9,14,16,17}$ These doubtful conclusions with regard to sole superiority of higher CM concentrations are in line with the results of other clinical studies, that have not shown any benefit of higher concentrated CM when IDR is kept identical. ${ }^{7,18-20}$ However, other publications reported no significant differences in attenuation when IDR differed between subgroups. ${ }^{21-27}$ Some of the studies included in our systematic review provided limited data concerning injection-, scanning- and patient-parameters. For example, body weight index (BMI) or both length and weight of the patient population were often not specified. ${ }^{15,19,21,22,25,28-41}$ Therefore, possible effects of these missing parameters on attenuation of the vessels could not be accounted for in this analysis. All these factors, however, may have a significant impact and should probably be integrated in individualized scan and $\mathrm{CM}$ injection protocols in clinical routine. In order to be able to fully comprehend the impact of different injection parameters on CCTA, the individual influence of these parameters has to be studied while all other parameters are kept identical. 


\section{ESTABLISHING THE DECISIVE INJECTION PARAMETERS: IN VITRO / VIVO EXPERIMENTS}

\section{In vitro experiments}

In the in vitro part of this thesis, experiments were conducted in order to establish the influence of IDR, high flow rates as well as viscosity and temperature on vessel attenuation and peak pressure. Viscosity of CM proved to play an important role for the overall enhancement pattern in previous literature. ${ }^{2,42-44}$ Viscosity is directly influenced by temperature, which means viscosity decreases with increasing temperature. ${ }^{28,45-48}$ Higher viscosity increases the friction resistance and the pressure needed for the same flow rate. ${ }^{49}$ In chapter 3 , we evaluated different $\mathrm{CM}$ concentrations at different temperatures and investigated its influence on injection parameters, with special regard to injection pressure. The results of these experiments show in a standardized way that low viscosity decreases injection pressure. This can be facilitated by prewarming CM (high temperature) and using CM with low iodine concentration.

In these experiments, significant differences in peak pressure (psi) were found at $20^{\circ} \mathrm{C}, 30^{\circ} \mathrm{C}$, and $37^{\circ} \mathrm{C}$ for iodinated CM 240,300,370, and $400 \mathrm{mg} / \mathrm{ml}$. Overall, the lowest peak pressure was found for the lowest concentrated CM (e.g. $240 \mathrm{mg} / \mathrm{ml}$ ) at body temperature $\left(92 \mathrm{psi}\right.$ at $\left.37^{\circ} \mathrm{C}\right)$. These findings not only stress the positive effect of preheating $\mathrm{CM}$ to reduce viscosity and injection pressure, but also display the potential reduction in peak pressure which can be generated when using lower concentrated CM. Lower viscosity can be advantageous in several ways and has an influence on different aspects in $\mathrm{CM}$ injection: accelerated $\mathrm{CM}$ distribution, facilitating the mixing of $\mathrm{CM}$ with blood and lower injection pressure..$^{20,50}$ These benefits subsequently create the doorway towards injection with higher flow rates.

Chapter 4 aimed to investigate the influence of $\mathrm{CM}$ concentration and IDR on intravascular attenuation in a circulation phantom. The use of a circulation phantom provides a unique opportunity for repetitive and systematic scanning of an identical subject, ruling out variables such as varying heart rate, blood pressure, different body weights as well as cardiac output. In this study, comparison of protocols using different CM concentrations (varying between 240-400mg/ml) established comparable intravascular enhancement patterns when IDR and other CM and scan related factors were kept standardized. In previous literature, significant differences in attenuation of the coronary arteries are often attributed to higher concentrated CM (e.g. 370 and $400 \mathrm{mg} / \mathrm{ml}$ ) in comparison to lower concentrated CM (e.g. 300mg/ml). ${ }^{15,28,31,51}$ However, these conclusions are to be viewed with caution, as IDR was often not kept comparable. For example, Cademartiri et al. prospectively evaluated coronary attenuation in 5 groups with different $\mathrm{CM}$ concentrations. ${ }^{28}$ Both $\mathrm{CM}$ volume and injection rate were kept identical in all groups $(140 \mathrm{ml} \mathrm{CM}$ volume injected at $4 \mathrm{ml} / \mathrm{s})$. Mean attenuation values were significantly lower in the lower CM group and higher in 
the high CM group. The authors conclude that higher iodine concentration CM yield significantly higher attenuation in coronary arteries. However, due to the use of an identical injection rate in these groups, IDR varied significantly $(1.2$ to $1.6 \mathrm{gl} / \mathrm{s})$, rendering doubtful conclusions with regard to the sole superiority of higher CM concentrations. In our phantom experiments, higher CM concentrations did not increase attenuation levels and comparable attenuation levels can be reached with very low CM concentrations (e.g. $240 \mathrm{mg} / \mathrm{ml}$ ) when IDR is kept identical. These findings stress IDR as the decisive factor for vascular attenuation. The understanding of this direct correlation offers a robust basis for further in vivo testing.

\section{In vivo experiments}

In the in vivo part of this thesis, feasibility of higher injection rates was tested and image quality of lower concentrated $\mathrm{CM}$ concentrations injected with higher flow rates was evaluated. As lower concentrated and subsequently lower viscose CM might be beneficial, this does come at the expenditure of higher flow rates in order to achieve the desired IDR to be utilized. In clinical practice, IDR's varying between $1.5-2.2 \mathrm{gl} / \mathrm{s}$ have been advocated for CCTA. ${ }^{11,31}$ As was shown in previous studies, higher IDR's result in higher peak enhancement, which is considered an important determining factor for computed tomographic angiography (CTA) studies, especially in CCTA. 2, 11, 28, 42, 52

In present daily clinical routine, there is reluctance towards application of high flow rates (e.g. injection rates $\geq 5 \mathrm{ml} / \mathrm{s}$ ) with normal intravenous injection needles, as it has been stated that injection of high iodine concentrated CM with high flow rates may lead to disconnection of the cannula due to an increase in injection pressure. ${ }^{42,43}$ In addition, there is an hypothesized increase of extravasation and a possible decrease in patient comfort. $^{49,53}$ To facilitate higher injection rates, dedicated intravenous needles have been developed, with a strengthened design that reduces the forces during injection. In chapter 5, these needles were tested in both in vitro and in vivo experiments, where we aimed to test high flow application of CM using novel high flow needles in a circulation phantom and assessed feasibility of high flow rates in an in vivo setup. Using these high flow needles, high flow rates proved to be feasible in a phantom setting $(\leq 15 \mathrm{ml} / \mathrm{s})$ as well as in a clinical cohort where a maximum flow rate of $9.6 \mathrm{ml} / \mathrm{s}$ was administered. As $10 \mathrm{ml} / \mathrm{s}$ is the maximum flow rate possible with current CT power injectors and peak flow rates are known to be slightly higher than the pre-determined injection rates, a flow rate of $9 \mathrm{ml} / \mathrm{s}$ was applied in this clinical study. Injection with these high flow rates proved to be safe in a clinical setup. No flow related problems were observed and the maximum injection pressure of $325 \mathrm{psi}$ was not reached in both the phantom and patient setting. These findings are supported by a study (chapter 6 ), were peak injection pressures and both objective and subjective image quality were monitored using low concentrated CM $(240 \mathrm{mg} / \mathrm{ml})$ injected at high flow rates $(9 \mathrm{ml} / \mathrm{s})$ in comparison to a standard injection protocol with an identical IDR for both groups. No contrast related 
problems such as extravasation at the injection site or flow related side effects (e.g. streak artifacts or CM reflux) were encountered. Also, no significant differences in peak pressure and image quality were found between both groups.

There is not much literature on the associated risk and discomfort during CM injection rates. One study evaluated local discomfort at the site of injection plus general discomfort after injection, rated on a scale from 0 (no discomfort) to 10 (worst imaginable discomfort) in flow rates up to $4.3 \mathrm{ml} / \mathrm{s} .{ }^{20}$ No significant differences in terms of discomfort were found. To the best of our knowledge, patient discomfort in terms of pain sensation during injection with higher flow rates has not been quantified. Also, data is lacking regarding the incidence of access site complications in high flow rates $(\geq 5 \mathrm{ml} / \mathrm{s})$. One study prospectively evaluated 4.457 patients and assessed the frequency and type of i.v. injection site complications associated with high flow power injection up to $8 \mathrm{ml} / \mathrm{s}^{49}$ The authors concluded, that automated CM injection is performed without increased risk of extravasation or injection related complications. These results prove that reluctance towards usage of high flow rates is merely based on hypothetical flow related issues or anecdotal and personal experience.

\section{TOWARDS INDIVIDUALLY TAILORED CM APPLICATION}

In chapter 7, vascular attenuation of the coronary arteries as well as injection parameters and overall image quality were evaluated within different weight classes using dedicated individually tailored CM injection software. The software adapted the IDR and total iodine load based upon a non-linear relationship between patient weight and scan duration in order to achieve diagnostic attenuation. ${ }^{41,54}$ Diagnostic attenuation in the entire coronary tree and a more homogeneous enhancement pattern between different weight groups was found in comparison to a fixed injection protocol. CM volume decreased significantly in patients $<95 \mathrm{~kg}$ when utilizing body weight adapted individualized CM bolus application. These findings show a clear benefit of individual tailored CM injection software in CCTA. Body weight and BMI are known to have a substantial impact on peak vascular attenuation and time to peak in CTA. ${ }^{14,55-57}$ In the literature, various individually tailored injection protocols have been proposed, where CM volume and/or IDR were adapted to either patient's body weight, $\mathrm{BMI}$ and/or heart rate with promising results. ${ }^{40,41,52,54,58}$ All these publications do report some benefit of individually tailored CM injection protocol. However, most studies compared different body weight tailored protocols between each other and mean attenuation of the different weight classes were often not specified. Subsequently, a sub analysis for differences in attenuation values between weight classes was not performed, which does provide the best insight in the benefits of body weight adapted CM injection protocols. This is a major difference and benefit of our study. 


\section{FUTURE DIRECTIONS}

A thorough understanding of the influence of different injection parameters is considered a necessity towards the ultimate goal of individualized medicine. For CT scanning, CM injection protocols are highly tailored towards body weight and/or BMI. Lowering the amount of CM could lower the risk for development of contrast-induced nephropathy $(\mathrm{CIN}){ }^{59}$ Additionally, when continuous diagnostic image quality of the coronary tree in all patients can be achieved using lower total iodine load, this might lead to a substantial decrease in costs.

Disentangling the influence of patient related parameters on attenuation and overall image quality will be helpful in defining optimal bolus shaping in future injection protocols, hereby creating a doorway towards extensive individualized CM application. Whilst in daily clinical routine a large variety in IDR is applied in CCTA, no literature or consensus exists on the optimal IDR for attenuation of the coronary arteries. Goal is to create a personalized $\mathrm{CM}$ injection protocol, where some patients (e.g. lower weight and/or length or heart rate $\leq 60 \mathrm{bpm}$ ) might require less CM with a different scan timing protocol than other patients (e.g. higher BMI or heart rate $\geq 60 \mathrm{bpm}$ ) to reach the same attenuation value. ${ }^{2}$ Research needs to be directed towards defining individualized optimal IDR tailored towards patient related factors (e.g. weight, heart rate, cardiac output) with further incorporation of different scan- and injection parameters into computer modeling software.

An indicative initial flow chart towards the implementation and integration of various different contrast injection and scan timing parameters has been created by Bae et al (Figure 2). ${ }^{2}$ In this figure, patient's demographic information from a clinical database has been integrated together with scan and injection parameters, aiming to optimize the injection protocol.

Automated implementation of this flow chart will optimize scan delay after CM injection, modify the injection profile as well as terminate the injection seamlessly in order to achieve a desirable organ specific contrast enhancement for a given patient and clinical application. ${ }^{2}$

The results of our in vivo and in vitro experiments have helped to gain a better insight in the influence of multiple different parameters on all three levels in the flow chart (e.g. scan variables, injector and patient related factors). The next step is directed towards evaluating the role of flow rate, IDR and different CM concentrations in a double-blinded prospective randomized controlled trial. For this reason, the EICAR trial (Effects on Intra-Coronary Attenuation using low iodine concentrations while maintaining constant IDR) was created. This trial, registered on ClinicalTrials.gov (NCT02462044), aims to evaluate intravascular attenuation of the coronary arteries and image quality using different iodine concentrations (e.g. $240 \mathrm{mg} / \mathrm{ml}, 300 \mathrm{mg} / \mathrm{ml}$ and $370 \mathrm{mg} / \mathrm{ml}$ ) while maintaining identical IDR and total iodine load. In this study patient comfort at the injection site with usage of flow rates varying $5.4-8.3 \mathrm{ml} / \mathrm{s}$ as well as 


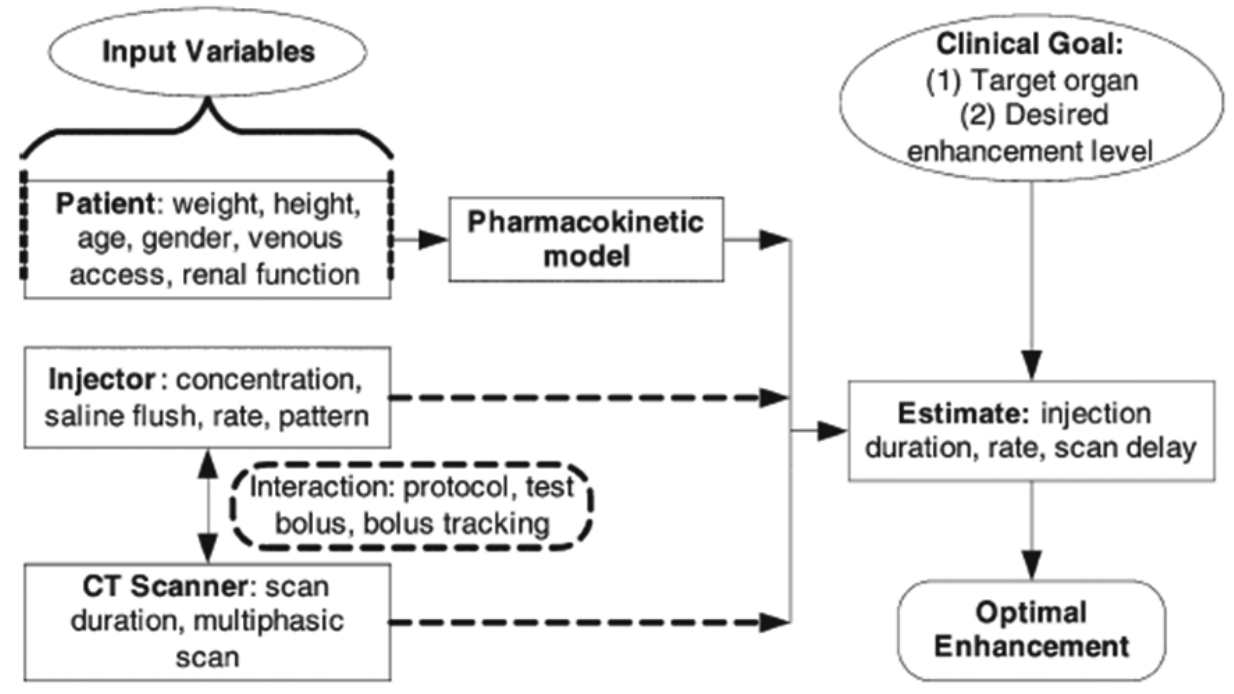

Figure 2: adapted from Bae at al. Intravenous contrast medium administration and scan timing at ct: Considerations and approaches. Radiology. 2010;256:32-61

heart rate variability and incidence of contrast extravasation will be evaluated. In chapter 5 and 6 , extravasation at the injection site with administration of high flow rates was evaluated only. More specific parameters such as pain and comfort were not quantified nor measured. Testing the hypothesis in a double-blinded randomized setting that high flow rates will not lead to an increase of patient discomfort during injection creates a doorway towards more individualized injection protocols tailored to weight and length of the patient with applicability of a broad variety in flow rates and a large diversity in IDR accordingly.

In addition to individualized CM application protocols, newer technical developments are moving towards broad clinical application of lower kV settings. The latter may allow a further reduction of CM volume and IDR in terms of enhancement. Vascular enhancement is dependent on the tube voltage applied. Attenuation increases at lower $\mathrm{kV}$ settings, as lower $\mathrm{x}$-ray tube voltages are closer to the k-edge of iodine, hereby owing to a greater photoelectric effect. ${ }^{60,61}$ The lowering of tube voltage settings are therefore accompanied not only by lowering radiation dose but with possible reduction of $\mathrm{CM}$ volume and IDR as well, due to increased vascular attenuation. ${ }^{62-64}$ This technique of lowering tube voltage is presently often used as a CM volume and dose-reducing strategy. Utilizing this technique, tube voltages of $70-80 \mathrm{kV}$ are already investigated in lower extremity CTA. A recent study found tube voltages of $70 \mathrm{kV}$ with injection of $80 \mathrm{ml}$ of $\mathrm{CM}$ volume allows for both lower CM volume and radiation dose without compromising image quality in CTA of the peripheral arteries. ${ }^{65}$ In addition, an alternative image reconstruction method named iterative reconstruction 
allows for scanning with lower radiation doses with similar noise-levels and image quality in comparison to filtered back projection. ${ }^{66-69}$ Usage of newer generation iterative reconstruction algorithms in combination with low $\mathrm{kV}$ scan protocols and individually tailored CM application bare the potential for optimizing CM delivery and monitoring image quality according to the ALARA (as low as reasonably achievable) principle. 


\section{REFERENCES}

1. Hendel RC, Patel MR, Kramer CM, Poon M, Hendel RC, Carr JC, Gerstad NA, Gillam LD, Hodgson JM, Kim RJ, Kramer CM, Lesser JR, Martin ET, Messer JV, Redberg RF, Rubin GD, Rumsfeld JS, Taylor AJ, Weigold WG, Woodard PK, Brindis RG, Hendel RC, Douglas PS, Peterson ED, Wolk MJ, Allen JM, Patel MR. Accf/acr/scct/scmr/asnc/nasci/scai/sir 2006 appropriateness criteria for cardiac computed tomography and cardiac magnetic resonance imaging: A report of the American college of cardiology foundation quality strategic directions committee appropriateness criteria working group, American college of radiology, society of cardiovascular computed tomography, society for cardiovascular magnetic resonance, American society of nuclear cardiology, North American society for cardiac imaging, society for cardiovascular angiography and interventions, and society of interventional radiology. J Am Coll Cardiol. 2006;48:1475-1497

2. Bae KT. Intravenous contrast medium administration and scan timing at ct: Considerations and approaches. Radiology. 2010;256:32-61

3. Achenbach S, Ulzheimer S, Baum U, Kachelriess M, Ropers D, Giesler T, Bautz W, Daniel WG, Kalender WA, Moshage W. Noninvasive coronary angiography by retrospectively ecg-gated multislice spiral ct. Circulation. 2000;102:2823-2828

4. Hoffmann MH, Shi H, Schmitz BL, Schmid FT, Lieberknecht M, Schulze R, Ludwig B, Kroschel U, Jahnke N, Haerer W, Brambs HJ, Aschoff AJ. Noninvasive coronary angiography with multislice computed tomography. JAMA. 2005;293:2471-2478

5. Nieman K, Oudkerk M, Rensing BJ, van Ooijen P, Munne A, van Geuns RJ, de Feyter PJ. Coronary angiography with multi-slice computed tomography. Lancet. 2001;357:599-603

6. Sun Z. Multislice ct angiography in cardiac imaging: Prospective ecg-gating or retrospective ecg-gating? Biomed imaging Interv J. 2010;6:e4

7. Lell M, Marwan M, Schepis T, Pflederer T, Anders K, Flohr T, Allmendinger T, Kalender W, Ertel D, Thierfelder C, Kuettner A, Ropers D, Daniel WG, Achenbach S. Prospectively ecg-triggered high-pitch spiral acquisition for coronary ct angiography using dual source ct: Technique and initial experience. Eur Radiol. 2009;19:2576-2583

8. Sun Z, Ng KH. Prospective versus retrospective ecg-gated multislice ct coronary angiography: A systematic review of radiation dose and diagnostic accuracy. Eur J Radiol. 2012;81:e94-100

9. Bae KT. Optimization of contrast enhancement in thoracic mdct. Radiol Clin North Am. 2010;48:9-29

10. Budoff MJ, Dowe D, Jollis JG, Gitter M, Sutherland J, Halamert E, Scherer M, Bellinger R, Martin A, Benton R, Delago A, Min JK. Diagnostic performance of 64-multidetector row coronary computed tomographic angiography for evaluation of coronary artery stenosis in individuals without known coronary artery disease: Results from the prospective multicenter accuracy (assessment by coronary computed tomographic angiography of individuals undergoing invasive coronary angiography) trial. J Am Coll Cardiol. 2008;52:1724-1732

11. Kumamaru KK, Steigner ML, Soga S, Signorelli J, Bedayat A, Adams K, Mitsouras D, Rybicki FJ. Coronary enhancement for prospective ecg-gated single r-r axial 320-mdct angiography: Comparison of 60- and 80ml iopamidol 370 injection. AJR Am J Roentgenol. 2011;197:844-850

12. Johnson PT, Pannu HK, Fishman EK. IV contrast infusion for coronary artery ct angiography: Literature review and results of a nationwide survey. AJR Am J Roentgenol. 2009;192:W214-221

13. Meijboom WB, Meijs MF, Schuijf JD, Cramer MJ, Mollet NR, van Mieghem CA, Nieman K, van Werkhoven JM, Pundziute G, Weustink AC, de Vos AM, Pugliese F, Rensing B, Jukema JW, Bax JJ, Prokop M, Doevendans PA, Hunink MG, Krestin GP, de Feyter PJ. Diagnostic accuracy of 64-slice computed tomography coronary angiography: A prospective, multicenter, multivendor study. J Am Coll Cardiol. 2008;52:2135-2144

14. Awai K, Hiraishi K, Hori S. Effect of contrast material injection duration and rate on aortic peak time and peak enhancement at dynamic ct involving injection protocol with dose tailored to patient weight. Radiology. 2004;230:142-150

15. Becker CR, Vanzulli A, Fink C, de Faveri D, Fedeli S, Dore R, Biondetti P, Kuettner A, Krix M, Ascenti G. Multicenter comparison of high concentration contrast agent iomeprol-400 with iso-osmolar iodixanol320: Contrast enhancement and heart rate variation in coronary dual-source computed tomographic angiography. Invest Radiol. 2011;46:457-464 
16. Schoellnast H, Deutschmann HA, Berghold A, Fritz GA, Schaffler GJ, Tillich M. Mdct angiography of the pulmonary arteries: Influence of body weight, body mass index, and scan length on arterial enhancement at different iodine flow rates. AJR Am J Roentgenol. 2006;187:1074-1078

17. Bae KT, Heiken JP. Scan and contrast administration principles of mdct. Eur Radiol. 2005;15 Suppl 5:E4659

18. Behrendt FF, Plumhans C, Keil S, Muhlenbruch G, Das M, Seidensticker P, Mutscher C, Gunther RW, Mahnken $\mathrm{AH}$. Contrast enhancement in chest multidetector computed tomography: Intraindividual comparison of $300 \mathrm{mg} / \mathrm{ml}$ versus $400 \mathrm{mg} / \mathrm{ml}$ iodinated contrast medium. Acad Radiol. 2009;16:144-149

19. Rist C, Nikolaou K, Kirchin MA, van Gessel R, Bae KT, von Ziegler F, Knez A, Wintersperger BJ, Reiser MF, Becker CR. Contrast bolus optimization for cardiac 16-slice computed tomography: Comparison of contrast medium formulations containing 300 and 400 milligrams of iodine per milliliter. Invest Radiol. 2006; $41: 460-467$

20. Muhlenbruch G, Behrendt FF, Eddahabi MA, Knackstedt C, Stanzel S, Das M, Seidensticker P, Gunther RW, Wildberger JE, Mahnken AH. Which iodine concentration in chest ct? - A prospective study in 300 patients. Eur Radiol. 2008;18:2826-2832

21. Cademartiri F, Luccichenti G, Gualerzi M, Brambilla L, Brambilla V, Coruzzi P. Intravenous contrast material administration in multislice computed tomography coronary angiography. Acta Biomed. 2005;76:86-94

22. Tsai IC, Lee T, Tsai WL, Chen MC, Wu MJ, Lee WL, Ting HJ. Contrast enhancement in cardiac mdct: Comparison of iodixanol 320 versus iohexol 350. AJR Am J Roentgenol. 2008;190:W47-53

23. Halpern EJ, Levin DC, Zhang S, Takakuwa KM. Comparison of image quality and arterial enhancement with a dedicated coronary cta protocol versus a triple rule-out coronary cta protocol. Acad Radiol. 2009;16:1039-1048

24. Kim EY, Yeh DW, Choe YH, Lee WJ, Lim HK. Image quality and attenuation values of multidetector ct coronary angiography using high iodine-concentration contrast material: A comparison of the use of iopromide 370 and iomeprol 400. Acta Radiol. 2010;51:982-989

25. Ozbulbul NI, Yurdakul M, Tola M. Comparison of a low-osmolar contrast medium, iopamidol, and an isoosmolar contrast medium, iodixanol, in mdct coronary angiography. Coron Artery Dis. 2010;21:414-419

26. Nakaura T, Awai K, Yanaga Y, Namimoto T, Utsunomiya D, Hirai T, Sugiyama S, Ogawa H, Aoyama M, Yamashita Y. Low-dose contrast protocol using the test bolus technique for 64-detector computed tomography coronary angiography. Jpn J Radiol. 2011;29:457-465

27. Zheng M, Liu Y, Wei M, Wu Y, Zhao H, Li J. Low concentration contrast medium for dual-source computed tomography coronary angiography by a combination of iterative reconstruction and low-tube-voltage technique: Feasibility study. Eur J Radiol. 2014;83:e92-99

28. Cademartiri F, Mollet NR, van der Lugt A, McFadden EP, Stijnen T, de Feyter PJ, Krestin GP. Intravenous contrast material administration at helical 16-detector row ct coronary angiography: Effect of iodine concentration on vascular attenuation. Radiology. 2005;236:661-665

29. Cademartiri F, Mollet N, van der Lugt A, Nieman K, Pattynama PM, de Feyter PJ, Krestin GP. Non-invasive 16-row multislice ct coronary angiography: Usefulness of saline chaser. Eur Radiol. 2004;14:178-183

30. Utsunomiya D, Awai K, Sakamoto T, Nishiharu T, Urata J, Taniguchi A, Nakaura T, Yamashita Y. Cardiac 16mdct for anatomic and functional analysis: Assessment of a biphasic contrast injection protocol. AJR Am J Roentgenol. 2006;187:638-644

31. Cademartiri F, de Monye C, Pugliese F, Mollet NR, Runza G, van der Lugt A, Midiri M, de Feyter PJ, Lagalla R, Krestin GP. High iodine concentration contrast material for noninvasive multislice computed tomography coronary angiography: Iopromide 370 versus iomeprol 400. Invest Radiol. 2006;41:349-353

32. Yamamuro M, Tadamura E, Kanao S, Wu YW, Tambara K, Komeda M, Toma M, Kimura T, Kita T, Togashi K. Coronary angiography by 64-detector row computed tomography using low dose of contrast material with saline chaser: Influence of total injection volume on vessel attenuation. J Comput Assist Tomogr. 2007; 31:272-280

33. Kerl JM, Ravenel JG, Nguyen SA, Suranyi P, Thilo C, Costello P, Bautz W, Schoepf UJ. Right heart: Splitbolus injection of diluted contrast medium for visualization at coronary ct angiography. Radiology. 2008;247:356-364

34. Kim DJ, Kim TH, Kim SJ, Kim DP, Oh CS, Ryu YH, Kim YJ, Choi BW. Saline flush effect for enhancement of aorta and coronary arteries at multidetector ct coronary angiography. Radiology. 2008;246:110-115

35. Nakaura T, Awai K, Yauaga Y, Nakayama Y, Oda S, Hatemura M, Nagayoshi Y, Ogawa H, Yamashita Y. Contrast injection protocols for coronary computed tomography angiography using a 64-detector 
scanner: Comparison between patient weight-adjusted- and fixed iodine-dose protocols. Invest Radiol. 2008;43:512-519

36. Pazhenkottil AP, Husmann L, Buechel RR, Herzog BA, Nkoulou R, Burger IA, Vetterli A, Valenta I, Ghadri JR, von Schulthess $P$, Kaufmann PA. Validation of a new contrast material protocol adapted to body surface area for optimized low-dose ct coronary angiography with prospective ecg-triggering. Int J Cardiovasc Imaging. 2010;26:591-597

37. Wuest W, Zunker C, Anders K, Ropers D, Achenbach S, Bautz W, Kuettner A. Functional cardiac ct imaging: A new contrast application strategy for a better visualization of the cardiac chambers. Eur J Radiol. 2008;68:392-397

38. Tatsugami F, Kanamoto T, Nakai G, Takeda Y, Morita H, Morinaga I, Yoshikawa S, Narabayashi I. Reduction of the total injection volume of contrast material with a short injection duration in 64-detector row ct coronary angiography. Br J Radiol. 2010;83:35-39

39. Kidoh M, Nakaura T, Nakamura S, Awai K, Utsunomiya D, Namimoto T, Harada K, Yamashita Y. Novel contrast-injection protocol for coronary computed tomographic angiography: Contrast-injection protocol customized according to the patient's time-attenuation response. Heart Vessels. 2013

40. Tatsugami F, Matsuki M, Inada Y, Kanazawa S, Nakai G, Takeda Y, Morita H, Takada H, Ashida K, Yoshikawa S, Fukumura K, Narumi Y. Feasibility of low-volume injections of contrast material with a body weightadapted iodine-dose protocol in 320-detector row coronary ct angiography. Acad Radiol. 2010;17:207-211

41. Isogai T, Jinzaki M, Tanami Y, Kusuzaki H, Yamada M, Kuribayashi S. Body weight-tailored contrast material injection protocol for 64-detector row computed tomography coronary angiography. Jpn J Radiol. 2011;29:33-38

42. Behrendt FF, Bruners P, Keil S, Plumhans C, Mahnken AH, Stanzel S, Das M, Gunther RW, Muhlenbruch G. Impact of different vein catheter sizes for mechanical power injection in ct: In vitro evaluation with use of a circulation phantom. Cardiovasc Intervent Radiol. 2009;32:25-31

43. Knollmann F, Schimpf K, Felix R. lodine delivery rate of different concentrations of iodine-containing contrast agents with rapid injection. RoFo. 2004;176:880-884

44. Brunette J, Mongrain R, Laurier J, Galaz R, Tardif JC. 3d flow study in a mildly stenotic coronary artery phantom using a whole volume piv method. Med Eng Phys. 2008;30:1193-1200

45. Halsell RD. Heating contrast media: Role in contemporary angiography. Radiology. 1987;164:276-278

46. Halsell RD. Heating contrast media in a microwave oven. Radiology. 1987;163:279-280

47. Schwab SA, Kuefner MA, Anders K, Adamietz B, Heinrich MC, Baigger JF, Janka R, Uder M, Kramer M. Peripheral intravenous power injection of iodinated contrast media: The impact of temperature on maximum injection pressures at different cannula sizes. Acad Radiol. 2009;16:1502-1508

48. Schwab SA, Uder M, Anders K, Heinrich MC, Kuefner MA. Peripheral intravenous power injection of iodinated contrast media through $22 \mathrm{~g}$ and $20 \mathrm{~g}$ cannulas: Can high flow rates be achieved safely? A clinical feasibility study. Rofo. 2009;181:355-361

49. Wienbeck S, Fischbach R, Kloska SP, Seidensticker P, Osada N, Heindel W, Juergens KU. Prospective study of access site complications of automated contrast injection with peripheral venous access in mdct. AJR Am J Roentgenol. 2010;195:825-829

50. Bae KT, Tran HQ, Heiken JP. Uniform vascular contrast enhancement and reduced contrast medium volume achieved by using exponentially decelerated contrast material injection method. Radiology. 2004;231:732-736

51. Christensen JD, Meyer LT, Hurwitz LM, Boll DT. Effects of iopamidol-370 versus iodixanol-320 on coronary contrast, branch depiction, and heart rate variability in dual-source coronary mdct angiography. AJR Am J Roentgenol. 2011;197:W445-451

52. Liu J, Gao J, Wu R, Zhang Y, Hu L, Hou P. Optimizing contrast medium injection protocol individually with body weight for high-pitch prospective ecg-triggering coronary ct angiography. Int J Cardiovasc Imaging. 2013;29:1115-1120

53. Sistrom CL, Gay SB, Peffley L. Extravasation of iopamidol and iohexol during contrast-enhanced ct: Report of 28 cases. Radiology. 1991;180:707-710

54. Seifarth H, Puesken M, Kalafut JF, Wienbeck S, Wessling J, Maintz D, Heindel W, Juergens KU. Introduction of an individually optimized protocol for the injection of contrast medium for coronary ct angiography. Eur Radiol. 2009;19:2373-2382

55. Bae KT, Seeck BA, Hildebolt CF, Tao C, Zhu F, Kanematsu M, Woodard PK. Contrast enhancement in cardiovascular mdct: Effect of body weight, height, body surface area, body mass index, and obesity. AJR Am J Roentgenol. 2008;190:777-784 
56. Platt JF, Reige KA, Ellis JH. Aortic enhancement during abdominal ct angiography: Correlation with test injections, flow rates, and patient demographics. AJR Am J Roentgenol. 1999;172:53-56

57. Husmann L, Leschka S, Boehm T, Desbiolles L, Schepis T, Koepfli P, Gaemperli O, Marincek B, Kaufmann P, Alkadhi $\mathrm{H}$. Influence of body mass index on coronary artery opacification in 64-slice ct angiography. RoFo. 2006;178:1007-1013

58. Zhu $X$, Zhu $Y, X u H$, Tang $L, X u Y$. The influence of body mass index and gender on coronary arterial attenuation with fixed iodine load per body weight at dual-source ct coronary angiography. Acta Radiol. 2012;53:637-642

59. Mitchell AM, Jones AE, Tumlin JA, Kline JA. Incidence of contrast-induced nephropathy after contrastenhanced computed tomography in the outpatient setting. Clin J Am Soc Nephrol. 2010;5:4-9

60. Weininger M, Barraza JM, Kemper CA, Kalafut JF, Costello P, Schoepf UJ. Cardiothoracic ct angiography: Current contrast medium delivery strategies. AJR Am J Roentgenol. 2011;196:W260-272

61. Schindera ST, Nelson RC, Yoshizumi T, Toncheva G, Nguyen G, DeLong DM, Szucs-Farkas Z. Effect of automatic tube current modulation on radiation dose and image quality for low tube voltage multidetector row ct angiography: Phantom study. Acad Radiol. 2009;16:997-1002

62. Vlahos I, Chung R, Nair A, Morgan R. Dual-energy ct: Vascular applications. AJR Am J Roentgenol. 2012;199:S87-97

63. Strocchi S, Vite C, Callegari L, Conte L. Optimisation of multislice computed tomography protocols in angio-ct examinations. Radiol Med. 2006;111:238-244

64. Cao JX, Wang YM, Lu JG, Zhang Y, Wang P, Yang C. Radiation and contrast agent doses reductions by using 80-kv tube voltage in coronary computed tomographic angiography: A comparative study. Eur J Radiol. 2014;83:309-314

65. Qi L, Meinel FG, Zhou CS, Zhao YE, Schoepf UJ, Zhang LJ, Lu GM. Image quality and radiation dose of lower extremity ct angiography using $70 \mathrm{kvp}$, high pitch acquisition and sinogram-affirmed iterative reconstruction. PloS one. 2014;9:e99112

66. Prakash P, Kalra MK, Digumarthy SR, Hsieh J, Pien H, Singh S, Gilman MD, Shepard JA. Radiation dose reduction with chest computed tomography using adaptive statistical iterative reconstruction technique: Initial experience. J Comput Assist Tomogr. 2010;34:40-45

67. Gervaise A, Osemont B, Lecocq S, Noel A, Micard E, Felblinger J, Blum A. Ct image quality improvement using adaptive iterative dose reduction with wide-volume acquisition on 320-detector ct. Eur Radiol. 2012;22:295-301

68. Funama Y, Taguchi K, Utsunomiya D, Oda S, Yanaga Y, Yamashita Y, Awai K. Combination of a low-tubevoltage technique with hybrid iterative reconstruction (idose) algorithm at coronary computed tomographic angiography. J Comput Assist Tomogr. 2011;35:480-485

69. Willemink MJ, Takx RA, de Jong PA, Budde RP, Bleys RL, Das M, Wildberger JE, Prokop M, Buls N, de Mey J, Leiner T, Schilham AM. Computed tomography radiation dose reduction: Effect of different iterative reconstruction algorithms on image quality. J Comput Assist Tomogr. 2014;38:815-823 

CHAPTER 9

Supplemental Material

Summary

Valorisation

Dankwoord

Curriculum Vitae

List of publications 


\section{Chapter 9}

\section{CHAPTER 2}

Table 1: Results of the included studies, indicating attenuation values and significance of the evidence. Listed according to year of publication. CA: coronary artery, LM: left main artery, LAD: left anterior descending artery, RCA: right coronary artery, Cx: circumflex artery, seg: segment, CM: contrast media, IDR: iodine delivery rate, HU: Hounsfield unit, BMI: body mass index.

\begin{tabular}{|c|c|c|c|c|c|}
\hline Author & $\begin{array}{c}\mathrm{CM} \\
(\mathrm{mg} / \mathrm{ml})\end{array}$ & $\begin{array}{c}\text { Flow rate } \\
(\mathrm{ml} / \mathrm{s})\end{array}$ & $\operatorname{IDR}(\mathrm{g} / / \mathrm{s})$ & Attenuation (HU; group 1 vs. group 2 vs. group 3....) & Significance ( $P$ value) \\
\hline \multirow[t]{4}{*}{ Cademartiri $^{43}$} & 320 & 4 & 1.28 & LM: $324 \pm 45$ vs. $319 \pm 46$ & $>0.05$ \\
\hline & 320 & 4 & 1.28 & LAD: $318 \pm 46$ vs. $312 \pm 42$ & $>0.05$ \\
\hline & & & & Cx: $313 \pm 41$ vs. $304 \pm 37$ & $>0.05$ \\
\hline & & & & RCA: $321 \pm 42$ vs. $319 \pm 46$ & $>0.05$ \\
\hline \multirow[t]{5}{*}{ Cademartiri $^{15}$} & 300 & 4 & 1.2 & Mean attenuation CA: & Group 1 vs. group $2-5<0.05$ \\
\hline & 320 & 4 & 1.28 & $273 \pm 45$ vs. $333 \pm 51$ vs. $320 \pm 55$ vs. $322 \pm 43$ vs. $397 \pm 72$ & Group 5 vs. group $1-4<0.05$ \\
\hline & 350 & 4 & 1.4 & & \\
\hline & 350 & 4 & 1.4 & & \\
\hline & 400 & 4 & 1.6 & & \\
\hline \multirow[t]{4}{*}{ Cademartiri $^{44}$} & 320 & 4 & 1.28 & LM: $321 \pm 51$ vs. $314 \pm 54$ v.s $321 \pm 55$ & $>0.05$ \\
\hline & 320 & $5 \rightarrow 3$ & $1.6 \rightarrow 0.96$ & LAD: $316 \pm 52$ vs. $310 \pm 53$ vs. $314 \pm 54$ & $>0.05$ \\
\hline & 320 & 4 & 1.28 & Cx: $309 \pm 52$ vs. $299 \pm 49$ vs. $307 \pm 53$ & $>0.05$ \\
\hline & & & & RCA: $298 \pm 50$ vs. $290 \pm 46$ vs. $304 \pm 55$ & $>0.05$ \\
\hline \multirow[t]{5}{*}{ Cademartiri $^{16}$} & 370 & 4 & 1.48 & LM $322 \pm 45$ vs. $350 \pm 52$ & No value \\
\hline & 400 & 4 & 1.6 & LAD: $295 \pm 57$ vs. $321 \pm 65$ & No value \\
\hline & & & & Cx: $287 \pm 46$ vs. $331 \pm 60$ & No value \\
\hline & & & & RCA: $315 \pm 58$ vs. $357 \pm 66$ & No value \\
\hline & & & & Mean attenuation CA: $313 \pm 42$ vs. $340 \pm 53$ & $<0.05$ \\
\hline \multirow[t]{2}{*}{ Rist $^{19}$} & 300 & 3.3 & 0.99 & Mean attenuation CA: $259.1 \pm 46.7$ vs. $251.6 \pm 51.0$ & No value \\
\hline & 400 & 2,5 & 1.0 & & \\
\hline \multirow[t]{7}{*}{ Utsunomiya $^{45}$} & 350 & $3 \rightarrow 1.5$ & $1.05 \rightarrow 0.26$ & LM: $311.1 \pm 27.6$ vs. $303.4 \pm 27.8$ vs. $299.3 \pm 37.8$ & 0.63 \\
\hline & 350 & 3 & 1.05 & ProxLAD: $296.9 \pm 34.7$ vs. $286.2 \pm 35.9$ vs. $275.8 \pm 18.1$ & 0.22 \\
\hline & 350 & 3 & 1.05 & MidLAD: $259.5 \pm 33.1$ vs. $249.8 \pm 31.2$ vs. $236.8 \pm 17.3$ & 0.28 \\
\hline & & & & ProxCx: $277.2 \pm 23.0$ vs. $262.1 \pm 30.4$ vs. $269.9 \pm 16.9$ & 0.30 \\
\hline & & & & MidCx: $235.6 \pm 25.9$ vs. $222.6 \pm 25.9$ vs. $227.8 \pm 13.6$ & 0.28 \\
\hline & & & & ProxRCA: $291.1 \pm 25.1$ vs. $270.6 \pm 21.5$ vs. $286.2 \pm 45.1$ & 0.28 \\
\hline & & & & MidRCA: $247.8 \pm 19.7$ vs. $230.1 \pm 17.4$ vs. $245.2 \pm 37.2$ & 0.22 \\
\hline \multirow[t]{7}{*}{ Yamamuro $^{46}$} & 350 & $3.5 \rightarrow 2.8$ & $1.23 \rightarrow 0.98$ & LM: $322.9 \pm 60.9$ vs. $356.3 \pm 58.5$ & $<0.05$ \\
\hline & 350 & $3.5 \rightarrow 2.8$ & $1.23 \rightarrow 0.98$ & ProxLAD: $322.9 \pm 60.9$ vs. $350.7 \pm 57.7$ & $<0.05$ \\
\hline & & & & DistLAD: $295.8 \pm 61.3$ vs. $342.8 \pm 56.1$ & $<0.01$ \\
\hline & & & & ProxCx: $306.9 \pm 67.9$ vs. $347.6 \pm 60.8$ & $<0.05$ \\
\hline & & & & DistCx: $287.9 \pm 62.7$ vs. $325.8 \pm 62.4$ & $<0.05$ \\
\hline & & & & ProxRCA: $302.9 \pm 59.3$ vs. $355.1 \pm 64.7$ & $<0.01$ \\
\hline & & & & DistRCA: $284.0 \pm 62.6$ vs. $338.9 \pm 85.8$ & $<0.01$ \\
\hline
\end{tabular}




\begin{tabular}{|c|c|c|c|c|c|}
\hline Author & $\begin{array}{c}\mathrm{CM} \\
(\mathrm{mg} / \mathrm{ml})\end{array}$ & $\begin{array}{c}\text { Flow rate } \\
(\mathrm{ml} / \mathrm{s})\end{array}$ & $\operatorname{IDR}(\mathrm{g} / / \mathrm{s})$ & Attenuation (HU; group 1 vs. group 2 vs. group 3....) & Significance ( $P$ value) \\
\hline \multirow[t]{3}{*}{ Husmann $^{47}$} & 320 & 5 & 1.6 & Mean attenuation CA: $386 \pm 102$ vs. $385 \pm 64$ & $>0.05$ \\
\hline & 320 & $4.0-5.0$ & $1.28-1.6$ & LM: $393 \pm 109$ vs. $397 \pm 78$ & No value \\
\hline & & & & RCA: $378 \pm 99$ vs. $373 \pm 62$ & No value \\
\hline \multirow[t]{6}{*}{$\operatorname{Kerl}^{48}$} & 370 & 5 & 1.85 & ProxLAD: $378 \pm 29$ vs. $360 \pm 31$ vs. $352 \pm 36$ & 0.843 \\
\hline & 370 & 5 & 1.85 & DistLAD: $214 \pm 16$ vs. $215 \pm 15$ vs. $250 \pm 30$ & 0.407 \\
\hline & 370 & 5 & $1.85 \rightarrow 0.56$ & ProxCx: $363 \pm 30$ vs. $339 \pm 21$ vs. $322 \pm 23$ & 0.504 \\
\hline & & & & DistCx: $245 \pm 19$ vs. $249 \pm 18$ vs. $244 \pm 25$ & 0.979 \\
\hline & & & & ProxRCA: $322 \pm 18$ vs. $336 \pm 21$ vs. $368 \pm 32$ & 0.391 \\
\hline & & & & DistRCA: $291 \pm 26$ vs. $270 \pm 27$ vs. $305 \pm 16$ & 0.575 \\
\hline \multirow[t]{5}{*}{$\mathrm{Kim}^{49}$} & 350 & 4 & 1.4 & LAD: $316 \pm 49$ vs. $363 \pm 44$ vs. $364 \pm 49$ vs. $355 \pm 53$ vs. $360 \pm 66$ & Group 1 vs. group $2-5<0.05$ \\
\hline & 350 & 4 & 1.4 & Cx: $300 \pm 49$ vs. $345 \pm 63$ vs. $346 \pm 52$ vs. $336 \pm 42$ vs. $349 \pm 58$ & Group 1 vs. group $2-5<0.05$ \\
\hline & 350 & 4 & 1.4 & RCA: $310 \pm 54$ vs. $373 \pm 58$ vs. $382 \pm 51$ vs. $387 \pm 66$ vs. $374 \pm 75$ & Group 1 vs. group $2-5<0.05$ \\
\hline & 350 & 4 & 1.4 & & \\
\hline & 350 & 4 & 1.4 & & \\
\hline \multirow[t]{3}{*}{ Nakaura $^{50}$} & 370 & 4 & 1.48 & ProxRCA: $398 \pm 94$ vs. $374 \pm 53$ & 0.22 \\
\hline & 370 & $3.96 \pm 0.85$ & 1.47 & MidRCA: $387 \pm 85$ vs. $358 \pm 83$ & 0.19 \\
\hline & & & & DistRCA: $370 \pm 97$ vs. $337 \pm 73$ & 0.14 \\
\hline \multirow[t]{5}{*}{ Tsai $^{51}$} & 350 & 4 & 1.4 & Mean attenuation CA: $370.3 \pm 46.6$ vs. $361.8 \pm 46.7$ & $>0.05$ \\
\hline & 320 & 4 & 1.28 & LM: $375.8 \pm 51.0$ vs. $369.8 \pm 61.0$ & $>0.05$ \\
\hline & & & & LAD: $371.4 \pm 54.5$ vs. $360.8 \pm 52.5$ & $>0.05$ \\
\hline & & & & Cx: $347.3 \pm 53.8$ vs. $343.2 \pm 49.5$ & $>0.05$ \\
\hline & & & & RCA: $386.6 \pm 59.9$ vs. $373.6 \pm 51.7$ & $>0.05$ \\
\hline \multirow[t]{5}{*}{ Wuest $^{52}$} & 350 & 5 & 1.75 & ProxLAD: $361 \pm 70$ vs. $398 \pm 62$ & $<0.001$ \\
\hline & 350 & 5 & $1.75 \rightarrow 0.35$ & MidLAD: $340 \pm 70$ vs. $382 \pm 57$ & $<0.001$ \\
\hline & & & & DistLAD: $314 \pm 79$ vs. $351 \pm 68$ & $<0.001$ \\
\hline & & & & ProxRCA: $362 \pm 63$ vs. $410 \pm 62$ & $<0.001$ \\
\hline & & & & DistRCA: $369 \pm 88$ vs. $417 \pm 80$ & $<0.001$ \\
\hline \multirow[t]{2}{*}{ Halpern ${ }^{53}$} & 350 & 5.5 & 1.93 & LM: $308 \pm 74$ vs. $313 \pm 78$ & 0.59 \\
\hline & 350 & 5 & $1.75 \rightarrow 0.88$ & RCA: $315 \pm 77$ vs. $316 \pm 85$ & 0.93 \\
\hline \multirow[t]{4}{*}{ Seifarth $^{54}$} & 370 & 6 & $2.22 \rightarrow 0.67$ & ProxLAD: $398.4 \pm 61.1$ vs. $398.9 \pm 49.8$ vs. $356.3 \pm 71.2$ & Group 3 vs. group $1-2<0.05$ \\
\hline & 370 & $5.1 \pm 0.6$ & $1.89 \rightarrow 0.57$ & MidLAD: $352.9 \pm 56.4$ vs. $364.6 \pm 45.8$ vs. $323.0 \pm 68.8$ & Group 3 vs. group $1-2<0.05$ \\
\hline & 370 & 5 & $1.85 \rightarrow 0.56$ & ProxRCA: $416.7 \pm 69.4$ vs. $414.9 \pm 51.1$ vs. $366.0 \pm 66.0$ & Group 3 vs. group $1-2<0.05$ \\
\hline & & & & DistRCA: $366.0 \pm 65.1$ vs. $396.1 \pm 53.3$ vs. $341.6 \pm 74.3$ & Group 2 vs. group $1-3<0.05$ \\
\hline \multirow[t]{5}{*}{$\mathrm{Kim}^{55}$} & 370 & 4 & 1.48 & Mean attenuation CA: 454 (213-780) vs. 464 (208-809) & 0.264 \\
\hline & 400 & 4 & 1.6 & LM: 454 (271-746) vs. 455 (241-677) & 0.476 \\
\hline & & & & LAD: 459 (213-778) vs. 472 (236-757) & 0.103 \\
\hline & & & & Cx: 449 (280-716) vs. 457 (252-745) & 0.519 \\
\hline & & & & RCA: 457 (219-780) vs. 472 (208-809) & 0.253 \\
\hline \multirow[t]{4}{*}{$\mathrm{Lu}^{56}$} & 350 & 5 & 1.75 & LM: $379.8 \pm 70.3$ vs. $428.3 \pm 56.8$ vs. $375.7 \pm 64.2$ vs. & $<0.01$ \\
\hline & 350 & 5 & 1.75 & $365.5 \pm 71.6$ vs. $376.2 \pm 76.9$ & \\
\hline & 350 & 5 & $1.75 \rightarrow 0.53$ & RCA: $366.7 \pm 86.7$ vs. $409.6 \pm 62.9$ vs. $373.3 \pm 48.3$ vs. & $<0.05$ \\
\hline & 350 & 5 & $1.75 \rightarrow 0.88$ & $356.9 \pm 70.3$ vs. $364.8 \pm 83.1$ & \\
\hline
\end{tabular}


Chapter 9

\begin{tabular}{|c|c|c|c|c|c|}
\hline Author & $\begin{array}{c}\mathrm{CM} \\
(\mathrm{mg} / \mathrm{ml})\end{array}$ & $\begin{array}{c}\text { Flow rate } \\
(\mathrm{ml} / \mathrm{s})\end{array}$ & $\operatorname{IDR}(\mathrm{gl} / \mathrm{s})$ & Attenuation (HU; group 1 vs. group 2 vs. group 3....) & Significance ( $P$ value) \\
\hline & 350 & 5 & $1.75 \rightarrow 1.23$ & & \\
\hline \multirow[t]{2}{*}{ Ozbulbul ${ }^{57}$} & 320 & 4 & 1.28 & LM: $309 \pm 58$ vs. $319 \pm 59$ & $\geq 0.41$ \\
\hline & 370 & 4 & 1.48 & RCA: $299 \pm 51$ vs. $314 \pm 54$ & $\geq 0.41$ \\
\hline \multirow[t]{4}{*}{ Pazhenkotti $^{58}$} & 8320 & 5 & 1.6 & Mean attenuation CA: $418 \pm 104$ (264-700) vs. & No value \\
\hline & 320 & $3.5-5.0$ & $1.1-1.6$ & $370 \pm 49(268-500)$ & \\
\hline & & & & LM: $424 \pm 110$ (range $280-712$ ) vs. $378 \pm 56$ (range $262-490$ ) & No value \\
\hline & & & & RCA: $413 \pm 103$ (248-688) vs. $363 \pm 49(260-510)$ & No value \\
\hline \multirow[t]{4}{*}{ Tatsugami $^{59}$} & 350 & $4 \pm 0.56$ & 1.4 & LM: $410.6 \pm 47.9$ vs. $416.8 \pm 52.6$ & 0.52 \\
\hline & 350 & $4.06 \pm 0.57$ & $1.42 \pm 0.2$ & 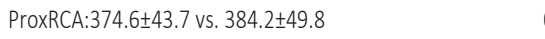 & 0.38 \\
\hline & & & & MidRCA: $361.6 \pm 47.0$ vs. $364.4 \pm 48.8$ & 0.98 \\
\hline & & & & DistRCA: $357.8 \pm 51.6$ vs. $361.2 \pm 46.1$ & 0.79 \\
\hline \multirow[t]{7}{*}{ Tatsugami $^{60}$} & 350 & $3.3 \pm 0.37$ & 1.16 & LM: $332.4 \pm 63.3$ vs. $380.5 \pm 45.3$ vs. $362.8 \pm 46.8$ & Group 1 vs. group $2<0.05$; other $>0.05$ \\
\hline & 350 & $4.4 \pm 0.48$ & 1.54 & ProxLAD: $310.6 \pm 48.4$ vs. $362.0 \pm 36.8$ vs. $332.1 \pm 34.8$ & Group 1 vs. group $2<0.01$; other $>0.05$ \\
\hline & 350 & $4.0 \pm 0.55$ & 1.40 & DistLAD: $286.3 \pm 33.4$ vs. $314.8 \pm 27.6$ vs. $295.9 \pm 41.9$ & Group 1 vs. group $2<0.05$; other $>0.05$ \\
\hline & & & & ProxCx: $304.5 \pm 45.5$ vs. $345.8 \pm 42.8$ vs. $339.2 \pm 53.4$ & Group 1 vs. group $2<0.05$; other $>0.05$ \\
\hline & & & & DistCx: $274.8 \pm 34.8$ vs. $324.7 \pm 48.4$ vs. $306.2 \pm 42.8$ & Group 1 vs. group $2<0.01$; other $>0.05$ \\
\hline & & & & ProxRCA: $332.5 \pm 47.8$ vs. $369.2 \pm 57.6$ v.s $338.1 \pm 44.4$ & Group 1 vs. group $2<0.05$; other $>0.05$ \\
\hline & & & & DistRCA: $310.3 \pm 36.6$ vs. $342.9 \pm 40.5$ vs. $294.5 \pm 36.7$ & $\begin{array}{l}\text { Group } 1 \text { vs. group } 2<0.05 \text {; group } 2 \text { vs. } \\
\text { group } 3<0.01 \text {; other }>0.05\end{array}$ \\
\hline \multirow[t]{4}{*}{ Becker $^{61}$} & 320 & 5 & 1.6 & Mean attenuation $L M+R C A$ & \\
\hline & 400 & 5 & 2 & Reader 1: $362.1 \pm 80.0$ vs. $440.0 \pm 87.2$ & 0.0001 \\
\hline & & & & Reader $2: 365.5 \pm 76.6$ vs. $441.4 \pm 99.9$ & 0.0031 \\
\hline & & & & Reader 3: $354.6 \pm 81.7$ vs. $433.1 \pm 92.8$ & 0.0038 \\
\hline \multirow[t]{10}{*}{ Isogai } & 300 & 4.5 & 1.35 & Reader 1 & \\
\hline & 350 & 3.9 & 1.37 & ProxLAD: $337 \pm 48$ vs. $334 \pm 37$ vs. $412 \pm 59$ & Group 3 vs. group $1-2<0.05$; other $>0.05$ \\
\hline & 350 & 4.6 & 1.61 & ProxCx: $335 \pm 50$ vs. $331 \pm 36$ vs. $408 \pm 59$ & Group 3 vs. group $1-2<0.05$; other $>0.05$ \\
\hline & & & & ProxRCA: $336 \pm 49$ vs. $340 \pm 39$ vs. $409 \pm 58$ & Group 3 vs. group $1-2<0.05$; other $>0.05$ \\
\hline & & & & DistRCA: $332 \pm 53$ vs. $337 \pm 41$ vs. $407 \pm 60$ & Group 3 vs. group $1-2<0.05$; other $>0.05$ \\
\hline & & & & Reader 2 & \\
\hline & & & & ProxLAD: $329 \pm 48$ vs. $339 \pm 42$ vs. $411 \pm 60$ & Group 3 vs. group $1-2<0.05$; other $>0.05$ \\
\hline & & & & ProxCx: $327 \pm 52$ vs. $330 \pm 42$ vs. $396 \pm 59$ & Group 3 vs. group $1-2<0.05$; other $>0.05$ \\
\hline & & & & ProxRCA: $337 \pm 52$ vs. $349 \pm 37$ vs. $415 \pm 59$ & Group 3 vs. group $1-2<0.05$; other $>0.05$ \\
\hline & & & & DistRCA: $314 \pm 46$ vs. $330 \pm 45$ vs. $393 \pm 62$ & Group 3 vs. group $1-2<0.05$; other $>0.05$ \\
\hline \multirow[t]{7}{*}{ Kumamaru $^{62}$} & 370 & 6 & 2.22 & LM: 460.1 vs. 584.4 & $<0.05$ \\
\hline & 370 & 6 & 2.22 & ProxLAD: 417.2 vs. 543.1 & $<0.05$ \\
\hline & & & & DistLAD: 358.9 vs. 487.1 & $<0.05$ \\
\hline & & & & ProxCx: 433.3 vs. 537.3 & $<0.05$ \\
\hline & & & & DistCx: 372.2 vs. 468.9 & $<0.05$ \\
\hline & & & & ProxRCA: 409.3 vs. 536.6 & $<0.05$ \\
\hline & & & & DistRCA: 386.2 vs. 488.3 & $<0.05$ \\
\hline \multirow[t]{2}{*}{ Nakaura $^{63}$} & 350 & $3.8 \pm 0.7$ & $1.33 \pm 0.23$ & LM: $391.5 \pm 60.9$ vs. $374.1 \pm 55.6$ & 0.29 \\
\hline & 350 & $4.4 \pm 0.7$ & $1.55 \pm 0.25$ & ProxRCA: $376.7 \pm 67.7$ vs. $370.8 \pm 56.8$ & 0.92 \\
\hline
\end{tabular}




\begin{tabular}{|c|c|c|c|c|c|}
\hline Author & $\begin{array}{c}\mathrm{CM} \\
(\mathrm{mg} / \mathrm{ml})\end{array}$ & $\begin{array}{c}\text { Flow rate } \\
\quad(\mathrm{ml} / \mathrm{s})\end{array}$ & $\operatorname{IDR}(\mathrm{gl} / \mathrm{s})$ & Attenuation (HU; group 1 vs. group 2 vs. group 3....) & Significance ( $P$ value) \\
\hline & & & & MidRCA: $363.7 \pm 90.0$ vs. $356.6 \pm 63.2$ & 0.81 \\
\hline & & & & DistRCA: $336.1 \pm 73.2$ vs. $338.1 \pm 60.3$ & 0.93 \\
\hline \multirow[t]{4}{*}{ Zhu $^{64}$} & 370 & $4.15(2.6-5.7)$ & 1.54 & LM: $385.4 \pm 64.7$ vs. $366.1 \pm 59.9$ vs. $366.5 \pm 62.1$ & 0.068 \\
\hline & 370 & $4.19(2.6-6)$ & 1.55 & LAD: $369.6 \pm 61.8$ vs. $351.0 \pm 56.5$ vs. $345.2 \pm 59.6$ & Group 1 vs. group $2-3<0.05$; other $>0.05$ \\
\hline & 370 & $4.08(2.7-5.9)$ & 1.51 & Cx: $373.8 \pm 64.3$ vs. $356.0 \pm 61.3$ vs. $350.5 \pm 62.3$ & Group 1 vs. group $2-3<0.05$; other $>0.05$ \\
\hline & & & & RCA: $372.3 \pm 58.0$ vs. $362.3 \pm 55.3$ vs. $360.2 \pm 60.8$ & 0.284 \\
\hline \multirow[t]{10}{*}{ Zhu $u^{65}$} & 370 & $4.69 \pm 0.95$ & 1.74 & $\mathrm{BMl}<24.0$ & Group 1: $\mathrm{BMI}<24.0$ vs. BMI $>24.0:<0.05$ \\
\hline & 370 & $4.38 \pm 0.66$ & 1.62 & LM: 391.2 vs. 392.4 & No value between CM groups \\
\hline & & & & LAD: 377.6 vs. 383.6 & No value between CM groups \\
\hline & & & & Cx: 381.6 vs. 382.0 & No value between CM groups \\
\hline & & & & RCA: 384.0 vs. 388.9 & No value between CM groups \\
\hline & & & & $\mathrm{BMI}>24.0$ & Group 2: $\mathrm{BMI}<24.0$ vs. $\mathrm{BMI}>24.0$ : $>0.05$ \\
\hline & & & & LM: 428.3 vs. 385.4 & No value between CM groups \\
\hline & & & & LAD: 414.1 vs. 368.7 & No value between CM groups \\
\hline & & & & Cx: 413.8 vs. 374.6 & No value between CM groups \\
\hline & & & & RCA: 434.6 vs. 380.3 & No value between CM groups \\
\hline \multirow[t]{10}{*}{ Zhu $^{66}$} & 370 & $4.69(2.3-7.4)$ & 1.74 & men & Group 1: men vs. women >0.05 \\
\hline & 370 & $4.37(2.5-6.6)$ & 1.62 & LM: $410.5 \pm 50.5$ vs. $416.9 \pm 52.2$ & No value between CM groups \\
\hline & & & & LAD: $403.0 \pm 55.3$ vs. $403.4 \pm 50.8$ & No value between CM groups \\
\hline & & & & Cx: $398.4 \pm 56.4$ vs. $412.9 \pm 46.1$ & No value between CM groups \\
\hline & & & & RCA: $413.3 \pm 63.8$ vs. $416.4 \pm 58.5$ & No value between CM groups \\
\hline & & & & women & Group 2: men vs. women $<0.05$ \\
\hline & & & & LM: $415.0 \pm 60.9$ vs. $391.6 \pm 54.0$ & No value between CM groups \\
\hline & & & & LAD: $394.8 \pm 58.4$ vs. $376.4 \pm 53.0$ & No value between CM groups \\
\hline & & & & Cx: $400.0 \pm 64.8$ vs. $380.9 \pm 48.9$ & No value between CM groups \\
\hline & & & & RCA: $409.2 \pm 64.4$ vs. $387.0 \pm 56.4$ & No value between CM groups \\
\hline \multirow[t]{4}{*}{ Kidoh $^{67}$} & 350 & $4.5 \pm 0.9$ & 1.58 & LM: $369 \pm 55$ vs. $399 \pm 67$ & 0.02 \\
\hline & 350 & 5 & 1.75 & ProxRCA: $363 \pm 56$ vs. $393 \pm 66$ & 0.01 \\
\hline & & & & MidRCA: $351 \pm 62$ vs. $380 \pm 74$ & 0.04 \\
\hline & & & & DistRCA: $336 \pm 58$ vs. $371 \pm 72$ & 0.01 \\
\hline \multirow[t]{4}{*}{$\operatorname{Kidoh}^{68}$} & 350 & 4.1 & 1.44 & LM: $352.4 \pm 39.4$ vs. $382.9 \pm 48.6$ & 0.01 \\
\hline & 350 & 4.8 & 1.68 & ProxRCA: $331.6 \pm 42.6$ vs. $351.3 \pm 53.8$ & 0.12 \\
\hline & & & & MidRCA: $310.5 \pm 51.2$ vs. $321.7 \pm 79.7$ & 0.52 \\
\hline & & & & DistRCA: $299.9 \pm 62$ vs. $307.3 \pm 81.2$ & 0.70 \\
\hline \multirow[t]{8}{*}{$\operatorname{Liu}^{69}$} & 370 & $5.0 / 6.0$ & \multicolumn{2}{|c|}{1.85 ( $\leq 85 \mathrm{~kg}$ ); LM: $465.2 \pm 82.2$ vs. $473.3 \pm 75.7$ vs. $458.0 \pm 83.9$} & 0.764 \\
\hline & & & \multicolumn{2}{|c|}{2.22 (>85kg) ProxLAD: $443.8 \pm 62.4$ vs. $430.8 \pm 63.0$ vs. $440.3 \pm 81.1$} & 0.755 \\
\hline & 370 & $5.0 / 6.0$ & \multicolumn{2}{|c|}{1.85 ( $\leq 85 \mathrm{~kg}$ );MidLAD: $397.3 \pm 74.3$ vs. $414.4 \pm 85.3$ vs. $403 \pm 73.4$} & 0.691 \\
\hline & & & \multicolumn{2}{|c|}{2.22 (>85kg) DistLAD: $304.3 \pm 87.2$ vs. $349.2 \pm 66$ vs. $320.5 \pm 73.7$} & 0.059 \\
\hline & 370 & $5.0 / 6.0$ & \multicolumn{2}{|c|}{1.85 (s85kg);ProxCx: $462.5 \pm 76.4$ vs. $441.8 \pm 70.9$ vs. $439 \pm 94.5$} & 0.479 \\
\hline & & & \multicolumn{2}{|c|}{2.22 (>85kg) MidCx: $410.2 \pm 79$ vs. $397.1 \pm 62.2$ vs. $413.8 \pm 68.8$} & 0.625 \\
\hline & & & & DistCx: $338.7 \pm 78.4$ vs. $335.3 \pm 60.9$ vs. $324.4 \pm 73.4$ & 0.719 \\
\hline & & & & ProxRCA: $456.8 \pm 68.2$ vs. $457.6 \pm 76$ vs. $459.4 \pm 75.2$ & 0.991 \\
\hline
\end{tabular}




\section{Chapter 9}

\begin{tabular}{|c|c|c|c|c|c|}
\hline Author & $\begin{array}{c}\mathrm{CM} \\
(\mathrm{mg} / \mathrm{ml})\end{array}$ & $\begin{array}{c}\text { Flow rate } \\
(\mathrm{ml} / \mathrm{s})\end{array}$ & $\operatorname{IDR}(\mathrm{gl} / \mathrm{s})$ & Attenuation (HU; group 1 vs. group 2 vs. group 3....) & Significance ( $P$ value) \\
\hline & & & & MidRCA: $439 \pm 55.6$ vs. $435.5 \pm 85.4$ vs. $442.9 \pm 86.8$ & 0.932 \\
\hline & & & & DistRCA: $416 \pm 67$ vs. $422.8 \pm 79.1$ vs. $431.8 \pm 80.6$ & 0.738 \\
\hline \multirow[t]{2}{*}{ Yang $^{70}$} & 370 & 4 & 1.48 & LM: $335.8 \pm 42.4$ vs. $340.4 \pm 51.4$ & 0.497 \\
\hline & 370 & 4 & 1.48 & DistRCA: $334.9 \pm 49.2$ vs. $341.2 \pm 50.4$ & 0.512 \\
\hline \multirow[t]{3}{*}{ Tomizawa $^{71}$} & 370 & $3.5 \pm 0.7$ & 1.3 & Mean attenuation ProxCA: $391 \pm 76$ vs. $428 \pm 80$ vs. $427 \pm 68$ & Group 1 vs. group $2-3<0.005$ \\
\hline & 370 & $3.3 \pm 0.5$ & 1.22 & Mean attenuation MidCA: $349 \pm 74$ vs. $386 \pm 75$ vs. $395 \pm 62$ & Group 1 vs. group 2-3<0.005 \\
\hline & 370 & $3.6 \pm 0.8$ & 1.33 & Mean attenuation DistCA: $300 \pm 70$ vs. $341 \pm 70$ vs. $358 \pm 45$ & Group 1 vs. group 2-3<0.005 \\
\hline \multirow[t]{12}{*}{ Zheng $^{72}$} & 270 & 5 & 1.35 & BMI: $<25$ & \\
\hline & 370 & 5 & 1.85 & Mean attenuation CA: $576.63 \pm 95.50$ vs. $569.51 \pm 118.93$ & 0.647 \\
\hline & & & & LM: $598.24 \pm 86.25$ vs. $583.77 \pm 104.27$ & 0.602 \\
\hline & & & & LAD: $568.95 \pm 117.79$ vs. $535.90 \pm 93.27$ & 0.285 \\
\hline & & & & Cx: $567.06 \pm 80.31$ vs. $552.80 \pm 139.71$ & 0.663 \\
\hline & & & & RCA: $605.31 \pm 108.93$ vs. $572.54 \pm 117.17$ & 0.320 \\
\hline & & & & $\mathrm{BMI} \geq 25$ & \\
\hline & & & & Mean attenuation CA: $394.19 \pm 68.09$ vs. $383.72 \pm 63.11$ & 0.212 \\
\hline & & & & LM: $396.93 \pm 62.21$ vs. $382.44 \pm 59.66$ & 0.395 \\
\hline & & & & LAD: $381.45 \pm 57.41$ vs. $373.27 \pm 60.09$ & 0.618 \\
\hline & & & & Cx: $388.55 \pm 67.61$ vs. $379.64 \pm 66.93$ & 0.635 \\
\hline & & & & RCA: $409.82 \pm 83.07$ vs. $399.54 \pm 66.08$ & 0.624 \\
\hline \multirow[t]{5}{*}{ Lembcke $^{73}$} & 370 & & 1.85 & Mean attenuation CA: 377.4 (344.9-409.9) vs. & $<0.0001$ \\
\hline & 370 & & 1.85 & 402.1 (369.7-434.6) vs. 458.3 (425.9-490.8) vs. & \\
\hline & 370 & & 1.85 & 484.4 (451.9-516.9) vs. $525.0(492.5-557.5)$ & \\
\hline & 370 & & 1.85 & & \\
\hline & 370 & & 1.85 & & \\
\hline \multirow[t]{6}{*}{ Kawaguchi ${ }^{74}$} & 350 or & & 1.75 or 1.85 & LM: $345.7 \pm 23$ vs. $302.3 \pm 44.8$ & $<0.05$ \\
\hline & 370 & & & ProxLAD: $343.7 \pm 21$ vs. $294.0 \pm 46.6$ & $<0.05$ \\
\hline & 370 & & 1.37 & ProxCx: $341.8 \pm 21.6$ vs. $295.5 \pm 45.5$ & $<0.05$ \\
\hline & & & & ProxRCA: $350.7 \pm 23.6$ vs. $301.6 \pm 45.2$ & $<0.05$ \\
\hline & & & & MidRCA: $344.9 \pm 25.3$ vs. $298.4 \pm 42.7$ & $<0.05$ \\
\hline & & & & DistRCA: $349.5 \pm 27.9$ vs. $300.5 \pm 48.2$ & $<0.05$ \\
\hline
\end{tabular}


CHAPTER 9

Supplemental Material

Summary

Valorisation

Dankwoord

Curriculum Vitae

List of publications 
In daily clinical routine, contrast media (CM) administration in coronary computed tomography angiography (CCTA) is generally applied as a standard injection protocol with a fixed amount of $\mathrm{CM}$ and a standard injection rate. However, attenuation of the coronary arteries and overall image quality in CCTA is influenced by numerous factors, divided in three major subgroups (e.g. scan related parameters, injection related parameters, and patient related factors). The underlying relation of these parameters has not been investigated extensively and hardly any literature neither consensus exists on the optimal scan protocol in CCTA. The aim of this thesis was to gain insight into the influence of various different injection parameters (e.g. CM concentration, flow rates, viscosity and iodine delivery rate [IDR]) on attenuation and image quality in CCTA.

In chapter 2, we presented a comprehensive overview of the existing literature in order to provide an update on the determining factors for optimal contrast enhancement of the coronary arteries. Contradicting outcomes were reported in the included publications. Arguable outcomes and conclusions with regard to image quality and attenuation of the coronary arteries were drawn when different CM concentrations were injected with variable injection parameters. In most of the included studies limited data concerning injection-, scan- and patient-related parameters were provided. These factors, however, may also have had a substantial impact on image quality in CCTA. Therefore, the influence of some of these individual injection parameters on vessel attenuation needed to be unravelled.

The aim of the study in chapter 3 was to evaluate the viscosity of different CM concentrations in a standardized manner at different temperatures and its influence on injection parameters, with focus on injection pressures. The results of these experiments show in a standardized way that low viscosity decreases injection pressure. This can be facilitated by prewarming CM (high temperature) and using CM with low iodine concentration. In these experiments, significant differences in peak pressure (psi) were found at $20^{\circ} \mathrm{C}, 30^{\circ} \mathrm{C}$, and $37^{\circ} \mathrm{C}$ for iodinated $\mathrm{CM} \mathrm{240,300,370,} \mathrm{and} 400 \mathrm{mg} / \mathrm{ml}$. Overall, the lowest peak pressure was found for the lowest concentrated CM (e.g. $240 \mathrm{mg} / \mathrm{ml}$ ) at body temperature $\left(92 \mathrm{psi}\right.$ at $\left.37^{\circ} \mathrm{C}\right)$. Strikingly, the peak pressure for the highest concentrated CM $(400 \mathrm{mg} / \mathrm{ml})$ was even higher at body temperature (135psi at $37^{\circ} \mathrm{C}$ ) in comparison to $\mathrm{CM}$ with $240 \mathrm{mg} / \mathrm{ml}$ at room temperature $\left(107 \mathrm{psi}\right.$ at $\left.20^{\circ} \mathrm{C}\right)$. These findings not only stressed the positive effect of preheating $\mathrm{CM}$ to reduce viscosity and injection pressure, but also displayed the potential reduction in peak pressure, which can be generated when using lower concentrated $\mathrm{CM}$. The latter finding subsequently creates the doorway towards injection with higher flow rates. Chapter 4 aimed to investigate the influence of CM concentration and IDR on intravascular attenuation in a circulation phantom. The influence of $\mathrm{CM}$ concentration on intravascular attenuation has been of great interest in the literature, with varying outcomes. Current evidence is controversial as to whether higher concentrated $\mathrm{CM}$ is beneficial in intravascular 
attenuation, when the calculated IDR (e.g. CM concentration $\mathrm{x}$ injection rate) is kept identical. The use of a circulation phantom provided a unique opportunity for repetitive and standardized scanning of an identical subject, ruling out variables such as varying heart rate, blood pressure and cardiac output. In this study, comparison of protocols using different CM concentrations (varying between 240-400mg/ml) established comparable intravascular enhancement patterns when IDR and all other influencing factors were kept constant. Higher iodine concentrations on itself did not increase attenuation levels. This implicates that IDR, and not CM concentration, is the determinant factor in the opacification of the vascular tree. Based on these experiments, comparable attenuation levels should be feasible in daily clinical routine with very low CM concentrations (e.g. $240 \mathrm{mg} / \mathrm{ml}$ ) when IDR is kept identical. The aim of chapter 5 was to test high flow application of $\mathrm{CM}$ in a circulation phantom and to assess feasibility of high flow rates in a patient population. Injection with high flow rates proved to be feasible in a phantom setting $(\leq 15 \mathrm{ml} / \mathrm{s})$. In a clinical cohort, maximum flow rate of $9.6 \mathrm{ml} / \mathrm{s}$ were administered. These flow rates did not cause injection-related problems (e.g. extravasation at the injection site, material damage) or negative imagerelated side effects (e.g. streak artifacts or CM reflux) while reaching optimal vessel enhancement levels. The maximum injection pressure of 325 psi was never reached in both the phantom and patient setting. In chapter 6, the results from the previous chapters form the basis for an additional pilot study. In this study we evaluated peak injection pressures and both objective and subjective image quality in CCTA using low concentrated CM $(240 \mathrm{mg} / \mathrm{ml})$ injected at high flow rates in comparison to a standard injection protocol (CM: $300 \mathrm{mg} / \mathrm{ml}$ ) with identical IDR. No contrast related problems such as extravasation at the injection site or negative flow related effects (e.g. streak artifacts or CM reflux) were encountered. No significant differences in attenuation of the coronary arteries, peak pressure levels and image quality were found between both groups. This study proved again, that reluctance towards usage of high flow rates is merely based on hypothetical flow related issues. In addition, IDR is the decisive factor in intravascular attenuation. In chapter 7, a study was conducted in which vascular attenuation of the coronary arteries as well as all major injection parameters were evaluated using an individual tailored body weight adapted CM injection software. This software customizes a triphasic injection protocol for each patient and procedure, adapting the IDR and total iodine load based upon a non-linear relationship between patient weight and scan duration in order to achieve diagnostic attenuation. Diagnostic attenuation in all coronary arteries and a more homogeneous enhancement pattern between different weight groups was found in comparison to a fixed injection protocol. Total injected CM volume could be reduced for the majority of patients when utilizing body weight adapted individualized CM bolus application in comparison to a standard injection protocol. Chapter 8 discusses the main findings of this thesis in the light of existing literature and its future directions. 



\section{CHAPTER 9}

Supplemental Material

Summary

Valorisation

Dankwoord

Curriculum Vitae

List of publications 
As coronary artery disease (CAD) is a continuous rising global health problem, early detection remains to be of utmost importance. In the past decade coronary computed tomographic angiography (CCTA) has attributed significantly to the early detection of $C A D$. Its sensitivity and negative predictive value for detection of CAD is high, making this an ideal tool to rule out CAD in patients presenting with stable chest pain with lowto intermediate risk. ${ }^{1,2}$ As CT technology is continuously improving, this allows for a shorter acquisition time and a subsequently lower radiation dose. Lowering radiation dose as low as reasonably achievable (ALARA) remains an important strategy for decreasing its potential associated risk of radiation induced malignancies.

Acquisition timing is closely linked to shaping and timing of the contrast media (CM) bolus. Due to its faster acquisition times, present CT scanners bare the potential for a significant decrease of the injected CM volume in comparison to older CT scanners with longer acquisition times. Therefore, in addition to a subsequent decrease in radiation dose comes a targeted decrease in total injected CM volume. Reduction of total injected CM volume is an important goal, as potential side effects of CM application are the risk of development of contrast-induced nephropathy (CIN) in patients. ${ }^{3}$ In addition, reduction of $\mathrm{CM}$ volume to a minimal effective $\mathrm{CM}$ load can lead to a substantial reduction in costs. ${ }^{4}$

Attenuation levels of the coronary arteries $>325 \mathrm{HU}$ are usually considered diagnostically sufficient for CCTA. ${ }^{5}$ Lower attenuation levels influence image quality in a negative way and attenuation values over $500 \mathrm{HU}$ may lead to underestimation of the degree of stenosis. ${ }^{6}$

In daily clinical routine, patients receive a standard CM injection bolus for CCTA, which is administered independently of weight, length or cardiac output. However, it has been shown that these individual parameters have an influence on image quality. For example, some patients (e.g. lower weight and/or length) require less CM than other patients (e.g. higher body mass index [BMI]) to reach the same diagnostic attenuation value. ${ }^{7}$ Not just the patient characteristics, but also different CM injection parameters have a substantial impact on attenuation but are presently not individually tailored in $\mathrm{CM}$ injection protocols as the influence of these parameters have not been defined yet.

A thorough understanding of the different injection parameters and its influence on image quality is considered a primary step towards optimization of $\mathrm{CM}$ injection protocols and subsequent reduction of total injected CM volume. This thesis investigated and unravelled the role of iodine delivery rate (IDR), flow rate, CM concentration and $\mathrm{CM}$ viscosity on attenuation of the coronary arteries and overall image quality in CCTA. The established pivotal influence of some of these injection parameters will help to further elaborate on and develop more individually tailored CM injection protocols. An individually tailored CM bolus injection will lower the chance of an over- or underestimation of the injected CM volume and a subsequent decrease in image quality. In addition, a reduction in total injected CM volume can subsequently 
lower the associated risks that are involved by injection of $\mathrm{CM}$ and will also lead to a decrease in variable examination costs.

\section{TARGET POPULATION}

CCTA is carried out in patients presenting with stable chest pain with low- to intermediate risk to rule out CAD. As this is considered to be a relatively healthy patient group, it is very important to keep the necessary side effects of CCTA (e.g. radiation dose, $\mathrm{CM}$ associated allergic reactions or contrast induced-nephropathy $[\mathrm{CIN}]$ ) to a bare minimum.

Understanding the underlying parameters influencing image quality and in particular attenuation of the coronary arteries is considered to be of decisive importance, as this will help us to further bring down these risks while optimizing the diagnostic image quality in this patient group. The patient will benefit from the results in this thesis, as optimization of $\mathrm{CM}$ volume will lower the possible risks associated with injection of iodine concentrated $\mathrm{CM}$ and improve image quality. An increased knowledge of the influence of different injection parameters on image quality in CCTA can eventually assist the radiologist and cardiologist in their clinical decision making to rule out or depict CAD. As this thesis provides more insight into different injection parameters influencing attenuation of the coronary arteries, the results of these studies are also of interest for companies that develop software that integrates different patient characteristics in a semi-automated injection protocol. In addition, the results regarding the influence of viscosity of different $\mathrm{CM}$ concentrations on injection pressure and the benefits from injection of lower concentrated CM might be of interest to the companies developing contrast agents.

\section{INNOVATION, PRODUCTS AND IMPLEMENTATION}

The next step is directed towards integrating a broad variety in flow rates for an equally diverse IDR in a more individualized injection protocol tailored to BMI of the patient as well as other patient related parameters such as heart rate and cardiac output. The hypothesis that high flow rates will not lead to an increase of patient discomfort during injection needs to be tested in a double-blinded prospective randomized controlled setting (EICAR trial). In this trial, registered on ClinicalTrials.gov (NCT02462044), patient comfort at the injection site with usage of various different flow rates $($ e.g. $5.4 \mathrm{ml} / \mathrm{s}$, $6.7 \mathrm{ml} / \mathrm{s}$ and $8.3 \mathrm{ml} / \mathrm{s}$ ) and incidence of contrast extravasation will be evaluated. Future directions are targeted towards the question, which individual IDR is best suitable for each individual weight and length of the patient, in order to provide diagnostic attenuation CCTA while keeping total injected CM volume as low as possible. In 
addition, newer generation iterative reconstruction algorithms in combination with low $\mathrm{kV}$ scan protocols and individually tailored CM application bare the potential for further reduction of total $\mathrm{CM}$ volume and radiation dose in the near future without compromising image quality. The challenge is to identify an optimal individual tailored CM injection protocol where patient's demographic information has been integrated together with scan and injection parameters. 


\section{REFERENCES}

1. Budoff MJ, Dowe D, Jollis JG, Gitter M, Sutherland J, Halamert E, Scherer M, Bellinger R, Martin A, Benton R, Delago A, Min JK. Diagnostic performance of 64-multidetector row coronary computed tomographic angiography for evaluation of coronary artery stenosis in individuals without known coronary artery disease: Results from the prospective multicenter accuracy (assessment by coronary computed tomographic angiography of individuals undergoing invasive coronary angiography) trial. J Am Coll Cardiol. 2008;52:1724-1732

2. Miller JM, Rochitte CE, Dewey M, Arbab-Zadeh A, Niinuma H, Gottlieb I, Paul N, Clouse ME, Shapiro EP, Hoe J, Lardo AC, Bush DE, de Roos A, Cox C, Brinker J, Lima JA. Diagnostic performance of coronary angiography by 64-row ct. NEJM. 2008;359:2324-2336

3. Mitchell AM, Jones AE, Tumlin JA, Kline JA. Incidence of contrast-induced nephropathy after contrastenhanced computed tomography in the outpatient setting. Clin J Am Soc Nephrol. 2010;5:4-9

4. Kuhn MJ, Baker MR. Optimization of low-osmolality contrast media for cranial ct: A dose comparison of two contrast agents. AJNR Am J Neuroradiol. 1990;11:847-849; discussion 850-841

5. Isogai T, Jinzaki M, Tanami Y, Kusuzaki H, Yamada M, Kuribayashi S. Body weight-tailored contrast material injection protocol for 64-detector row computed tomography coronary angiography. Jpn J Radiol. 2011;29:33-38

6. Fei X, Du X, Yang Q, Shen Y, Li P, Liao J, Li K. 64-mdct coronary angiography: Phantom study of effects of vascular attenuation on detection of coronary stenosis. AJR Am J Roentgenol. 2008;191:43-49

7. Bae KT. Intravenous contrast medium administration and scan timing at ct: Considerations and approaches. Radiology. 2010;256:32-61 

CHAPTER 9

Supplemental Material

Summary

Valorisation

Dankwoord

Curriculum Vitae

List of publications 
Tenslotte een dankwoord; het laatste onderdeel van mijn proefschrift.

De afgelopen 5 jaar zijn een geweldige periode geweest waarin ik veel heb geleerd. Zonder de hulp van de volgende personen was dit niet gelukt.

Professor Wildberger, beste Joachim, naast mijn promotor ook de persoon bij wie ik aanklop met diverse vragen buiten mijn promotie onderzoek. Altijd een eerlijk en direct antwoord. Altijd een schaterlach. Een groot voorbeeld, dank!

Beste Marco, dit proefschrift is het begin van een trein die we samen in beweging hebben gebracht. Deze trein was niet gestart zonder jou en hetzelfde geldt zeer waarschijnlijk voor het proefschrift dat nu voor je ligt. Dank voor het in mij gestelde vertrouwen! Jouw enthousiasme en tomeloze inzet heeft grote indruk gemaakt op mij.

Beste Bas, ik heb je leren kennen als een enthousiaste en betrokken cardioloog. Dank voor je inzet en commentaar. Dit proefschrift heeft hiermee naast een technische kant ook een klinisch randje gekregen.

Leden van de beoordelingscommissie, veel dank voor de tijd die jullie hebben geïnvesteerd in de inhoudelijke beoordeling van dit proefschrift.

Madeleine, deze trein heeft pas echt snelheid gekregen toen jij bij het team kwam. Jouw enthousiasme en "recht door zee" mentaliteit zijn niet alleen van onschatbare waarde geweest in dit proefschrift maar hebben ook voor een fantastische sfeer gezorgd in ons team. Ik wens je heel veel plezier en succes in Utrecht, woooooop!!

Herm, wat zou Maastricht zijn zonder jou. Samen hebben we in de afgelopen jaren prachtige projecten gerealiseerd. Onze ondernemingsgeest mag een nuchtere kijk op zaken soms in de weg hebben gestaan (veel sneeuw en weinig champagnes), deze verhalen blijven. Ik kijk uit naar het volgende plan! De verdediging van mijn proefschrift doe ik zelf - met jou als paranimf aan mijn zijde.

Mathijs, jaren hebben we samen gewerkt, gefietst en carnaval gevierd. Onze engelduivel combinatie was een bescheiden succes. Nu jij in Utrecht woont, is er helaas geen wekelijkse afspraak meer. Gelukkig hebben we onze jaarlijkse terugkerende rituelen. Geweldig dat jij hier naast mij staat!

Sibel, kamergenoot, jouw input vanuit de cardiologische hoek is erg belangrijk geweest. Nog even, en dan is jouw proefschrift ook een feit. 
Professor de Haan, beste Michiel, ik ben een van de laatste assistenten waarvan jij opleider bent. Jouw deur staat altijd open. Dank voor al je hulp en begeleiding tijdens het gehele traject.

Veel dank ben ik verschuldigd aan de assistenten en radiologen van onze afdeling. Jullie maken de sfeer, die zo enorm belangrijk is tijdens het werk. Jullie betrokkenheid en enthousiaste begeleiding werkt inspirerend.

Alle laboranten van de afdeling radiologie. Jullie steun is onmisbaar. Speciale dank gaat uit naar Ralf, Jef, Sandra en Jeroen. Hoeveel dagen en avonden hebben wij niet samen aan het fantoom zitten klussen? Zonder jullie was die klus niet geklaard.

Christianne, Elfie, Monique, Peggy en nog eens Monique, jullie waren altijd in voor een praatje en altijd bereid om te helpen. Geweldig!

Mijn lieve ouders en broer. Ooit vertrok Guus als student vanuit Voorburg naar het zuiden. Enkele jaren hierna volgde ik. Nu woont de hele familie hier. Hoe zaken toch kunnen lopen... Pap en mam, veel dank voor de cover van dit proefschrift. Ook de stellingen kregen een persoonlijk tintje door jullie.

Lieve Martine, jouw nuchtere kijk op de zaken is de ideale aanvulling op mijn karakter. Naast mijn grote liefde en reisgenoot ben je waarschijnlijk ook de enige vrouw die de statistieken in een cricket wedstrijd begrijpt. Ik kijk uit naar alle avonturen die wij samen nog gaan beleven! 
Chapter 9

"Don't cry because it's over, smile because it happened." Theodor Seuss Geisel 
CHAPTER 9

Supplemental Material

Summary

Valorisation

Dankwoord

Curriculum Vitae

List of publications 

Casper Mihl was born on the $15^{\text {th }}$ of December 1979 in Delft, the Netherlands. In 1998, he graduated from secondary school (Gymnasium) in Voorburg, the Netherlands. He studied physiotherapy at the University of Applied Sciences in Leiden with a 6 month elective internship sports physiotherapy in Brisbane (Australia) and graduated in 2003. That same year, he began his medical training at the faculty of Health, Medicine, and Life Sciences at the University of Maastricht and obtained his medical degree in 2009. He commenced his registrar training radiology at the Maastricht University Medical Center (MUMC) in 2010 under supervision of prof. dr. M. de Haan. In 2011, he started as a PhD fellow at the department of radiology under supervision of prof. dr. J.E. Wildberger and dr. M. Das. In the fall of 2013, he received 4 months of training at the Royal Prince Alfred Hospital in Sydney (Australia) under the supervision of dr. Y.X. Kitzing.

The most important scientific results of his research are described in this thesis. Results of his studies were presented at several (inter)national congresses. He was nominated and awarded for parts of his research, of which the "NVVR travel grant" for best abstract at the Radiological Society of the Netherlands annual meeting in 2015. He completed his registrar training in July 2016. Subsequently, he started as a fellow abdominal radiology at the MUMC. 

CHAPTER 9

Supplemental Material

Summary

Valorisation

Dankwoord

Curriculum Vitae

List of publications 
1. Kok M, Mihl C, Hendriks BM, Altintas S, Kietselaer BL, Wildberger JE, Das M. Optimizing contrast media application in coronary CT angiography at lower tube voltage: Evaluation in a circulation phantom and sixty patients. Eur J Radiol. 2016 Jun;85(6):1068-74.

2. Kok M, Mihl C, Hendriks BM, Altintas S, Eijsvoogel NG, Kietselaer BL, Wildberger JE, Das M. Patient Comfort During Contrast Media Injection in Coronary Computed Tomographic Angiography Using Varying Contrast Media Concentrations and Flow Rates: Results From the EICAR Trial. Invest Radiol. 2016 May 10. (Epub ahead of print)

3. Mihl C*, Kok M*, Altintas S, Kietselaer BLJH, Turek J, Wildberger JE, Das M. Evaluation of individually body weight adapted contrast media injection in coronary CT-angiography. Eur J Radiol. 2016;85(4):830-6. (*shared first authorship)

4. Kok M, de Haan MW, Mihl C, Eijsvoogel NG, Hendriks BM, Sailer AM, Derks K, Schnerr RS, Schurink GW, Wildberger JE, Das M. Individualized CT angiography protocols for evaluation of the aorta: a feasibility study. J Vasc Interv Radiol. 2016; 27(4):531-8.

5. Hendriks BM, Kok M, Mihl C, Bekkers SC, Wildberger JE, Das M. Individually tailored contrast enhancement in CT pulmonary angiography. $\mathrm{Br} J$ Radiol. 2016; Jan 22:20150850.

6. Kok M, Mihl C, Seehofnerová A, Turek J, Jost G, Pietsch H, Haberland U, Wildberger JE, Das M. Automated tube voltage selection for radiation dose reduction in CT angiography Using different contrast media concentrations and a constant iodine delivery rate. AJR Am J Roentgenol. 2015;205(6):1332-8.

7. Kok M, Turek J, Mihl C, Reinartz SD, Gohmann RF, Nijssen EC, Kats S, van Ommen VG, Kietselaer BL, Wildberger JE, Das M. Low contrast media volume in pre-TAVI CT examinations. Eur Radiol. 2015 Nov 11. (Epub ahead of print)

8. Mihl C, Kok M, Wildberger JE, Altintas S, Labus D, Nijssen EC, Hendriks BMF, Kietselaer BLJH, Das M. Coronary CT angiography using low concentrated contrast media injected with high flow rates: feasible in clinical practice. Eur J Radiol. 2015;84(11):2155-60.

9. Mihl C, Kok M, Wildberger JE, Turek J, Muehlenbruch G, Das M. CT angiography with high flow rates: an in vitro and in vivo feasibility study. Invest Radiol. 2015;50(7):464-9.

10. Jurencak T, Turek J, Kietselaer BL, Mihl C, Kok M, van Ommen VG, van Garsse LA, Nijssen EC, Wildberger JE, Das M. MDCT evaluation of aortic root and aortic valve prior to TAVI. What is the optimal imaging time point in the cardiac cycle? Eur Radiol. 2015;25(7):1975-83. 
11. Kok M, Kietselaer BL, Mihl C, Altintas S, Nijssen EC, Wildberger JE, Das M. Contrast enhancement of the right ventricle during coronary $\mathrm{CT}$ angiography: is it necessary? PLoS One. 2015;10(6):e0128625.

12. Seehofnerova A, Kok M, Mihl C, Douwes D, Sailer S, Nijssen E, de Haan MJW, Wildberger JE, Das M. Feasibility of low contrast media volume in CT angiography of the aorta. Eur J Radiol Open. 2015;58-65.

13. Mihl C, Loeffen D, Versteylen MO, Takx RAP, Nelemans PJ, Nijssen EC, Vega-Higuera F, Wildberger JE, Das M. Automated quantification of epicardial adipose tissue (EAT) in coronary CT angiography; comparison with manual assessment and correlation with coronary artery disease. J Cardiovasc Comput Tomogr. 2014;8(3):215-21.

14. Külcü K, Elenbaas TW, Nguyen DT, Verhees RP, Mihl C, Verberkmoes NY, van Straten $\mathrm{AH}$, Soliman Hamad MA. Patency of the internal mammary arteries after removal of the Nuss bar: an initial report. Interact Cardiovasc Thorac Surg. 2014;19(1):6-9.

15. Mihl C*, Kok M*, Mingels AA, Kietselaer BL, Mühlenbruch $G$, Seehofnerova $A$, Wildberger JE, Das $\mathrm{M}$. Influence of contrast media viscosity and temperature on injection pressure in computed tomographic angiography: a phantom study. Invest Radiol. 2014;49(4):217-23. (*shared first authorship)

16. Mihl C, Wildberger JE, Jurencak T, Yanniello MJ, Nijssen EC, Kalafut JF, Nalbantov G, Muhlenbruch G, Behrendt FF, Das M. Intravascular enhancement with identical iodine delivery rate using different iodine contrast media in a circulation phantom. Invest Radiol. 2013;48(11):813-8.

17. Versteylen MO, Bekkers SCAM, Smulders MW, Winkens B, Mihl C, Winkens MHM, Leiner T, Waltenberger JL, Kim RJ, Gorgels APM. The performance of angiographic, electrocardiographic and magnetic resonance imaging methods to assess the area at risk in acute myocardial infarction. Heart. 2012;98(2):109-15.

18. Bekkers SCAM, Lemmert ME, Lima Passos V, Mihl C, Schalla S, Wildberger JE, Waltenberger JL, Gorgels APM. ST segment recovery in relation to underlying infarct characteristics and adverse remodeling as assessed by cardiovascular magnetic resonance imaging. J Electrocardiol. 2011;44(5):561-7.

19. Alzand BSN, Mihl C, Brunner La Rocca HP. Dehydration with High Natriuretic Peptide Levels! A word of caution. Cardiology. 2011;118(2):75-8.

20. Alzand BSN, Mihl C, Cheriex EC. Haemorrhagic myocardial infarction after percutaneous coronary intervention. Echographic versus necropsy findings. Cardiol J. 2011;18(4):448-9. 
21. Mihl C, Alzand BSN, van Opstal JM. Conduction blocks and dancing rhythms. Neth Heart J. 2010;18(10):505.

22. Mihl C, Geyik Z, Cheriex EC, van Opstal JM. A challenging lead endocarditis. Eur J Echocardiogr. 2010;11(2):E1.

23. Mihl C, Alzand BSN, Winkens M. A rare coronary anomaly; one ostium fits all. Cardiol Res Pract. 2010;20;2010.

24. Alzand BSN, Mihl C. Atrial fibrillation with phase III aberration? A wolf in sheep's clothing? Neth Heart J. 2010;18(4):212-216.

25. Mihl C, Dassen WRM, Kuipers H. Cardiac remodeling: concentric versus eccentric hypertrophy in strength and endurance athletes. Neth Heart J. 2008;16(4):129-33. 

A

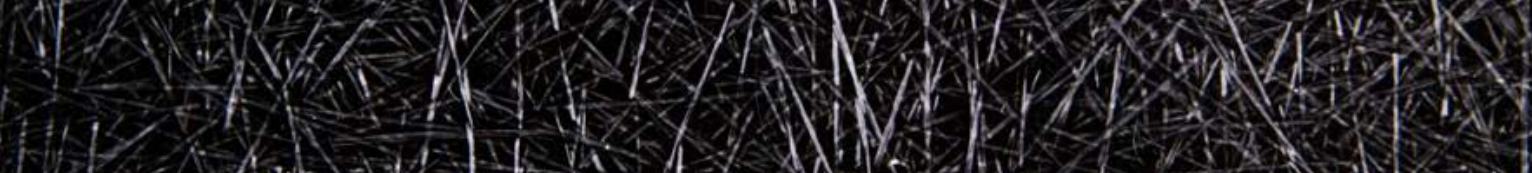

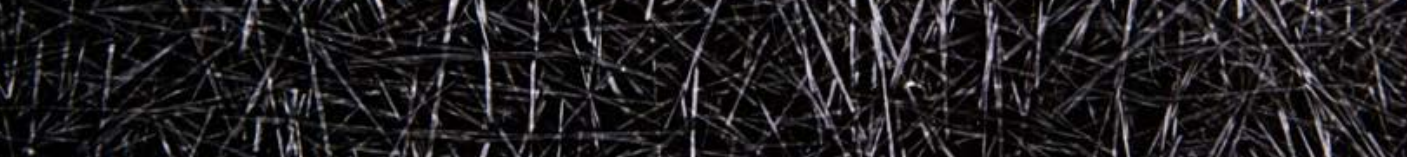

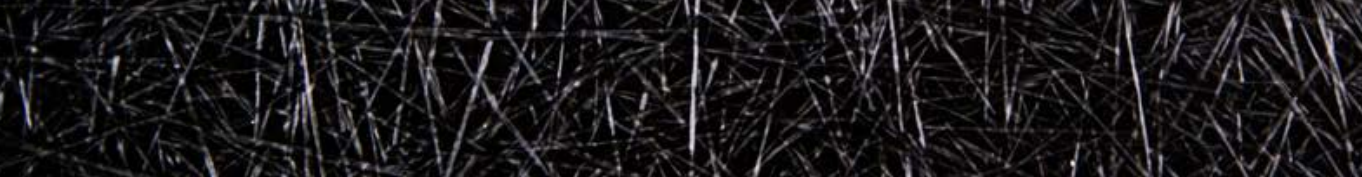

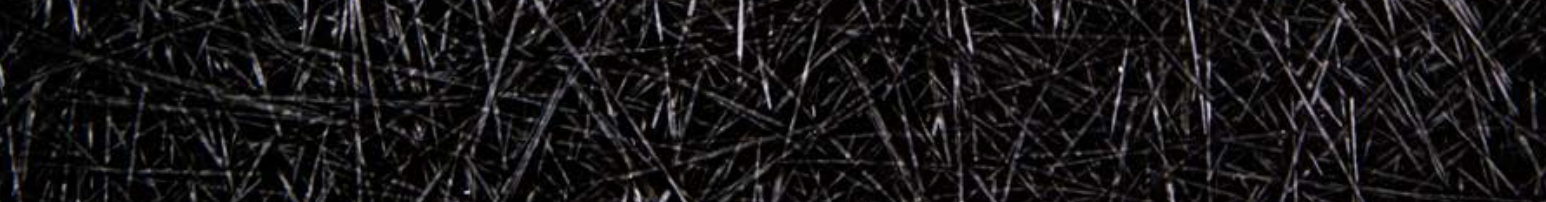

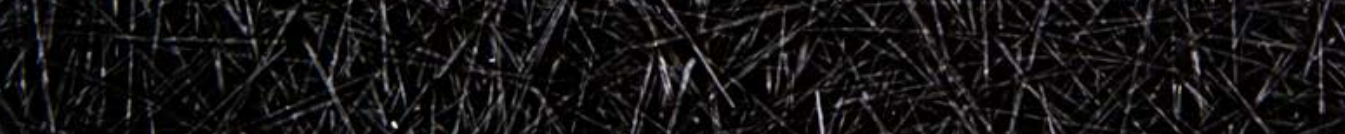

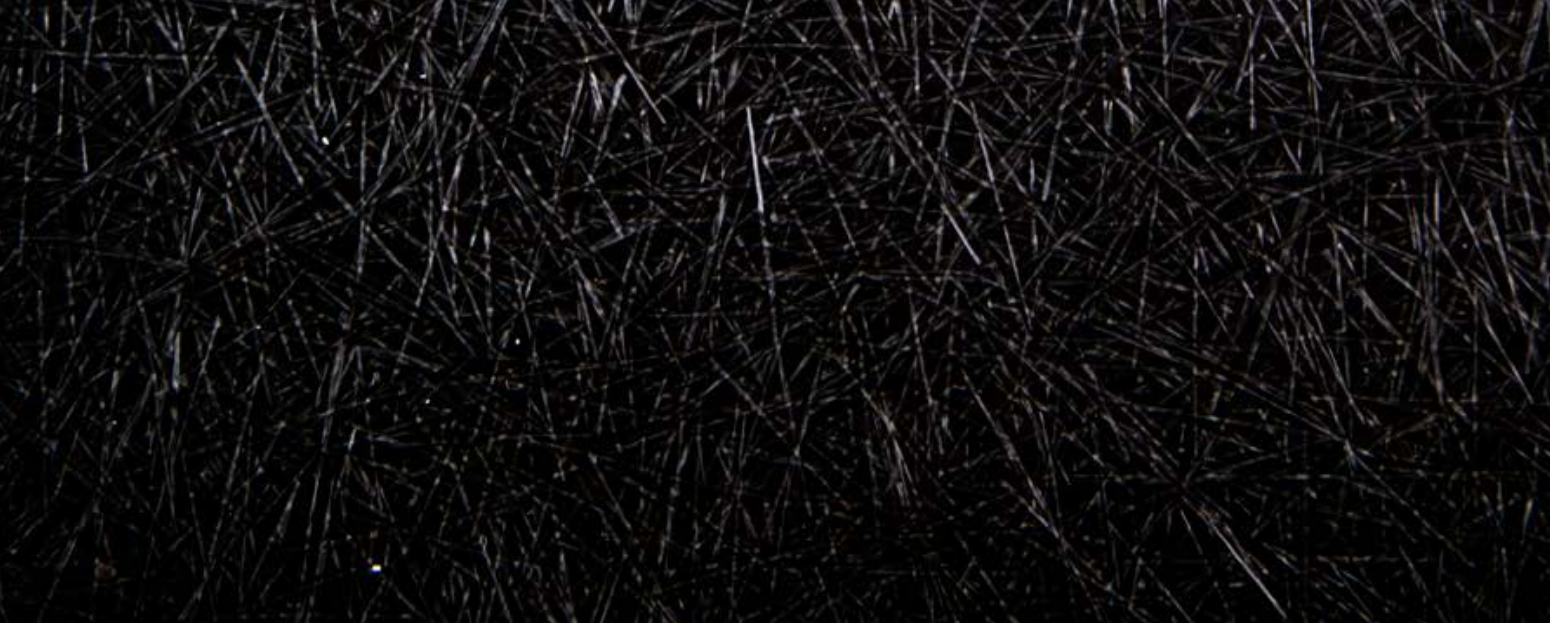

